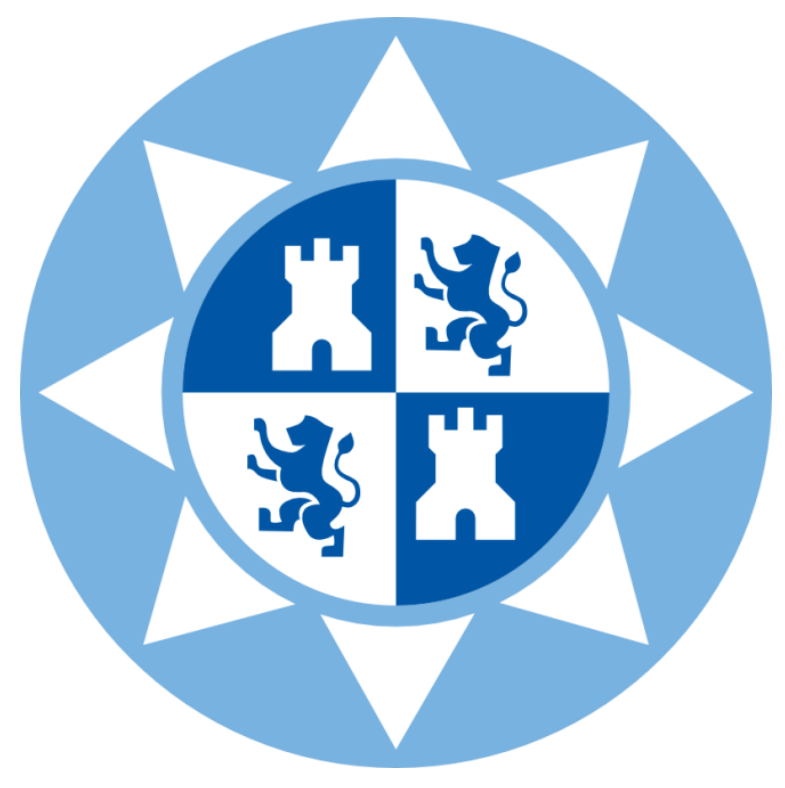

Universidad Politécnica de Cartagena

ESTUDIO DE LOS RESIDUOS Y SUBPRODUCTOS AGROINDUSTRIALES DE LA REGIÓN DE MURCIA. OPCIONES DE VALORIZACIÓN MEDIANTE COMPOSTAJE Y BIOMETANIZACIÓN

Tesis doctoral

Ana Belén Morales Moreno 


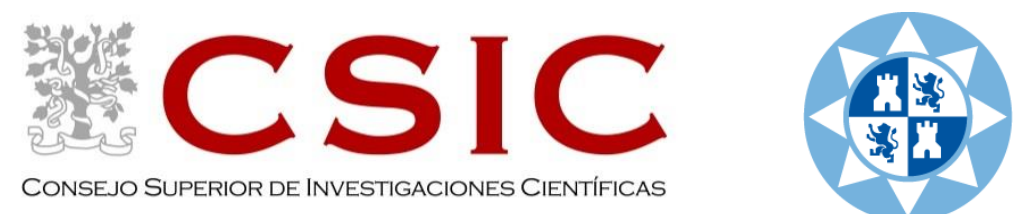

Universidad Politécnica de Cartagena

\title{
ESTUDIO DE LOS RESIDUOS Y SUBPRODUCTOS AGROINDUSTRIALES DE LA REGIÓN DE MURCIA. OPCIONES DE VALORIZACIÓN MEDIANTE COMPOSTAJE Y BIOMETANIZACIÓN
}

\author{
Ana Belén Morales Moreno \\ Doctorado en Ingeniería Ambiental y de Procesos Químicos y Biotecnológicos
}

Director

José Antonio Pascual Valero

Codirectores

Luis Miguel Ayuso García

Mercedes Alacid Cárceles 



\section{CONFORMIDAD DE DEPÓSITO DE TESIS DOCTORAL POR LA COMISIÓN ACADÉMICA DEL PROGRAMA}

D. José María Obón de Castro, Presidente de la Comisión Académica del Programa de Ingeniería Ambiental y de Procesos Químicos y Biotecnológicos.

\section{INFORMA:}

Que la Tesis Doctoral titulada, "ESTUDIO DE LOS RESIDUOS Y SUBPRODUCTOS AGROINDUSTRIALES DE LA REGIÓN DE MURCIA. OPCIONES DE VALORIZACIÓN MEDIANTE COMPOSTAJE Y BIOMETANIZACIÓN", ha sido realizada, dentro del mencionado programa de doctorado, por $\mathrm{D}^{\mathrm{a}}$. Ana Belén Morales Moreno, bajo la dirección y supervisión del Dr. José Antonio Pascual Valero, siendo codirectores la Dra. Mercedes Alacid Cárceles y el Dr. Luis Miguel Ayuso García.

En reunión de la Comisión Académica de fecha 28 de septiembre de 2015, visto que en la misma se acreditan los indicios de calidad correspondientes y la autorización del Director de la misma, se acordó dar la conformidad, con la finalidad de que sea autorizado su depósito por la Comisión de Doctorado.

La Rama de conocimiento por la que esta tesis ha sido desarrollada es:

\section{Ciencias}

Ciencias Sociales y Jurídicas

凶 Ingeniería y Arquitectura

En Cartagena, a 28 de septiembre de 2015

EL PRESIDENTE DE LA COMISIÓN ACADÉMICA DEL PROGRAMA

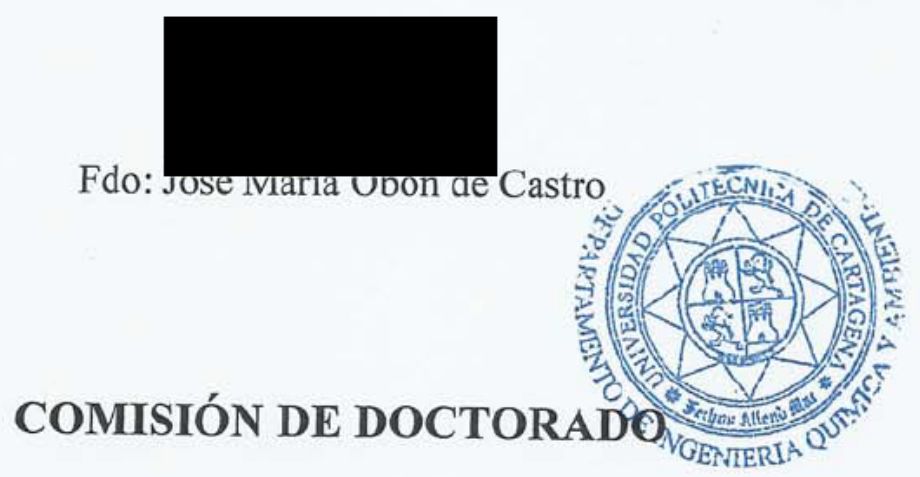





\section{Universidad}

Politécnica

de Cartagena

DT-16

\section{CONFORMIIDAD DE SOLICITUD DE AUTORIZACIÓN DE DEPÓSITO DE TESIS DOCTORAL POR EL DIRECTOR DE LA TESIS}

D. José Antonio Pascual Valero, Director de la Tesis doctoral "Estudio de los residuos y subproductos agroindustriales de la Región de Murcia. Opciones de valorización mediante compostaje y biometanización" y D. Luis Miguel Ayuso García y Da. Mercedes Alacid Cárceles, codirectores de la misma.

\section{INFORMAN:}

Que la referida Tesis Doctoral, ha sido realizada por $\mathrm{D}^{\mathrm{a}}$. Ana Belén Morales Moreno, dentro del programa de doctorado Ingeniería Ambiental y de Procesos Químicos y Biotecnológicos, dando mi conformidad para que sea presentada ante la Comisión de Doctorado para ser autorizado su depósito.

La rama de conocimiento en la que esta tesis ha sido desarrollada es:

( Ciencias

- Ciencias Sociales y Jurídicas

\& Ingeniería y Arquitectura

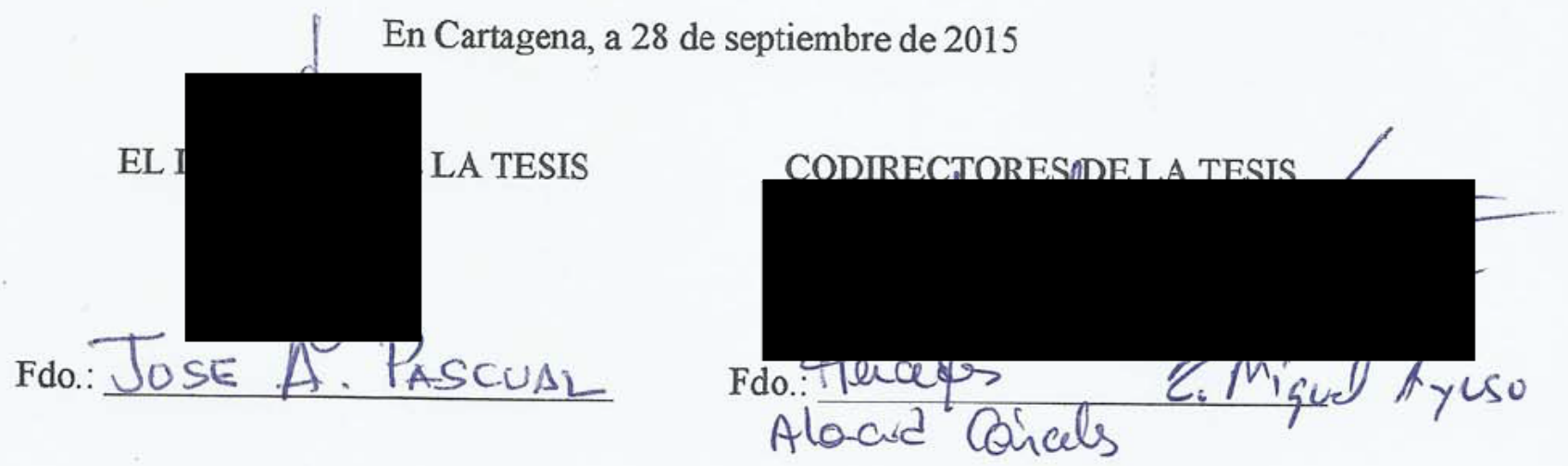

\section{COMISIÓN DE DOCTORADO}





\section{Agradecimientos}

Quisiera comenzar diciendo un GRACIAS "en mayúsculas", dirigido a todas las personas que han hecho realidad esta tesis doctoral. Han sido años de trabajo donde me he rodeado de gente muy especial y trabajadores que la han hecho posible, pero quiero destacar el apoyo recibido este último año para ver el final.

Mi mayor agradecimiento es para los doctores D. José Antonio Pascual Valero, D. Luis Miguel Ayuso García, Dña. Mercedes Alacid Cárceles, Dña. Margarita Ros Muñoz y D. Pedro Segura Artero, director, codirectores y colaboradores de esta tesis doctoral, ya que sin su orientación y apoyo esta tesis no hubiera sido posible. Gracias por creer en mí, además de por dedicarme vuestro tiempo. Especialmente a D. Pedro Segura por brindarme la oportunidad de conocer su trabajo y por su implicación en esta tesis. Beni y Miguel, gracias por dejarme trabajar con vosotros y proponerme esta experiencia. Marga, gracias por tu necesario empujón. Mercedes, gracias por estar siempre apoyando. Todos sois grandes profesionales de los que me llevo mucho.

En segundo lugar mi agradecimiento es para todas las personas que me han acompañado durante estos años. Ángel, Ma del Mar y Salva, nada más que puedo decir que ha sido un placer compartir espacio con vosotros y que sois los mejores compañeros que una haya podido tener. Salva, más que un compañero, un amigo. Gracias por todo. A todo el personal del CTC quiero agradecer su acogida desde el principio y su colaboración, pero muy especialmente a Lola, Sese, Milagros, David, Pedro, Ángel, María, Juan, Jose, Ascen, Lina y Juan Luis por todos los buenos ratos que hemos pasado, con risas, prisas y favores. Sois parte de esta tesis y de mi vida. Tampoco quiero olvidarme de las chicas del CEBAS, desde Bárbara a Rocío pasando por María, Yesica y Pepa, porque las horas de campo juntas se merecen un reconocimiento. Gracias Pepa, y también Ana, por todo lo que me habéis enseñado y la positividad mostrada siempre. Ni tampoco olvidarme de Enrique y $M^{a}$ Ángeles de la $\mathrm{UMH}$, porque siempre han estado dispuestos a sacarme de dudas y ayudarme en todo momento.

Son muchas las personas que me han ayudado a la hora de elaborar esta tesis, pero quiero hacer especial mención, por su desinteresado apoyo, a Juan de la Sociedad de Depuración Virgen de los Dolores S.L., que desde el primer día estuvo dispuesto a prestarme su colaboración. Un millón de gracias por abrirme las puertas y mostrarme que con interés se puede hacer mucho.

A Marisa Rubio, jefa del Negociado de Postgrado y Doctorado de la UPCT, por su simpatía y rapidez en responder a mis dudas administrativas. Muchas gracias.

Finalmente, a mi madre y a mi padre también quiero dedicarles la mayor de las gracias por quererme, levantarme el ánimo y por haberme dado la mejor educación del mundo. Sois los mejores padres que se puede tener y juntos hemos conseguido llegar hasta aquí. A mi hermano, le dedico esta tesis por la apuesta que siempre hace por mí y a Ángela por apoyarlo, sois maravillosos y vuestra familia es y será maravillosa.

Al pequeño Jose y a David les guardo una dedicatoria especial por el cariño que me demuestran. A Jose por sacar lo mejor de mí y porque con solo su presencia ha conseguido reanimarme en muchos momentos para continuar. A David por todos los años compartidos, pero sobre todo por aguantarme durante los momentos más difíciles, disfrutar de menos vacaciones y ser mi soporte informático. Sin vosotros hubiese sido más difícil el camino.

Para terminar, y esperando no dejarme a gente en el tintero, gracias a todos los que han valorado el trabajo de esta tesis. GRACIAS DE CORAZóN 

A todos los que me han acompañado para hacerla realidad 



\section{Resumen}

Los residuos industriales, y en particular los procedentes de la actividad agroindustrial, son un problema tanto ambiental como económico, ya que las mismas empresas tienen que asumir costes de disposición de éstos para una adecuada gestión tal como indica la normativa actual de residuos, la Ley $22 / 2011$.

Este trabajo ha tenido como objetivo identificar el problema, mediante su cuantificación, y proponer opciones de valorización de biorresiduos y subproductos del sector de conservas de frutas y hortalizas de la Región de Murcia, conocido como transformados vegetales, además de otros residuos orgánicos generados en el sector agrícola vitícola, que suponen también un problema ambiental y pueden tener un papel complementario en el tratamiento de gran parte de los residuos generados en la actividad agroindustrial en estudio. En concreto, se ha estudiado la valorización de lodos de depuradora producidos en el tratamiento de depuración de las aguas residuales de las empresas del sector, los subproductos vegetales generados en el propio proceso industrial, así como los restos agrícolas de la viticultura. El propósito marcado trata de dar a conocer las diferentes opciones de valorización de residuos, que permiten cumplir con la jerarquía de residuos, y de desarrollar una gestión adecuada de los mismos aprovechando el potencial que tienen para darles un valor añadido destacando su aplicación en agricultura mediante compostaje y biometanización previa.

En primer lugar, se llevaron a cabo acciones de recopilación de información mediante encuestas y entrevistas con personal técnico de las empresas del sector y búsqueda bibliográfica de alternativas de valorización englobadas en el campo de la alimentación humana, animal, agricultura y energía. Posteriormente se desarrollaron diversas experiencias de compostaje y estas se enfocaron a la mejora del producto final desarrollando compostajes dirigidos mediante el uso de agentes estructurantes y diferentes agentes co-compostantes, pero siempre buscando un compost de calidad. Además, se evaluó la incorporación de microorganismos beneficiosos como Trichoderma harzianum durante el compostaje de restos de poda de vid, para su empleo en suelos marginales con elevada salinidad, evaluando su efecto sobre la calidad biológica. Finalmente se estudió el potencial de generación de energía mediante la realización de ensayos de digestión anaerobia con lodos de depuración y, mezclas de lodos y otros co-sustratos generados en la propia actividad industrial que evalúen su idoneidad para la producción de biogás y la degradación de la materia orgánica.

Los resultados obtenidos reflejan que los biorresiduos del sector de conservas de frutas y hortalizas, así como los restos agrícolas de la viticultura, pueden dar lugar a compost con un contenido nutricional interesante, una calidad agronómica adecuada y están exentos de compuestos fitotóxicos, además de que pueden emplearse como sustratos de cultivo con propiedades beneficiosas en cuanto a su capacidad biopesticida y en la recuperación de suelos agrícolas con alta concentración de sal. Por otro lado, se ha demostrado que la co-digestión anaerobia de lodos de depuración agroalimentarios y subproductos, en condiciones mesófilas, permite degradar la materia orgánica de la alimentación produciendo biogás con una concentración de metano del orden del $60 \%$.

En la actualidad existen diversas tecnologías probadas en experiencias industriales que hacen posible que la gestión de estos biorresiduos pueda generar un beneficio económico lo suficientemente interesante como para que las empresas del sector se planteen la realización de inversiones necesarias para la implantación de dichas tecnologías de valorización. 


\section{Summary}

Industrial waste, and in particular those from the agro-industrial activity, are both environmental and economic problem, since companies have to take these disposal costs for proper management as indicated by the current waste regulations, Law 22/2011.

The aim of this thesis is to identify the problem through its quantification, and propose options for valorisation of biowaste and by-products from Murcia fruit and vegetable processing industries, known as vegetable processing industry in addition to other organic waste generated in the wine-growing agricultural sector, which also represent an environmental problem and have a complementary role in the treatment of most of the waste generated in the agroindustrial activity under study. Specifically, we have studied the valorisation of sewage sludge produced in the wastewater treatment from companies of this sector, vegetable by-products generated in the manufacturing process itself, as well as agricultural residues of the viticulture. The final purpose presents the different options of waste valorisation, which allow compliance with the waste hierarchy, and to develop an appropriate management of them.

First of all, data collection actions were carried out through surveys and interviews with technical personnel of companies of the sector and bibliographic search of alternative valorisation encompassed in the field of food, agriculture and energy. Subsequently various experiments of composting were developed and these were focused at improving the final product developing targeted composts using bulking agents and different co-composting agents but always looking for quality compost. In addition, the incorporation of beneficial microorganisms as Trichoderma harzianum was evaluated during the composting of vine pruning, for its use on marginal soils with high salinity, evaluating their effect on biological quality. Finally, the potential for energy generation was studied by performing anaerobic digestion trials with sewage sludge and, mixtures of sludge and other co-substrates generated by activity itself to assess their suitability for biogas production and organic matter degradation.

The results show that biowaste of fruit and vegetables processing industries, as well as agricultural residues from viticulture, can result in compost with an interesting nutritional content, proper agronomic quality and free of phytotoxic compounds, besides that they can be used as growing media with beneficial properties regarding their capacity as biopesticide and the recovery of agricultural soils with high salinity. Furthermore, it has been shown that anaerobic co-digestion of sludge treatment agrifood in mesophilic conditions, can degrade organics of food producing biogas with a methane concentration of $60 \%$.

Nowadays there are several technologies proven in industrial experiences that enable the management of this biowaste and can generate profit interesting enough for companies in the sector to make investments for the implementation of such valorisation technologies. 


\section{Índice}

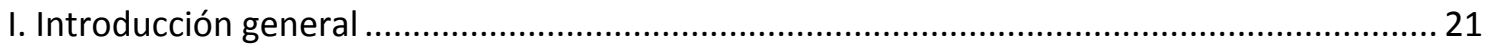

1. Problemática ambiental asociada a los residuos. La necesidad de gestionar ..................... 23

2. La Región de Murcia y su vinculación con la agricultura y la industria agroalimentaria .... 26

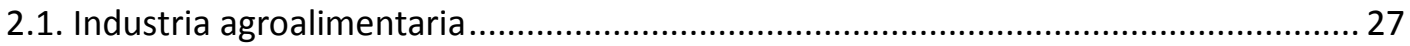

2.1.1. El sector de conservas de frutas y hortalizas. Región de Murcia ........................... 27

3. Caracterización y clasificación de los residuos orgánicos de producción agraria y

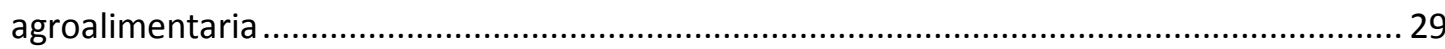

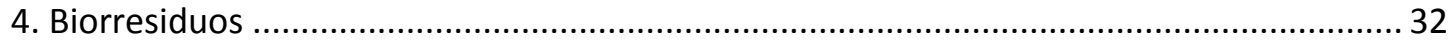

4.1. Las podas y restos vegetales de cultivos .................................................................. 32

4.1.1. Gestión actual de las podas y restos vegetales de cultivos................................... 34

4.2. Restos vegetales y partes de frutos en el sistema productivo de las empresas del sector de conservas de frutas y hortalizas de la Región de Murcia .................................... 34

4.2.1. Generación de biorresiduos en los diferentes subsectores del transformado de

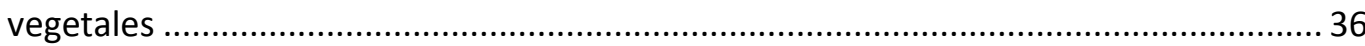

4.2.2. Gestión actual de los restos vegetales y partes de frutos generados en el proceso

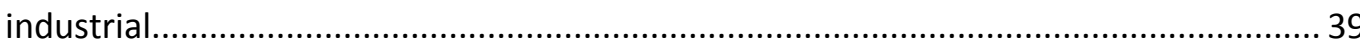

4.3. Lodos de depuración de aguas residuales de la industria agroalimentaria en la Estación Depuradora de Aguas Residuales (EDAR) .......................................................... 40

4.3.1. EDAR industrial con tratamiento biológico ............................................................ 41

4.3.2. Gestión actual de los lodos de depuración en las industrias agroalimentarias .... 44

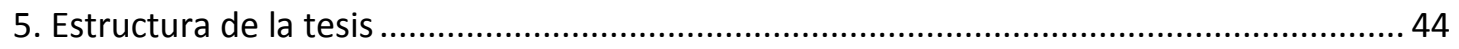

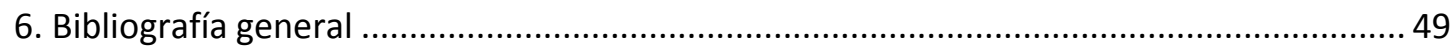

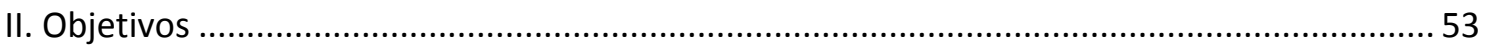

III. Opciones de valorización agrícola de lodos agroalimentarios del sector de conservas de frutas y hortalizas: el caso de la Región de Murcia ...................................................................... 57

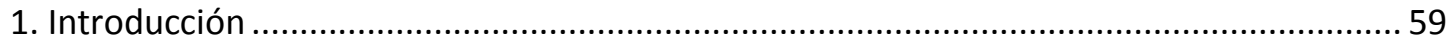

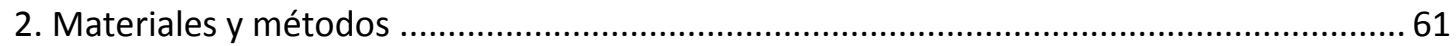

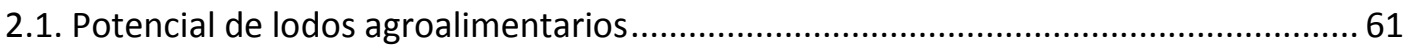

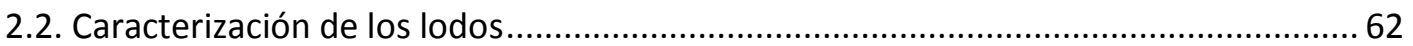

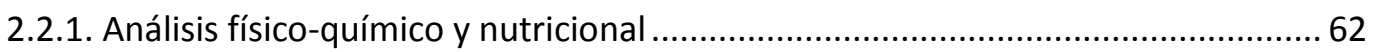

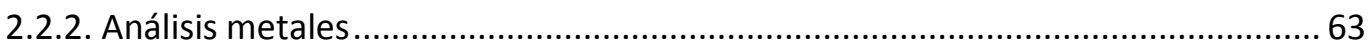

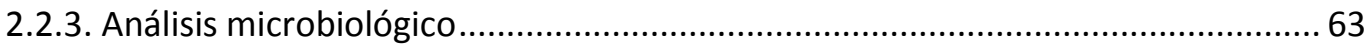

2.2.4. Análisis de contaminantes orgánicos. Plaguicidas .................................................. 64

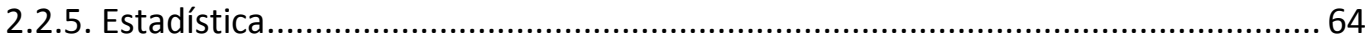


2.3. Opciones de valorización de lodos de depuración. .64

3. Resultados y discusión

3.1. Potencial de valorización de los lodos agroalimentarios en la Región de Murcia. Localización y cuantificación.

3.1.1. Estimación del potencial generador de lodos de depuración del subsector de conservas de vegetales

3.1.2. Aproximación a la economía del tratamiento de efluentes hídricos y producción

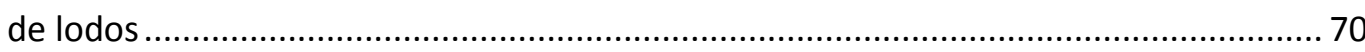

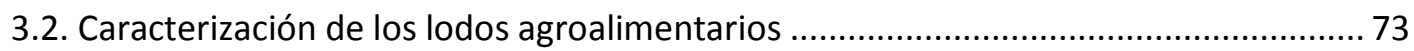

3.3. Opciones de valorización agrícola de los lodos agroalimentarios ............................... 77

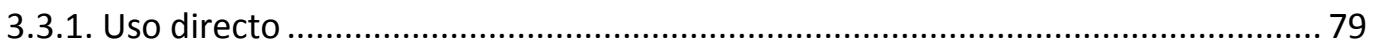

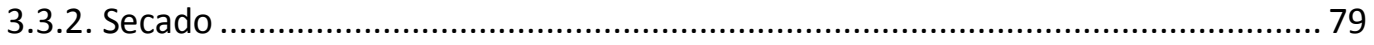

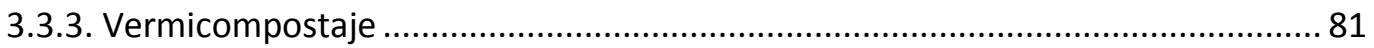

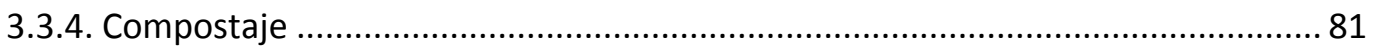

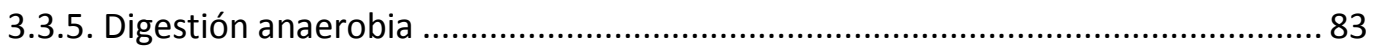

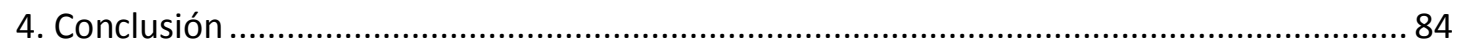

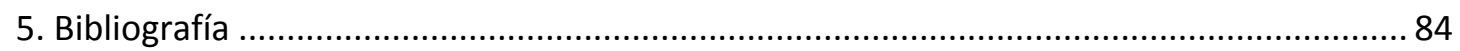

IV. Valorización de subproductos agroalimentarios de la Región de Murcia .............................. 93

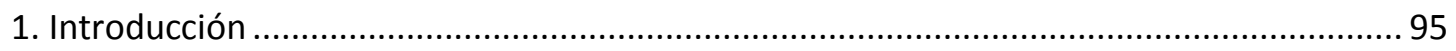

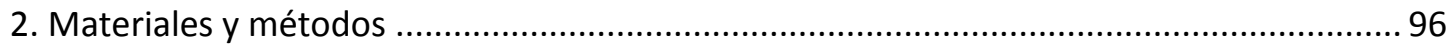

2.1. Potencial de los subproductos agroalimentarios .......................................................... 96

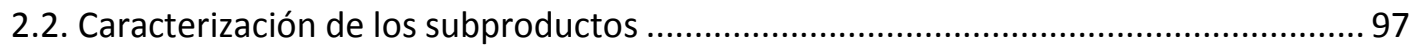

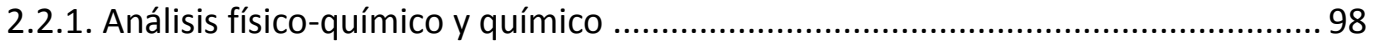

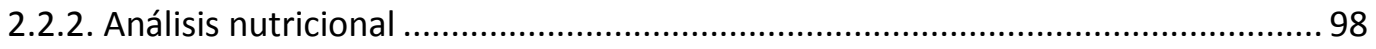

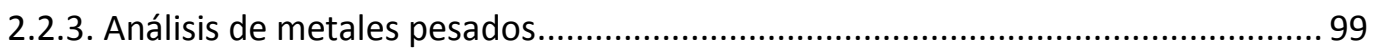

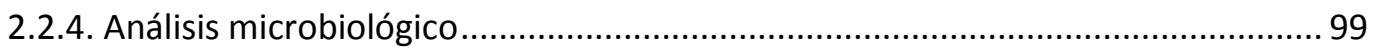

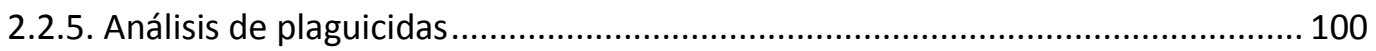

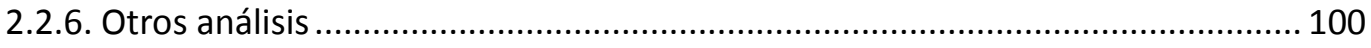

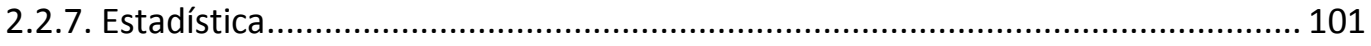

2.3. Opciones de valorización de los subproductos ........................................................... 101

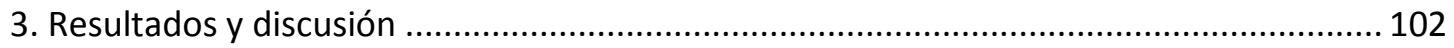

3.1. Potencial de valorización de los subproductos agroalimentarios en la Región de

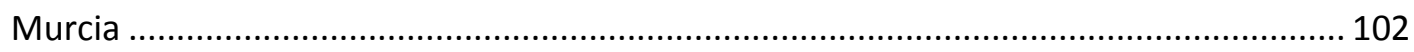

3.2. Aproximación a la economía de los biorresiduos/subproductos............................... 110

3.3. Caracterización de los subproductos agroalimentarios ........................................... 114 
3.4. Opciones de valorización de los subproductos agroalimentarios

3.4.1. Valorización con destino alimentación humana. Obtención de compuestos de interés 120

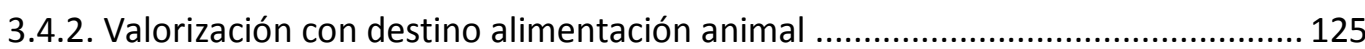

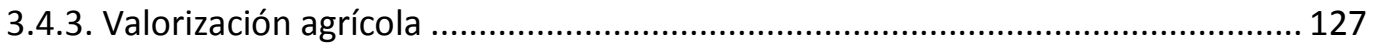

3.4.4. Valorización energética ........................................................................... 131

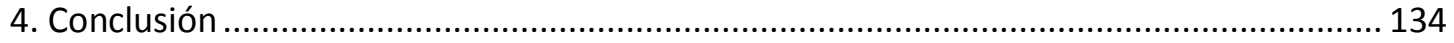

5. Bibliografía ................................................................................................... 134

V. Valorización de restos de poda de vid de la Región de Murcia ....................................... 145

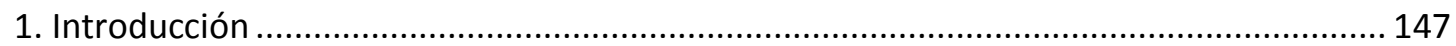

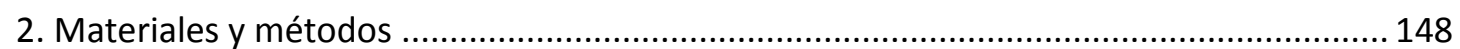

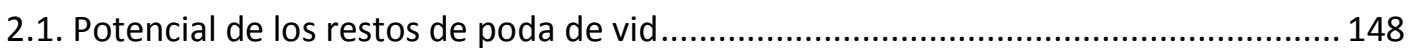

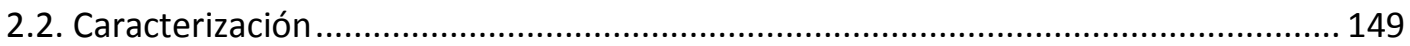

2.2.1. Métodos analíticos y estadísticos ..................................................... 149

2.3. Opciones de valorización de los restos de poda de vid ......................................... 149

3. Resultados y discusión ................................................................................... 150

3.1. Potencial de valorización de restos de poda de vid en la Región de Murcia ............ 150

3.2. Caracterización de los restos de poda de vid.................................................. 152

3.3. Opciones de valorización de los restos de poda de vid .................................... 153

3.3.1. Valorización agrícola ........................................................................... 156

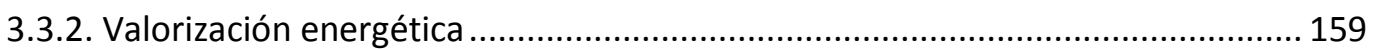

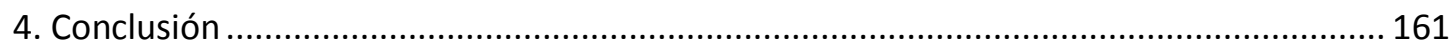

5. Bibliografía ...................................................................................................... 161

VI. Gestión de lodos agroalimentarios mediante diferentes estrategias de co-compostaje: estudio del valor añadido de los compost obtenidos ................................................ 165

1. Introducción ................................................................................................ 167

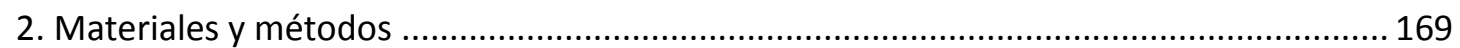

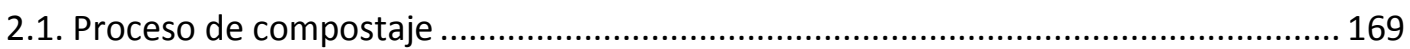

2.2. Análisis químico de las muestras de compost.................................................... 172

2.3. Determinación microbiológica y análisis de las actividades enzimáticas ................. 172

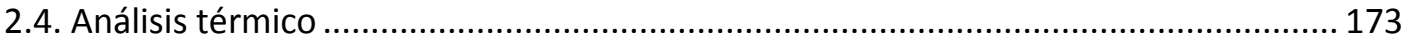

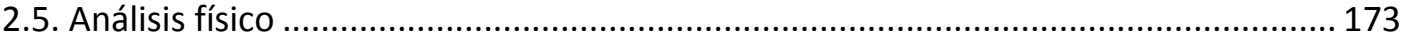

2.6. Ensayo en semillero para determinar la capacidad supresiva de los compost obtenidos 


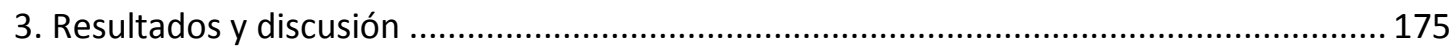

3.1. Evolución de la temperatura durante el proceso de compostaje.............................. 175

3.2. Evolución de la fracción orgánica y estudio de la calidad del compost ...................... 176

3.2.1. Determinaciones químicas y biológicas .......................................................... 176

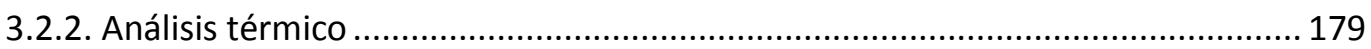

3.3. Propiedades y potencial valor añadido de los compost obtenidos ........................... 182

3.3.1. Propiedades físico-químicas, químicas y microbiológicas................................... 182

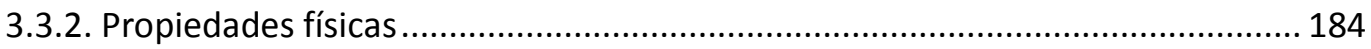

3.3.3. Capacidad supresiva de los compost frente a F. oxysporum melonis: ensayo en semillero 184

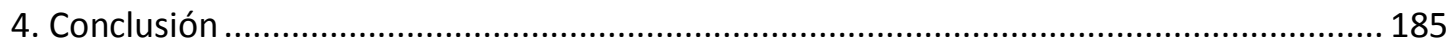

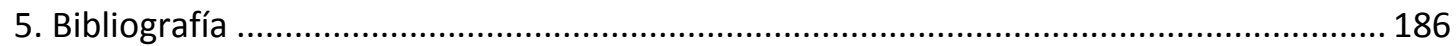

VII. Compostaje de residuos orgánicos y subproductos agroindustriales para reducir el uso de

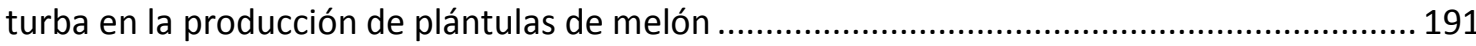

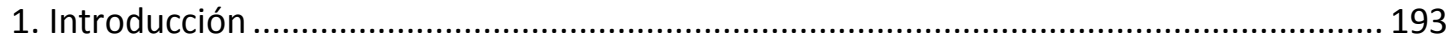

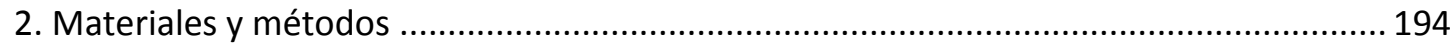

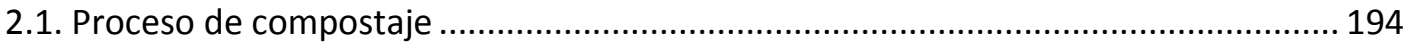

2.2. Propiedades físicas, químicas y microbiológicas de los compost ............................. 195

2.3. Ensayo en semillero (índice de germinación, peso de plántulas de melón e incidencia

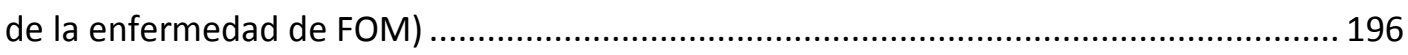

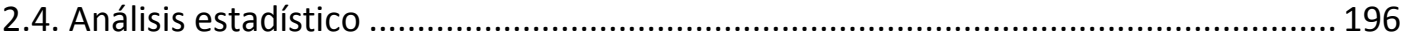

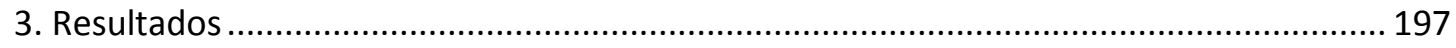

3.1. Evolución de la temperatura del proceso de compostaje ......................................... 197

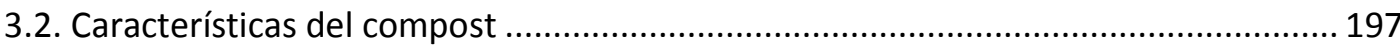

3.3. Efecto de los compost como sustrato de cultivo en melón y su capacidad supresividad

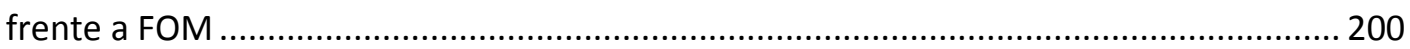

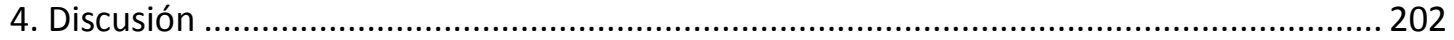

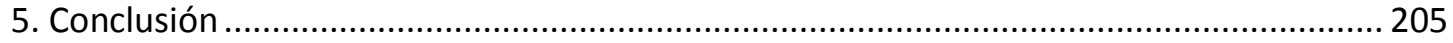

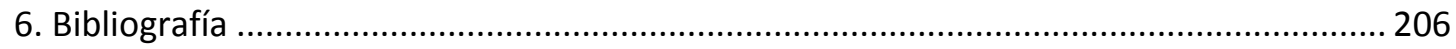

VIII. Mejora de la calidad de un suelo salino del Mediterráneo mediante una enmienda con compost de restos de poda de vid enriquecido con Trichoderma harzianum T78.................... 211

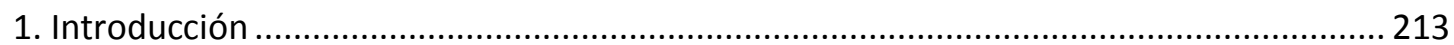

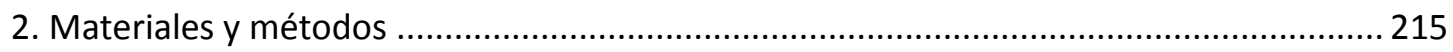

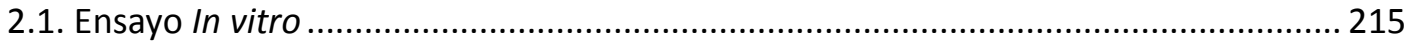

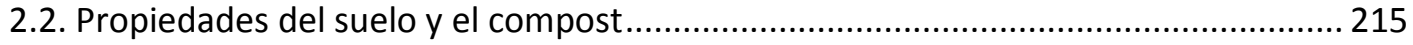


2.4. Parámetros determinados ........................................................................... 216

2.5. Análisis estadístico ....................................................................... 217

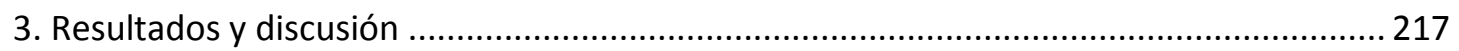

3.1. Demostración In vitro de la tolerancia a la sal de la cepa T. harzianum T-78........... 217

3.2. Ensayo de incubación ................................................................................. 219

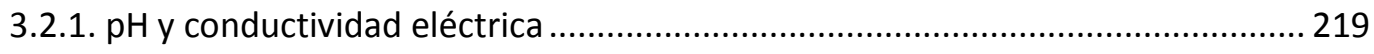

3.2.2. Trichoderma harzianum y la evolución de bacterias y hongos ........................... 219

3.2.3. Carbono orgánico total, carbono de la biomasa microbiana y actividades enzimáticas................................................................................... 222

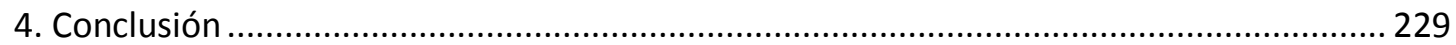

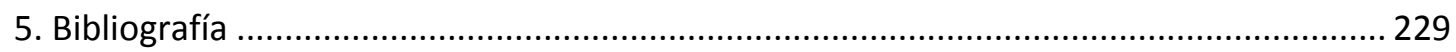

IX. Co-digestión anaerobia mesófila de lodos agroalimentarios con restos de alcachofa para su biometanización. Dinámica de la comunidad Archaea y características abióticas del proceso233

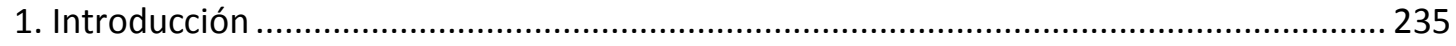

2. Materiales y métodos ............................................................................. 236

2.1. Parámetros físicos y químicos del análisis del lodo .......................................... 236

2.2. El reactor y el análisis de las muestras de digestato ......................................... 237

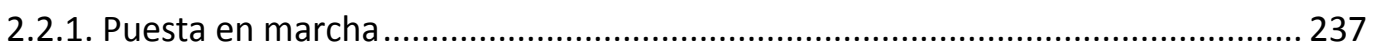

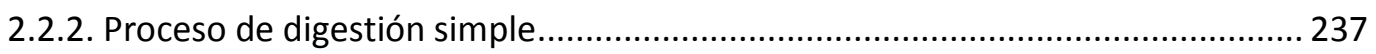

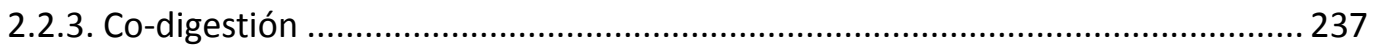

2.3. Extracción de ADN ................................................................................... 238

2.4. Análisis con microarray ANAEROCHIP ......................................................... 238

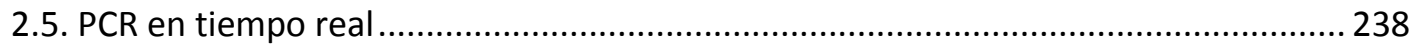

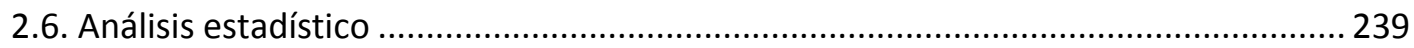

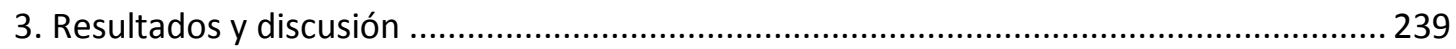

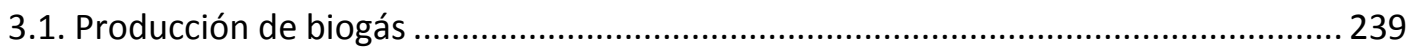

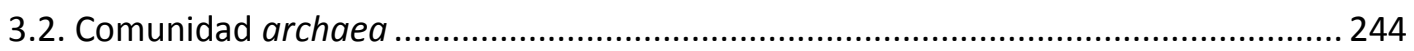

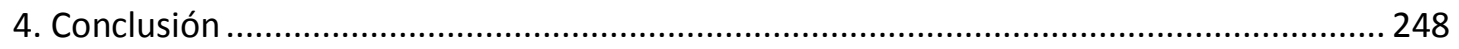

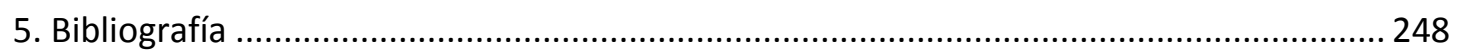

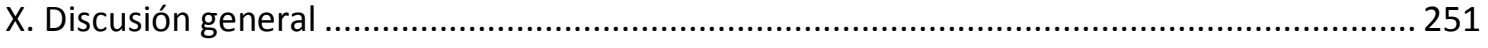

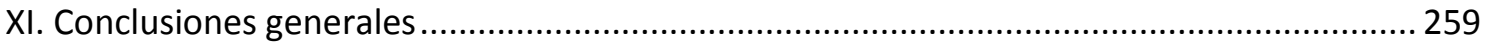

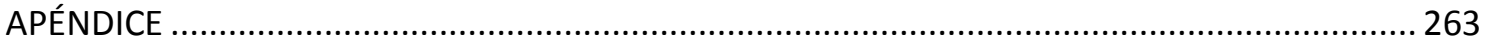



I. Introducción general 



\section{Introducción general}

\section{Problemática ambiental asociada a los residuos. La necesidad de gestionar}

En los últimos años a nivel mundial se ha incrementado considerablemente la preocupación por cuestiones ambientales, aunque el origen de los problemas de contaminación ocasionados es tan antiguo como el hombre: la alteración de los cursos de agua, el deterioro del suelo o las emisiones de gases contaminantes son parte del legado dejado por los pueblos prehistóricos, sobre todo después de la invención del fuego (Pérez Cebada, 2001).

El fuerte incremento en el consumo de materias primas útiles en los procesos industriales y la aplicación de nuevas tecnologías y fuentes de energía como el petróleo, aumentan y diversifican hasta extremos desconocidos la escala de impactos ambientales (Ponting, 1992; González de Molina, 1993). La introducción repentina de componentes de mayor o menor toxicidad en el medio natural puede superar la capacidad de metabolización de los diversos ecosistemas receptores dando como resultado la acumulación de contaminantes que pueden resultar problemáticos y perjudiciales para los mismos.

Como bien es conocido, la historia de la contaminación da un salto cualitativo fundamental a partir de la Revolución Industrial. Actualmente, el deterioro del medio ambiente es una realidad y la sociedad actual se enfrenta a problemas como el cambio climático, escasez de recursos naturales y eutrofización de las aguas que limita la calidad de nuestra vida. La afección al medio ambiente es consecuencia de las actividades económicas, de producción y de consumo, que los humanos realizamos. Por este motivo es necesario aplicar medidas que eviten, o por lo menos mitiguen, los daños que la actividad humana e industrial ocasiona sobre el medio ambiente. Como consecuencia de todo ello, la Unión Europea dictó la Directiva 2008/1/CE y, actualmente la Directiva 2010/75/UE de 24 de noviembre de 2010 (DOUE, 2010), cuyo propósito es conseguir la prevención y control integral de la contaminación, estableciendo la base legal para la protección del medioambiente resultante de las actividades que aparecen en su Anexo I, suponiendo además la aplicación del principio de prevención en el funcionamiento de las instalaciones industriales mediante la implantación de medidas para evitar, o al menos reducir, en origen las emisiones de estas actividades en la atmósfera, el agua y el suelo, incluidos los residuos para alcanzar un nivel elevado de protección del medio ambiente considerado en su conjunto.

Además, la Unión Europea ha desarrollado la Directiva comunitaria 2008/98/CE (DOUE, 2008), conocida como Directiva Marco de Residuos, con el fin de favorecer políticas de gestión de residuos cuyo objetivo es mitigar el impacto de los mismos sobre la salud y el medio ambiente, así como mejorar la eficiencia en el uso de los recursos. A largo plazo, el marco legal europeo persigue reducir la generación de 
residuos o, cuando su producción es inevitable, promover su reutilización o su reciclaje, así como su eliminación por una vía segura. Por otro lado, también mediante la Directiva 91/271/CE, sobre el tratamiento de las aguas residuales (DOUE, 1991), la Unión Europea pretende proteger el medio ambiente de los efectos negativos de las aguas residuales contemplando la obligatoriedad de cumplir, entre otros, con el tratamiento de las aguas residuales y con unos requisitos de vertido en cuanto a analítica y rendimientos.

La Ley 22/2011, de 28 de julio, de residuos y suelos contaminados (BOE, 2011) es la que incorpora al ordenamiento jurídico español la Directiva comunitaria 2008/98/CE (DOUE, 2008). Esta ley establece una jerarquía de residuos para conseguir el mejor resultado ambiental global con el siguiente orden de prioridad (Figura 1), donde la valorización se define como "cualquier operación cuyo resultado principal sea que el residuo sirva a una finalidad útil al sustituir a otros materiales, que de otro modo se habrían utilizado para cumplir una función particular, o que el residuo sea preparado para cumplir esa función en la instalación o en la economía en general". También incluye apartados específicos que hacen referencia al concepto de subproducto y biorresiduo (artículo 4.2), pero no establece cual es la mejor solución para los subproductos, aunque sí indica que las autoridades ambientales promoverán medidas que se incluirán en los planes y programas de gestión de residuos en lo que respecta a los biorresiduos (artículo 24).

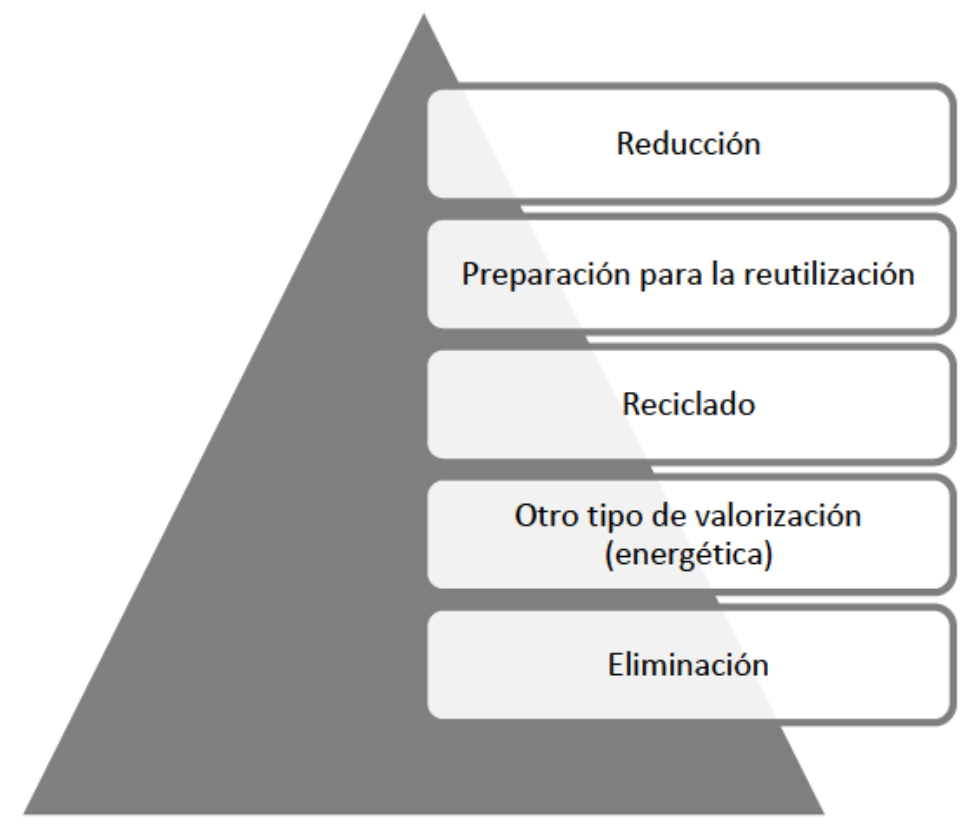

Figura 1. Jerarquía de residuos (Ley 22/2011)

Otro documento legal a considerar para la toma de decisiones en materia de gestión de residuos es la Orden MAM/304/2002 (BOE, 2002), documento que transpone la Decisión 2000/532/CE (DOUE, 2000) a la legislación española, donde se incluye la Lista Europea de Residuos y en el que los residuos se clasifican en 20 
categorías distintas en función de su naturaleza y de su origen. Además, propone un listado de opciones de valorización donde se incluyen el reciclado o recuperación de sustancias orgánicas que no se utilizan como disolventes (incluidos el compostaje y otros procesos de transformación biológica) (R3) y el tratamiento de los suelos que produzca un beneficio a la agricultura o una mejora ecológica de los mismos (R10). La Decisión 2000/532/CE (DOUE, 2000) ha sido modificada posteriormente por la Decisión 2001/118/CE (DOUE, 2001) y la reciente Decisión 2014/955/UE (DOUE, 2014), pero no se incluyen modificaciones que afecten a la Orden MAM/304/2002 (BOE, 2002).

Un tipo de residuos que presenta oportunidades atractivas de gestión son los residuos de naturaleza orgánica, donde se encuentran los residuos agrícolas y de industrias agroalimentarias, así como fangos o lodos generados en las Estaciones Depuradoras de Aguas Residuales (EDAR), además de residuos de actividades ganaderas y la fracción orgánica de los residuos sólidos urbanos. Además, teniendo en cuenta que el depósito de residuos en vertederos está limitado según la Directiva 1999/31/CE (DOUE, 1999) para que se produzca en el año 2016 una reducción de residuos biodegradables hasta el 35 \% de los cuantificados en el año 1995, la adopción de alternativas de valorización que incluye tratamiento biológico, como son el compostaje y la digestión anaerobia, pueden contribuir al cumplimiento de directiva mencionada.

Por otro lado, debido a que la gestión de residuos es un tema crucial que preocupa a las empresas desde hace escasas fechas y sobre la que se desconocen múltiples aspectos (Tamayo Orbegozo et al., 2012), tales como las ventajas derivadas de un tratamiento eficiente de los residuos, es necesario dar a conocer la potencialidad de la gestión de los residuos. En el caso concreto de los residuos agrícolas y de industrias agroalimentarias no existe una clara conciencia ambiental para su manejo, además de que falta capacidad tecnológica y recursos económicos para darles un destino final, así como una legislación específica para promover la gestión de este tipo de residuos, que asegure un buen manejo desde su generación hasta su disposición final. Por lo tanto, estudios encaminados a dar solución a esta problemática son de interés y especialmente para los empresarios del sector que han de cumplir con la legislación para satisfacer las demandas de la sociedad en el ámbito medioambiental.

Además, según Porter y Van Der Linde (1995), la gestión eficiente de la variable medioambiental puede erigirse en fuente de competitividad empresarial. De hecho, según numerosos autores, una gestión eficiente de la variable medioambiental puede proporcionar numerosas oportunidades de negocio (Hart, 1995; Melbin, 1995; Aragón, 1998; Bansal y Roth, 2000; Melnyk et al., 2003; Zhu y Sarkis, 2004; Telle, 2006; Herreborg, 2008). Entre otros, beneficios directos tales como la mejora de la satisfacción de los clientes o facilitar la obtención de ahorros en costes o la 
disminución de inversiones requeridas en la empresa (Autry et al., 2001), lo cual puede repercutir, tanto directa como indirectamente, sobre los resultados empresariales (Tamayo, 2009; Aguilera et al., 2011).

\section{La Región de Murcia y su vinculación con la agricultura y la industria agroalimentaria}

La Comunidad Autónoma de la Región de Murcia está situada al Sureste de España, en pleno arco mediterráneo. Ocupa una superficie total de $11.317 \mathrm{~km}^{2}$, que representa el $2,2 \%$ del territorio nacional y tiene una población que supera el millón de habitantes.

La Región de Murcia tiene una producción agrícola de alto valor añadido, generada en un clima árido con escasos recursos hídricos, pero con un intenso aprovechamiento de la radiación solar como factor diferencial y con una constante apuesta por la innovación tecnológica, dirigida a encontrar soluciones efectivas para obtener la más alta rentabilidad y productos agrícolas de primera calidad.

El cultivo de hortalizas en la Región de Murcia ocupa una superficie de 51.924 ha y el de cultivos leñosos 194.366 ha, según datos del Centro Regional de Estadística de la Región de Murcia del año 2013 (CREM, 2015). Los cultivos de brócoli, melón, sandía, lechuga, tomate, pimiento y alcachofa son los de mayor producción en cuanto a hortalizas, mientras que el limonero, melocotonero, naranjo y viñedos son los de mayor producción en cuanto a cultivos leñosos. Estos cultivos se llevan a cabo en sistemas agrarios intensivos, que presentan la ventaja de grandes producciones.

A pesar de la crisis económica actual que tan negativamente afecta al acceso de las empresas al crédito y a la demanda de sus productos, el sector agrario continúa teniendo un elevado protagonismo en la economía murciana por su contribución al PIB regional y a la generación de empleo. Esta importancia socioeconómica del agro murciano se ve incrementada, fuertemente, por los efectos inducidos que ejerce sobre otras actividades con una elevada dependencia del mismo.

Entre estas actividades destacan las desarrolladas por la industria alimentaria, a la que abastece de materias primas, y otras auxiliares, formadas por un denso entramado de empresas auxiliares dependientes de relaciones técnicas y económicas tanto con las empresas agrarias como alimentarias. Tal es el caso de las empresas de servicios (transporte, finanzas, informática, comercialización, mantenimiento, asesoramiento, etc.) y las que les dotan de las construcciones (edificios agrícolas y agroindustriales, embalses, caminos, invernaderos, etc.); maquinaria (agrícola y agroindustrial); instalaciones (de riego, eléctricas, frigoríficas, calefacción, etc.) e inputs (semillas, energía y lubricantes, plásticos, fertilizantes, plaguicidas, productos veterinarios y químicos, piensos, envases y embalajes, etc.) necesarios para el normal 
desarrollo de su actividad. De aquí el consenso existente en torno al carácter estratégico del sector agrario murciano.

\subsection{Industria agroalimentaria}

En España, la Industria de productos de alimentación y bebidas es la primera rama industrial, según la última Encuesta Industrial de Empresas del INE, a 31 de diciembre de 2013 , representando el $20,6 \%$ de las ventas netas de producto, el $18,2 \%$ de personas ocupadas, el 16,8 \% de las inversiones en activos materiales y el 15,3\% del valor añadido. Los sectores de Conservas de Frutas y Hortalizas y de Vinos, alcanzaron los 7.335 y 6.056 millones de euros, respectivamente, lo que supone el $8,0 \%$ y el 6,6 \% del total de las ventas netas de producto de la Industria Alimentaria (MAGRAMA, 2015).

La Región de Murcia es la que aporta el mayor porcentaje de ventas netas al sector de conservas de frutas y hortalizas a nivel nacional, un $24 \%$ y da empleo a un mayor número de personas frente al resto de Comunidades. Es por ello, de especial importancia este sector para la economía de la Región de Murcia sin olvidar su efecto sobre el medio ambiente, más teniendo en cuenta que su fuente de abastecimiento es el medio que recibe el impacto medioambiental de su propia actividad.

\subsubsection{El sector de conservas de frutas y hortalizas. Región de Murcia}

El sector de frutas y hortalizas transformadas se distribuye por todo el territorio nacional en atención a múltiples y variadas circunstancias, identificándose en el mismo importantes concentraciones muy localizadas geográficamente. Este último sería el caso de la Región de Murcia, que al igual que en algunas provincias del Valle del Ebro, dispone de una industria con gran tradición y es líder a nivel nacional.

Desde una perspectiva amplia, en la cadena de producción de conservas vegetales, se pueden distinguir tantas fases como tipos de transformaciones existen como almíbar, zumos, congelados, encurtidos, etc., pudiendo a su vez diferenciar estas según algunos tipos de productos con rasgos específicos (tomate, cítricos, frutas de hueso, etc.). Una simplificación de la misma, válida y complementaria con la anterior clasificación, plantea la existencia de únicamente tres grandes fases, que van a definir distintos mercados, flujos y relaciones en la cadena de producción. Según ésta, la cadena comenzaría en la producción de la materia prima agraria (frutas y hortalizas, foráneas o no). A esa etapa le sigue la de transformación del producto, pudiendo subdividir ésta entre lo que son productos de primera transformación y alimentos que requieren segundas transformaciones.

En el aspecto de la actividad agrícola, en la Región de Murcia, al igual que otras zonas productoras como el Valle del Ebro, el desarrollo de la industria conservera ha 
estado muy vinculado a la presencia en esas zonas de grandes producciones hortofrutícolas. El sector hortofrutícola murciano en fresco, de gran importancia en España destina una importante parte de su producción a la transformación, de la que, no obstante, no se dispone de datos que permitan su cuantificación exacta. Concretamente, la importancia que en la Región de Murcia adquieren determinadas producciones de conservas, como son las de alcachofa y pimiento, o de determinadas frutas (melocotón o albaricoque) está determinada por la dimensión que en la Región adquiere su producción, siendo muy importante la conexión y complementariedad que entre el sistema agrario regional y su agroindustria existe.

Por otro lado, en la fase de transformación del producto agrario, se puede distinguir entre primeras y segundas transformaciones, clasificación que permite explicar determinados flujos comerciales y orientaciones productivas dentro del sector. En el primero de los grupos se incluyen todas aquellas actividades en las que el agricultor (a nivel particular o asociativamente) entrega sus productos a una empresa (en alguna ocasión asociada a los propios agricultores, pero no habitualmente) para que sobre el producto se realice una primera transformación pudiendo llegar al consumidor final o a una empresa de segunda transformación si comercializan a granel productos elaborados o semielaborados. En el caso de las empresas de la segunda opción estas pueden dedicarse a envasar productos a granel para destinarlos al consumidor final directamente o bien pueden aplicar una segunda transformación y elaborar platos mezclando varios productos semielaborados o elaborados.

En la actualidad el sector conservero murciano presenta una amplia gama de elaborados alimenticios, que trasciende ampliamente el concepto tradicional de 'conserva vegetal'. Centrándonos en las actividades económicas, se pueden clasificar las industrias de procesado y conservación de frutas y hortalizas, de acuerdo con la Clasificación Nacional de Actividades Económicas (CNAE 2009), con código C103, en:

1. Zumos (de frutas y hortalizas). Incluye su extracción, así como la elaboración de cremogenados, concentrados y de otros derivados. Coincide por completo con la categoría CNAE 1032. Elaboración de zumos de frutas y hortalizas.

2. Conservas de vegetales (hortalizas y frutas). Se incluyen dentro de la categoría CNAE 1039. Otro procesado y conservación de frutas y hortalizas.

3. Congelados (de frutas y hortalizas). Esta actividad, por su particularidad en la operación de conservación del producto, se va a considerar por separado del resto de actividades del grupo al que pertenece, que es la categoría CNAE 1039. Otro procesado y conservación de frutas y hortalizas.

4. Aderezo y encurtidos. Esta producción, que también se encuentra dentro de la categoría CNAE 1039. Otro procesado y conservación de frutas y hortalizas, presenta algunas peculiaridades que llevan nuevamente a plantear el interés de que sea contemplada como un grupo aparte. 
En el caso de que las empresas lleven a cabo la elaboración de otros productos alimenticios, como las salsas y los platos y comidas preparadas, nos encontraremos con empresas cuya actividad está clasificada con los CNAE 1084 y 1085 respectivamente.

\section{Caracterización y clasificación de los residuos orgánicos de producción agraria y agroalimentaria}

Los residuos agroindustriales son materiales en estado sólido o líquido que se generan a partir del consumo directo de productos primarios o de su industrialización, y que ya no son de utilidad para el proceso que los generó, pero que son susceptibles de aprovechamiento o transformación para generar otro producto con valor económico, de interés comercial y/o social (Saval, 2012).

La caracterización y definición de los "residuos" vegetales generados por la actividad agrícola no plantea dificultades desde el punto de vista que se generan en los propios cultivos y están relacionados con él, pero la actividad productiva de transformación del producto agrario, considerado como materia prima en productomercado alimentario, plantea dificultades añadidas fruto de la dificultad en la identificación de las empresas, tal y como hemos comentado anteriormente, así como el tipo de materia prima tan diferente y variable en el tiempo dentro de la misma empresa debido a su variedad, determinada por su naturaleza inicial y características intrínsecas, así como a su modo de generación. También sus potencialidades de gestión, por medio de procesos alternativos y/o complementarios de valorización y de eliminación plantean dificultades para su caracterización y definición.

En el pasado hubo un reduccionismo exclusivista que, despreocupándose de la naturaleza y características intrínsecas de los residuos y de sus potencialidades, se orientó casi exclusivamente a su eliminación como modalidad de gestión preferente. Por ello, se hizo necesario progresar en la definición y clasificación de los materiales denominados genéricamente como residuos, desechos o subproductos. Actualmente, en la normativa vigente, la Ley 22/2011 de residuos y suelos contaminados (BOE, 2011), se han establecido definiciones como residuo, biorresiduo y subproducto (Tabla 1), pero aún es necesario progresar en la construcción de una definición integral y operativa, que requiere desarrollar una tipología basada en la caracterización y clasificación de estos materiales, pues en la Lista Europea de Residuos transpuesta a la legislación española en la Orden MAM/304/2002 (BOE, 2002), aún estos materiales se clasifican como "Residuos de tejidos vegetales" -№ 0201 03- o "Materiales inadecuados para el consumo o elaboración" -№ 0203 04-, por lo que existe una confusión entre si el material vegetal es un residuo, biorresiduo o subproducto y por lo tanto cual es la modalidad preferente de gestión. 
Por lo tanto, con el objeto de esclarecer generalidades respecto a la tipología del material que nos ocupa, y que no sean materiales destinados a su eliminación sin considerar su potencial valorización, se propone la clasificación tipológica siguiente atendiendo a características intrínsecas propias de la naturaleza de los materiales, fuente y modo de generación y funcionalidad potencial de valorización.

\section{A) Atendiendo a sus características naturales}

Se constata que la mayoría de los residuos agroalimentarios conservan, en todo o en parte, los valores y/o utilidades intrínsecas (p.e.: organolépticas) de los frutos originarios, diferenciándose de ellos en forma, calidad, etc. De acuerdo con este criterio se distinguen los tipos siguientes:

Residuos que conservan los valores y utilidades esenciales, tanto intrínsecos como aparenciales (p.e.: forma), de los frutos originarios, diferenciados de estos en términos de calidad. Se trata de materiales constituidos por frutos enteros que no alcanzan los parámetros de calidad y normalización requeridos por el proceso de transformación, denominados convencionalmente "destríos".

Residuos que conservan los valores intrínsecos propios del fruto originario, aunque no los de carácter aparencial. Se trata de materiales constituidos por partes de frutos eliminada en el proceso de acondicionamiento para su transformación en producto-mercado alimentario, constituyendo la mayor parte de los residuos generados en este sector.

Residuos que no conservan los valores y utilidades esenciales de los frutos originarios. Su naturaleza resulta alterada drásticamente por la acción de procesos de carácter físico-químico en el proceso productivo como los lodos derivados de las conservas vegetales, el alperujo del aceite y el de la vinificación.

\section{B) Atendiendo al modo de generación}

Aparecen determinados por tres factores: el tipo de proceso de producción aplicado incluyendo la tecnología empleada, el origen en cada una de las etapas del proceso productivo y el tipo de producto final. En relación con estos factores se distinguen los tipos siguientes:

Frutos enteros. Aquellos eliminados en la fase inicial y/o previa del proceso productivo debido a no cumplir los estándares de calidad y normalización requeridos.

Partes de frutos de diferente naturaleza (hojas, huesos, pieles, semillas, etc.). Son objeto de separación y eliminación en diferentes fases del proceso productivo y que, como se destacaba anteriormente, son las mayoritarias en el sector de transformados vegetales

Residuos de diversa naturaleza físico-química. Originados por intensos procesos de transformación como los mencionados originados por las actividades de conservación vegetal, elayotecnia o de vinificación. 


\section{C) Atendiendo al potencial de valorización}

Aparecen determinados por tres factores: las características intrínsecas y aparenciales de los materiales, la tecnología disponible y la viabilidad económica de los procesos de gestión y valorización aplicables en cada caso. En este sentido, se distinguen los tipos siguientes:

Residuos potencialmente recuperables para usos y utilidades relacionadas iguales 0 similares- con las inherentes al producto principal. En el caso del sector de transformados vegetales comprenden principalmente los frutos enteros de destrío y partes de frutos, especialmente tejidos, que son potencialmente valorizables para alimentación humana y animal, farmacológicos, cosméticos, etc.

Residuos valorizables para usos distintos al del producto principal. Son similares a los anteriores por su origen (p.e.: partes de frutos como los huesos y algunos tipos de pieles o cáscaras), pero se dirigen a la obtención de energía calorífica.

Residuos que requieren procesos de gestión y valorización diferenciados. Se engloban aquí los lodos, alperujos, etc., que principalmente conllevan un proceso de compostaje para usos agrícolas.

Residuos finales. Aquellos provenientes de procesos de valorización no susceptibles de nuevos tratamientos, que deben ser destinados incineración o depósito en vertedero.

A partir de esta caracterización y clasificación tipológica, y en orden a desarrollar procesos de gestión y valorización, se pueden utilizar las definiciones operativas indicadas en la Tabla 1. 
Tabla 1. Definiciones de interés

\begin{tabular}{|c|c|}
\hline JN LA & NICIONES OPERATIVAS \\
\hline $\begin{array}{l}\text { Residuo. Cualquier sustancia u objeto que su } \\
\text { poseedor deseche o tenga la intención o la } \\
\text { obligación de desechar. } \\
\text { Biorresiduo. Residuo biodegradable de jardines y } \\
\text { parques, residuos alimenticios y de cocina } \\
\text { procedentes de hogares, restaurantes, servicios de } \\
\text { restauración colectiva y establecimientos de venta } \\
\text { al por menor; así como, residuos comparables } \\
\text { procedentes de plantas de procesado de alimentos. } \\
\text { Subproducto. Sustancia u objeto, resultante de un } \\
\text { proceso de producción, cuya finalidad primaria no } \\
\text { sea la producción de esta sustancia u objeto, puede } \\
\text { ser considerada como subproducto y no como } \\
\text { residuo, definido en el artículo } 3 \text {, apartado a), } \\
\text { cuando se cumplan las siguientes condiciones: } \\
\text { a. Que se tenga la seguridad de que la sustancia u } \\
\text { objeto va a ser utilizado ulteriormente, } \\
\text { b. que la sustancia u objeto se pueda utilizar } \\
\text { directamente sin tener que someterse a una } \\
\text { transformación ulterior distinta de la práctica } \\
\text { industrial habitual, } \\
\text { c. que la sustancia u objeto se produzca como parte } \\
\text { integrante de un proceso de producción, y } \\
\text { d. que el uso ulterior cumpla todos los requisitos } \\
\text { pertinentes relativos a los productos así como a la } \\
\text { protección de la salud humana y del medio } \\
\text { ambiente, sin que produzca impactos generales }\end{array}$ & $\begin{array}{l}\text { Biorresiduo. Incluye los materiales vegetales - } \\
\text { frutos enteros o partes de frutos- generados en } \\
\text { los procesos de transformación del producto } \\
\text { agrario -materia prima- en producto-mercado } \\
\text { alimentario, tanto por su inferior calidad o } \\
\text { como resultado de las características del } \\
\text { proceso y de los productos alimentarios } \\
\text { obtenidos del mismo, que en el marco de esos } \\
\text { procesos específicos no presentan utilidades y, } \\
\text { por tanto, no alcanzan valor económico, pero } \\
\text { que son portadores de potenciales de } \\
\text { valorización para diferentes usos por medio de } \\
\text { la aplicación de tecnologías adecuadas a cada } \\
\text { uno de ellos. } \\
\text { Subproducto. Aquellos biorresiduos que han } \\
\text { sido sometidos a un proceso de tratamiento } \\
\text { mínimo y primario en el marco de la unidad de } \\
\text { producción básica en los que se han generado } \\
\text { en orden a facilitar su gestión y su posterior } \\
\text { valorización y comercialización, alcanzando un } \\
\text { valor económico determinado. } \\
\text { Coproductos. Productos sustantivos, } \\
\text { relacionados pero diferenciados del producto } \\
\text { originario, obtenidos a partir de subproductos } \\
\text { por medio de procesos de valorización, } \\
\text { aplicando tecnologías específicas. }\end{array}$ \\
\hline
\end{tabular}

\section{Biorresiduos}

\subsection{Las podas y restos vegetales de cultivos}

Muchas empresas, además de los agricultores, durante la etapa de producción de la materia prima, debido a los cultivos intensivos que utilizan se encuentran con el inconveniente de una gran cantidad de biorresiduos (masa vegetal producida en los cultivos). Estos biorresiduos agrícolas abarcan principalmente las partes de los cultivos que no son consumibles o comercializables y consisten en restos lignocelulósicos. Se pueden clasificar en función de su naturaleza y características físico-químicas en herbáceos y leñosos:

a) Los biorresiduos agrícolas herbáceos proceden de plantas de tallo no leñoso que mueren al final de su temporada de crecimiento.

b) Los biorresiduos agrícolas leñosos proceden principalmente de las podas de los olivos, viñedos y frutales, por lo que su producción, al igual que en el caso de 
los anteriores, tiene un carácter estacional. La práctica habitual de la poda se puede definir como la eliminación de las partes vivas de la planta (sarmientos, partes de los troncos, partes herbáceas, etc.) con el fin de modificar el hábito de crecimiento natural de los cultivos y obtener un adecuado rendimiento en la producción.

Por otro lado, se puede hablar de otros biorresiduos, constituidos principalmente por frutas que caen en la parcela o marras de plantas inmaduras, además de los destríos debidos a la clasificación en campo porque no cumplen los requisitos mínimos de calidad comercial. La generación de los mismos es variable y se caracteriza por presentar características similares a la propia materia prima. Este aspecto se considera en el apartado 4.2.

En la Región de Murcia el cultivo de leñosos incluye los frutales cítricos y no cítricos, el viñedo y el olivar principalmente, por lo que los principales biorresiduos leñosos -restos de poda- incluyen las ramas de olivar y los sarmientos de viñedos, pero sobre todo las ramas generadas por los frutales de hueso y los cítricos. En cuanto a los cultivos hortícolas destaca el especial volumen de los restos de cultivos en especies como tomate y pimiento.

Teniendo en cuenta la distribución temporal a lo largo de la duración del ciclo productivo, en los cultivos hortícolas nos encontramos con partes de la planta que quedan en campo tras la recolección y que no son de interés comercial, denominados convencionalmente restos de cultivo. Podemos decir que los cultivos de ciclo largo al aire libre generan un elevado volumen de residuos de este tipo, ligados principalmente a las sucesivas recolecciones características de los mismos. El caso más destacado en la Región de Murcia es el de la alcachofa con un periodo incremental que se produce desde octubre hasta mayo, aunque también los cultivos de ciclo largo correspondientes a hortalizas de fruto -tomate y pimiento como casos más representativos- en cultivo protegido o al aire libre, ya que su secuencia abarca la mayor parte del año, presenta un biorresiduo generado por la poda -deshoje y destalle- y otro en el momento posterior a la recolección en que se produce la retirada generalizada de restos de cultivo -plantas- de importante volumen, principalmente en los meses de julio, en el caso del tomate, y de septiembre en el del pimiento. Por otro lado, los cultivos de ciclo corto, generan restos vegetales principalmente relacionados con la recolección, pero debido a los sucesivos ciclos de cultivo, su dinámica abarca todo el año prácticamente. Entre ellos destacan por su importancia, en la Región de Murcia, las hortalizas de inflorescencia (brócoli y coliflor), las de hoja como la lechuga y las de tallo como el apio.

Por otro lado, la producción de biorresiduos de cultivos leñosos está definida por volúmenes determinados por el porte de cada especie y variedad, y por la densidad de cultivo. No se presenta todo el año, pues están sujetos a la estacionalidad de las operaciones que los generan, las podas principalmente. En los cítricos, 
particularmente destaca el limonero en la Región de Murcia, se generan durante el periodo abril-agosto, en que se produce la sucesión de podas de los dos principales grupos varietales: Verna y Fino. En cuanto a frutales de hueso destaca el melocotonero con dos periodos bien definidos: uno principal entre noviembre y enero, y otro secundario en julio y agosto, correspondientes a los grupos varietales media estación/tardíos y tempranos respectivamente. Otras especies como el albaricoquero y el ciruelo, se concentran en un solo periodo de octubre a enero, debido a su carácter estacional más estricto. Finalmente, otras especies con dinámica propia y un alto volumen unitario de biorresiduos son los frutales de pepita, el viñedo o el olivar, con periodos determinados asimismo por los factores expresados.

\subsubsection{Gestión actual de las podas y restos vegetales de cultivos}

Los restos de cultivos que se quedan en el campo se gestionan mayoritariamente en el marco de la explotación agraria como alimento para ganado de pastoreo, como materia orgánica y nutrientes para el suelo mediante labores de labranza, o por medio de la cremación. Los restos de podas, en el caso de cultivos leñosos, se gestionan también mediante cremación o bien aplicándolos al suelo previa trituración. No existe una normativa específica para este tipo de biorresiduos por lo que para ellos se aplica la ley de residuos vigente denominándose "Residuos de tejidos vegetales" (№ 0201 03), pero debido a que se utilizan en el sector agrario han de denominarse subproductos. Además, estos pueden ser valorizados, con una simple etapa de secado y triturado, para la producción de energía, y por tanto denominarse biomasa.

Actualmente existen problemas de índole técnica y económica para el aprovechamiento de la poda para biomasa, ya que un agricultor individual medio no tiene capacidad por sí mismo para, primero, adquirir la maquinaria necesaria para triturar los restos de poda $y$, en segundo lugar, gestionar el almacenamiento $y$ transporte a planta de los restos, de tal forma que el proceso global le sea viable económicamente. Por ello, puede ser necesaria la participación de empresas de servicios agrícolas o empresas cooperativas para la realización del triturado en campo y el transporte a destino (planta eléctrica o de producción de pellets) de los restos de poda, así como la gestión previa de la logística de almacenamiento en campo de los restos.

\subsection{Restos vegetales y partes de frutos en el sistema productivo de las empresas del sector de conservas de frutas y hortalizas de la Región de Murcia}

De forma genérica el proceso de elaboración de conservas de frutas y hortalizas se puede describir de la siguiente manera: 
a) Las materias primas (generalmente son productos estacionales que hay que elaborar durante el periodo de recolección) recibidas en la fábrica pueden ser conservadas durante un periodo de tiempo limitado en cámaras de refrigeración o almacenadas a temperatura ambiente hasta su introducción en el proceso de fabricación.

b) Los productos vegetales deben ser sometidos a una serie de operaciones de preparación, encaminadas a darles la forma deseada (mediante corte o troceado), eliminar la piel que los recubre (pelado), inactivar las enzimas y eliminar el aire que forma parte de su estructura (escaldado y enfriado), etc. El orden en que se realizan estas operaciones es variable dependiendo de la materia vegetal elaborada y del tipo de tecnología empleada.

c) El tratamiento de conservación aplicado, en el caso de las conservas, consiste en el cierre hermético de los envases que contienen el producto y en la aplicación de calor.

Teniendo en cuenta lo anterior, según el tipo de materia prima utilizada y el producto que se desee obtener se desarrollan una serie de etapas, en las que se generan biorresiduos, que a su vez difieren del uso de las tecnologías de procesado de alimentos que actualmente se encuentran en el mercado.

La generación de biorresiduos en el subsector de transformados vegetales es importante sobre todo en cuanto a su volumen o cantidad, ya que se incluyen en esta clasificación los restos de la materia prima que son desechados en el proceso de elaboración de transformados vegetales bien por destríos iniciales, bien por descartes en la adecuación del producto o materias primas agotadas, además de productos que no tienen la calidad comercial. En resumen, el porcentaje de estos puede ser elevado. En la Tabla 2 se presentan datos aportados por Centros Técnicos y disponible en la Guía de Mejores Técnicas Disponibles en España del sector de los transformados vegetales (MAGRAMA, 2006) referentes a los porcentajes aproximados de los considerados hasta entonces residuos para diferentes materias primas procesadas. 
Tabla 2. Porcentajes de residuos generados en función de la materia prima procesada

\begin{tabular}{|c|c|c|c|c|c|}
\hline Materia Prima & Tipo de restos & $\begin{array}{c}\% \text { restos } \\
\text { total }\end{array}$ & Materia Prima & Tipo de restos & $\begin{array}{c}\text { \% restos } \\
\text { total }\end{array}$ \\
\hline Tomate & $\begin{array}{l}\text { Piel, pepita, restos } \\
\text { no aptos }\end{array}$ & 15 & Borraja & Hojas & 28 \\
\hline Pimiento piquillo & Corazones, piel & 53 & Cardo & $\begin{array}{l}\text { Penca, } \\
\text { corazón }\end{array}$ & 65 \\
\hline Pimiento morrón & Corazones, pieles & $50-60$ & Acelga & Pencas, hojas & 48 \\
\hline Espárrago & Pieles, trozos & 51 & Espinacas & Hojas secas & 13 \\
\hline Alcachofa & Brácteas, tallos & $60-65$ & Melocotón & Pieles, huesos & $22-28$ \\
\hline Judía verde & Puntas & 28 & Ciruela, albaricoque & Pieles, huesos & $10-25$ \\
\hline Champiñón & Corte, raíz, destrío & 21 & Naranja, mandarina & $\begin{array}{l}\text { Piel, corteza, } \\
\text { semillas }\end{array}$ & $40-45$ \\
\hline Puerro & Hojas, raíces & 47 & Naranja zumo & $\begin{array}{l}\text { Piel, corteza, } \\
\text { semillas }\end{array}$ & $60-65$ \\
\hline \multirow[t]{2}{*}{ Brotes de ajo } & Partes blancas & 17 & Pera & $\begin{array}{l}\text { Piel, pecíolos, } \\
\text { corazón }\end{array}$ & $42-45$ \\
\hline & & & Manzana concent. & $\begin{array}{l}\text { Piel, pecíolos, } \\
\text { pepita }\end{array}$ & $10-15$ \\
\hline
\end{tabular}

Fuente: MAGRAMA, 2006. Guía de Mejores Técnicas Disponibles en España del sector de transformados vegetales

Los datos obtenidos del sector indican que el porcentaje de residuos orgánicos, con respecto a la materia prima elaborada, generados en el sector de transformados vegetales varía entre el $10 \%$ y el $65 \%$.

\subsubsection{Generación de biorresiduos en los diferentes subsectores del transformado de vegetales}

A continuación, se indican las etapas consideradas críticas del proceso de transformación de vegetales, en cuanto a generación de biorresiduos en los principales subsectores, atendiendo a su CNAE.

\section{Subsector de conservas (CNAE 1039)}

En la Región de Murcia destacan las conservas de fruta como las mandarinas, el melocotón y el albaricoque, sin olvidarse de las conservas de peras, de fresas, mezclas de frutas, y por otro lado las confituras y mermeladas. En conservas de hortalizas destacan las conservas de alcachofas, las conservas de setas (donde incluiríamos el champiñón) y las de pimiento. También son destacables las conservas de tomate.

En el proceso general de elaboración de conservas vegetales, la materia prima recibida puede ser introducida inmediatamente a la línea de procesamiento, o almacenada en cámaras frigoríficas durante un cierto periodo de tiempo. Antes de entrar en la línea, se debe lavar para eliminar los residuos orgánicos o inorgánicos que puede tener adheridos a la piel y realizar la calibración e inspección de los vegetales, donde se produce un destrío. 
Antes del envasado se realizan operaciones como el blanqueo, pelado, descorazonado, deshuesado, cortado y los pertinentes lavados a fin de adecuar las materias primas a su presentación final. En esta etapa vuelve a producirse una salida de biorresiduos. Finalmente, la conservación del producto se puede realizar mediante el envasado con adición de salmuera, jugo o almíbar y posterior esterilización. En caso de obtener un producto sin calidad comercial, se vuelve a generar otro biorresiduo. En la Figura 2 se muestra el diagrama del proceso incluyendo el tipo de residuo generado en cada una de las fases del mismo.

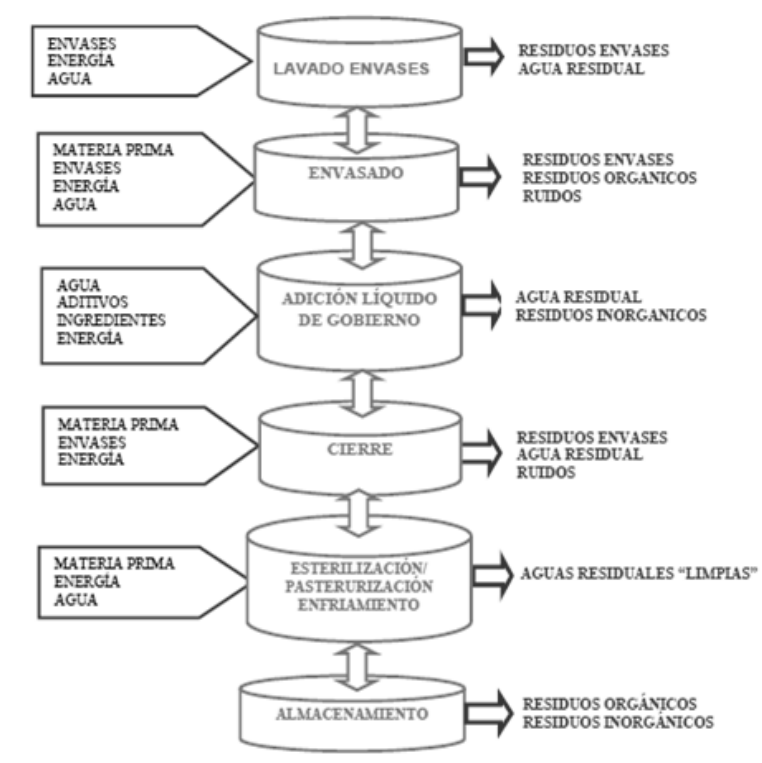

Figura 2. Diagrama de elaboración de conservas. Fuente: MAGRAMA, 2006.

\section{Subsector de zumos (CNAE 1032)}

En relación a las materias primas utilizadas para la elaboración de los zumos, cabe destacar que la mayoría corresponde al melocotón y la naranja. Pero también en la Región de Murcia se elaboran zumos de manzana, tomate, pera y mezcla de frutas y hortalizas.

Las operaciones básicas de los procesos de fabricación de los diversos zumos y concentrados vegetales son bastante similares. La fruta recibida se lava para eliminar las impurezas orgánicas e inorgánicas que pueda contener y posteriormente se prepara para la fase de extracción de jugo, con fases previas de deshuesado y pelado para algunos tipos de productos, donde se generan biorresiduos. Posteriormente se realiza la trituración de la fruta con o sin precalentamiento previo, y la extracción del jugo mediante prensado o tamizado. En algunos casos (cítricos) existen sistemas de extracción muy específicos que no precisan la trituración previa de la fruta y desde ahí la fruta agotada se convierte en biorresiduo. Una vez obtenida la papilla se procede al 
refino del zumo obtenido mediante decantación, clarificación y/o filtración. Una vez agotada se convierte en biorresiduo. Seguidamente se realizan las operaciones de conservación del producto mediante desaireación y pasterización. Por último, el jugo puede ser enviado a un almacenamiento refrigerado, para su posterior envasado, o pasar a una fase de concentración. Al igual que para el anterior proceso, si el producto no alcanza una calidad comercial es considerado un biorresiduo. En la Figura 3 se muestra el diagrama del proceso de elaboración de zumos con inclusión del tipo de residuos generados en dicho proceso.

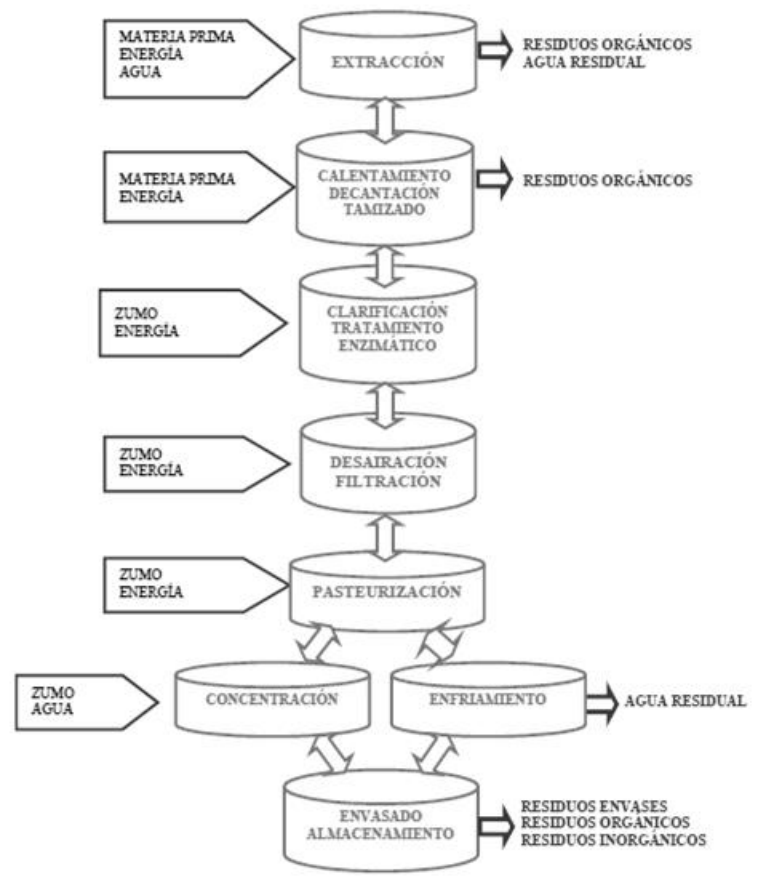

Figura 3. Diagrama de elaboración de zumos. Fuente: MAGRAMA, 2006.

\section{Subsector de congelados (CNAE 1039)}

El sector de congelados de la Región de Murcia procesa principalmente hortalizas, pero en los últimos años el congelado de frutas, como la fresa, está tomando relevancia.

El proceso de elaboración de congelados vegetales es similar al proceso de elaboración de conservas, con la diferencia del sistema de conservación, que es mediante congelación. En este caso, la generación de biorresiduos tiene lugar en las etapas previas de clasificación y adecuación del tamaño. Además, es destacable la generación de biorresiduos al final del proceso debido a que no se alcance la calidad comercial del producto por pérdidas de la cadena de frío o visualización de defectos notables de la materia prima tras el tratamiento. En la Figura 4 se muestra el diagrama del proceso de elaboración de congelados vegetales, incluyendo la tipología de residuos generados en cada una de sus fases. 


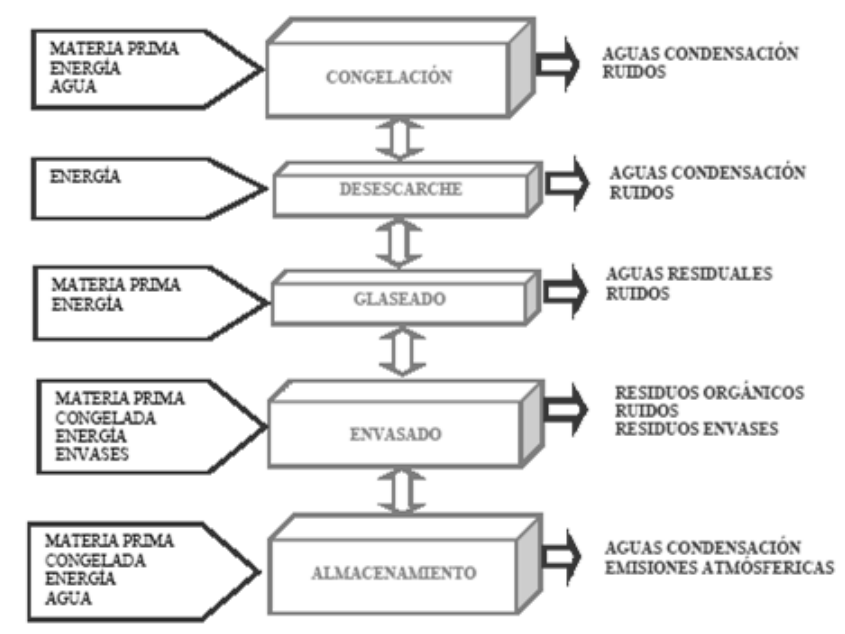

Figura 4. Diagrama del proceso de elaboración de congelados vegetales. Fuente: MAGRAMA, 2006.

\section{Subsector de encurtidos (CNAE 1039)}

Como encurtidos destaca la elaboración de aceitunas de mesa. Al igual que las conservas y los congelados, el proceso se inicia con una selección y calibración de las mismas donde se pueden generar biorresiduos. Posteriormente reciben un tratamiento para eliminar su amargor con hidróxido sódico y son lavadas y deshuesadas (si fuese necesario). A continuación, son llevadas a la etapa de fermentación, donde se introducen en barriles con salmuera de alta concentración. Tras esta etapa también puede tener lugar la clasificación y deshuesado, así como la adecuación del tamaño. Por último, las aceitunas son lavadas y envasadas en salmuera para su comercialización, pudiendo recibir o no un tratamiento de conservación.

Durante todo el proceso se pueden generar biorresiduos si se observan defectos durante la manipulación del producto.

\subsubsection{Gestión actual de los restos vegetales y partes de frutos generados en el proceso industrial}

El principal destino de los restos vegetales generados por la industria de los transformados tanto vegetales como hortícolas es la alimentación animal aprovechando su gran valor nutritivo. En la mayoría de los casos se hace un uso casi directo, es decir, los destríos de las empresas son recogidos por ganaderos, normalmente de la zona, y estos los vierten directamente sobre el campo para que sea comido por el ganado. En algunas ocasiones, excepcionales, la empresa recibe algún tipo de incentivo económico por parte del ganadero a la hora de retirar dichos restos orgánicos. En la mayoría de los casos los ganaderos que retiran los restos vegetales de 
las empresas lo hacen a cambio de "eliminar el problema" de estos restos a la industria.

La aplicación directa de los restos orgánicos sobre el suelo para la alimentación animal es un proceso de un rendimiento, cuanto menos, no óptimo, ya que deja al aire los residuos procedentes de las fábricas y la posibilidad de oxidación y putrefacción de los restos es alta, lo que produce, aparte de olores muy desagradables, problemas digestivos en los animales.

No solo existe este tipo de gestión de los subproductos, algunas empresas lo que hacen con estos restos es secarlos para de esta forma impedir su putrefacción e incluso hay una minoría de empresas que tras el proceso de secado aplican la técnica de peletizado para poder reducir el tamaño de los restos y poder ensilarlos fácilmente. De esta forma se podrá disponer de dichos restos a lo largo del año según la necesidad de los animales.

Por último, las partes de frutos retiradas de la materia prima, como los huesos de frutas, son empleados en muchos casos como biomasa para las calderas de las industrias o bien comercializados a gestores y vecinos de la zona para su uso en estufas.

Por lo tanto, ambos biorresiduos son considerados subproductos de la industria de transformados vegetales.

\subsection{Lodos de depuración de aguas residuales de la industria agroalimentaria en la Estación Depuradora de Aguas Residuales (EDAR)}

El sector agroalimentario, destacando el sector de transformados de frutas y hortalizas, tiene al agua como una materia prima esencial para el desarrollo de sus negocios. Es una de las actividades industriales que tiene un mayor consumo de agua y que por ello provoca grandes volúmenes de vertido al alcantarillado o a cauce público, debido a su utilización tanto como materia prima (formando parte del producto final, conocida como líquido de gobierno), como a su aprovechamiento como materia auxiliar de procesos. Las diferentes fases de su proceso, como son lavado de la materia prima, pelado, tratamientos térmicos con vapor de agua, etc. junto con otras etapas de limpieza de las instalaciones hacen de ella una gran consumidora de agua y que tenga a sus aguas residuales como fuente de impacto ambiental.

Los vertidos que pueden generar se caracterizan especialmente por una elevada carga orgánica, todo a causa de la aportación de contaminantes procedentes de la materia prima como piedras, tierra o restos vegetales (recortes, pieles, etc.); bien de aquellos compuestos de la materia prima solubilizados (proteínas, carbohidratos, compuestos fenólicos, etc.); o bien de restos de aceites y grasas empleados en las recetas del proceso industrial. El rango de esta carga contaminante depende sobre 
todo de la materia prima, de las técnicas empleadas y, además de estos factores, el vertido depende de los sistemas de reutilización de agua y del tratamiento de aguas residuales instalado en la empresa. Dichos contaminantes se traducen analíticamente en parámetros como Sólidos totales en suspensión (SST), Demanda bioquímica de oxigeno (DBO) y Demanda química de oxígeno (DQO) que son elevados. Por otro lado, el contenido salino de las aguas residuales generadas por este sector es también variable dependiendo fundamentalmente del tipo de agua utilizada (pozo, red, etc...), la materia prima procesada y por tanto de la tecnología en el procesado de la misma (por ejemplo, que se utilice o no el pelado químico), y también de los tratamientos de acondicionamiento del agua (ósmosis, descalcificación, cloración, etc...). Un foco de carga salina se debe a las pérdidas de agua en forma de vapor de las torres de enfriamiento y calderas que hace que las aguas de estos elementos se vayan concentrando progresivamente, teniendo que purgarlos frecuentemente para mantener un nivel de sales por debajo de un límite y llevarlos a la corriente de agua residual. Finalmente, en cuanto a la salinidad o concentración de sales, no existe un máximo definido como perjudicial, pero la presencia de altas concentraciones de sólidos disueltos en agua que se emplea en riego agrícola y en invernaderos, puede causar daños en las plantas y en el mismo suelo.

En el mercado nos podemos encontrar una amplia variedad de tecnologías de tratamiento de aguas residuales, que incluye tratamientos físicos, químicos y biológicos. Estas tecnologías se han desarrollado ampliamente y permiten complementarse en una EDAR para asegurar la calidad del vertido a la red de alcantarillado o a cauce público en su caso, generando lodos de depuración cuando se aplica un tratamiento biológico.

En las industrias agroalimentarias, debido a la práctica obligada de la depuración de sus aguas residuales desde la publicación de la Directiva 91/271/CEE de 21 de mayo (DOUE, 1991), y la necesidad de aplicar un tratamiento biológico, que es el que mejor se adapta a aguas de contenido orgánico (Christensen et al., 2009), la generación de lodos de depuración es una realidad.

\subsubsection{EDAR industrial con tratamiento biológico}

Las aguas residuales de la industria agroalimentaria responden a la dinámica productiva, de carácter estacional, por lo que presentan una particularidad (sobre todo en las pequeñas empresas) y es que a lo largo del año se producen paradas en la producción y por tanto en la generación de aguas residuales de forma irregular que dependen de factores tales como diferentes campañas, precios de la materia prima, estación del año, etc. Por ello, se debe seleccionar un proceso adaptable a cada empresa y que permita obtener unos parámetros de calidad. 
Los sistemas básicos que se adaptan a las características del agua y con los que se puede alcanzar un vertido adecuado, a pesar de la variabilidad de los parámetros de las aguas residuales, son un sistema de desbaste (rototamiz, etc.), un tanque de homogeneización y un sistema de regulación de $\mathrm{pH}$.

Con ellos se puede retirar los sólidos que aportan una alta carga orgánica, como restos de vegetales, así como mezclar los vertidos de cada una de las etapas del proceso industrial (unos son de mayor volumen que otros o tienen una carga contaminante mayor o menor) y regular el pH con dosificación de reactivos cuando hay focos de aguas con $\mathrm{pH}$ extremos como, por ejemplo, los vertidos de la etapa de pelado químico. En todo caso, dependiendo del vertido de cada empresa por el proceso industrial que realice, ha de evaluarse la ampliación del tratamiento con otras operaciones físicas, químicas o biológicas.

Los tratamientos físico-químicos, que son en muchas ocasiones empleados por las empresas, son caros y ellos solos no consiguen retirar los contaminantes completamente del agua. Este tipo de tratamientos se consideran primarios y se basan en la adición de reactivos químicos para reducir los sólidos en suspensión y los sólidos coloidales (que se ven favorecidos mediante procesos de coagulación-floculación para también poder retirarse de la corriente de agua).

Por otro lado, los procesos biológicos que se emplean en el tratamiento del agua residual tienen su origen en fenómenos y procesos que se producen en la naturaleza. En el proceso participan distintas reacciones microbiológicas para eliminar o transformar diferentes tipos de materia orgánica, nutrientes y muchos otros elementos químicos tales como el sulfuro y los metales. Estas reacciones pueden ser realizadas bajo condiciones aerobias (presencia de oxígeno disuelto), anóxicas (ausencia de oxígeno disuelto y presencia de nitratos) o anaerobias (ausencia de oxígeno disuelto y nitratos), dependiendo de la vía de degradación empleada. Asimismo, la biomasa empleada en el tratamiento se puede mantener en suspensión o adherida a un material de soporte (Lee, 1996; Droste, 1997).

Teniendo en cuenta que las aguas residuales se pueden someter a diferentes niveles de tratamiento, dependiendo del grado de purificación que se quiera obtener, las estaciones depuradoras de aguas residuales incluyen en su línea de agua etapas de pretratamiento, tratamiento primario, secundario y terciario, aunque muchas veces la separación entre ellas no es totalmente clara. El tratamiento secundario es el que se corresponde con el proceso biológico.

El tratamiento secundario biológico más utilizado es el de fangos activos (Figura 5), que consta de un reactor biológico seguido de un decantador, conocido como decantador secundario (aunque en los sistemas discontinuos el propio reactor hace de decantador y la superficie necesaria para la planta depuradora es menor). El reactor es un depósito de forma y dimensiones variables, según las necesidades, donde la masa 
activa de microorganismos es mantenida y retenida y, a través del cual, circula el agua a depurar. Aquí tiene lugar una etapa de oxidación, que deriva en la generación de nuevas bacterias, que tienden a unirse (floculación) y así formar agregados de mayor densidad que adsorben a su vez la materia coloidal, para una mejor separación. En el decantador tiene lugar la propia etapa de separación, donde las sustancias sedimentan y se forman los fangos biológicos o lodos de depuración.

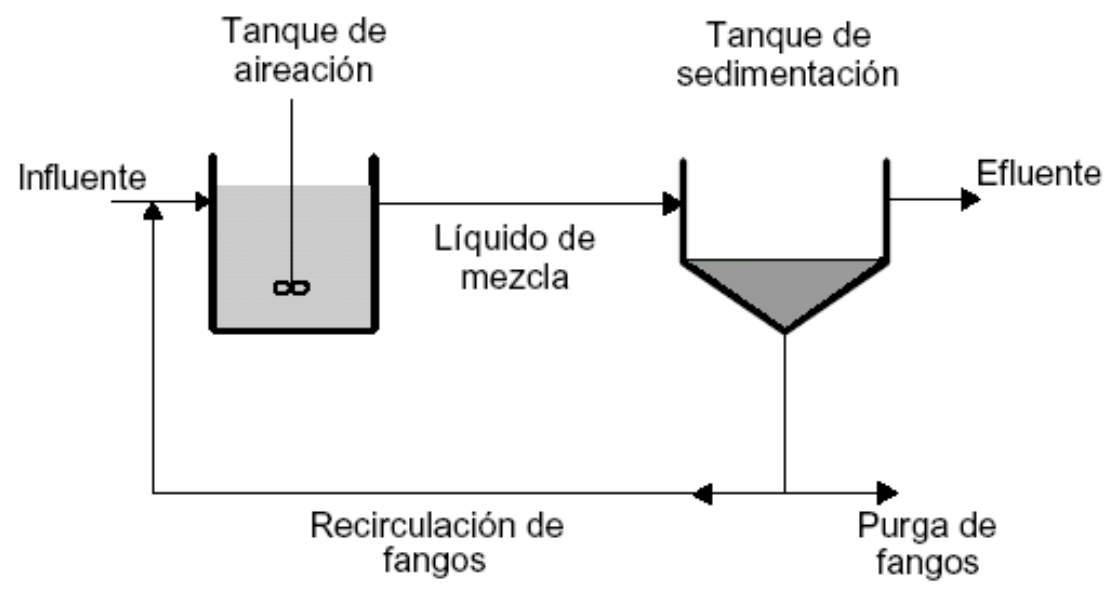

Figura 5. Esquema básico de un proceso de fangos activados

Los fangos producidos en la línea de agua, especialmente son fangos biológicos en exceso, que son conducidos a una línea de tratamiento con el objetivo básico de reducir su contenido de agua a fin de minimizar el volumen final a gestionar. Lo más habitual es que el espesado, acondicionamiento y deshidratación sean los procesos a aplicar a dichos fangos o lodos.

El espesado es el preprocesado de los lodos antes de la deshidratación. Consiste en agitar suavemente el fango en un recipiente cilíndrico (conocido como espesador) tratando de que el agua suba a la superficie y así recogerla como sobrenadante, mientras que el fango se espesa por gravedad. El acondicionamiento de fangos es un tratamiento químico o térmico para mejorar la eficiencia del espesado y la deshidratación. Lo más frecuente es el químico, utilizando polielectrolitos orgánicos que son productos sintéticos de cadena larga solubles en agua, los cuales desestabilizan la carga iónica de los sólidos de los lodos. Muchos polielectrolitos son de alto peso molecular proporcionando al flóculo la resistencia para soportar las fuerzas de cizalladura producidas por el equipo de deshidratación. Por último, la deshidratación se define como el proceso que extrae la mayor cantidad de agua al fango espesado haciendo uso de medios mecánicos. Lo habitual es introducir dicho fango espesado en una centrífuga de manera que, el agua sobrante sería la formada por el escurrido y los fangos quedarían más concentrados.

Estos lodos de depuración se caracterizan por el agua residual de partida, por lo que los lodos agroalimentarios destacan por su alto contenido en materia orgánica y 
ausencia de contaminantes como metales pesados debido al origen vegetal, lo que los diferencia de los lodos urbanos. En la Tabla 3 se muestra el volumen y las características de las aguas residuales en función de la campaña procesada.

Tabla 3. Volumen y características de las aguas residuales en función de la campaña procesada

\begin{tabular}{lcccc}
\hline Materia prima & $\begin{array}{c}\text { Agua Residual } \\
\left(\mathbf{m}^{\mathbf{3}} \mathbf{1 0 0} \text { T de materia prima) }\right.\end{array}$ & $\begin{array}{c}\text { DQO } \\
(\mathbf{m g} / \mathbf{L})\end{array}$ & pH & $\begin{array}{c}\text { SST } \\
(\mathbf{m g} / \mathbf{L})\end{array}$ \\
\hline Alcachofa & $500-1.600$ & $400-2.600$ & $6,0-8,5$ & $100-350$ \\
Pimiento & $500-900$ & $400-3.500$ & $5,0-9,5$ & $100-500$ \\
Tomate & $400-800$ & $1.000-4.000$ & $4,5-7,5$ & $400-2.500$ \\
Melocotón & $600-900$ & $1.200-4.400$ & $7,0-8,5$ & $150-550$ \\
Albaricoque & $600-900$ & $600-2.700$ & $6,0-8,0$ & $75-250$ \\
Mandarina & $500-900$ & $700-3.200$ & $5,5-7,5$ & $175-400$ \\
Naranja zumo & $400-1.000$ & $1.500-5.500$ & $5,0-7,5$ & $150-550$ \\
Congelados & N.D. & $1.000-4.000$ & $6,0-9,0$ & $100-1.200$ \\
\hline
\end{tabular}

DQO: Demanda química de oxígeno; SST: Sólidos totales en suspensión

Fuente: MAGRAMA, 2006. Guía de Mejores Técnicas Disponibles en España del sector de los transformados vegetales

\subsubsection{Gestión actual de los lodos de depuración en las industrias agroalimentarias}

Los lodos de depuración generados en las industrias agroalimentarias son considerados como residuos orgánicos, clasificados como "Lodos del tratamiento in situ de efluentes" (№ 0203 05). Su gestión actual es mediante la recogida por un gestor autorizado para llevarlo a vertedero o para uso en agricultura, cuya gestión conlleva un coste para la empresa.

Su uso en agricultura es de acuerdo a las directrices marcadas por la Comunidad Autónoma de Murcia en el Plan General de Saneamiento y Depuración de la Región de Murcia (2001-2010) (BORM, 2003), teniendo en cuenta las condiciones edáficas y agrícolas de la Región, así como el considerable déficit de materia orgánica en los suelos del territorio regional debido al avance de los procesos de desertificación.

\section{Estructura de la tesis}

Para lograr el propósito de poner de manifiesto opciones de valorización que respondan a las demandas medioambientales actuales, permitiendo cumplir con la jerarquía de residuos en cuanto a la gestión de los mismos, se ha desarrollado esta tesis estructurada en once capítulos de la siguiente manera:

- En el presente capítulo I (Introducción general) se ha pretendido situar el contexto de los residuos/biorresiduos que se generan en el sector agroindustrial y exponer la estructura de esta tesis según el trabajo realizado.

- En el capítulo II se abordan los objetivos de esta tesis doctoral.

- Desde el capítulo III al capítulo IX se ha incluido el trabajo realizado propiamente. Esta división de la tesis se ha realizado con la intención de abordar los diferentes objetivos siguiendo un orden de interés para el sector 
implicado, el sector agroindustrial, pero también para técnicos ambientales, debido a que en esta tesis se planteó evaluar el problema de la gestión de los residuos/biorresiduos del sector agroindustrial de la Región de Murcia y aportar soluciones de acuerdo a los resultados alcanzados en el desarrollo del trabajo. Además, cada uno de estos capítulos constituye un trabajo científico. Cuatro de los capítulos que constituyen esta Tesis Doctoral son artículos científicos ya enviados y/o publicados en revistas SCI (Science Citation Index). El capítulo VI con el título "Agri-food sludge management using different cocomposting strategies: study of the added-value of the composts obtained" ha sido enviado a la Revista Journal of Cleaner Production. El capítulo VII con el título "Conversion of organic residues and agroindustrial by-products into compost, to reduce the use of peat in the cultivation of muskmelon seedlings" se ha enviado a la Revista Scientia Horticulturae. El capítulo VIII con el título "Improvement of the quality of a salinised Mediterranean soil by amendment with vineyard compost supplemented with Trichodermna harzianum T78" se ha enviado a la Revista Journal of Plant Nutrition and Soil Science. Y el capítulo IX con el título "Archaeal community dynamics and abiotic characteristics in a mesophilic anaerobic co-digestion process treating fruit and vegetable processing waste sludge with chopped fresh artichoke waste" se ha publicado en la Revista Bioresource Technology (2013) 136, 1-7.

- En el capítulo X se incluye la discusión general de esta tesis.

- En el capítulo XI se resumen las conclusiones generales alcanzadas de acuerdo a los objetivos planteados.

A continuación, se describe el trabajo realizado de acuerdo a la división de los capítulos III, IV, V, VI, VII, VIII y IX, y el porqué de la elección del título de cada uno de ellos. En cada uno de los capítulos se incluyen apartados propios de Introducción, Materiales y métodos, Resultados y discusión, Conclusión y Bibliografía.

En el capítulo III, denominado "Opciones de valorización agrícola de lodos agroalimentarios del sector de conservas de frutas y hortalizas: el caso de la Región de Murcia" se ha pretendido incluir la parte del trabajo dedicada a la localización, cuantificación y coste asociado de la gestión de los lodos en el tratamiento de efluentes hídricos para cumplir con la Directiva 91/271/CEE (DOUE, 1991). Además, se incluyó la caracterización de los lodos de depuración que se gestionan en las empresas del sector de conservas de frutas y hortalizas de la Región de Murcia, conocido como sector de transformados vegetales (conservas, zumos y congelados) para proponer opciones de valorización de interés para las empresas, de acuerdo con la normativa actual de residuos, la Ley 22/2011 (BOE, 2011). Una vez estudiado y caracterizado "el problema" los resultados pusieron de manifiesto que el contenido en materia orgánica es, salvo excepciones muy elevado, con una media superior al $85 \%$; el valor de nutrientes es interesante para su uso agrícola; los valores de metales pesados están 
muy por debajo de los permitidos por la normativa tanto de aplicación agrícola de lodos de depuradora, como la de fertilizantes o afines; y la aparición de patógenos es dispar, por lo que se requiere su inclusión en tratamientos de higienización, como es el compostaje. Por todo ello, la aplicación de estos lodos agroalimentarios en agricultura es la opción de valorización que mayores ventajas aporta. Esta opción de valorización se puede diferenciar según el uso directo o tratamiento de estos lodos, por lo que se abordó una búsqueda bibliográfica que apoyara esta iniciativa, donde se obtuvo que el compostaje es una opción de valorización que permite gestionar el biorresiduo y obtener un producto con valor añadido. Además, se determinó que el proceso de digestión anaerobia, conocido como biometanización, permite obtener un producto estabilizado para uso agrícola y producir biogás para aprovechamiento energético, con el beneficio económico que ello puede suponer para las empresas del sector.

En el capítulo IV titulado "Valorización de subproductos agroalimentarios de la Región de Murcia" se incluye la parte de esta tesis basada en la cuantificación y descripción, así como la caracterización de los subproductos agroalimentarios generados por el sector de conservas de frutas y hortalizas de la Región de Murcia, para evaluar opciones de valorización. Posteriormente se llevó a cabo una aproximación económica para evaluar el coste de la generación de los subproductos considerándolos un producto dentro de la línea de producto principal. Con ello se trató de cifrar el problema para despertar el interés empresarial hacia la valorización. En la caracterización de los subproductos no se observó una clara diferenciación físicoquímica o por contaminación entre los mismos, debido a su naturaleza, pero sí se determinaron características específicas en cuanto a su contenido nutricional y de otros compuestos de interés, que podrían discriminar futuras opciones de valorización, pero en todo caso en el mercado existen muchas alternativas tecnológicas que pueden ser de interés clasificadas en cuanto a su valorización en alimentación humana, animal, agrícola y energética. Se puede destacar la amplia información disponible sobre procesos de obtención de coproductos destinados a la alimentación humana, que en muchas ocasiones puede emplear equipos ya utilizados en la línea principal de la actividad agroalimentaria, o bien otros fácilmente accesibles debido a que son empleados dentro de otro subsector alimentario. Por lo tanto, en este apartado de la tesis no se puede hablar solo de un tipo de valorización, lo que queda reflejado en el título de este capítulo, a pesar de que el compostaje es un tratamiento biológico con numerosas ventajas y ampliamente evaluado para los subproductos agroalimentarios, al igual que la digestión anaerobia (biometanización) de los mismos.

En el capítulo $V$ titulado "Valorización de restos de poda de vid de la Región de Murcia" se ha abordado la parte de esta tesis relacionada con la determinación de la cantidad de restos de poda de vid, conocidos como sarmientos, que se generan anualmente en la Región de Murcia y su caracterización para evaluar opciones de valorización. Se tomó como premisa que los biorresiduos de la viticultura son restos 
leñosos que presentan grandes dificultades por su volumen, que deben ser extraídos de la explotación agraria para facilitar la continuidad del proceso productivo. De los resultados obtenidos se pudo determinar la importancia de su potencial para las áreas involucradas, así pues, mediante sistemas de gestión que valoricen los mismos se buscó seleccionar opciones de valorización que pudieran crear nuevas oportunidades de negocio al tiempo que minimizan los efectos medioambientales negativos de las vías de gestión actuales. De esta manera se seleccionaron dos opciones de valorización: agrícola y energética. En el primer caso el compostaje se propuso como una solución adecuada, pudiendo incluso obtenerse compost de calidad al emplear la poda sola o como agente estructurante en el compostaje de otros materiales. Además, se obtuvo que el proceso permite incorporar agentes con capacidad biocontrol, como Trichoderma harzianum, que permite mejorar la calidad microbiológica del suelo y reducir el uso de fertilizantes y pesticidas. En el campo energético se determinó que los restos de poda de vid se pueden utilizar como biomasa y sustituir los usos tradicionales de la madera. En todo caso, la valorización energética requiere de una mayor capacidad técnico-económica por parte de los viticultores para una valorización propia o para desarrollar actividades específicas de valorización de biorresiduos en asociación con otras empresas localizadas en las áreas productivas de viñedo, por lo que parece interesante su valorización agrícola frente a otras. Aun así, no se puede seleccionar en particular una de ellas dejando el título de este capítulo de manera global.

En el capítulo VI de esta tesis titulado "Gestión de lodos agroalimentarios mediante diferentes estrategias de co-compostaje: estudio del valor añadido de los compost obtenidos" se abordó la parte del trabajo enfocada al estudio del proceso de compostaje de los lodos agroalimentarios para su valorización agrícola. Los lodos agroalimentarios son residuos que, aunque muestran características similares a las de los lodos producidos en las plantas de tratamiento de aguas residuales, no muestran desventajas, relacionadas con la presencia de metales pesados; por lo tanto, su potencial de uso agrícola es más viable que para los lodos de origen urbano. En este sentido, el compostaje puede constituir una alternativa viable para el tratamiento y el reciclaje de estos residuos, produciendo compost con un potencial valor añadido según los resultados previos, pero para llevar a cabo el proceso se requiere de condiciones de mezcla adecuadas, que pueden ser aportadas por un agente estructurante. En esta parte del trabajo se buscó optimizar la gestión de los lodos producidos por el sector agroalimentario mediante diferentes estrategias de cocompostaje basados principalmente en las características de los agentes estructurantes utilizados. Finalmente, los compost obtenidos se caracterizaron y su potencial valor añadido fue determinado en relación a su uso como sustratos de cultivo o como componentes de medios de crecimiento en semillero, destacando su posible efecto biopesticida por su capacidad supresiva frente a fitopatógenos, como Fusarium oxysporum f. sp. melonis. Por lo tanto, la selección del título de este capítulo 
responde a la búsqueda de un compost de calidad y con valor añadido mediante el cocompostaje de los lodos agroalimentarios y los restos de poda de vid como agente estructurante.

En el capítulo VII titulado "Compostaje de residuos orgánicos y subproductos agroindustriales para reducir el uso de turba en la producción de plántulas de melón" se aborda la parte de esta tesis enfocada a la obtención de compost de calidad incluyendo otros agentes co-compostantes que mejoren la calidad del compost, a partir de otros residuos como son los residuos de alcachofa, pimiento, cítricos, etc., tomando como punto de partida lodos agroalimentarios y el mejor agente estructurante seleccionado previamente (ver capítulo VI). En concreto, se ha buscado poner de manifiesto que los compost obtenidos a partir de los biorresiduos del sector agroindustrial tienen una aplicación de interés como sustrato de cultivo que puede sustituir, al menos parcialmente, a la turba, y que ciertos agentes co-compostantes mejoran sus características aportando un valor añadido en cuanto a su capacidad biofertilizante y biopesticida.

En el capítulo VIII titulado "Mejora de la calidad de un suelo salino del Mediterráneo mediante una enmienda con compost de restos de poda de vid enriquecido con Trichodermna harzianum T78" se aborda una demostración de compost agroindustriales sobre la calidad del suelo, con el fin de proponer un uso alternativo de los compost para su valorización, además de como sustrato de cultivo. En concreto se empleó un compost, obtenido previamente a partir de restos de poda al que se le añadió el microorganismo beneficioso Trichoderma harzianum T78, en un suelo salino, y se buscó evaluar la mejora de la calidad del propio suelo desde un punto de vista microbiológico, lo que podría garantizar su fertilidad. La experiencia se enfocó a la recuperación de un suelo de la Región de Murcia, típico del área Mediterránea, lo que llevó a incluir la palabra Mediterráneo en el título para una extrapolación de su uso.

Finalmente, en el capítulo IX titulado "Co-digestión anaerobia mesófila de lodos agroalimentarios con restos de alcachofa para su biometanización. Dinámica de la comunidad Archaea y características abióticas del proceso" se incluye la parte del trabajo enfocada a la biometanización de residuos generados por el sector de conservas de frutas y hortalizas, conocido como sector de transformados vegetales, de la Región de Murcia. En concreto se propuso evaluar la viabilidad de la obtención de metano en la digestión anaerobia de los mismos con la intención de proponer una opción de valorización con valor añadido debido a la producción de biogás y por tanto de energía. Se empleó un digestor anaerobio en condiciones mesófilas, el que se alimentó en primer lugar con solo lodos agroalimentarios y a continuación con una mezcla de lodo y restos de alcachofa pretratados mecánicamente para llevar a cabo una co-digestión que optimizase la producción de biogás. Posteriormente se estudió la comunidad archaea involucrada en la producción de metano. Por lo tanto, en el título 
de este capítulo se incluyen ambos aspectos debido al interés general de la producción de biogás, pero también científico en cuanto a las especies microbiológicas involucradas en el proceso. Esta opción de valorización se incluyó debido al interés presente en el sector empresarial debido a su implantación en la propia fábrica enfocado a la reducción de costes por el aprovechamiento energético.

Esta tesis, y en concreto los capítulos detallados, se ha realizado de acuerdo a las líneas de trabajo desarrolladas por el Grupo de Enzimología y Biorremediación de Suelos y Residuos Orgánicos del CEBAS-CSIC y el Área de Medio Ambiente del Centro Tecnológico Nacional de la Conserva y Alimentación (CTC). En especial se ha incluido el trabajo realizado gracias a la financiación de una beca concedida dentro del programa Becas Asociadas a la Realización de Proyectos de I+D, Innovación y Transferencia de Tecnología, en la modalidad cooperativa entre Centros de investigación y Centros Tecnológicos de la Región de Murcia, años 2009-2012, de la Fundación Séneca-Agencia de Ciencia y Tecnología de la Región de Murcia, y a la financiación del proyecto LIFE+ AGROWASTE (LIFE10ENV/ES/469).

\section{Bibliografía general}

Aguilera, J., Escudero, M. A., Hurtado, N. E., Vidal, M. D., 2011. La influencia de la diversificación y experiencia internacional en la estrategia medioambiental proactiva de las empresas. Investigaciones Europeas de Dirección y Economía de la Empresa 17, 75-91.

Aragón, J., 1998. Empresa y medio ambiente: Gestión estratégica de las oportunidades medioambientales. Granada. Comares.

Autry, W., Daugherty, P., Richey, G., 2001. The challenge of reverse logistics in catalog retailing. Int. J. Phys. Distr. Log. 31, 26-37.

Bansal, P., Roth, K., 2000. Why companies go green: a model of ecological responsiveness. Acad. Manage. J. 43, 717-736.

$B O E$, 2002. Orden MAM/304/2002 de 8 de febrero, por la que se publican las operaciones de valorización y eliminación de residuos y la lista europea de residuos. Boletín Oficial del Estado 43, 64946515.

BOE, 2011. Ley 22/2011, de 28 de julio, de residuos y suelos contaminados. Boletín Oficial del Estado $181,85650-85705$.

BOE, 2013. Real Decreto 506/2013 sobre productos fertilizantes. Boletín Oficial del Estado 164, 5111951207.

BORM, 2003. Resolución de 10 de enero de 2003 por la que se hace público el acuerdo del Consejo de Gobierno de la Comunidad Autónoma de Murcia de 20 de diciembre de 2002, por el que se aprueba definitivamente el Plan General de Saneamiento y Depuración de Aguas Residuales Urbanas de la Región de Murcia. Boletín Oficial de la Región de Murcia 30, 2147-2170.

Cascales, J.M., Segura, P., Navarro, F., 2001. La Industria de Conservas Vegetales en la Región de Murcia. Contribución a su estudio. Madrid. Dykinson. 
Christensen, A., Gurol, M.D., Garoma, T., 2009. Treatment of persistent organic compounds by integrated advanced oxidation processes and sequential batch reactor. Waste Res. 43, 3910-3921.

CREM, 2015. Datos estadísticos de la Región de Murcia. Centro Regional de Estadística de la Región de Murcia. Disponible en: http://www.carm.es/econet/sicrem/PU_datosBasicos/sec49.html.

DOUE, 1991. Directiva del Consejo, de 21 de mayo de 1991, sobre el tratamiento de las aguas residuales urbanas. Diario Oficial de las Comunidades Europeas 135, 40-52.

DOUE, 1999. Directiva 1999/31/CE del Consejo de 26 de abril de 1999 relativa al vertido de residuos. Diario Oficial de las Comunidades Europeas 182, 1-19.

DOUE, 2000. Decisión de la Comisión de 3 de mayo de 2000 que sustituye a la Decisión 94/3/CE por la que se establece una lista de residuos de conformidad con la letra a) del artículo 1 de la Directiva 75/442/CEE del Consejo relativa a los residuos y a la Decisión 94/904/CE del Consejo por la que se establece una lista de residuos peligrosos en virtud del apartado 4 del artículo 1 de la Directiva 91/689/CEE del Consejo relativa a los residuos peligrosos. Diario Oficial de las Comunidades Europeas 226, 3-24.

DOUE, 2001. Decisión de la Comisión de 16 de enero de 2001 por la que se modifica la Decisión 2000/532/CE en lo que se refiere a la lista de residuos. Diario Oficial de las Comunidades Europeas 47, 131.

DOUE, 2008. Directiva 2008/98/CE del Parlamento Europeo y del Consejo, de 19 de noviembre de 2008, sobre los residuos y por la que se derogan determinadas Directivas. Diario Oficial de las Comunidades Europeas 135, 40-52.

DOUE, 2010. Directiva 2010/75/UE del Parlamento Europeo y del Consejo de 24 de noviembre de 2010 sobre las emisiones industriales (prevención y control integrados de la contaminación). Diario Oficial de las Comunidades Europeas 334, 17-119.

DOUE, 2014. Decisión de la Comisión de 18 de diciembre de 2014 por la que se modifica la Decisión 2000/532/CE, sobre la lista de residuos, de conformidad con la Directiva 2008/98/CE del Parlamento Europeo y del Consejo. Diario Oficial de las Comunidades Europeas 370, 44-86.

Droste, R.L., 1997. Theory and practice of water and wastewater treatment. New York. John Wiley \& Sons Inc.

Fadel, J.G., 1999. Quantitative analysis of selected plant by-product feedstuffs, a global perspective. Anim. Feed Sci. Technol. 79, 255-268.

González de Molina, M., 1993. Historia y Medio Ambiente. Madrid. Eudema.

Grasser, L.A., Fadel, J.G., Garnett, I., De Peeters, E.J., 1995. Quantity and importance of nine selected byproducts used in California dairy rations. J. Dairy Sci. 78, 962-971.

Hart, S., 1995. A natural-resource based view of the firm. Acad. Manage. Rev. 20, 986-1014.

Herreborg, T., 2008. Towards more sustainable management systems: through life cycle management and integration. J. Clean. Prod., 16, 1071-1080.

Hosoda, E., 2010. Malfunction of Market in a Transaction of Waste Management. In: Vint, J., Metcalfe, S., Kurz, H.D., Salvadori, N., Samuelson, P. (Eds.), Economic theory and economic thought - essays in honour of Ian Steedman. London. Rutledge. pp. 234-253.

Hosoda, E., Mita, M., 2011. Recycling of Waste and downgrading of secondary resources in a classical type of production model. Journal of Economic Structures (pre-print 2012) pp. 1-7. 
Kalderis, D., Aivalioti, M., Gidarakos, E., 2010. Options for sustainable sewage sludge management in small wastewater treatment plants on islands: the case of Crete. Desalination 260, 211-217.

Lee, N.M., 1996. Parameters Affecting Microorganisms and the Process Performance in Biological Wastewater Treatment. PhD Thesis. Lund University. Lund. Sweden.

MAGRAMA, 2006. Guía de Mejores Técnicas Disponibles en España del sector de los transformados vegetales. Disponible en: http://www.magrama.gob.es/es/alimentacion/temas/industriaagroalimentaria/Gu\%C3\%ADa_MTD_en_Espa\%C3\%B1a_Transformados_Vegetales_tcm7-8221.pdf

MAGRAMA, 2015. Informe Industria Alimentaria 2012-2013, Datos CC.AA (Murcia) y Ficha sectorial (Conservas de Frutas y Hortalizas). Ministerio de Agricultura, Alimentación y Medio Ambiente. Disponible en:

http://www.magrama.gob.es/es/alimentacion/temas/industria-agroalimentaria/informacioneconomica-sobre-la-industria-agroalimentaria/

Melbin, J.E., 1995. The never-ending cycle. Distribution 94(11), 36-38.

Melnyk, S., Sroufe, R., Calantone, R., 2003. A model of site-specific antecedents of ISO 14001 certification. Production and Operations Management 12, 369-385.

Metcalf y Eddy Inc., 1995. Ingeniería de aguas residuales. Tratamiento, vertido y reutilización. Madrid. McGraw-Hill Interamericana de España S.A. 1485 pp.

Minervini, D., 2012. Waste Valuation Performed by Socio-Technical Connections. Sociologica 3.

Pascual, J.A., Segura, P., 2007. Diagnóstico de la situación de los residuos y subproductos generados en la actividad agraria de la Región de Murcia. FECOAM-Consejería de Agricultura y Agua de la Región de Murcia. Murcia. España.

Pérez Cebada, J.D., 2001. Minería y Medio Ambiente (en perspectiva histórica). Servicio de Publicaciones de la Universidad de Huelva. Huelva. España.

Ponting, C., 1992. Historia verde del mundo. Barcelona. Paidós Ibérica. 584 pp.

Porter, M., Van der Linde, C., 1995. Green and competitive: ending the stalemate. Harvard Bus. Rev. 73, 120-134.

Saval, S., 2012. Aprovechamiento de Residuos Agroindustriales: Pasado, Presente y Futuro. BioTecnología, 16, 14-46. Disponible en:

http://www.smbb.com.mx/revista/Revista_2012_2/Saval_Residuosagroindustriales.pdf

Telle, K., 2006. It pays to be green: a premature conclusion? Environ. Resour. Econ. 35, 195-220.

Tamayo, U., 2009. Un modelo normativo de marketing medioambiental estratégico orientado a la obtención de ventajas competitivas. Tesis doctoral. Universidad del País Vasco. Bilbao. España.

Tamayo Orbegozo, U., Vicente Molina, M.A., Izaguirre Olaizola, J., 2012. La gestión de residuos en la empresa: motivaciones para su implantación y mejoras asociadas. Investigaciones Europeas de Dirección y Economía de la Empresa 18, 216-227.

Zhu, Q., Sarkis, J., 2004. Relationship between operational practices and perfor-mance among early adopters of green supply chain management in Chinese manufacturing entreprises. J. Oper. Manage. 22, 265-289. 



\section{Objetivos}





\section{Objetivos}

El objetivo global de esta Tesis Doctoral ha sido identificar, cuantificar y valorizar los residuos y subproductos generados en la actividad industrial de transformados de frutas y vegetales, proponiendo diferentes formas de valorización beneficiosas para el sector productivo, con la premisa de que estas respondan a las demandas medioambientales actuales tendentes hacia el residuo cero y su favorable repercusión sobre el cambio climático. Se ha incluido también el estudio de residuos agrícolas procedentes de viticultura por el interés que tiene para el manejo de estos biorresiduos agroindustriales dada su complementariedad, así como su difícil solución medioambiental.

En este sentido, se ha procedido a estudiar los subproductos o residuos de naturaleza orgánica tales como productos enteros, originados en la función de destrío, o partes específicas de los mismos, originados en diferentes fases del proceso productivo; y por otro, los lodos de depuradora, considerados como un material o residuo secundario, originado a partir del tratamiento de depuración de las aguas residuales generadas en los procesos productivos efluentes hídricos con elevada carga de materia orgánica, que constituyen el biorresiduo primario de la industria en estudio, las cuales no pueden ser objeto de valorización directa ni inmediata, sino que deben ser sometidos al citado tratamiento depurativo, dando como resultado los lodos de depuración. Los residuos orgánicos relacionados con viticultura incluidos en este estudio han sido los originados tras la poda de los mismos denominados comúnmente sarmientos de vid.

Los objetivos concretos a abordar para conseguir nuestro objetivo general y que constituyen los diversos capítulos de esta Tesis se han dividido en dos partes y han sido:

Por un lado, la cuantificación y caracterización de los distintos biorresiduos, dividiéndose en tres:

1) Cuantificación, caracterización y evaluación económica resultante de la producción de lodos de depuradora de la industria del transformado vegetal en la Región de Murcia, así como recopilación y discusión de los medios de valorización existentes en la actualidad.

2) Cuantificación, caracterización y evaluación económica resultante de la producción de los subproductos orgánicos generados en la industria del transformado vegetal en la Región de Murcia, así como recopilación y discusión de los medios de valorización existentes en la actualidad. 
3) Cuantificación y caracterización de los restos agrícolas generados en viticultura (restos de poda de vid o sarmientos de vid) de la Región de Murcia, atendiendo a las Denominaciones de Origen, recopilando y discutiendo las opciones de valorización de los mismos. La selección de este tipo de residuo en esta Tesis doctoral se basó por un lado en su problemática y difícil solución, pero más concretamente en su necesidad y complementariedad para una adecuada gestión de los biorresiduos del sector agroindustrial en estudio, en particular en la gestión de sus lodos generados, al poder dotar a estos últimos de estructura suficiente en algunos tratamientos; resolviéndose así un doble problema, el de los lodos y el de los residuos agrícolas originados de la acción vitícola.

Por otro lado, se han realizado demostraciones prácticas de valorización de este tipo de biorresiduos mediante el empleo de técnicas dirigidas hacia dos campos importantes: la agricultura (compostaje) y la obtención de energía (biometanización). De estas aproximaciones, los objetivos concretos fueron:

4) Estudio de optimización del proceso de compostaje de lodos de la industria del transformado vegetal, empleando restos agrícolas como agentes estructurantes, con objeto de obtener productos finales con valor añadido biofertilizante y supresivo para su empleo como alternativa a la turba.

5) Estudio de aprovechamiento de subproductos de la industria del transformado vegetal mediante compostaje con objeto de obtener sustratos orgánicos, y a ser posible con valor añadido en cuanto a su efecto biofertilizante y supresivo.

6) Estudio del efecto de los composts de residuos de poda de vid enriquecidos con el microorganismo beneficioso Trichoderma harzianum sobre suelos salinos, y evaluar si el empleo de los mismos tenía un efecto positivo en las propiedades del suelo, haciendo un especial hincapié en la influencia del compost sobre las propiedades biológicas de los mismos.

7) Estudio del potencial empleo de lodos del sector agroindustrial para la producción de metano, tanto por si solos como mediante el empleo de otros residuos del sector, con el objeto de optimizar el proceso mediante el estudio de las poblaciones microbianas a través de aproximaciones moleculares. 
III. Opciones de valorización agrícola de lodos agroalimentarios del sector de conservas de frutas y hortalizas: el caso de la Región de Murcia 



\section{Opciones de valorización agrícola de lodos agroalimentarios del sector de conservas de frutas y hortalizas: el caso de la Región de Murcia}

\section{Introducción}

La industria agroalimentaria es la principal actividad de la industria manufacturera europea (Food Drink Europa, 2012). En España, la industria de alimentación y bebidas ocupa la primera posición, según la última Encuesta Industrial de Empresas del INE, a 31 de diciembre de 2013, representando el 20,6 \% de las ventas netas de producto, donde se engloba el sector de conservas de frutas y hortalizas (INE, 2015). La Región de Murcia es la que aporta el mayor porcentaje de ventas netas de este sector a nivel nacional, llegando hasta el $24 \%$. Es por ello, de especial importancia este sector para la economía de la Región de Murcia sin olvidar su afección al medio ambiente, más teniendo en cuenta que su fuente de abastecimiento es el medio que recibe el impacto medioambiental de su propia actividad. No se puede obviar que la resolución de los problemas medioambientales de la industria alimentaria viene establecida por el marco legal a nivel europeo, nacional y también autonómico o local, pero además es necesario debido a que la Región de Murcia es deficitaria en recursos hídricos y el tratamiento de sus aguas residuales es necesario para reutilizar las aguas cuando sea posible. En concreto, la depuración de las aguas residuales es de acuerdo con la Directiva 91/271/CEE de 21 de mayo (DOUE, 1991a), donde se define como principal objetivo proteger al medio ambiente de los efectos negativos de los vertidos de las aguas residuales urbanas y de los sectores industriales, donde se incluye el alimentario.

Este sector se caracteriza porque la mayor cantidad de agua residual generada está altamente contaminada con materia orgánica, sólidos disueltos, sólidos suspendidos y aceites y grasas (Guerrero et al., 1999). El tratamiento biológico es el proceso utilizado más comúnmente para tratar aguas residuales de contenido orgánico (Christensen et al., 2009) y ricas en nutrientes (Najafpour et al., 2006) como son las aguas de industrias alimentarias, por lo que las empresas requieren de la instalación de plantas que garanticen un adecuado tratamiento a sus efluentes hídricos. Debido a la amplia variedad de aguas residuales de la industria de conservas estas son tratadas en distintos tipos de plantas de depuración (Najafpour et al., 2006), dando por un lado, aguas depuradas con calidad suficiente para su vertido a cauce (Mosquera-Losada et al., 2010); y por el otro un residuo denominado lodos de depuradora, que tienen que ser gestionados por parte de la empresa, suponiendo un coste adicional.

En la Lista Europea de Residuos -LER- publicada en la Orden MAM/304/2002 de la legislación española (BOE, 2002), estos lodos agroalimentarios, referidos al procesado de frutas y hortalizas (subsectores de conservas, zumos y congelados, 
además de otras empresas de transformado y manipulado vegetal) están clasificados con el código 020305.

La Directiva 2008/98/CE (DOUE, 2008) y su transposición al ordenamiento jurídico interno de España, con la Ley 22/2011 (BOE, 2011), establecen una jerarquía de residuos para conseguir el mejor resultado ambiental global y proponen un listado de opciones de valorización donde se incluyen por un lado el Reciclado o recuperación de sustancias orgánicas que no se utilizan como disolventes (incluidos el compostaje y otros procesos de transformación biológica) (R3); así como el Tratamiento de los suelos para que se produzca un beneficio a la agricultura o una mejora ecológica de los mismos (R10). La aplicación de lodos de depuración en terrenos agrícolas tiene muchos aspectos positivos y garantiza el reciclado de nutrientes para mejorar la fertilidad en una situación global donde las fuentes de nutrientes, particularmente fósforo, están siendo reducidas (Van Vuuren et al., 2010). Esta es la actual opción elegida en muchos países, con más de la mitad de los 27 miembros de la EU, reciclando más del $50 \%$ de los lodos de depuración tratados en terrenos agrícolas, bien directamente o mediante procesos de compostaje (European Commission, 2010; Kelessidis y Stasinakis, 2012; Zhang et al., 2015).

Por otro lado, la Directiva 86/278/CEE (DOUE, 1986) regula la utilización de los lodos de depuradora en agricultura de modo que se eviten efectos nocivos en los suelos, en la vegetación, en los animales y en el ser humano, al mismo tiempo que se estimula su utilización correcta mediante una serie de pautas que se resumen en: i) los lodos deben sufrir tratamiento previo a su uso, ii) estos deben de utilizarse teniendo en cuenta las necesidades de nutrientes de las plantas, y iii) no superar la concentración de metales que fija la Directiva, ni en ellos, ni en los suelos donde se incorporen. Además, esta Directiva indica un necesario control de la producción de lodos, sus características, el tratamiento que pudiera recibir y su destino. El Real Decreto 1310/1990 transpone la Directiva 86/278/CEE a la normativa española y está desarrollado por la Orden AAA/1072/2013, de 7 de junio, sobre la utilización de lodos de depuración en el sector agrario (DOUE, 1986; BOE, 1990; BOE, 2013a). Según este Decreto los lodos de depuración, como fuente de materia orgánica y de elementos fertilizantes, se pueden utilizar en la actividad agraria al permitir su incorporación a los ciclos naturales de la materia y la energía.

El marco jurídico comunitario de los lodos de depuración también viene definido de forma particular por la Directiva 91/676/CE, relativa a la protección de las aguas contra la contaminación producida por nitratos empleados en agricultura (DOUE, 1991b), que contempla como fertilizante a los lodos de depuración. Además, el Real Decreto 506/2013, sobre productos fertilizantes (BOE, 2013b), recoge a los lodos de depuración como materiales orgánicos biodegradables que pueden ser compostados para la obtención de enmiendas orgánicas y en su Anexo $\mathrm{V}$ expone criterios de aplicación para estas enmiendas orgánicas. Por lo tanto, los lodos 
agroalimentarios en España deben someterse a un tratamiento para reducir su contenido en agua, en patógenos y asegurar la estabilidad de la materia orgánica. Posteriormente podrán recibir otras operaciones de tratamiento finalista para asegurar un destino final adecuado como es la aplicación en el sector agrario.

En la Región de Murcia se cuantifican actualmente un total de 140.000 toneladas de lodos de depuración (CARM, 2015), pero no se especifica su origen. Además, en el Plan Nacional de Lodos de Depuradora dentro del Plan Nacional Integrado de Residuos (2008-2015) (BOE, 2009) no existe una diferenciación para los lodos de origen agroalimentario, por lo que no se ha incluido una caracterización particular de estos lodos agroalimentarios, con ventajas frente a los urbanos debido a su origen vegetal.

Por ello, este capítulo pretende poner de manifiesto la cantidad de lodos agroalimentarios que genera en exclusiva el sector de conservas de frutas y hortalizas, de importancia en la Región de Murcia, sus características y las posibles opciones de valorización de interés para el propio sector agroalimentario, como es su aplicación agrícola. Es una iniciativa para obtener un coste positivo de los lodos agroalimentarios y diferenciarlos de los lodos de depuradoras urbanas.

\section{Materiales y métodos}

\subsection{Potencial de lodos agroalimentarios}

En primer lugar, se realizaron encuestas referentes a poder establecer los volúmenes de lodos generados anualmente en las empresas del sector de conservas de frutas y hortalizas de la Región de Murcia; para lo cual el conjunto de empresas se clasificaron según los tres principales subsectores: conservas, zumos y congelados vegetales. El sistema de depuración de sus efluentes también fue incluido en la evaluación. En total fueron 56 empresas las localizadas para el estudio a partir de la base de datos Alimarket (2010) y el listado de asociados del Centro Tecnológico Nacional de la Conserva y Alimentación -Murcia (CTC). Las encuestas se realizaron vía telefónica para dar respuesta a un cuestionario que incluyó información sobre la localización de la empresa, el tipo y la cantidad de materia prima procesada, el volumen de agua residual, el tipo de sistema de depuración y la cantidad de lodos de depuración gestionados (ver Apéndice).

Se obtuvo datos reales del año 2008 del 64 \% de las empresas que disponen de tratamiento biológico en sus plantas de depuración de aguas, según información facilitada por empresas colaboradoras. Debido al porcentaje de participación empresarial y futuras incorporaciones de tratamientos biológicos en las estaciones depuradoras de las empresas, los datos también se extrapolaron, concretamente para el subsector de conservas vegetales, que es el de mayor número de empresas, para determinar el potencial de generación de lodos agroalimentarios de la Región de 
Murcia. Posteriormente, durante los años 2012 y 2013, se realizaron encuestas/entrevistas a directivos y técnicos de producción, calidad ambiental, etc., en número de 10, con objeto de completar y validar la información obtenida previamente, en los cuales se hizo un hincapié especial en los aspectos técnicoeconómicos en general del sistema de depuración, y realizar una aproximación a la economía del tratamiento de sus efluentes hídricos y sus lodos (ver encuestas Apéndice).

Dado que la cantidad de lodo generada es dependiente de la cantidad de materia prima procesada, que es variable dependiendo de las campañas llevadas a cabo año a año; entendiéndose por campaña, el procesado de un tipo de producto determinado en una unidad de tiempo, siendo por tanto la generación de agua residual y su carga contaminante una característica intrínseca del producto tratado y por tanto de la campaña (ver Tabla 1 del capítulo Introducción general); se decidió emplear intervalos de valores a partir de datos de los años 2008-2010.

\subsection{Caracterización de los lodos}

En orden a obtener información representativa de los lodos de depuración del sector de conservas de frutas y hortalizas, se tomaron muestras para su análisis. Se recogieron 38 muestras, procedentes de 14 empresas en sus diferentes campañas procesadas (pimiento, alcachofa, melocotón, pera, zumos de cítricos, membrillo, albaricoque, fresa y otros), las cuales se almacenaron a $4{ }^{\circ} \mathrm{C}$ hasta su análisis. Se llevaron a cabo ensayos analíticos en cuanto a caracterización físico-química, de contenido en metales pesados, contaminación microbiológica y presencia de plaguicidas.

\subsubsection{Análisis físico-químico y nutricional}

Los lodos agroalimentarios fueron analizados de acuerdo con los parámetros químicos estándar. Se les determinó el $\mathrm{pH}$ y la conductividad eléctrica (CE) en un extracto soluble de agua 1:5 (p/v) en un pHmetro y conductímetro (Crison mod. 2001, Barcelona, Spain), después de $1 \mathrm{~h}$ de agitación y $1 \mathrm{~h}$ de reposo. La humedad se determinó por diferencia de peso entre material inicial y seco a $105{ }^{\circ} \mathrm{C}$ ( 24 horas) de acuerdo al método estándar CEN13039 (European Committee for Standardization, 1999). El contenido en materia orgánica (MO) fue determinado por pérdida de peso mediante calcinación a $550^{\circ} \mathrm{C}$, durante 24 horas.

A partir de aquí, la parte de muestra de lodo para el análisis químico se secó al aire, molió y tamizó.

El nitrógeno total $(\mathrm{N})$ y el carbono orgánico total fueron determinados por microanálisis automático (Navarro et al., 1991). El fósforo (P) fue determinado 
espectrofotométricamente midiendo la intensidad de la coloración amarilla del ácido molibdovanadato fosfórico (Kitson y Mellon, 1944). Y el potasio (K) por fotometría de llama.

\subsubsection{Análisis metales}

Las muestras ya secas, molidas y tamizadas se emplearon para determinar las concentraciones de cadmio $(\mathrm{Cd})$, cromo $(\mathrm{Cr})$, cobre $(\mathrm{Cu})$, mercurio $(\mathrm{Hg})$, níquel $(\mathrm{Ni})$, plomo $(\mathrm{Pb})$ y cinc $(\mathrm{Zn})$ mediante espectrofotometría de masas con plasma de acoplamiento inductivo (ICP-MS) (EPA, 1998), tras una digestión $\mathrm{HNO}_{3} / \mathrm{HClO}_{4}$ previa. Los valores fueron expresados como $\mathrm{mg} / \mathrm{kg}$ en peso seco.

\subsubsection{Análisis microbiológico}

Dos microorganismos fueron utilizados como indicadores de la sanidad de los residuos orgánicos: cuantificación de Escherichia coli (E. coli) y detección de Salmonella spp., de acuerdo con la legislación española sobre productos fertilizantes, el Real Decreto 824/2005 y actualmente el Real Decreto 506/2013 (BOE, 2013b), ya que la legislación sobre la utilización de lodos de depuración en el sector agrario no incluye aspectos microbiológicos. Además, también se evaluó otros microorganismos que pueden ser fuente de contaminación en este tipo de material tales como: Estreptococos fecales y Listeria monocytogenes. La presencia de estos diferentes grupos de microorganismo patógenos fue determinada de acuerdo a métodos oficiales llevados a cabo en el laboratorio microbiológico del Centro Tecnológico Nacional de la Conserva y Alimentación, los microorganismos fueron medidos en el material original, mantenido a $4{ }^{\circ} \mathrm{C}$ hasta su análisis (máximo 24 horas después de la toma de muestra). Los métodos utilizados fueron Salmonella spp. (pre-enriquecimiento agua peptona tamponada $\left(24 \mathrm{~h}\right.$ a $37^{\circ} \mathrm{C}$ ), incubación caldo Salmonella Xpress $\left(24 \mathrm{~h}\right.$ a $41,5^{\circ} \mathrm{C}$ ), test VIDAS), Listeria monocytogenes (incubación caldo Fraser, $24 \mathrm{~h}$ a $30^{\circ} \mathrm{C}$, test VIDAS), Coliformes fecales (E. coli) (incubación TBX, $24 \mathrm{~h}$ a $44{ }^{\circ} \mathrm{C}$ ) y estreptococos fecales (incubación KAA, 24-48 h a $37^{\circ} \mathrm{C}$ ). Los resultados para Salmonella spp., Listeria monocytongenes y $E$. coli fueron expresados como presencia o ausencia en $25 \mathrm{~g}$ material fresco y para estreptococos fecales como número de unidades de colonias formadoras por gramo de material fresco (UFC/g).

Todos los controles se hicieron de acuerdo al Real Decreto 3484/2000 (BOE, 2001) y llevando a cabo diluciones decimales de la muestra en el diluyente de tal manera que después de incubar las placas se calculara el número de colonias en base a resultados significativos. 


\subsubsection{Análisis de contaminantes orgánicos. Plaguicidas}

La determinación de residuos de plaguicidas organoclorados y organofosforados se llevó a cabo mediante el método de extracción QuEChERS (Quick Easy Cheap Effective Rugged and Safe) y posterior cuantificación de los residuos de plaguicidas por cromatografía gaseosa (multirresiduos) y cromatografía líquida acoplada a espectrometría de masas (multilíquidos), de acuerdo a protocolos del laboratorio instrumental del Centro Tecnológico Nacional de la Conserva y Alimentación. Los equipos utilizados fueron un HP-6890 con detector de masas y un HPLC serie 1200 de Agilent Technologies acoplado a un detector de masas de trampa de iones. Los resultados fueron expresados como $\mathrm{mg} / \mathrm{kg}$.

\subsubsection{Estadística}

Los valores medios de cada parámetro fueron determinados usando el análisis de la varianza con un factor (ANOVA). Para el análisis estadístico se utilizó el software SPSS 22.0 (SPSS Inc., Chicago, IL, EE.UU.).

\subsection{Opciones de valorización de lodos de depuración}

En este apartado se realizó un amplio estudio de oportunidades tecnológicas, sistemas de gestión y valorización de este tipo de materiales a través de metabuscadores, con capacidad de chequear en distintos sistemas y redes de información y vigilancia, bases de datos de patentes, bibliografía científico técnica, etc. El enfoque metodológico para la revisión bibliográfica se basó en la utilización de palabras clave dirigidas a proyectos de $I+D$, tesis doctorales, artículos técnicos $y$ patentes, y en bases de datos de revistas científicas, como Scopus y ScienceDirect dirigidas a la evaluación de artículos científicos principalmente. Las palabras clave seleccionadas fueron: biorresiduos; valorización biorresiduos; lodos de depuración; lodos agroindustriales; gestión de biorresiduos; tecnologías de valorización de lodos de depuración. Finalmente se utilizaron palabras clave referenciadas a cada una de las tecnologías, como por ejemplo: lodos de depuración en agricultura, secado de lodos, compostaje de lodos de depuración, digestión anaerobia de lodos de depuración, etc.

A partir de ello se dispuso de un amplio inventario de oportunidades tecnológicas y de gestión sobre el que operar analíticamente, las cuales se estudiaron y analizaron, preseleccionando aquellas orientadas al uso de lodos de depuración para su empleo en agricultura, como opción de valorización finalista. De estas tecnologías se establecieron las principales ventajas y desventajas de su implantación en el tejido productivo de la Región de Murcia. 


\section{Resultados y discusión}

\subsection{Potencial de valorización de los lodos agroalimentarios en la Región de Murcia. Localización y cuantificación}

En la Figura 1 se localizan los focos de generación de lodos agroalimentarios y en la Tabla 1 se muestran los datos de cantidades clasificados según el subsector agroalimentario: conservas, zumos y congelados vegetales.

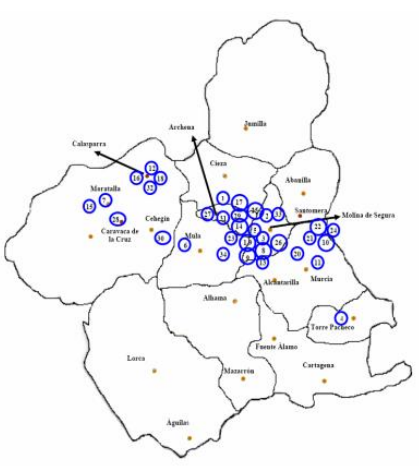

A

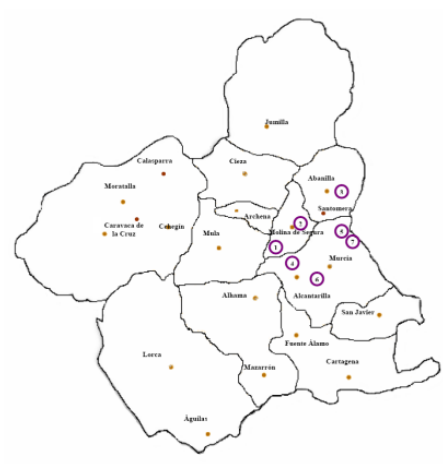

B

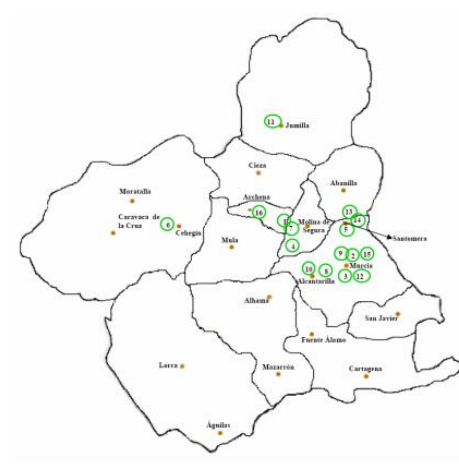

C

Figura 1. Ubicación de los lodos agroalimentarios generados por empresas de la Región de Murcia: A) Subsector conservas vegetales, B) Subsector congelados vegetales y C) Subsector zumos

En la Tabla 1 se indican los datos aportados por las empresas que disponen de tratamiento secundario, y por tanto generan lodos de depuración. Entre los tipos de tratamiento secundario, el tipo fangos activos es el más implantado, pero según la Comisión Europea (European Commission, 2006) el agua residual de procesado de frutas y hortalizas es deficiente en nitrógeno y fósforo y puede requerir aporte de estos nutrientes para la adecuada actividad del proceso biológico. Además, las etapas de nitrificación y desfosfatación pueden ser facilitadas mediante el control de la aireación.

Tabla 1. Cuantificación de lodos agroalimentarios generados en la Región de Murcia

\begin{tabular}{|c|c|c|c|c|}
\hline Comarca & $\begin{array}{c}\text { Subsector } \\
\text { Conservas } \\
\text { (T lodos/año) } \\
\end{array}$ & $\begin{array}{c}\text { Subsector } \\
\text { Congelados } \\
\text { (T lodos/año) }\end{array}$ & $\begin{array}{c}\text { Subsector } \\
\text { Zumos } \\
\text { (T lodos/año) } \\
\end{array}$ & $\begin{array}{c}\text { TOTAL } \\
\text { (T lodos/año) }\end{array}$ \\
\hline Altiplano & & & $1.200-3.000$ & $1.200-3.000$ \\
\hline Huerta de Murcia & $1.150-2.200$ & $2.800-4.000$ & $6.700-9.000$ & $10.650-15.200$ \\
\hline Noroeste & $2.910-4.450$ & & & $2.910-4.450$ \\
\hline Río Mula & $1.200-2.000$ & & & $1.200-2.000$ \\
\hline Vega Media & $1.200-2.100$ & & & $1.200-2.100$ \\
\hline TOTAL & $6.460-10.750$ & $2.800-4.000$ & $7.900-12.000$ & $17.160-26.750$ \\
\hline
\end{tabular}

Fuente: Elaboración propia. Datos 2008-2010

Subsector de Conservas vegetales. Se manejó información de 34 empresas de conservas vegetales de entre las aproximadamente 50 localizadas en la Región de 
Murcia en los años 2008-2010 (Figura 1A). Estas se ubicaron en seis de las doce comarcas que tiene la Región de Murcia. En la comarca de la Vega Media es donde hubo una mayor concentración de empresas de conservas vegetales; sin embargo, la mayor parte de ellas fueron de pequeño tamaño y sólo dos empresas se consideraron grandes. Las empresas de mayor tamaño se localizaron en las comarcas de Río Mula (incluyendo las dos mayores empresas de conservas vegetales de la Región de Murcia) y el Noroeste, siendo esta última comarca la segunda en número de empresas activas. De las 34 empresas colaboradoras con el estudio, el 44 \% (15 empresas) fueron las que disponían de un tratamiento secundario, y por tanto generaban lodos; aunque no todas disponían de información sobre cantidades de lodos generados o el dato no fue facilitado en el estudio, por lo que sólo 10 de las empresas de conservas vegetales localizadas generaron anualmente entre 6.460 y 10.750 toneladas de lodos agroalimentarios. La zona de mayor producción de este tipo de lodos agroalimentarios para el subsector de conservas vegetales fue la comarca del Noroeste, donde el $83 \%$ de sus empresas ( 5 empresas de 6 en total) con depuración biológica aportaron datos de generación de lodos. Sin embargo, la comarca de la Vega Media fue la que ubicó al mayor número de empresas de conservas vegetales, lo que puede situar esta comarca en la de mayor potencial en el futuro.

Subsector de Congelados vegetales. En la Figura 1B se muestra la distribución de las empresas de congelados vegetales de la Región de Murcia. En sólo tres de las doce comarcas de la Región de Murcia se localizaron empresas de congelados vegetales. El número total de empresas localizadas fue de 7, pero sólo 2 empresas disponían de un tratamiento secundario y las dos de tipo biológico de fangos activos. La ubicación de estas empresas fue en la comarca de la Huerta de Murcia. El total de lodos cuantificados en ellas fue de entre 2.800 y 4.000 toneladas al año (datos 2008-2010). El que este subsector sea en el que menos haya implantado el sistema de depuración de sus aguas se debe a que la calidad de sus aguas de vertido y su homogeneización previa, les permite ajustarse a los parámetros de vertido establecidos por la normativa, Decreto 16/1999 para el vertido de aguas residuales industriales al alcantarillado (BORM, 1999).

Subsector de Zumos. En la Figura 1C se muestra la distribución de las empresas de zumos en la Región de Murcia. En cuatro de las doce comarcas de la Región se localizaron empresas de zumos. En total fueron 15 las empresas de zumos y más del 73 \% disponían de un tratamiento biológico para la depuración de sus aguas residuales. En la comarca de la Huerta de Murcia fue donde se localizó el mayor número de empresas, 10 del total de 15 empresas contactadas. La cantidad de lodos generados por el subsector de zumos se corresponden con los datos aportados por 6 de las empresas y fue de 7.900 a 12.000 toneladas de lodos al año (datos 2008-2010).

Los datos totales obtenidos de las empresas indicaron que el total de lodos de depuración generados anualmente por las empresas del sector de conservas de frutas 
y hortalizas fue de entre 17.160 y 26.750 toneladas. Las comarcas de la Vega Media y de la Huerta de Murcia fueron las que ubicaron a un mayor número de empresas, y además la comarca de la Huerta de Murcia fue la que presentó más empresas con sistema de depuración biológico. Por otro lado, el mayor porcentaje de empresas con sistema de depuración biológico que participaron en el estudio se ubicaron en la comarca del Noroeste. Teniendo en cuenta las anteriores afirmaciones, la comarca de la Huerta de Murcia fue la que mayor cantidad de lodos agroalimentarios generó con entre 10.650 y 15.200 toneladas y le siguió la comarca del Noroeste con entre 2.910 y 4.450 toneladas anuales. Los datos no aportados por el resto de empresas con sistema de depuración biológico impidieron determinar si la comarca de la Vega Media (con un alto número de empresas) aportaría valores similares a los de la comarca del Noroeste, pero sí se puede decir que presentó un potencial elevado debido a ese alto número de empresas, mayoritariamente del subsector de conservas vegetales. Además, respecto al subsector de conservas vegetales podemos decir que será el que incremente su potencial en el futuro con respecto a ese número de empresas porque solo se dispuso de datos del $26 \%$ de las empresas frente al $40 \%$ de las empresas de zumos, y de las empresas que no aportaron datos cuantificables sí que se conoce que el tratamiento biológico instalado es mayoritariamente anaerobio, lo que genera una baja cantidad de lodos de depuración (Chan et al., 2009). Por otro lado, del subsector de congelados vegetales solo se aportaron datos del $28 \%$ de las empresas, pero no se prevé que en un futuro próximo instalen sistemas de depuración de tipo biológico debido a la calidad de sus aguas de vertido, sobre todo porque la homogeneización de caudales de su proceso productivo les permite ajustarse a los parámetros de vertido establecidos por el Decreto 16/1999 para el vertido de aguas residuales industriales al alcantarillado (BORM, 1999).

\subsubsection{Estimación del potencial generador de lodos de depuración del subsector de conservas de vegetales}

Para determinar el potencial generador de lodos de depuración del subsector de conservas vegetales se realizaron estimaciones en base a la generación de lodos agroalimentarios a partir de un tratamiento biológico de las aguas residuales de tipo aerobio. En primer lugar se calcularon ratios de generación de lodos por tonelada de materia prima en cada una de las principales campañas a partir de los datos aportados por las empresas, y posteriormente se utilizó la cantidad de materia prima procesada en cada campaña del año 2008 para establecer el total de lodos de depuración generados en la Región de Murcia, si en todos los casos se emplease un tratamiento biológico aerobio, como es el de fangos activos, el mayoritario implantado en las empresas del sector de conservas de frutas y hortalizas. En la Tabla 2 se muestra el total de lodos agroalimentarios estimados para el subsector de conservas vegetales y los ratios establecidos. El potencial total de lodos agroalimentarios correspondientes al 
subsector de conservas vegetales fue de entre 12.895 y 22.520 toneladas, según estimaciones a partir de datos de producciones del año 2008. Como ya se ha comentado, se estableció un intervalo debido a que la producción es variable en las empresas del sector debido principalmente al precio y la disponibilidad de la materia prima. La generación de lodos depende de la cantidad de agua residual a tratar en cada campaña y su carga contaminante.

Tabla 2. Estimación de la cantidad de lodos de depuradora generados en las diferentes campañas en función de la materia prima procesada en la Región de Murcia en el año 2008

\begin{tabular}{lcccc}
\hline Materia prima & T procesadas/año & $\begin{array}{c}\text { T lodos/100 T } \\
\text { procesadas }\end{array}$ & $\begin{array}{c}\text { Lodos } \\
\text { (T/año) }\end{array}$ & \% lodos anuales \\
\hline Alcachofa & 120.000 & $2-4$ & $2.400-4.800$ & $18,6-21,3$ \\
Pimiento & 60.000 & $2-3$ & $1.200-1.800$ & $9,3-8,0$ \\
Tomate & 29.000 & $5-7$ & $1.450-2.030$ & $11,2-9,0$ \\
Melocotón & 120.000 & $4-7$ & $4.800-8.400$ & $37,2-37,3$ \\
Albaricoque & 65.000 & $2-4$ & $1.300-2.600$ & $10,1-11,5$ \\
Pera & 19.500 & $4-6$ & $780-1.170$ & $6,0-5,2$ \\
Fresa & 22.000 & $2-4$ & $440-880$ & $3,4-3,9$ \\
Mandarina & 10.500 & $5-8$ & $525-840$ & $4,1-3,7$ \\
TOTAL & $\mathbf{4 4 6 . 0 0 0}$ & - & $\mathbf{1 2 . 8 9 5 - \mathbf { 2 2 . 5 2 0 }}$ & $\mathbf{1 0 0}$ \\
\hline
\end{tabular}

Teniendo en cuenta las campañas $u$ orientaciones productivas (OP), se puede decir que más del $50 \%$ de la generación de lodos anual se correspondió con las OP melocotón y alcachofa, con un $37 \%$ de participación y alrededor de un $20 \%$ respectivamente, tal como se muestra en la última columna de la Tabla 2.

La generación de efluentes líquidos -aguas residuales procedentes de las actividades de transformación industrial de especies vegetales- y de lodos -resultantes del proceso de tratamiento y depuración de las mencionadas aguas residualespresentó, en su dimensión temporal, un importante nivel de concentración en el periodo enmarcado por los meses de abril y octubre con porcentajes agregados del $87,6 \%$ y del $96,5 \%$ (Figura 2). Esta distribución temporal aparece determinada por los factores o variables siguientes:

a) La dinámica temporal de las diferentes campañas en cuanto al volumen de materia prima procesada.

b) La especialización y, derivadamente, la composición productiva de cada campaña, basada en orientaciones productivas específicas, que definen gamas y/o tipos de productos diferenciados y modos y técnicas de producción específicas que, a su vez, determinan pautas de generación de aguas residuales y lodos en términos tanto de proporción de volumen y de peso como en el de composición físico-química en cada caso, con promedios de $7,40 \mathrm{~m}^{3}$ agua residual generada por tonelada de materia prima procesada y 0,0081 toneladas de lodos generadas por $\mathrm{m}^{3}$ de agua residual depurada. 


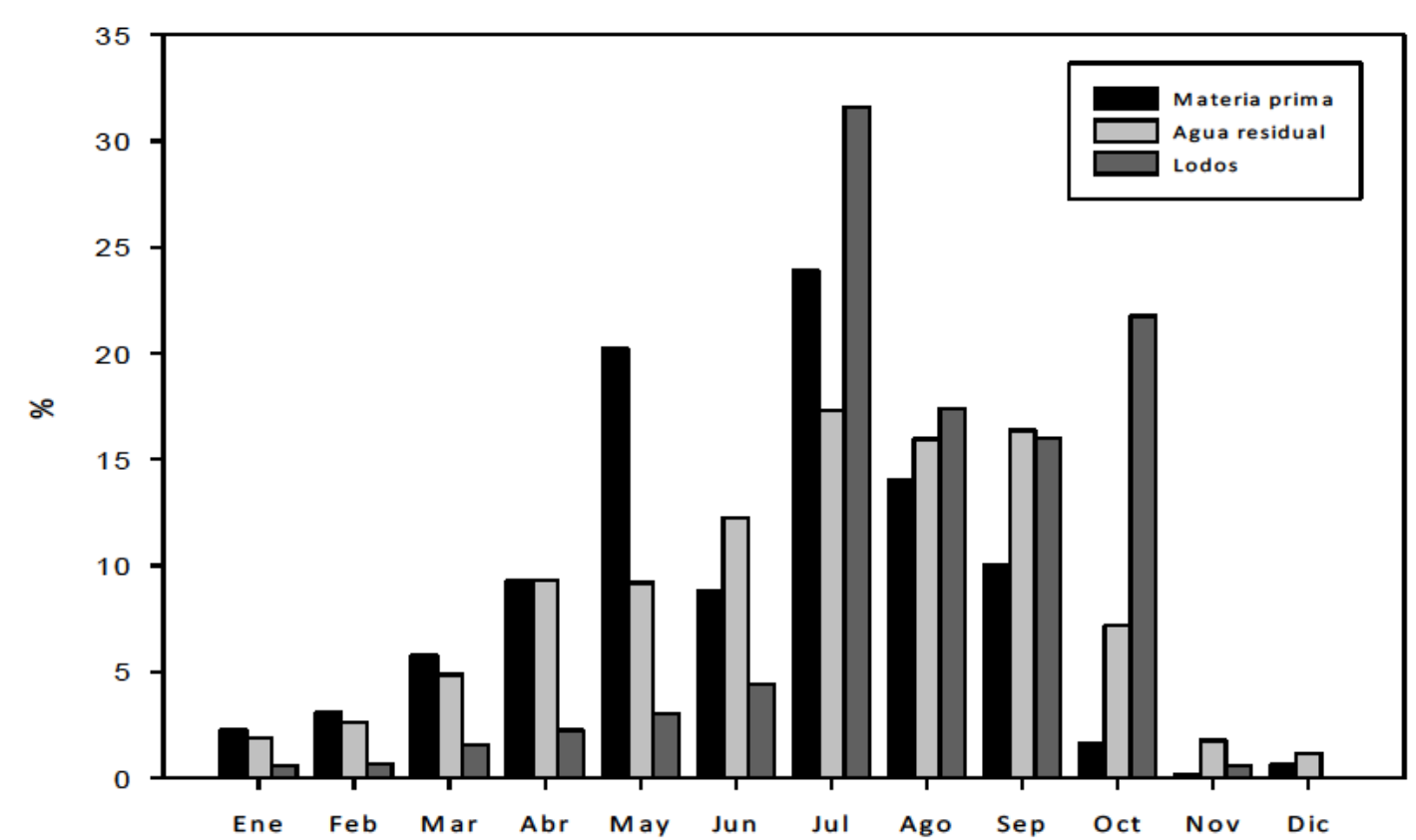

Figura 2. Porcentaje mensual de la generación de aguas residuales y lodos en comparación con la materia prima procesada

En la Figura 2 se puede observar que el período de octubre a marzo estuvo caracterizado por las aguas residuales derivadas especialmente del procesado de alcachofa, que tienen un alto nivel unitario relativo de $1.050 \mathrm{~m}^{3} / 100$ toneladas de materia prima procesada, pero una baja carga contaminante, lo que provoca un nivel unitario reducido de generación de lodo. El periodo de marzo-abril a octubre representó el mayor nivel de concentración productiva del año, pivotando principalmente sobre el procesado de fruta de hueso que induce un alto nivel potencial de generación de aguas residuales $\left(750 \mathrm{~m}^{3} / 100\right.$ toneladas de materia prima procesada), que unido a que la carga orgánica de las aguas generadas es muy alta, hace que la proporción de lodo generado por unidad de materia prima procesada sea alta, dando lugar a la elevada generación de lodos en esta época.

También, en la Figura 2, se puede observar un relativo nivel de desacoplamiento temporal entre el volumen de agua tratada y el volumen de lodos generados, cosa que no ocurre entre la materia prima procesada y el agua tratada. Esto es atribuible al tiempo de residencia del agua residual hasta que esta se depure, además de que la retirada de lodos no ocurre tras un tiempo de residencia sino cuando la planta esté colmatada, factores derivados de las características del proceso aplicado en la EDAR, un proceso de fangos activos. Según Amanatidou et al. (2015), debido a la naturaleza del tratamiento de fangos activos, una gran cantidad de fangos en exceso es generada diariamente, proporcional a la carga del influente. Esta cantidad de fangos se extrae y es la que controla el tiempo necesario (tiempo de retención celular o edad 
del fango) para que la mezcla de células nuevas con células viejas conduzca a la oxidación completa de la materia orgánica. Por otro lado, un tiempo de retención celular mínimo de 3 días es el requerido por las bacterias para formar agregados y ser capaces de separarse por gravedad (Hreiz et al., 2015). Teniendo en cuenta que el tratamiento de fangos activos opera a altos tiempos de retención celular, baja carga másica y alta tasa de recirculación de fangos (Grady et al., 1999), la extracción de fangos del sistema es baja para regular dicho tiempo de retención celular y se incrementa para conseguir los rendimientos adecuados de la planta en base a mantener la concentración de sólidos en suspensión en el reactor según la carga másica que recibe en todo momento.

Finalmente, los datos obtenidos en la Región de Murcia se trataron de comparar con los datos disponibles para este tipo de lodos a nivel nacional y así determinar su importancia. Solo se encontraron datos registrados en el inventario de residuos sobre lodos de depuradora urbanos y asimilables del Gobierno de Navarra, que también depende de la participación de las empresas. En Navarra, los lodos de depuración del sector de conservas de frutas y hortalizas, registrados con el código 0203 05, fueron 8.153 toneladas para el año 2011 (Gobierno de Navarra, 2015), cantidad inferior a la determinada para la Región de Murcia. A continuación, para establecer la importancia de la generación de lodos de depuración de este sector a nivel nacional, se tomaron como referencia los datos de las ventas netas de producto en el sector de conservas de frutas y hortalizas de ambas Comunidades Autónomas. En Navarra las ventas representaron el $13 \%$ y en Murcia el $24 \%$, el mayor porcentaje a nivel nacional (MAGRAMA, 2015). Teniendo en cuenta la relación observada entre ventas netas de producto y generación de lodos de depuración, se puede decir que el potencial de lodos de depuración de este sector en la Región de Murcia es el mayor de España.

\subsubsection{Aproximación a la economía del tratamiento de efluentes hídricos y producción de lodos}

Las operaciones de tratamiento de aguas residuales y la subsiguiente de retirada de lodos representan para las empresas del sector de conservas de frutas y hortalizas un importante esfuerzo técnico, organizativo y económico. Para su ejecución deben dotarse de medios materiales, principalmente de una estación depuradora de aguas residuales (EDAR) y humanos adecuados con el consiguiente coste imputable a los mismos.

La determinación de los costes correspondientes a las operaciones mencionadas se realizó tomando como base la valoración de los medios materiales necesarios y los costes incurridos en los casos de las principales empresas de este sector ubicadas en la Región de Murcia, cuyos resultados han sido proveídos por parte 
de algunas de ellas, quedando recogidos en la Tabla 3. En resumen, el fundamento del cálculo realizado fue el siguiente:

a) Medios materiales (valoración total de la inversión en infraestructuras, instalaciones y equipos: $1.000 .000 €$, según datos promediados de los casos estudiados)

i) Sistema EDAR de depuración (incluyendo tratamiento físico-químico + tratamiento biológico + tratamiento de lodos), con diseño para una capacidad real media de $2.500 \mathrm{~m}^{3} /$ día, con un nivel medio de $200.000-$ $300.000 \mathrm{~m}^{3}$ /año de efluentes hídricos tratados.

ii) Equipos correspondientes a filtración, bombeo, recirculación y decantación en el caso de las aguas, y de deshidratación y espesamiento en el caso de los lodos.

iii) Amortización cifrada en $70.000 €$ /año, correspondiente al promedio ponderado de los casos estudiados.

iv) Costes de mantenimiento, reparaciones y reposición de componentes singulares establecidos en $20.000 € /$ año.

b) Otros costes

i) Energía. Según las características de los casos estudiados y para una demanda de 200.000-300.000 $\mathrm{m}^{3} /$ año tratados, se ha estimado un consumo efectivo de $2,91 \mathrm{kWh} / \mathrm{m}^{3}$ de agua tratada, con un precio de tarifa industrial preferencial de 0,09 €/kWh.

ii) Consumibles. Se trata principalmente de reactivos químicos, como polielectrolito, dióxido de carbono, nitrato amónico, fosfato mono amónico, ácido fosfórico, antiespumante, etc., con un valor cercano a los $100.000 € / a n ̃ o$, según datos promediados de los casos estudiados.

iii) Mano de obra, con dos componentes fundamentales:

- Mano de obra directa (operarios planta). Su demanda efectiva se cifra, de acuerdo al criterio adoptado, 3.520 h/año, prestados por dos operarios a razón de jornada regulada de ocho horas durante 220 días hábiles, con un coste bruto de $11 € / \mathrm{h}$.

- Mano de obra general (relativa a responsable en medio ambiente), con un coste bruto de un técnico titulado.

iv) Gestión de lodos. Se requiere un gestor autorizado, con un coste establecido en $10 € / T$.

El coste total de estos componentes, para una dimensión del sistema promedio de los casos estudiados, se situó en torno a los 350.000 €/año. Esto implicó, considerando los promedios de volumen de aguas residuales tratadas y de los lodos derivados de ellas, un coste unitario de $1,36 € / \mathrm{m}^{3}$ agua tratada y de $185,54 € / T$ equivalente de lodo (Tabla 3). 
Tabla 3. Costes asociados al tratamiento de efluentes hídricos y la gestión de lodos

\begin{tabular}{lcccc} 
& \multicolumn{2}{c}{ COSTE UNITARIO } & \multicolumn{2}{c}{ COSTE TOTAL } \\
& $\begin{array}{c}€ / \mathrm{m}^{3} \text { agua } \\
\text { tratada }\end{array}$ & $\begin{array}{c}€ / \text { T lodo } \\
\text { producido }\end{array}$ & $\begin{array}{c}\text { Mínimo } \\
€ / \text { año }\end{array}$ & $\begin{array}{c}\text { Máximo } \\
€ / \text { año }\end{array}$ \\
\hline INFRAESTRUCTURAS & 0,353 & 48,19 & 621.410 & 1.085 .239 \\
Instalaciones & 0,274 & 37,48 & 483.305 & 844.050 \\
Equipos & 0,079 & 10,71 & 138.105 & 241.189 \\
ENERGÍA & 0,255 & 34,84 & 449.262 & 784.597 \\
CONSUMIBLES & 0,385 & 52,56 & 677.761 & 1.183 .615 \\
MANO DE OBRA & 0,294 & 39,95 & 515.155 & 899.674 \\
Mano de obra directa & 0,163 & 22,22 & 286.527 & 500.394 \\
Mano de obra general & 0,131 & 17,72 & 228.499 & 399.054 \\
GESTION LODOS & 0,073 & 10,00 & 128.950 & 225200 \\
TOTAL & $\mathbf{1 , 3 6 0}$ & $\mathbf{1 8 5 , 5 4}$ & $\mathbf{2 . 3 9 2 . 5 3 8}$ & $\mathbf{4 . 1 7 8 . 3 6 1}$ \\
\hline
\end{tabular}

En resumen, teniendo en cuenta el coste unitario del tratamiento de las aguas residuales y la gestión de los lodos, para el total de lodos estimados en el sector de conservas vegetales, con las opciones máxima (22.520 T/año) y mínima (12.895 T/año) (Tabla 2), el coste total anual de las empresas del sector de conservas vegetales de la Región de Murcia, asociado a la demanda ambiental para el vertido de aguas, es de 2.392.538 € para la opción mínima y de 4.178.361 € para la máxima, y una media de ambas magnitudes de 3.285.450€.

En la Figura 3 se representa la composición, destacando el coste asociado a los consumibles (productos químicos) y el correspondiente a la amortización y mantenimiento de las infraestructuras (instalaciones, equipo, etc.). En el primer caso se obtuvo un coste unitario de $0,385 € / \mathrm{m}^{3}$ y $52,56 € / T$ de lodo equivalente, mientras que en el segundo fue de $0,353 € / \mathrm{m}^{3}$ de agua tratada y de $48,19 € / T$ equivalente de lodo. Dentro de esta segunda partida el coste más importante correspondió al de amortizaciones de las instalaciones, representando casi el $78 \%$ del mismo pero destacando asimismo el de mantenimiento, reparaciones, etc., con gran importancia en este tipo de actividad, alcanzando un porcentaje de más del $22 \%$ del total, lo que supone $0,079 € / \mathrm{m}^{3}$ y $10,71 € / T$ equivalente de lodo.

Por otro lado, en último lugar se situó el coste de gestión de lodos, establecido en $10 € / T$, que supone un coste atribuido de $0,073 € / \mathrm{m}^{3}$ y representa el 5,39\% del total de los costes del proceso. 


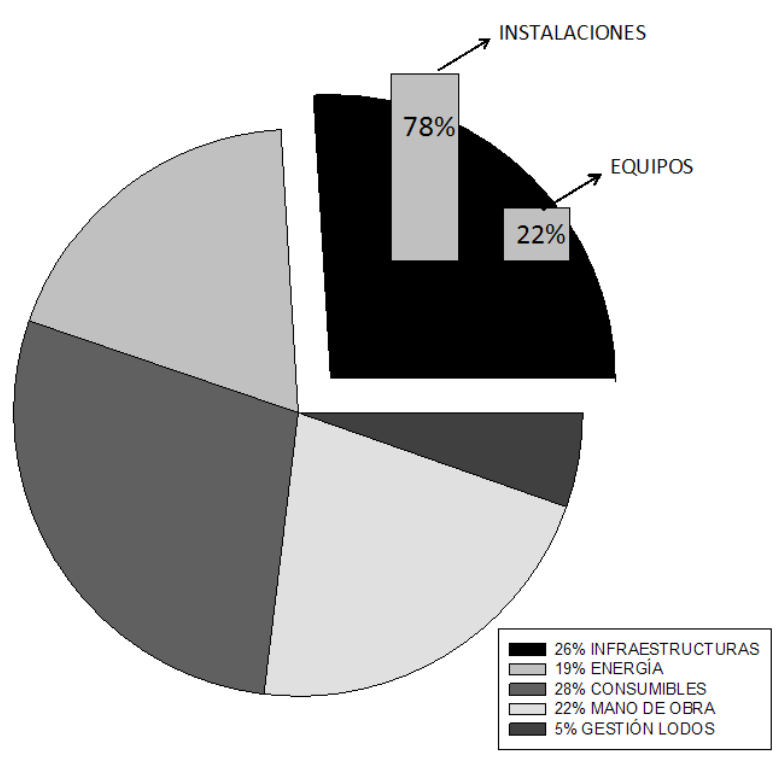

Figura 3. Porcentaje de costes asociados al tratamiento de efluentes hídricos y gestión de lodos

\subsection{Caracterización de los lodos agroalimentarios}

Las características de los lodos agroalimentarios son presentadas en la Tabla 4. Los datos disponibles indican fluctuaciones debido a los procesos productivos y al tipo de materia prima procesada, y por tanto a la carga contaminante de las aguas residuales tratadas en el sistema de depuración de las empresas evaluadas. Los parámetros físico-químicos, así como los agronómicos van a mejorar las propiedades del suelo donde se apliquen estos lodos, pero su concentración en metales pesados o contaminantes microbiológicos impiden su uso en el sector agrícola.

$\mathrm{El} \mathrm{pH}$ y la conductividad eléctrica muestran valores característicos del propio material vegetal industrializado y la calidad de las aguas utilizadas en el proceso industrial. El contenido en carbono orgánico total y materia orgánica de estos lodos es más elevado que los lodos de depuración urbana (García-Delgado et al., 2007). El valor de la relación $\mathrm{C} / \mathrm{N}$ también es variable y dependiente de la materia prima procesada, de acuerdo con lo reportado por Parnaudeau et al. (1998) donde los lodos normalmente manifiestan amplias diferencias en los valores de su relación $\mathrm{C} / \mathrm{N}$ dependiendo de su origen, debido fundamentalmente al variable contenido en nitrógeno dependiendo del origen del agua residual. Así pues, la relación $\mathrm{C} / \mathrm{N}$ puede variar desde 6 hasta 64 porque el nitrógeno varía desde aproximadamente 0,5 a 7,6 \% (Tabla 4), con un valor medio de 3,29 \%. También el fósforo y el potasio varían dependiendo de la materia prima procesada, pero sus valores no son muy altos en los lodos debido a que provienen de la propia materia prima, excepto en el caso de lodos procedentes del tratamiento de aguas de procesado de melocotón donde se utiliza la potasa como reactivo químico de pelado. El potasio es un elemento cuyo contenido en 
los lodos es bajo en comparación con los otros dos macroelementos, al igual que establecieron Cabre et al. (1990) para lodos urbanos. Según la materia prima procesada estos valores varían y por tanto los lodos pueden ser de más o menos interés para su utilización agrícola, destacando el contenido en nitrógeno (Hernández et al., 1991) pero en todo caso pueden ser utilizados.

Por otro lado, es de destacar que el nivel de contaminación por metales pesados es uno de los primeros parámetros que debe ser evaluado para determinar la calidad de los lodos de depuradora y es muy importante en caso de utilizarlo para la aplicación al suelo (Ghazy et al., 2009). Los valores medios de los metales pesados analizados en los lodos procedentes de la industria agroalimentaria estuvieron muy por debajo de los permitidos por la normativa tanto de aplicación agrícola de lodos de depuradora como la de fertilizantes o afines. Por lo tanto, para los lodos agroalimentarios se puede asegurar concentraciones bajas debido al origen de los mismos, mientras que los lodos urbanos han mostrados concentraciones mayores en numerosos estudios (Fuentes et al., 2004; MAGRAMA, 2009; Murcia-Navarro, 2013).

Otro de los parámetros importantes en cuanto al uso de lodos en agricultura es el cumplimiento en cuanto al contenido en patógenos humanos. En este caso, la Directiva 86/278/CEE, transpuesta a la normativa española en el Real Decreto 1310/1990 (DOUE, 1986; BOE, 1990) no establece límites máximos de concentración por patógenos en la reutilización de lodos, pero sí el Real Decreto 506/2013 (BOE, 2013b) establece valores máximos para las enmiendas utilizadas como fertilizantes químicos, siendo estos ausencia de Salmonella spp. en $25 \mathrm{~g}$ de producto y un nivel máximo de $E$. coli de $1.000 \mathrm{NMP} / \mathrm{g}$ de producto elaborado, lo que hace necesario un control de los mismos en los lodos a emplear para la elaboración de enmiendas orgánicas. En los lodos de la industria agroalimentaria analizados no se observó presencia de Salmonella spp. ni Listeria monocytogenes, pero sí se observó E. coli en aproximadamente un $20 \%$ de las muestras analizadas, parámetro indicador de contaminación fecal (Dufour y Schaub, 2007), por lo que su detección en el lodo se debe a su presencia en las aguas tratadas. En el lodo es donde se concentra gran cantidad de bacterias y parásitos del agua tratada (García et al., 2013). Strauch (1987) consideró que los estreptococos fecales son indicadores de la desinfección de los lodos de depuración compostados, por lo que su valor en los lodos iniciales es también de interés aunque este parámetro no esté contemplado en la legislación en la actualidad. La determinación de estreptococos fecales también se ha utilizado como indicador de contaminación de origen fecal, indicando la presencia de este microorganismo que es capaz de sobrevivir en condiciones anaerobias, así como condiciones termófilas debido a su capacidad de formar estructuras de resistencia en forma de esporas. Todos los lodos analizados presentaron contaminación por estreptococos fecales, lo que evidencia aportación de aguas fecales al sistema de depuración de las aguas de estas 
empresas y/o bien una contaminación de estas características en la materia prima procesada.

Finalmente, el análisis de plaguicidas en los lodos procedentes de depuradoras de industrias del sector de conservas de frutas y hortalizas refleja que en ocasiones pueden aparecer restos de plaguicidas procedentes de los tratamientos de la materia prima procesada. En particular los resultados positivos se deben a tres materias activas: clorpirifos, imazalil y ortofenilfenol. Clorpirifos es un insecticida que se utiliza para el control de insectos en numerosos cultivos, mientras que el imazalil y el ortofenilfenol se utilizan como tratamientos postcosecha con el fin de reducir pérdidas en frutas y hortalizas después de recolectadas, destacando su uso en el sector citrícola. Según Marín Galvín et al. (2009), en zonas con actividad agrícola pueden detectarse compuestos como clorpirifos en las aguas residuales mixtas que entran a la EDAR por escorrentías o malas prácticas agrícolas, pero también se le asocia con actividades industriales relacionadas con fabricación de productos agrícolas. Su presencia en los lodos se debe a una concentración de estas materias activas presentes en las aguas residuales. Las concentraciones de clorpirifos determinadas fueron bajas y estuvieron por debajo de las detectadas en aguas mixtas de entrada a EDAR por Marín Galvín et al. (2009). Sin embargo, las concentraciones de imazalil detectadas en muestras de lodos de industrias de cítricos fueron las más altas (hasta 1,49 mg/kg), aunque el nivel máximo establecido para consumo humano es de $5 \mathrm{mg} / \mathrm{kg}$, según el Real Decreto 280/1994 (BOE, 1994), por lo que su presencia es destacable desde un punto de vista científico, aunque no debe de ser problemática para la salud humana o medioambiental. 


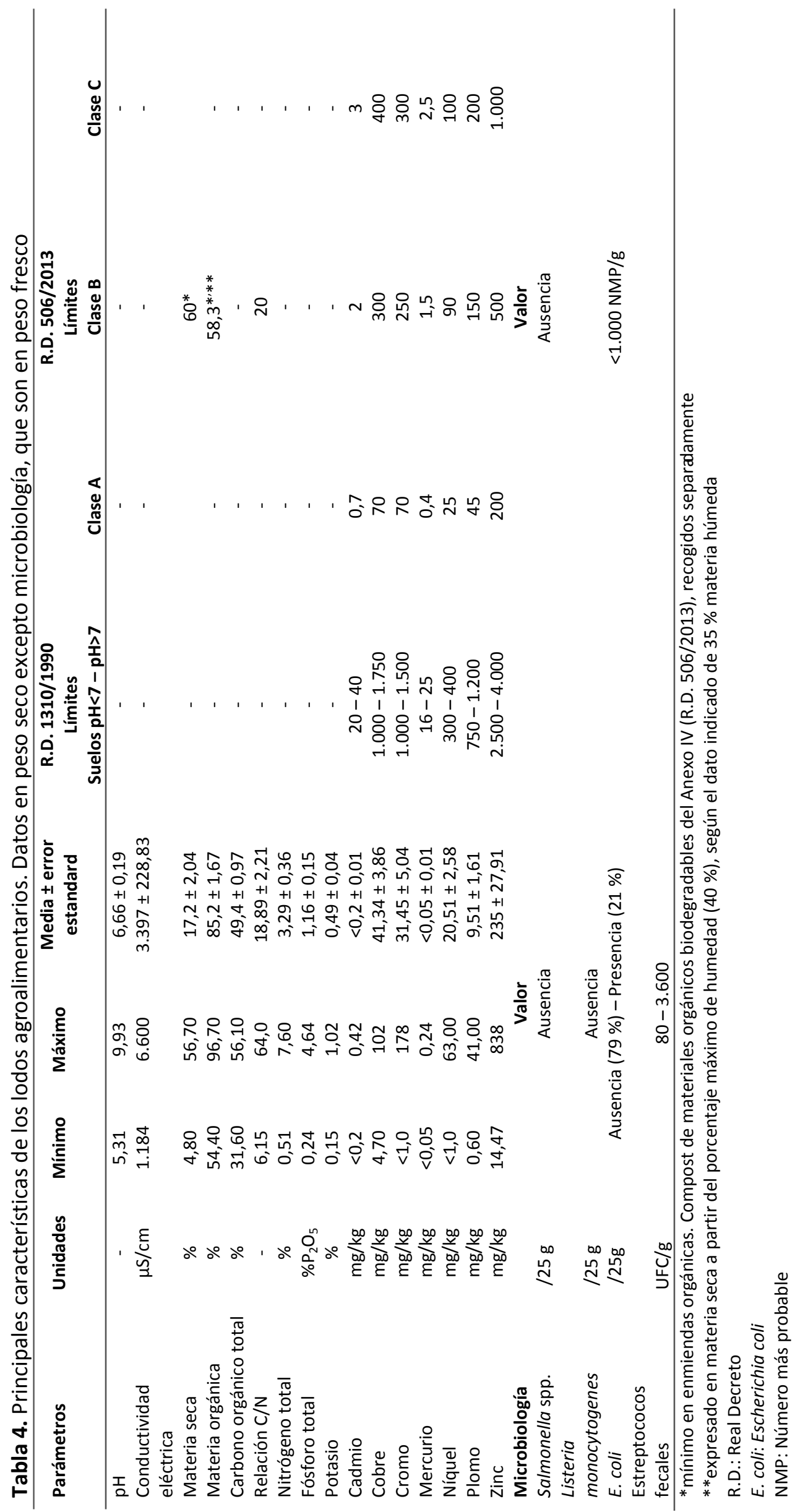




\subsection{Opciones de valorización agrícola de los lodos agroalimentarios}

Los residuos y subproductos del sistema agroalimentario representan actualmente un recurso prácticamente sin explotar (Kahiluoto et al., 2011). Los residuos contienen grandes cantidades de materia orgánica y variedad de nutrientes que los hacen aptos para ser reciclados y ya la Ley 22/2011 de residuos y suelos contaminados (BOE, 2011) lo prioriza. Los lodos de depuración se engloban dentro de este tipo de residuos aprovechables por sus características, pero al igual que otros residuos su reciclado directo está limitado debido a la presencia de ciertos contaminantes, tal y como hemos mencionado anteriormente, y que, en grandes rasgos, los lodos de este sector agroindustrial no suponen un problema para su aprovechamiento agrícola. La aplicación al suelo de los lodos de depuradora es una opción común de eliminación empleada en muchos países debido a que los lodos de depuradora contienen abundantes compuestos orgánicos, macronutrientes y micronutrientes, y ha ido ganando popularidad en la agricultura debido a sus valores de fertilizantes y las propiedades de acondicionamiento de suelos (Sreesai et al., 2013). El reciclado mediante su aplicación en agricultura es la valorización más apoyada en la Región de Murcia para todos los lodos de depuración.

El uso directo de lodos de depuración en campos de cultivo es una opción de reciclado, pero en todo caso se requiere de un manual o código de Buenas Prácticas Agrícolas para la Aplicación de Lodo EDAR como Enmienda (Murcia-Navarro, 2013). En el caso de la Región de Murcia este ha de estar de acuerdo con el Código de Buenas Prácticas Agrarias de la Región de Murcia (BORM, 2003). En todo caso, es necesario haber realizado un tratamiento adecuado al lodo de depuración para reducir su poder de fermentación y los inconvenientes sanitarios de su utilización. Por otro lado, las estrategias más recientes de valorización llevan a la estabilización del material y su reducción de volumen.

Los lodos de depuradora de aguas residuales urbanas han sido evaluados en agricultura durante muchos años, ya que elimina estos residuos y reduce la contaminación del medio ambiente, al incorporar la materia orgánica $y$ macronutrientes, especialmente N y P, al suelo (Mosquera-Losada et al., 2010; Rigueiro-Rodríguez et al., 2012). Los lodos agroindustriales, de producción de azúcar y vino, también han sido evaluados y tienen un interesante potencial para ser aplicados en el suelo (Alvarenga et al., 2008, 2015). Por otro lado, el propósito de la tecnología industrial, hasta la década de 1990, era para tratar desechos y residuos de vertedero (Mateo y Maicas, 2015), pero actualmente son muchas las tecnologías disponibles para tratar los residuos y por tanto los lodos de depuración.

En la Tabla 5 se resumen las opciones de valorización agrícola propuestas para lodos de depuración del sector agroalimentario y sus principales características. 


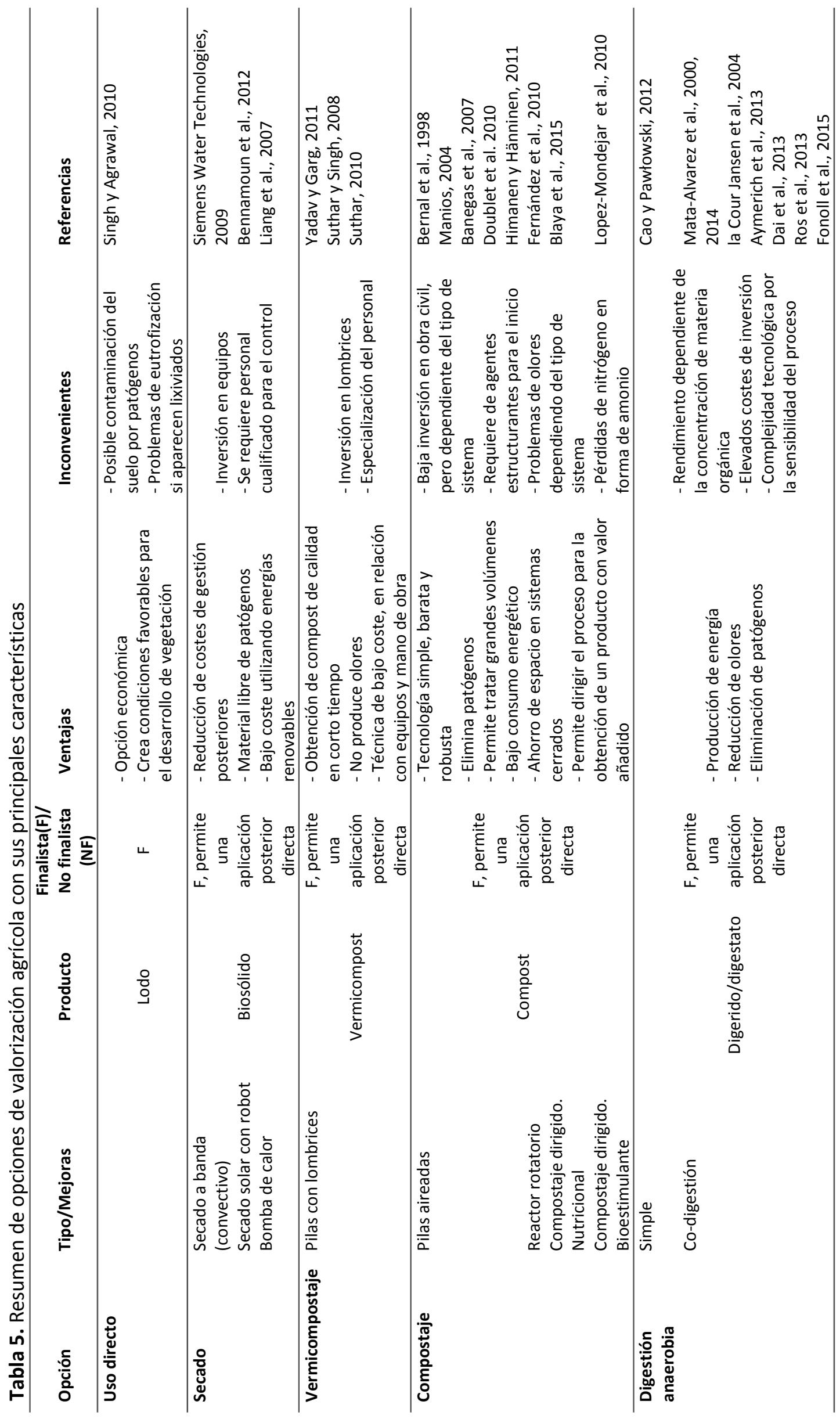




\subsubsection{Uso directo}

Las características de los lodos agroalimentarios son apropiadas para su uso directo en agricultura, pero las dosis de aplicación deben fijarse en función de las características agronómicas y edafológicas del suelo, así como de las exigencias nutricionales de los cultivos, de acuerdo al Plan Nacional Integrado de Residuos 20082015 (BOE, 2009). Los lodos de depuración han sido ampliamente estudiados, aunque no tanto los lodos agroalimentarios, y numerosos autores indicaron que el rendimiento de cosecha era mayor con el incremento de las dosis de los lodos de depuración (Bouzerzour et al., 2002; Tamrabet et al., 2009; Pirdashti et al., 2010; Singh y Agrawal, 2010; Latare et al., 2014). Mantovi et al. (2005) evaluaron los lodos de depuración en tierras de cultivo durante un periodo de 12 años comparando el lodo líquido, deshidratado y compostado, y obtuvieron beneficios en cuanto a fertilidad del suelo, aunque observaron acumulación de metales pesados, hecho que no ocurriría de un modo tan rápido en el caso del empleo de los lodos de la industria de zumos y hortalizas, dado que su contenido es controlado desde la materia prima, tal y como hemos comentado anteriormente. Dolgen et al. (2007) también desarrollaron experimentos con lodos obtenidos de una planta de tratamiento de aguas residuales de una fábrica de procesamiento de vegetales para investigar el potencial de reciclaje de lodos industriales en la agricultura examinando los efectos de las diferentes dosis de lodo sobre el crecimiento de la planta, y sus experimentos han demostrado que la aplicación de lodos aumentó el crecimiento de las plantas en comparación con el control.

Según Singh y Agrawal (2010), la aplicación de lodos al suelo puede ser una de las opciones más económicas y útiles de eliminación de lodos de depuradora, donde el transporte, el análisis de los lodos y el suelo, así como el seguimiento necesario son los únicos costes. Sin embargo, el coste se puede incrementar si el suelo es contaminado porque existen bacterias, virus, hongos y parásitos en el lodo. A través de tratamiento de lodos, estos pueden ser reducidos; sin embargo, su eliminación completa requiere de un tratamiento avanzado y sólo está plenamente garantizado bajo condiciones especiales (Bengtsson y Tillman, 2004).

\subsubsection{Secado}

El residuo (lodo de depuración) contiene una alta proporción de agua que puede ser reducida por secado, con la ventaja de que el lodo secado tiene unos menores costes de transporte y es más fácil de almacenar y distribuir (MosqueraLosada et al., 2010). Los beneficios de utilizar fango deshidratado en agricultura han sido evaluados en numerosos estudios. Mantovi et al. (2005) indicaron que la aplicación de lodo deshidratado mejora las propiedades físicas, químicas y biológicas 
del suelo e incrementa la producción agrícola al incorporar nutrientes y materia orgánica.

El progreso tecnológico, en el campo del secado, ha permitido desarrollar varias técnicas para la obtención de biosólidos, que pueden dividirse en: secado convectivo, secado conductivo y finalmente, secado solar (Bennamoun et al., 2013). Los secadores convectivos más utilizados industrialmente son: secadores a banda, secadores flash, secadores de fluidización y secadores rotatorios. Siemens Water Technologies (2009) ha desarrollado un secador a banda convectivo para fangos deshidratados que puede mejorar los biosólidos obtenidos. Por otro lado, las principales tecnologías utilizadas en el secado conductivo son: secadores de discos, secadores de palas y secadores de película delgada. Los secadores conductivos operan calentando la superficie del secador que proporciona el calor al lodo. El secado solar puede llevarse a cabo en túneles abiertos o bien en invernaderos cerrados. La superficie es calentada mediante la radiación solar y el fango es extendido en lechos. La ventilación o corrientes de aire son utilizadas para renovar el aire del interior y evacuar el aire humidificado. En algunas instalaciones se utiliza un robot para desplazar, voltear y airear el lodo, renovando así la superficie de intercambio y evitando la formación de una corteza (Bennamoun et al., 2012).

Dado que el secado está considerado como un proceso que consume una alta cantidad de energía, que conlleva operaciones costosas; investigadores científicos y tecnológicos dirigen sus trabajos hacia fuentes de energía alternativa, especialmente hacia el secado solar, pero también hacia el uso bombas de calor. Liang et al. (2007) experimentaron sobre la deshidratación de lodo con bombas de calor, pero mostraron que la capacidad de deshidratación fue alta cuando la humedad disminuyó de $46 \%$ al $19 \%$ y muy baja hasta llegar de $19 \%$ a 5,4 \%, por lo que puede necesitar de otra fuente de calor de secado para reducir el contenido en humedad de los lodos por debajo del $10 \%$.

Las principales ventajas de los tres modos de secado incluyen que se obtiene un producto seco apto para su uso en agricultura (Bennamoun et al., 2013), pero una higienización completa se conseguiría mediante un secado basado en la inmersión de los lodos de depuradora en un fluido no miscible climatizado (grasas animales, aceites usados, etc.), el fry-drying (Peregrina et al., 2008; Romdhana et al., 2009), que es a alta temperatura.

El uso de lodo de depuración secado térmicamente y posteriormente peletizado también fue estudiado por Fernández et al. (2007) en suelos agrícolas degradados, obteniendo que en general, el uso de lodos conduce a un aumento de la materia orgánica del suelo y los resultados obtenidos para los lodos secados térmicamente sugieren que existe un proceso de mineralización superior a cuando se aplican lodos compostados. La peletización de lodos de depuración es un proceso de estabilización con el que se puede mejorar la eficiencia de la producción de cultivos 
frente a la fertilización mineral. Mosquera-Losada et al. (2010) utilizaron como referencia las dosis de nitrógeno necesarias de los cultivos y determinaron que el lodo peletizado es más beneficioso, que otros compostados y digeridos anaeróbicamente cuando se añade al suelo, porque produce mayor mineralización de nitrógeno. Además, desde un punto de vista práctico, la baja proporción de materia seca en el lodo peletizado es importante porque permite reducir costes de transporte entre la planta de tratamiento del lodo y el punto de aplicación agrícola.

\subsubsection{Vermicompostaje}

El vermicompostaje es un efectivo proceso biotecnológico donde el lodo es digerido por lombrices para generar un producto conocido como vermicompost (Yadav y Garg, 2011). En este proceso, los nutrientes presentes en el lodo de tratamiento de las aguas residuales son convertidos en una forma más accesible por las plantas, tras la digestión que sufren (Joo et al., 2015). Según Yadav y Garg (2011), el proceso de vermicompostaje produce lodos de alta calidad en un tiempo relativamente corto, pero el proceso parece depender de la vida útil de las lombrices, por lo que puede ser una opción para aquellos lodos con baja concentración de metales, como son los lodos agroalimentarios. Son numerosos los estudios sobre vermicompostaje, pero podemos destacar el de Suthar y Singh (2008) donde proponen que los lodos agroindustriales no deberían ser tratados como un residuo debido a que tienen un gran potencial agronómico porque su bioestabilización utilizando lombrices lo convierten en un rico biofertilizante. Además, Suthar (2010) sugirió que el vermicompost de lodos agroindustriales puede ser una opción económica y ecológica para la sostenibilidad de la fertilidad de suelos degradados.

\subsubsection{Compostaje}

El uso de lodos de depuradora en la agricultura puede reciclar los residuos de una forma sostenible y evitar la pérdida de la fertilidad del suelo (Haudin et al., 2013). Por lo tanto, el efecto fertilizante de los lodos compostados es un índice importante para la aplicación al suelo, sobre todo para la agricultura (Chen et al., 2014). Los principales factores del proceso de compostaje son el contenido de humedad de la alimentación, el sistema de ventilación, la temperatura, el pH, el tamaño de partícula y la relación C/N (Kumar et al., 2010). Para el compostaje de lodos se requieren los siguientes valores: contenido de humedad del $50 \%-60 \%$, pH entre 5 y 9 , relación $\mathrm{C} / \mathrm{N}$ entre 25 y 35 , el contenido de materia orgánica del $20 \%$ - $80 \%$ y un tamaño de partícula de entre 12 y $60 \mathrm{~mm}$ (Chen, 2012). Por lo tanto, los lodos agroalimentarios son adecuados, aunque ciertos parámetros deberían ajustarse. Según Ingelmo et al. (2012), la adición de un agente estructurante para el compostaje puede optimizar las propiedades del sustrato tales como el espacio de aire, contenido de humedad, la 
relación $\mathrm{C} / \mathrm{N}$, la densidad de partículas, $\mathrm{pH}$ y la estructura mecánica, que afectan positivamente la velocidad de descomposición. En este sentido, los subproductos lignocelulósico, tales como virutas de madera y aserrín, se utilizan comúnmente como agentes estructurantes (Maboeta y van Rensburg, 2003; Pasda et al., 2005; Neves et al., 2009), así como otros (Li et al., 2013).

Numerosos autores han empleado el lodo como material de partida para la elaboración de compost (Bernal et al., 1998; Manios, 2004; Banegas et al., 2007; Doublet et al., 2010; Himanen y Hänninen, 2011). Gallardo et al. (2007) obtuvieron un compost fácil de almacenar para su uso como enmienda orgánica o fertilizante utilizando virutas de madera como agente estructurante, Fernández et al. (2010) utilizaron un reactor rotatorio para el compostaje de lodos de depuración de un sistema de depuración anaerobio con otros biorresiduos y demostraron que es una opción viable para la gestión de estos biorresiduos, también Joo et al. (2015), en su revisión del estado del arte de las técnicas de reutilización de estos biosólidos, indicaron que el compostaje es una técnica para convertir el lodo residual en un producto beneficioso.

Si bien es cierto que el proceso de compostaje está muy estudiado, son muchas las posibilidades de mejoras del proceso y reducción de costes, tales como el estudio de diferentes agentes estructurantes (Doublet et al., 2011; Zhou et al., 2014), pero también la manipulación del proceso con el objeto de la obtención de un compost "a la carta", conocido como compostaje dirigido. La selección de materiales iniciales como agentes co-compostantes permitirá dirigir el proceso a una mejora nutricional del compost y poder demostrar un carácter supresivo frente a diversos patógenos (Blaya et al., 2015), y por tanto incrementar la productividad donde se emplee. También la adición de microorganismos específicos, tales como Trichoderma harzianum en el compost permite aumentar el rendimiento de crecimiento y reduce enfermedades de las plantas, por lo que son bioestimulantes (Bernal-Vicente et al., 2014) y operan como agentes de control biológico (Blaya et al., 2013). Con respecto a esto, Lopez-Mondejar et al. (2010) obtuvieron que la combinación de un compost de cítricos con microorganismos del género Trichoderma sp. ( $T$. harzianum T-78) podría ser un sustituto de la turba y minimizaría la aplicación de productos químicos (por ejemplo, fertilizantes sintéticos, agentes de protección de plantas, etc.) al presentar efecto biocontrol contra la Fusariosis.

El compostaje es una opción de gestión que aporta ventajas, tales como que el manejo del compost es más fácil (menos agua), garantiza de destrucción de los patógenos que pudiera haber en la materia orgánica (Moreno y Mormeneo, 2007) y mejora rendimientos en la producción agrícola (como enmienda orgánica normalmente, pero también como un compost dirigido). 


\subsubsection{Digestión anaerobia}

La estabilización anaeróbica puede ser una alternativa a la estabilización aeróbica (Cieslik et al., 2015) ya que el lodo después de la fermentación también puede ser adecuado para su uso en la agricultura y recuperación de suelos. Además, se produce biogás, que tiene un alto contenido en metano (Mills et al., 2014). Este método de gestión de los lodos de depuradora tiene algunas limitaciones, como es garantizar la eficacia del proceso de fermentación de metano manteniendo las condiciones adecuadas para el desarrollo de los microorganismos fermentativos. Sin embargo, la digestión anaeróbica es la tecnología más popular de estabilización de lodos actualmente en el mercado (Cao y Pawłowski, 2012).

Las características de los lodos agroalimentarios los hacen aptos para su empleo como materias de partida en digestión anaerobia debido a su similitud con los lodos de depuradoras urbanas y las experiencias llevadas a cabo en los últimos años (Ros et al., 2013), pudiendo ser empleados con una concentración mínima de sólidos totales en suspensión del $4 \%$ o su equivalente al 15-18 \% cuando estos han sido deshidratados. Los lodos más concentrados muestran un mayor potencial de generación de biogás (IDAE, 2007), por lo que parece ventajosa su utilización. Sin embargo, la tecnología de digestión anaerobia no se aplica de manera extendida en las industrias agroalimentarias debido a los costes de inversión inicial y la necesidad de requerir de personal especializado y específico para el control del proceso. Además, debido a las características del proceso de digestión anaerobia, es ventajoso que los lodos sean digeridos con otros cosustratos para aumentar el rendimiento del sistema. Numerosos estudios indican que los lodos aerobios pueden ser co-digeridos con otros materiales para realizar una gestión integrada (Righi et al., 2013), mantener estable el sistema e incrementar el potencial de producción de biogás, con las mejoras ambientales y económicas que ello supone. La adición de residuos de alimentos a la digestión de lodos de depuración ha sido ampliamente referenciada en la bibliografía (Mata-Alvarez et al., 2000, 2014; la Cour Jansen et al., 2004; Aymerich et al., 2013; Dai et al., 2013; Ros et al., 2013; Fonoll et al., 2015). Con ello, los residuos orgánicos son gestionados de acuerdo a la normativa actual, y el producto final producido denominado digerido o digestato, puede llegar a ser un fertilizante mejorado en términos de su disponibilidad para las plantas (Tafdrup, 1995) y su reología (Pain y Hepherd, 1985).

De todos modos, la digestión anaerobia tiene como resultado la producción de energía, pero también un material digerido o digestato, cuya aplicación a campo está restringida en cumplimiento de las demandas de los cultivos y su concentración de contaminantes, siguiendo los Códigos de Buenas Prácticas Agrarias, tal como se indica en el Real Decreto 506/2013 (BOE, 2013b). En este caso, una etapa de estabilización aerobia puede ser necesaria para reducir los contaminantes (Hospido et al., 2005; Alburquerque et al., 2012a; Cukjati et al., 2012). 
Alburquerque et al. (2012b) utilizaron el digestato resultante de la digestión de purines y lodos de depuración como fertilizante en campos de cultivo y obtuvieron un efecto positivo en el rendimiento del cultivo de sandías frente a una fertilización con estiércol, pero la aplicación debe ser optimizada según el tipo de cultivo. Por lo tanto, el uso de digeridos o digestatos como fertilizante permite valorizar los lodos de depuradora en uso agrícola. En todo caso, el compostaje permite obtener un producto con mejores características como fertilizante (Bernal et al., 2011).

\section{Conclusión}

Las empresas del sector de conservas de frutas y hortalizas realizan algún tratamiento previo al vertido de sus aguas residuales para cumplir con los parámetros exigidos por ley, y en el caso de aquellas con mayor volumen de vertido y carga contaminante también tienen instalado un sistema de depuración del tipo biológico, lo que genera lodos de depuración. En la Región de Murcia existiría un potencial de lodos agroalimentarios de cerca de 40.000 toneladas anuales, destacando las operaciones productivas de melocotón y alcachofa como las de mayor generación. Además, esa producción tiene lugar principalmente en las comarcas de la Huerta de Murcia y el Noroeste y se concentra en los meses de abril-octubre.

Por otro lado, el necesario tratamiento de las aguas residuales y la gestión de los lodos supone a las empresas del sector de la Región de Murcia un coste total de más de 3.000.000 €/año. Por lo tanto, opciones de valorización permitirían poder recuperar parte de estos costes. La caracterización de los lodos ha permitido determinar el alto contenido orgánico de los mismos, así como su alto contenido en nutrientes interesante para su uso agrícola, además de que no presentan contaminación por metales pesados (diferenciable y mejorable con respecto a los lodos de depuración urbanos). La aplicación de estos en agricultura es la opción de valorización que mayores ventajas aporta, aunque un tratamiento aerobio previo tal y como el compostaje tiene un valor añadido. La digestión anaerobia seguida de un sistema de estabilización aerobio, como es el compostaje, puede aportar beneficios debido a la recuperación del biogás producido en el reactor anaerobio para la producción de energía, además de su aprovechamiento agrícola.

\section{Bibliografía}

Alburquerque, J.A., de la Fuente, C., Bernal, M.P., 2012a. Chemical properties of anaerobic digestates affecting $\mathrm{C}$ and $\mathrm{N}$ dynamics in amended soils. Agric. Ecosyst. Environ. 160, 15-22.

Alburquerque, J.A., de la Fuente, C., Campoy, M., Carrasco, L., Nájera, I., Baixauli, C., Caravaca, F., Roldán, A., Cegarra, A., Bernal, M.P., 2012b. Agricultural use of digestate for horticultural crop production and improvement of soil properties. Eur. J. Agron. 43, 119-128.

Alimarket, 2010. Disponible en: http://www.alimarket.es/buscador_avanzado_empresas 
Alvarenga, P., Mourinha, C., Farto, M., Santos, T., Palma, P., Sengo, J., Morais, M., Cunha-Queda, C., 2015. Sewage sludge, compost and other representative organic wastes as agricultural soil amendments: Benefits versus limiting factors. Waste Manage. 40, 44-52.

Alvarenga, P., Palma, P., Gonçalves, A.P., Baião, N., Fernandes, R.M., de Varennes, A., Vallini, G., Duarte, E., Cunha-Queda, A.C., 2008. Assessment of chemical, biochemical and ecotoxicological aspects in a mine soil amended with sludge of either urban or industrial origin. Chemosphere 72, 1774-1781.

Amanatidou, E., Samiotis, G., Trikoilidou, E., Pekridis, G., Taousanidis, N., 2015. Evaluating sedimentation problems in activated sludge treatment plants operating at complete sludge retention time. Water Res. 69, 20-29.

Aymerich, E., Esteban-Gutiérrez, M., Sancho, L., 2013. Analysis of the stability of high-solids anaerobic digestion of agro-industrial waste and sewage sludge. Bioresour. Technol. 144, 107-114.

Banegas, V., Moreno, J.L., Moreno, J.I., García, C., León, G., Hernández, T., 2007. Composting anaerobic and aerobic sewage sludges using two proportions of sawdust. Waste Manage. 27(10), 1317-1327.

Bennamoun, L., 2012. Solar drying of wastewater sludge: a review. Renew. Sust. Energ. Rev. 16(1), 10611073.

Bennamoun, L., Arlabosse, P., Léonard, A., 2013. Review on fundamental aspect of application of drying process to wastewater sludge. Renew. Sust. Energ. Rev. 28, 29-43.

Bengtsson, M., Tillman, A., 2004. Actors and interpretations in an environmental controversy: the Swedish debate on sewage sludge use in agricultura. Resour. Conserv. Recy. 42, 65-82.

Bernal, M.P., Alburquerque, J.A., Bustamante, M.A., Clemente, R., 2011. Guía de utilización agrícola de los materiales digeridos por biometanización. CSIC 2011. Disponible en: http://213.229.136.11/bases/ainia_probiogas.nsf/0/89A368DD73F7282DC125753F00587325/\$FILE/PR OBIOGAS_GuiaDigerido.pdf.

Bernal, M. P., Navarro, A.F., Sánchez-Monedero, M.A., Roig, A., Cegarra, J., 1998. Influence of sewage sludge compost stability and maturity on carbon and nitrogen mineralization in soil. Soil Biol. Biochem. 30(3), 305-313.

Bernal-Vicente, A., Pascual, J.A., Tittarelli, F., Hernández, J.A., Diaz-Vivancos, P., 2014. Trichoderma harzianum T-78 supplementation of compost stimulates the antioxidant defence system in melon plants. J. Sci. Food Agric. DOI: 10.1002/jsfa.6936.

Blaya, J., Lopez-Mondejar, R., Lloret, E., Pascual, J.A., Ros, M., 2013. Changes induced by Trichoderma harzianum in suppressive compost controlling Fusarium wilt. Pestic. Biochem. Phys. 107, 112-119.

Blaya, J., Lloret, E., Ros, M., Pascual, J.A., 2015. Identification of predictor parameters to determine agroindustrial compost suppressiveness against Fusarium oxysporum and Phytophthora capsici diseases in muskmelon and pepper seedlings. J. Sci. Food Agric. 95, 1482-1490.

BOE, 1990. Real Decreto 1310/1990, de 29 de octubre, por el que se regula la utilización de los lodos de depuración en el sector agrario. Boletín Oficial del Estado 262, 32339-32340.

BOE, 1994. Real Decreto 280/1994, de 18 de febrero, por el que se establece los límites máximos de residuos de plaguicidas y su control en determinados productos de origen vegetal. Boletín Oficial del Estado 58, 7723-7726.

BOE, 2001. Real Decreto 3484/2000, de 29 de diciembre, por el que se establecen las normas de higiene para la elaboración, distribución y comercio de comidas preparadas. Boletín Oficial del Estado 11, 14351441. 
$B O E$, 2002. Orden MAM/304/2002 de 8 de febrero, por la que se publican las operaciones de valorización y eliminación de residuos y la lista europea de residuos. Boletín Oficial del Estado 43, 64946515.

BOE, 2009. Resolución de 20 de enero de 2009, de la Secretaría de Estado de Cambio Climático, por la que se publica el Acuerdo del Consejo de Ministros por el que se aprueba el Plan Nacional Integrado de Residuos para el período 2008-2015. Boletín Oficial del Estado 49, 19893-20016.

BOE, 2011. Ley 22/2011, de 28 de julio, de residuos y suelos contaminados. Boletín Oficial del Estado $181,85650-85705$.

BOE, 2013a. Orden AAA/1072/2013, de 7 de junio, sobre utilización de lodos de depuración en el sector agrario. Boletín Oficial del Estado 142, 44966-44973.

BOE, 2013b. Real Decreto 506/2013, de 28 de junio, sobre productos fertilizantes. Boletín Oficial del Estado 164, 51119-51207.

BORM, 1999. Decreto 16/1999, de 22 de abril, sobre Vertidos de Aguas Residuales Industriales al Alcantarillado. Boletín Oficial de la Región de Murcia 97, 5459-5464.

BORM, 2003. Orden de 3 de diciembre de 2003, de la Consejería de Agricultura, Agua y Medio Ambiente, por la que se aprueba el Código de Buenas Prácticas Agrarias de la Región de Murcia. Boletín Oficial de la Región de Murcia 286, 20517-20530.

Bouzerzour, H., Tamrabet, L., Kribba, M., 2002. Response of barley and oat to the wastewater irrigation and to the sludge treatment. In: The Proc. Int. Seminar: Biol. Environ. University Mentouri. Consantine. Algeria. $71 \mathrm{pp}$.

Cao, Y., Pawłowski, A., 2012. Sewage sludge-to-energy approaches based on anaerobic digestion and pyrolysis: brief overview and energy efficiency assessment. Renew. Sust. Energ. Rev. 16, 1657-1665.

Cabre, J., Arraez, J., Aragoneses, R., 1990. Eliminación de lodos de aguas residuales. La E.D.A.R de Reus: un ejemplo de aprovechamiento mediante compostaje. Quimica e Industria 36, 537-541.

CARM, 2015. Comunidad Autónoma de la Región de Murcia. Consejería de Agricultura y Agua.

Chan, Y.J., Chong, M.F., Law, C.L., Hassell, D.G., 2009. A review on anaerobic-aerobic treatment of industrial and municipal wastewater. Chem. Eng. J. 155, 1-18.

Chen, Y., 2012. Sewage Sludge Aerobic Composting Technology Research Progress. 2012 AASRI Conference on Computational Intelligence and Bioinformatics. AASRI Procedia 1, 339-343.

Chen, Y., Yu, F., Liang, S., Wang, Z., Liu, Z., Xiong, Y., 2014. Utilization of solar energy in sewage sludge composting: Fertilizer effect and application. Waste Manage. 34, 2014-2021.

Christensen, A., Gurol, M.D., Garoma, T., 2009. Treatment of persistent organic compounds by integrated advanced oxidation processes and sequential batch reactor. Waste Res. 43, 3910-3921.

Cieslik, B.M., Namiesnik, J., Konieczka, P., 2015. Review of sewage sludge management: standards, regulations and analytical methods. J. Clean. Prod. 90, 1-15.

Cukjati, N., Zupančič, G.D., Ros, M., Grilc, V., 2012. Composting of anaerobic sludge: An economically feasible element of a sustainable sewage sludge management. J. Environ. Manage. 106, 48-55.

Dai, X., Duan, N., Dong, B., Dai, L., 2013. High-solids anaerobic co-digestion of sewage sludge and food waste in comparison with mono digestions: stability and performance. Waste Manage. 33, 308-316.

Dolgen, D., Alpaslan, M.N., Denle, N., 2007. Agricultural recycling of treatment-plant sludge: A case study for a vegetable-processing factory. J. Environ. Manage. 84, 274-281. 
Doublet, J., Francou, C. Poitrenaud, M., Houot, S., 2010. Sewage sludge composting: influence of initial mixtures on organic matter evolution and $\mathrm{N}$ availability in the final composts. Waste Manage.30, 19221930.

Doublet, J., Francou, C., Poitrenaud, M., Houot, S., 2011. Influence of bulking agents on organic matter evolution during sewage sludge composting; consequences on compost organic matter stability and $\mathrm{N}$ availability. Bioresour. Technol. 102, 1298-1307.

DOUE, 1986. Directiva del consejo de 12 de junio de 1986 relativa a la protección del medio ambiente y, en particular, de los suelos, en la utilización de los lodos de depuradora en agricultura. Diario Oficial de las Comunidades Europeas 181, 6-12.

DOUE, 1991a. Directiva del Consejo, de 21 de mayo de 1991, sobre el tratamiento de las aguas residuales urbanas. Diario Oficial de las Comunidades Europeas 135, 40-52.

DOUE, 1991b. Directiva del Consejo, de 12 de diciembre de 1991, relativa a la protección de las aguas contra la contaminación producida por nitratos utilizados en la agricultura. Diario Oficial de las Comunidades Europeas 375, 1-8.

DOUE, 2008. Directiva 2008/98/CE del Parlamento Europeo y del Consejo, de 19 de noviembre de 2008, sobre los residuos y por la que se derogan determinadas Directivas. Diario Oficial de las Comunidades Europeas 135, 40-52.

Dufour, A.P., Schaub, S., 2007. The evolution of water quality criteria in the United States, 1922-2003. In: Wymer, L.J. (Ed.), Statistical Framework for Recreational Water Quality Monitoring. Chichester. John Wiley \& Sons. pp. 1-12.

EPA, 1998. Method EPA 3015. Microwave Assisted Acid Digestion of Sediments, Sludges, Soils and Oils. Washington, DC.

European Commission, 2006. Reference Document on Best Available Techniques in the Food, Drink and Milk Industries. Ed. European Commission. Disponible en:

http://www.prtr-es.es/data/images/BREF\%20Industria\%20Alimentaria-0D1FD3D62FB0DB4D.pdf

European Commission, 2010. Environmental, economic and social impacts of the use of sewage sludge on land. Final Report. Part III: Project Interim Reports (10/02/2010, DG ENV.G.4/ETU/2008/0076r).

European Committee for Standardization, 1999. Soil Improvers and Growing Media - Determination of Organic Matter and Ash. Standard CEN EN 13039:1999 E. European Committee for Standardization, Brussels.

Fernández, J.M., Hernández, D., Plaza, C., Polo, A., 2007. Organic matter in degraded agricultural soils amended with composted and thermally-dried sewage sludges. Sci. Total Environ. 378, 75-80.

Fernández, F.J., Sánchez-Arias, V., Rodríguez, L., Villaseñor, J., 2010. Feasibility of composting combinations of sewage sludge, olive mill waste and winery waste in a rotary drum reactor. Waste Manage. 30, 1948-1956.

Fonoll, X., Astals, S., Dosta, J., Mata-Alvarez, J., 2015. Anaerobic co-digestion of sewage sludge and fruit wastes: Evaluation of the transitory states when the co-substrate is changed. Chem. Eng. J. 262, 12681274.

Food Drink Europa, 2012. Data \& Trends of the European Food and Drink Industry 2012. Disponible en: http://www.fooddrinkeurope.eu/uploads/publications_documents/Data_Trends_\%28interactive\%29.p df

Fuentes, A., Liorens, M., Sáez, J., Soler, A., Aguilar, M.I., Ortuño, J.F., Meseguer, V.F., 2004. Simple and sequential extractions of heavy metals from different sewage sludges. Chemosphere 54(8), 1039-1047. 
Gallardo, A., Bovea, M.D., Contreras, R., Lapeña, L., Ingelmo, F., Molina, M.J., 2007. Production of Compost with Woodchips and Stabilized Sludge from Urban Wastewater Treatment Plants. Influence of Temperature on the Composting Process. 11th International Congress of Projects Engineering. Agroforestry Engineering Department, Lugo (Spain). 26-28 September. I.S.B.N. 978-84-690-8134-1.

García, J., Salas, J.J., Marin, I., Vymazal, J., 2013. Reseach and innovation on ecotechnologies applied to improve wastewater treatment efficiency. Ecol. Eng. 50, 1-4.

García-Delgado, M., Rodríguez-Cruz, M.S., Lorenzo, L.F., Arienzo, M., Sánchez-Martín, M.J., 2007. Seasonal and time variability of heavy metal content and of its chemical forms in sewage sludges from different wastewater treatment plants. Sci. Total Environ. 382, 82-92.

Ghazy, M., Dockhorn, T., Dichtl, N., 2009. Sewage sludge management in Egypt: Current status and perspectives towards a sustainable agricultural use. World Academy of Science, Engineering and Technology 57, 299-307.

Gobierno de Navarra, 2015. Inventario subprograma Lodos-Edar y asimilables. Disponible en: http://www.navarra.es/home_es/Temas/Medio+Ambiente/Residuos/Inventarios.htm

Grady, C.P.L., Daigger Jr., G.T., Lim, H.C., 1999. Biological Wastewater Treatment. New York. 2nd Ed., Revised and Expanded. Marcel Dekker, Inc.

Guerrero, L., Omil, F., Mendez, R., Lema, J.M., 1999. Anaerobic hydrolysis and acidogenesis of wastewaters from food industries with high content of organic solids and protein. Water Res. 33, 32813290.

Haudin, C.S., Zhang, Y.H., Dumény, V., Lashermes, G., Bergheaud, V., Barriuso, E., Houot, S., 2013. Chemosphere 92, 1280-1285.

Hernández, T., Moreno, J.L., Costa, F., 1991. Influence of sewage sludge application on crop yields and heavy metal availability. Soil Sci. Plant Nutr. 37, 201-210.

Himanen, M., Hänninen, K., 2011. Composting of bio-waste, aerobic and anaerobic sludges - Effect of feedstock on the process and quality of compost. Bioresour. Technol. 102, 2842-2852.

Hospido, A., Moreira, M.T., Martín, M., Rigola, M., Feijoo, G., 2005. Environmental evaluation of different treatment processes for sludge from urban wastewater treatments: anaerobic digestion versus thermal processes. Int. J. LCA 10(5), 336-345.

Hreiz, R., Latifi, M.A., Roche, N., 2015. Optimal design and operation of activated sludge processes: State-of-the-art. Chem. Eng. J. 281, 900-920.

IDAE, 2007. Biomasa: Digestores anaerobios. Energías Renovables - Energía de la Biomasa. Instituto para la Diversificación y Ahorro de la Energía. Disponible en:

http://www.idae.es/uploads/documentos/documentos_10737_Biomasa_digestores_07_a996b846.pdf.

INE, 2015. Encuesta Industrial de Empresas del INE. Disponible en:

http://www.magrama.gob.es/es/alimentacion/temas/industriaagroalimentaria/fs0_totalindustriaalime ntariaabril-15_tcm7-270402.pdf

Ingelmo, F., Molina, M.J., Soriano, M.D., Gallardo, A., Lapeña. L., 2012. Influence of organic matter transformations on the bioavailability of heavy metals in a sludge based compost. J. Environ. Manage. 95, S104-S109.

Joo, S.H., et al., 2015. Sustainable approaches for minimizing biosolids production and maximizing reuse options in sludge management: A review, J. Environ. Manage.

http://dx.doi.org/10.1016/j.jenvman.2015.05.014. 
Kahiluoto, H., Kuisma, M., Havukainen, J., Luoranen, M., Karttunen, P., Lehtonen, E., Horttanainen, M., 2011. Potential of agrifood wastes in mitigation of climate change and eutrophication - Two case regions. Biomass Bioenergy 35, 1983-1994.

Kelessidis, A., Stasinakis, A.S., 2012. Comparative study of the methods used for treatment and final disposal of sewage sludge in European countries. Waste Manage. 32, 1186-1195.

Kitson, R.E., Mellon, M.G., 1944. Colorimetric determination of $\mathrm{P}$ as molybdovanato phosphoric acid. Ind. Eng. Chem. 42(3), 379-383.

Kumar, M., Ou, Y.L., Lin, J.G., 2010. Co-composting of green waste and food waste at low C/N ratio. Waste Manage. 30, 602-609.

la Cour Jansen, J., Gruvberger, C., Hanner, N., Aspegren, H., Svärd, A., 2004. Digestion of sludge and organic waste in the sustainability concept for Malmö, Sweden. Water Sci. Technol. 49, 163.

Latare, A.M., Kumar, O., Singh, S.K., Gupta, A., 2014. Direct and residual effect of sewage sludge on yield, heavy metals content and soil fertility under rice-wheat system. Ecol. Eng. 69, 17-24.

Li Z., Lu H., Ren L., He L., 2013. Experimental and modeling approaches for food waste composting: A review. Chemosphere 93, 1247-1257.

Liang, L., Bi-Guang, Z., Yong-Dong, Z., Yue-Fei, F., 2007. Experimental study on sludge drying with heat pump dehumidifier. In: 5th Asia-Pacific Drying Conference. Hong Kong. pp. 13-15.

Lopez-Mondejar, R., Bernal-Vicente, A., Ros, M., Tittarelli, F., Canali, S., Intrigiolo, F., Pascual, J.A., 2010. Utilisation of citrus compost-based growing media amended with Trichoderma harzianum T-78 in Cucumis melo L. seedling production. Bioresour. Technol. 101, 3718-3723.

Maboeta, M.S., van Rensburg, L., 2003. Vermicomposting of industrially produced woodchips and sewage sludge utilizing Eisenia fetida. Ecotoxicol. Environ. Saf. 56(2), 265-270.

MAGRAMA, 2009. Caracterización de los lodos de depuradoras generados en España. Disponible en: http://www.magrama.gob.es/es/calidad-y-evaluacion-ambiental/temas/prevencion-y-gestionresiduos/Caracterizaci\%C3\%B3n_de_los_lodos_de_depuradoras_generados_en_Espa\%C3\%B1a_(NIPO_ 770-10-256-5)_tcm7-183315.pdf.

MAGRAMA, 2015. Informe Industria Alimentaria 2012-2013, Datos CC.AA (Murcia) y Ficha sectorial (Conservas de Frutas y Hortalizas). Disponible en:

http://www.magrama.gob.es/es/alimentacion/temas/industria-agroalimentaria/informacioneconomica-sobre-la-industria-agroalimentaria.

Manios, T., 2004. The composting of different organic solid waste: experience from the island of Crete. Environ. Int. 29, 1079-1089.

Mantovi, P., Baldoni, G., Toderi, G., 2005. Reuse of liquid, dewatered, and composted sewage sludge on agricultural land: effects of long-term application on soil and crop. Water Res. 39, 289-296.

Marín Galvín, R., Ripollés Pascual, F., Santateresa Forcada, E., Lahora Cano, A., González Canal, I., Mantecón Pascual, R., Rodríguez Amaro, R., 2009. Contaminación convencional, sustancias prioritarias y contaminantes emergentes en saneamientos públicos españoles. Revista Tecnología del Agua 313, 4054.

Mata-Alvarez, J., Dosta, J., Romero-Güiza, M.S., Fonoll, X., Peces, M., Astals, S., 2014. A critical review on anaerobic co-digestion achievements between 2010 and 2013. Renew. Sust. Energ. Rev. 36, 412-427.

Mata-Alvarez, J., Macé, S., Llabrés, P., 2000. Anaerobic digestion of organic solid wastes. An over view of research achievements and perspectives. Bioresour. Technol. 74, 3-16. 
Mateo, J.J., Maicas, S., 2015. Valorization ofwinery and oil mill wastes by microbial technologies, Food Res. Int. http://dx.doi.org/10.1016/j.foodres.2015.03.007.

Mills, M., Pearce, P., Farrow, J., Thorpe, R.B., Kirkby, N.F., 2014. Environmental \& economic life cycle assessment of current $\&$ future sewage sludge to energy technologies. Waste Manag. 34, 185-195.

Moreno, J., Mormeneo, S., 2007. Microbiología y bioquímica del proceso de compostaje. In: Moreno, J., Moral, R. (Eds.), Compostaje. Madrid. Mundi-prensa.

Mosquera-Losada, M.R., Muñoz-Ferreiro, N., Rigueiro-Rodríguez, A., 2010. Agronomic characterisation of different types of sewage sludge: Policy implications. Waste Manage. 30, 492-503.

Murcia-Navarro, F.J., 2013. Lodos de Depuradora: una Visión Integral para su posible Aplicación a Suelos desde una Perspectiva Agrícola. Tesis Doctoral. Universidad de Murcia. Murcia. España.

Najafpour, G.D., Zinatizadeh, A.A.L., Lee, L.K., 2006. Performance of a three-stage aerobic RBC reactor in food canning wastewater treatment. Biochem. Eng. J. 30, 297-302.

Navarro, A.F., Cegarra, J., Roig, A., Bernal, M.P., 1991. An automatic microanalysis method for the determination of organic carbon in wastes. Commun. Soil Sci. Plant Anal. 22, 2137-2144.

Neves, L., Ferreira, V., Oliveira, R., 2009. Co-composting cow manure with food waste: the influence of lipids content. World Acad. Sci. Eng. Technol. 58, 986-991.

Pain, B.F., Hepherd, R.Q., 1985. Anaerobic digestion of livestock wastes. In: Pain, B.F., Hepherd, R.Q. (Eds.), Anaerobic Digestion of Farm Waste. NIRD Technical Bulletins. Reading. pp. 9-14.

Parnaudeau, V., Marcovecchio, F., Alavoine, G., Nicolardot, B., 1998. Determination of relevant quality criteria to predict decomposition and $\mathrm{N}$ mineralization of solid organic wastes in soil. In: Martínez, J., Maudet, M.N. (Eds.), Proceedings Ramiran 98 8th International Conference on Management Strategies for Organic Wastes Use in Agriculture. Rennes. FAO and Cemagref. pp. 26-29.

Pasda, N., Limtong, P., Oliver, R., Montange, D., Panichsakpatana, S., 2005. Influence of bulking agents and microbial activator on thermophilic aerobic transformation of sewage sludge. Environ. Technol. 26(10), 1127-1136.

Peregrina, C., Rudolph, V., Lecompte, D., Arlabosse, P., 2008. Immersion frying for the thermal drying of sewage sludge: an economic assessment. J. Environ. Manage. 86(1), 246-261.

Pirdashti, H., Motaghian, A., Bahmanyar, M.A., 2010. Effect of organic amendments application on grain yield, leaf chlorophyll content and some morphological characteristics in soybean cultivars. J. Plant Nutr. $33,485-495$.

Righi, S., Oliviero, L., Pedrini, M., Buscaroli, A., Della Casa, C., 2013. Life Cycle Assessment of management systems for sewage sludge and food waste: centralized and decentralized approaches. J. Clean. Prod. 44, 8-17.

Rigueiro-Rodríguez, A., Mosquera-Losada, M.R., Ferreiro-Domínguez, N., 2012. Pasture and soil zinc evolution in forest and agriculture soils of Northwest Spain three years after fertilisation with sewage sludge. Agric. Ecosyst. Environ. 150, 111-120.

Romdhana, M.H., Lecomte, D., Ladevie, B., Sablayrolles, C., 2009. Monitoring of pathogenic microorganisms contamination during heat drying process of sewage sludge. Process Saf. Environ. 87, 377-386.

Ros, M., Franke-Whittle, I.H., Morales, A.B., Insam, H., Ayuso, M., Pascual, J.A., 2013. Archaeal community dynamics and abiotic characteristics in a mesophilic anaerobic co-digestion process treating fruit and vegetable processing waste sludge with chopped fresh artichoke waste. Bioresour. Techonol. $136,1-7$. 
Siemens Water Technologies, 2009. Sludge belt dryer improves biosolids management. Filtr. Separat. 46(1), 11.

Singh, R.P., Agrawal, M., 2010. Variations in heavy metal accumulation, growth and yield of rice plants grown at different sewage sludge amendment rates. Ecotoxicol. Environ. Safe. 73, 632-641.

Sreesai, S., Peapueng, P., Tippayamongkonkun, T., Sthiannopkao, S., 2013. Assessment of a potential agricultural application of Bangkok-digested sewage sludge and finished compost product. Waste Manage. Res. 31, 925-936.

Strauch, D., 1987. Microbiological specification of desinfected compost. In: De Bertoldi, M., Ferranti, M.P., L'Hermite, P., Zucconi, F. (Eds.), Compost: Production, Quality and Use. London and New York. Elsevier Applied Science Publishers Ltd. 210 pp.

Suthar, S., 2010. Recycling of agro-industrial sludge through vermitechnology. Ecol. Eng. 36, 1028-1036.

Suthar, S., Singh, S., 2008. Feasibility of vermicomposting in biostabilization of sludge from a distillery industry. Sci. Total Environ. 394, 237-243.

Tafdrup, S., 1995. Viable energy production and waste recycling from anaerobic digestion of manure and other biomass materials. Biomass Bioenergy 9, 303-314.

Tamrabet, L., Bouzerzour, H., Kribaa, M., Makhlouf, M., 2009. The effect of sewage sludge on durum wheat (Triticum aestivum). Int. J. Agric. Biol. 11, 741-745.

Van Vuuren, D.P., Bouwman, A.F., Beusen, A.H.W., 2010. Phosphorus demand for the 1970-2100 period: a scenario analysis of resource depletion. Glob. Environ. Chang. 20(3), 428-439.

Yadav, A., Garg, V.K., 2011. Industrial wastes and sludges management by vermicomposting. Rev. Environ. Sci. Biotechnol. 10, 243-276.

Zhang, Z. Le Velly, M., Rhind, S.M., Kyle, C.E., Hough, R.L., Duff, E.I., McKenzie, C., 2015. A study on temporal trends and estimates of fate of Bisphenol $A$ in agricultural soils after sewage sludge amendment. Sci. Total Environ. 515-516, 1-11.

Zhou, H.B., Ma, C., Gao, D., Chen, T.B., Zheng, G.D., Chen, J., Pan, T.H., 2014. Application of a recyclable plastic bulking agent for sewage sludge composting. Bioresour. Technol. 152, 329-336. 

IV. Valorización de subproductos agroalimentarios de la Región de Murcia 



\section{Valorización de subproductos agroalimentarios de la Región de Murcia}

\section{Introducción}

La industria alimentaria está presente en la Región de Murcia y contribuye considerablemente a su economía. Además, la industria conservera en Murcia tiene un sentido inmediato, que ha sido y es el de aprovechar la rica producción agrícola, y transformarla. Este esfuerzo hace que la Región de Murcia encabece las ventas netas del sector de conservas de frutas y hortalizas en España (INE, 2013). Sin embargo, para las empresas, sus resultados económicos se ven afectados por las obligaciones derivadas del cumplimiento de la normativa vigente, entre las que se encuentra la Ley $22 / 2011$, de residuos y suelos contaminados (BOE, 2011), donde se establece la obligación de la gestión de los residuos y subproductos con coste a cargo del productor inicial, de acuerdo con el principio de "quien contamina paga".

La alimentación de subproductos de las industrias agrícolas y de procesamiento de alimentos para el ganado es una práctica tan antigua como la domesticación de los animales por los seres humanos (Bampidis y Robinson, 2006). En la Región de Murcia, la alimentación animal, como vía de gestión de los restos vegetales de origen agrícola y agroindustrial, se utiliza desde hace años por su alto valor nutritivo, pero puede presentar inconvenientes tales como que cada grupo animal tiene unos requerimientos específicos que en algunos casos producen baja digestibilidad llegando en algunos casos al envenenamiento. Además, los ganaderos que aprovechan estos residuos no son, en muchos casos, gestores autorizados según la Ley 22/2011 (BOE, 2011), y hay que tener en cuenta la normativa existente sobre alimentación animal en cuanto a autorizaciones y registros, así como la trazabilidad de los piensos y condiciones de higiene y análisis necesarias para minimizar el riesgo sobre la salud animal y humana (Reglamento (CE) no 183/2005 (DOUE, 2005), Directiva 96/25/CE (DOUE, 1996)). Esta práctica también puede llevar a vertidos incontrolados que comprometen el cumplimiento de la normativa relativa a la prevención y control de la contaminación (Directiva 2010/75/UE (DOUE, 2010)), por lo que otras opciones de gestión de estos subproductos han de evaluarse.

En Europa, los materiales residuales producidos por las más relevantes industrias agroalimentarias, como molinos de aceite de oliva, bodegas, tomate $y$ procesamiento de frutas, a menudo no se valoriza o en algunos casos incluso se desperdician (Bacenetti et al., 2015), por lo que pueden tratarse de residuos. La explotación de estos materiales residuales resulta compleja por la disponibilidad concentrada en tiempo y espacio reducidos y el manejo difícil de un material más bien inestable. Sin embargo, en la Región de Murcia estos materiales vegetales, no incluyendo los lodos de depuración, se consideran subproductos del sector de 
conservas de frutas y hortalizas (industrias de transformado vegetal) cuando son gestionados con destino a alimentación animal directa, aunque presentan el inconveniente de que su disposición se hace en muchos casos de manera incontrolada con contratos a ganaderos de la zona o intermediarios.

Por otro lado, la gestión eficiente de la variable ambiental en la empresa puede ser fuente de una competitividad empresarial (Porter y Van Der Linde, 1995), de hecho, las empresas han incluido mejoras en la eficiencia de los procesos aplicando las mejores técnicas disponibles y apostando por el control de sus consumos de agua y energía, lo que ha permitido una reducción en sus costes, además de una posible diferenciación de la competencia por su oferta. Los residuos y subproductos generados en la industria agroalimentaria representan a menudo un coste añadido para las empresas debido a los procesos de eliminación y gestión, pero su potencial valorización mediante una gestión adecuada puede llegar a ser una adecuada ventaja. Actualmente los subproductos se venden a un precio bajo para alimentación de animales e incluso en muchos casos se entregan de forma gratuita con la finalidad de quitarse el problema de encima. Este modo de actuar supone una pérdida de valor de estos, ya que son susceptibles de valorización debido a su origen, además de que pueden generar coproductos con valor añadido aplicando nuevas formas de gestión.

Teniendo en cuenta la variable económica, como principal interés de las empresas, es necesario poner de manifiesto los costes asociados a la generación de subproductos que despierten el interés por la valorización de los mismos, así como poner dichas opciones de valorización en conocimiento del sector. Por lo tanto, el objetivo de este capítulo es poder cuantificar el potencial de subproductos de la industria de transformados vegetales y su aproximación económica en la empresa, caracterizarlos y proponer nuevas opciones de valorización de los mismos que respondan a demandas medioambientales y sean beneficiosas para el sector agroalimentario. Esta información podrá ayudar en la toma de decisiones de las empresas para valorizar sus subproductos.

\section{Materiales y métodos}

\subsection{Potencial de los subproductos agroalimentarios}

El estudio del potencial de generación de biorresiduos en el sector murciano de transformados vegetales se ha desarrollado en el marco del proyecto LIFE+AGROWASTE coordinado por el Centro de Edafología Aplicada del Segura-CSIC (CEBAS-CSIC), con la colaboración del Centro Tecnológico Nacional de la Conserva y Alimentación (CTC) y la Agrupación de Empresas de Alimentación de Murcia, Alicante y Albacete (Agrupal) también localizados en la Región de Murcia y se ha basado en:

a) La realización de encuestas a 48 empresas, que representan más del $90 \%$ de la producción sectorial en esta región, de las cuales 43 empresas han 
proporcionado datos completos y utilizables, alcanzando una representatividad superior al $85 \%$ de la producción, basado en un cuestionario estructurado específico (ver Apéndice).

b) La realización de encuestas/entrevista en profundidad a directivos y técnicos de producción, calidad ambiental, etc. del subsector de conservas vegetales, en número de 10 , con el objetivo de completar y validar la información obtenida mediante la encuesta mencionada anteriormente, especialmente respecto a aspectos técnico-económicos en general. También, en este caso, se ha utilizado un cuestionario estructurado específico (ver Apéndice) que incluye otros campos de interés.

c) Reelaboración de datos específicos, disponibles en publicaciones, estadísticas oficiales y bases de datos del departamento de medio ambiente de la Comunidad Autónoma de la Región de Murcia (CARM), CTC y CEBAS-CSIC.

d) Tratamiento y análisis de datos basados en la determinación de las diferentes dimensiones del fenómeno estudiado, particularmente: origen/fuente de generación, naturaleza/tipología, volúmenes/cantidades, estructura de los procesos secuenciales de generación y/o tratamiento, dimensión espacial (áreas geográficas de generación), dimensión temporal, modalidades de gestión, estructura técnico-económica, etc. Elaboración de coeficientes relacionales.

La valoración económica de los subproductos se determinó en el marco del proceso de producción conjunta, considerándolos como un producto secundario, pero en el mismo nivel conceptual que el producto o productos-mercado principales. Por tanto, de forma concreta, se realizó por medio de la imputación proporcional de los diferentes costes en los que se incurre en el proceso productivo para su generación.

Los datos solicitados correspondieron a los años 2012 y 2013. Debido a la confidencialidad de la información aportada por las empresas, se asignó un número a cada una de las empresas y los datos se trataron de forma total y por subsectores.

\subsection{Caracterización de los subproductos}

Se llevó a cabo una recogida de muestras de subproductos de las empresas de transformados vegetales de la Región de Murcia participantes en el estudio (empresas de conservas, de congelados y de elaboración de zumos de frutas) y se analizaron en los laboratorios del CTC. Una parte de las muestras se mantuvo en refrigeración $\left(4{ }^{\circ} \mathrm{C}\right)$ hasta su análisis y el resto en congelación $\left(-18{ }^{\circ} \mathrm{C}\right)$ para posibles análisis posteriores. Con cada tipo de muestra diferente se procedió a elaborar una ficha del subproducto con datos relativos a su análisis físico-químico, químico, nutricional, de metales pesados, microbiológico y de restos de plaguicidas. También ciertos compuestos de 
interés fueron analizados en algunos de los subproductos para corroborar su presencia y por tanto su capacidad de valorización enfocada a la obtención de coproductos.

\subsubsection{Análisis físico-químico y químico}

Los subproductos agroalimentarios fueron analizados de acuerdo con los parámetros químicos estándar. Se les determinó el $\mathrm{pH}$ y la conductividad eléctrica (CE) en un extracto soluble de agua $1: 10(\mathrm{p} / \mathrm{v})$ con un pHmetro y conductímetro (Crison mod. 2001, Barcelona, Spain), después de $1 \mathrm{~h}$ de agitación y $1 \mathrm{~h}$ de reposo. La humedad se determinó por diferencia de peso entre material inicial y seco a $105^{\circ} \mathrm{C}(24$ horas). Las cenizas totales (diferencia de la materia orgánica (MO)) fueron determinadas por gravimetría después de la calcinación de la muestra en un horno de mufla a $550{ }^{\circ} \mathrm{C}$, durante 24 horas.

La materia orgánica fácilmente oxidable se determinó utilizando el método de oxidación húmeda, mediante el contenido en carbono orgánico por el método Walkley-Black, en el cual la muestra se oxida con una disolución de dicromato de potasio, utilizando el calor producido por la dilución de ácido sulfúrico concentrado, en la solución crómica (Walkley y Black, 1934). La determinación se realizó valorando la cantidad de dicromato que no ha sido reducido por la $\mathrm{MO}$, con una solución de sulfato ferroso, utilizando como indicador difenilamina. Finalmente, se empleó el factor de Van Bemmelen $(1,724)$ para determinar la materia orgánica fácilmente oxidable.

A partir de aquí, la parte de muestra de subproducto para el análisis químico se secó al aire, molió y tamizó.

El nitrógeno $(\mathrm{N})$ fue analizado usando el método Kjeldahl, donde se determina el nitrógeno orgánico más amoniacal. El fósforo $(P)$ fue determinado espectrofotométricamente midiendo la intensidad de la coloración amarilla del ácido molibdovanadato fosfórico (Kitson y Mellon, 1944). Los minerales tales como el potasio $(\mathrm{K})$, calcio $(\mathrm{Ca})$, magnesio $(\mathrm{Mg})$, sodio $(\mathrm{Na})$, hierro $(\mathrm{Fe})$, manganeso $(\mathrm{Mn})$, cobre (Cu) y cinc $(\mathrm{Zn})$ se determinaron mediante espectrometría de masas de plasma acoplado inductivamente (ICP-MS), técnica con la que los componentes de la muestra se ionizan por efecto de un plasma de argón. Estos iones producidos se separan en base a su relación masa/carga en un espectrómetro de masas y son posteriormente cuantificados por un detector multiplicador de electrones. El equipo utilizado fue un ICP-MS serie 7500ce de Agilent Technologies.

\subsubsection{Análisis nutricional}

La grasa se determinó mediante el método Soxhlet utilizando como disolvente el éter dietílico. En este método el disolvente se calienta, se volatiliza y condensa goteando sobre la muestra la cual queda sumergida en el disolvente. Posteriormente 
éste es sifoneado al matraz de calentamiento para empezar de nuevo el proceso. El contenido de grasa se cuantifica por diferencia de peso (Nielsen, 2003).

Las proteínas se determinaron utilizando el método Kjeldahl, a partir del valor del nitrógeno total y multiplicando por el factor 6,25 (Gil, 2005). Los hidratos de carbono $(\mathrm{HC})$ se determinaron como el valor obtenido restando de 100 la suma de los porcentajes de agua, proteína bruta, cenizas y grasa bruta, de acuerdo al Real Decreto 930/1992, de 17 de julio, por el que se aprueba la norma de etiquetado sobre propiedades nutritivas de los productos alimenticios (BOE, 1992).

La fibra bruta (FB) se determinó mediante método gravimétrico, por la pérdida de peso que se produce en la incineración del residuo seco obtenido tras la digestión de las muestras con $\mathrm{H}_{2} \mathrm{SO}_{4}$ y $\mathrm{KOH}$ bajo condiciones específicas.

Finalmente, el valor energético, definido como la cantidad de energía que se origina cuando el alimento es totalmente oxidado o metabolizado, se calculó a partir de los parámetros anteriores utilizando los factores de conversión establecidos en el Real Decreto 930/1992, de 17 de julio (BOE, 1992). Los resultados se expresaron como $\mathrm{kJ} / 100 \mathrm{~g}$ de producto. En concreto el cálculo se realizó según la ecuación:

$$
\frac{k J}{100 g}=(\text { Proteínas } / 100 g+\text { Hidratos de carbono } / 100 g) \times 17+(\text { Grasa } / 100 g) \times 37
$$

\subsubsection{Análisis de metales pesados}

Las muestras ya secas, molidas y tamizadas se emplearon también para determinar las concentraciones de cadmio ( $\mathrm{Cd})$, cromo $(\mathrm{Cr})$, níquel (Ni), plomo $(\mathrm{Pb})$, arsénico (As) y mercurio $(\mathrm{Hg})$ mediante espectrofotometría de masas con plasma de acoplamiento inductivo (ICP-MS) (EPA, 1998), tras una digestión $\mathrm{HNO}_{3} / \mathrm{HClO}_{4}$ previa. Los valores fueron expresados como $\mathrm{mg} / \mathrm{kg}$ en peso seco.

\subsubsection{Análisis microbiológico}

Dos microorganismos fueron utilizados como indicadores de la sanidad de los subproductos agroalimentarios: cuantificación de Escherichia coli (E. coli) y detección de Salmonella spp., de acuerdo con la legislación española sobre productos fertilizantes, Real Decreto 824/2005 y actualmente Real Decreto 506/2013 (BOE, 2013). Además también se evaluó otros microorganismos que pueden ser fuente de contaminación en este tipo de material tales como: Estreptococos fecales, Listeria monocytogenes y Clostridium sulfito reductores. La presencia de estos diferentes grupos de microorganismo patógenos fue determinada de acuerdo a métodos oficiales llevados a cabo en el laboratorio microbiológico del Centro Tecnológico Nacional de la Conserva y Alimentación, los microorganismos fueron medidos en el material original, mantenido a $4{ }^{\circ} \mathrm{C}$ hasta su análisis (máximo 24 horas después de la toma de muestra). 
Los métodos utilizados fueron Salmonella spp. (pre-enriquecimiento agua peptona tamponada (24 h a $37{ }^{\circ} \mathrm{C}$ ), incubación caldo Salmonella Xpress $\left(24 \mathrm{~h}\right.$ a $41,5^{\circ} \mathrm{C}$ ), test VIDAS), Listeria monocytogenes (pre-enriquecimiento en caldo Fraser-medio ( $24 \mathrm{~h}$ a 30 $\left.{ }^{\circ} \mathrm{C}\right)$, incubación caldo Fraser $\left(24 \mathrm{~h}\right.$ a $\left.30^{\circ} \mathrm{C}\right)$, test VIDAS), Coliformes fecales (E. coli) (incubación TBX, $24 \mathrm{~h}$ a $44^{\circ} \mathrm{C}$ ), estreptococos fecales (incubación KAA, 24-48 h a $37^{\circ} \mathrm{C}$ ) y clostridium sulfito reductores (incubación SPS, 24-48 h -anaerobiosis- a $44{ }^{\circ} \mathrm{C}$ ). Los resultados para Salmonella spp., Listeria monocytongenes y $E$. coli fueron expresados como presencia o ausencia en $25 \mathrm{~g}$ material fresco y para estreptococos fecales como número de unidades de colonias formadoras por gramo de material fresco (UFC/g).

Todos los controles se hicieron de acuerdo al Real Decreto 3484/2000 (BOE, 2001) y llevando a cabo diluciones decimales de la muestra en el diluyente de tal manera que después de incubar las placas se calculara el número de colonias en base a resultados significativos.

\subsubsection{Análisis de plaguicidas}

La determinación de residuos de plaguicidas organoclorados y organofosforados se llevó a cabo mediante el método de extracción QuEChERS (Quick Easy Cheap Effective Rugged and Safe) y posterior cuantificación de los residuos de plaguicidas por cromatografía gaseosa (multirresiduos) y cromatografía líquida acoplada a espectrometría de masas (multilíquidos), de acuerdo a protocolos del laboratorio instrumental del Centro Tecnológico Nacional de la Conserva y Alimentación. Los equipos utilizados fueron un HP-6890 con detector de masas y un HPLC serie 1200 de Agilent Technologies acoplado a un detector de masas de trampa de iones. Los resultados fueron expresados como $\mathrm{mg} / \mathrm{kg}$.

\subsubsection{Otros análisis}

Se realizaron análisis de compuestos de interés tales como la cinarina, hesperidina, licopeno y $\beta$-caroteno, así como de fibra alimentaria, en los materiales que se conocían eran fuente de ellos.

El método para determinar la cinarina utilizó una extracción con reflujo utilizando agua como disolvente. Posteriormente se cuantificó la concentración en un HPLC serie 1200 de Agilent utilizando una columna C18 y la siguiente fase móvil: $94 \%$ agua con ácido fosfórico $(0,2 \%) / 6 \%$ acetonitrilo. En el caso de la hesperidina la extracción fue en caliente y utilizó oxalato amónico y dimetilformamida. También un equipo HPLC serie 1200 de Agilent se utilizó para cuantificar la concentración del compuesto con una columna C18 y la siguiente fase móvil: $200 \mathrm{~mL}$ de acetonitrilo + $800 \mathrm{~mL}$ de agua $+0,5 \mathrm{~mL}$ de ácido acético. Para el licopeno y $\beta$-caroteno la extracción utilizó hexano como disolvente y la cuantificación utilizó un equipo HPLC serie 1200 de 
Agilent utilizando una columna C18 y la siguiente fase móvil: $25 \%$ agua/75 \% acetona. Ambos compuestos se determinaron en el mismo análisis observando los tiempos de retención.

Finalmente, para la determinación de fibra alimentaria se siguió el método analítico oficial de análisis (AOAC, 2000) basado en digerir las proteínas e hidratos de carbono con enzimas. En este método, el remanente se adjudica a la fibra alimentaria previo descuento del contenido de cenizas y proteínas remanentes. Se trata de un método enzimático gravimétrico (AOAC Official method 985.29) (Rodriguez et al., 2006), donde se ha de conocer el valor de la humedad, grasa y contenido en azúcares para corregir el resultado obtenido.

\subsubsection{Estadística}

Los valores medios de cada parámetro fueron evaluados para observar diferencias significativas utilizando el análisis de la varianza con un factor (ANOVA) y los mismos fueron comparados mediante el test de Tukey para $p<0,05$. Todos los análisis estadísticos se llevaron a cabo con el software SPSS 22.0 (SPSS Inc., Chicago, IL, EE.UU.).

\subsection{Opciones de valorización de los subproductos}

Se realizó un amplio estudio de chequeo de oportunidades tecnológicas, sistemas de gestión, etc., para tratamiento de biorresiduos. Para ello se utilizaron diversos medios, además de una búsqueda bibliográfica, como estudios propios del CTC y el CEBAS-CSIC, asistencia a ferias y congresos, consulta de catálogos de ingeniería ambiental y alimentaria, y de visitas a empresas del sector con tecnologías de valorización implantadas.

El enfoque metodológico para la revisión bibliográfica se basó en la utilización de palabras clave en buscadores y metabuscadores tales como google, bing, copernic, etc. dirigidas a proyectos de I+D, tesis doctorales, artículos técnicos y patentes, y en bases de datos de revistas científicas, como Scopus y ScienceDirect, dirigidas a la evaluación de artículos científicos principalmente. Las palabras clave seleccionadas fueron: biorresiduos; valorización biorresiduos; subproductos de la industria agroalimentaria; valorización subproductos de la industria agroalimentaria; gestión de biorresiduos; gestión de subproductos de la industria agroalimentaria; tecnologías de valorización. Finalmente se utilizaron palabras clave referenciadas a cada una de las tecnologías, como por ejemplo: secado subproductos, secado alimentos, compostaje subproductos, digestión anaerobia subproductos, compuestos bioactivos subproductos, pectina, alimentación animal, etc. Se evaluaron más de 1.000 referencias y se seleccionaron las opciones tecnológicas más relevantes para clasificar 
en cuatro campos: valorización en alimentación humana, alimentación animal, agricultura y energía.

A partir de ello se dispuso de un amplio inventario de oportunidades tecnológicas y de gestión sobre el que operar analíticamente, las cuales se estudiaron y analizaron, preseleccionando aquellas que tenían una relación oportunidad-beneficio de interés para las empresas del sector agroalimentario. Este modo de operar hizo que muchas de las tecnologías existentes fuesen descartadas dada su complejidad o bajo rendimiento. Finalmente, se pudo diferenciar estas tecnologías como opciones de valorización finalistas o no, por la necesidad de implantar sistemas integrados de valorización.

\section{Resultados y discusión}

\subsection{Potencial de valorización de los subproductos agroalimentarios en la Región de Murcia}

Las comarcas de la Vega Media y la Huerta de Murcia son las que presentan un mayor número de empresas, por lo que se espera una mayor actividad y por lo tanto de generación de subproductos. Sin embargo, gran parte de las empresas de la Vega Media son empresas pequeñas o medianas (PYMEs), lo que hace que los subproductos generados por estas empresas no sean muy elevados. Por tanto, la cantidad de subproductos generados en cada comarca no será proporcional al número de empresas que haya en ella sino más bien al consumo y tipo de materias primas consumidas.

Según datos del año 2012, las empresas agroindustriales participantes en el estudio procesaron un total de 25 tipos de materias primas, además de algunas otras no especificadas en la encuesta y que fueron denominadas otras frutas o vegetales; de ellas el subsector de conservas procesó 21 tipos, mientras que las de congelados procesaron 12 y las de zumos de frutas un total de 6 tipos. La amplia variedad de materias primas procesadas se resume en la Tabla 1.

Tabla 1. Materias primas consumidas por subsectores

\begin{tabular}{ll}
\hline Conservas & \multicolumn{1}{c}{ Materia prima } \\
& $\begin{array}{l}\text { Cebolla, Ciruela, Fresa, Limón, Mandarina, Manzana, Melocotón, Membrillo, } \\
\text { Naranja, Pera, Pimiento, Tomate, Uva y Zanahoria. }\end{array}$ \\
Zumos & Albaricoque, Limón, Mandarina, Melocotón, Naranja y Zanahoria. \\
Congelados & $\begin{array}{l}\text { Alcachofa, Apio, Berenjena, Brócoli, Calabacín, Cebolla, Coliflor, Fresa, } \\
\text { Guisante, Pimiento, Romanesco y Tomate. }\end{array}$ \\
\hline Fuente: Encuesta LIFE+AGROWASTE
\end{tabular}

Fuente: Encuesta LIFE+AGROWASTE 
Por otro lado, se ha podido determinar que en la actividad de las empresas y sus prácticas, la generación de subproductos es variada con más de 50 tipos de subproductos, y que también hay algunas empresas donde no se generan subproductos debido a que la materia prima alimentada a la línea está preprocesada. Además, es destacable que las empresas no realizan una cuantificación en base a una clasificación, sino que directamente unifican todos los subproductos para la gestión según salen de la línea. Por lo tanto, esta práctica no facilita una selección de los subproductos para su cuantificación y se ha aunado el tipo de subproducto en base a las orientaciones productivas. En las Tablas 2 y 3 se indica el estudio de la generación de biorresiduos para especies hortícolas y frutícolas respectivamente de aquellos subproductos que se generan en mayor cantidad en la Región de Murcia y su actual gestión. 


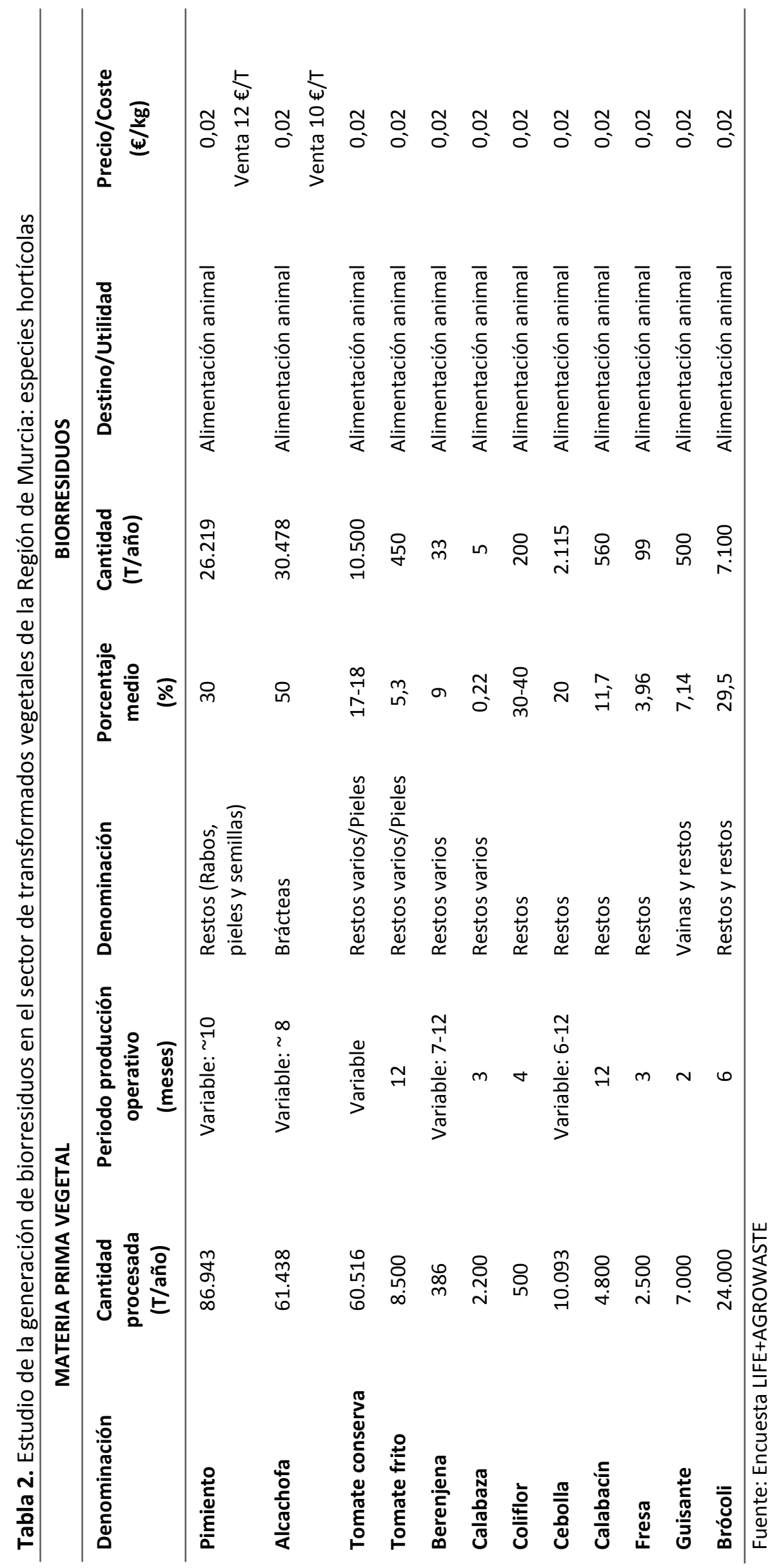




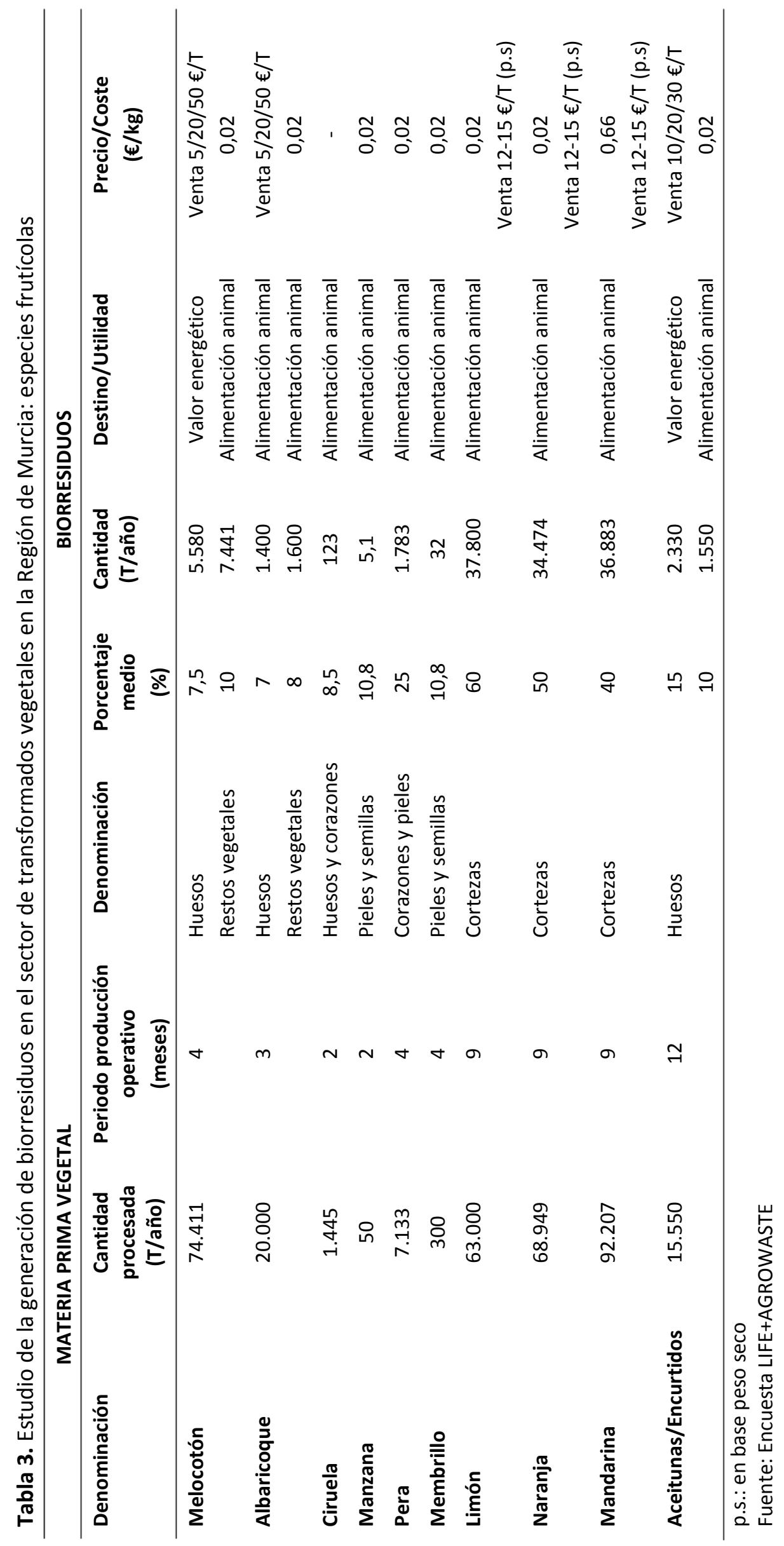


De acuerdo a las orientaciones productivas basadas en especies hortícolas se puede destacar el predominio absoluto de tres especies vegetales: pimiento, tomate y alcachofa. A continuación, se posicionan otras especies vegetales como el brócoli y la cebolla, seguidas de otras minoritarias. Estas especies vegetales son, asimismo, las que contribuyen en mayor medida a la generación de biorresiduos, tanto por el elevado volumen procesado como, especialmente, por sus características naturales específicas y las de los procesos de transformación a las que son sometidas. Asimismo, son las que presentan un flujo de biorresiduos más continuado en el tiempo, debido a que cuentan con campañas prolongadas en el marco del periodo anual (Tabla 4), lo que garantizaría el aprovisionamiento de material -subproducto- como materia prima para procesos de valorización, asegurando la viabilidad de los mismos al reducirse al mínimo la estacionalidad.

Tabla 4. Calendario de campañas de producción materia prima

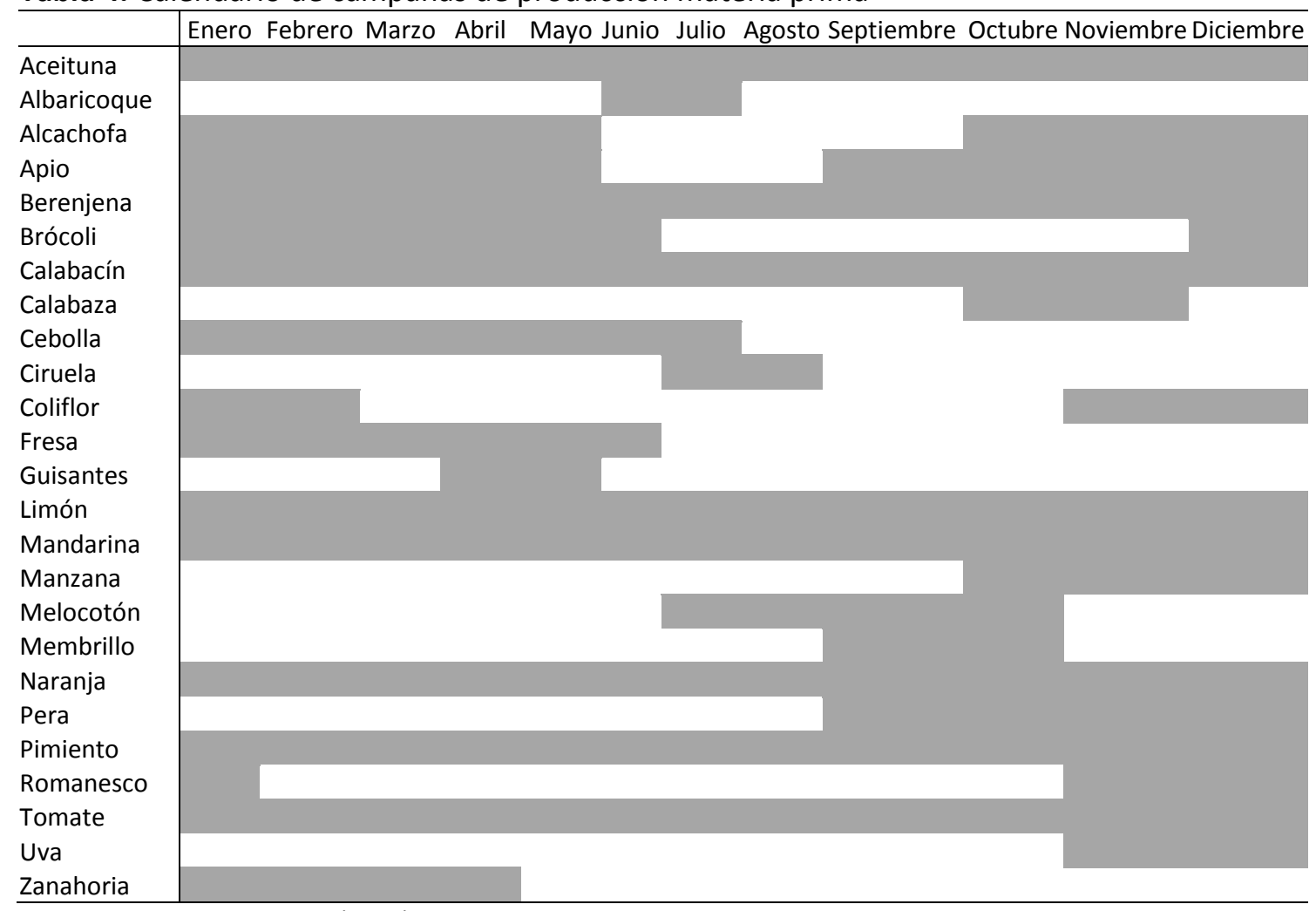

Fuente: Empresas del sector (2012).

La naturaleza de los subproductos de origen hortícola consiste fundamentalmente en productos enteros y, principalmente, en partes de los mismos, que son cortadas y eliminadas del proceso productivo para la elaboración del producto final alimentario. En este caso destacan: los subproductos de alcachofa, consistentes en las brácteas exteriores del fruto que, aun considerando los mejores estándares de rendimiento, representan el $50 \%$ del volumen procesado como mínimo; los subproductos de pimiento, consistentes particularmente en los rabos, pieles y semillas del fruto, con el elevado porcentaje promedio del $30 \%$ del volumen procesado, 
aunque por su naturaleza con escaso valor añadido y potencial de valoración; y los subproductos de tomate, constituidos principalmente por la piel de fruto y, asimismo, por frutos enteros -o parte de los mismos- dañados en el proceso de elaboración. En este caso, se cifran en un 17-18 \% en el proceso de producción de tomate entero en conserva y del 5,3\% en el de producción de tomate frito, el cual obtiene un elevado rendimiento con el consiguiente reducido volumen de subproducto generado. Asimismo, su valor añadido y potencial de valorización es muy limitado.

Entre las orientaciones productivas basadas en especies frutícolas es destacable que las mayoritarias corresponden, en primer lugar, a las especies de frutos cítricos seguidas de las de frutos de hueso y, con menor importancia, las de pepita. En el caso de los frutos cítricos destaca en primer lugar la mandarina, seguida de la naranja y el limón. En el caso de las frutas de hueso destacan el melocotón y el albaricoque, mientras que en el caso de las frutas de pepita solo es relevante la pera.

En estas gamas de productos, el periodo de procesado es diverso y contrapuesto, determinado por los ciclos y campañas de las diferentes especies vegetales. Por una parte, los frutos cítricos se procesan principalmente en nueve meses que se extiende desde octubre a julio, con especial intensidad en los tres primeros meses del año (enero-marzo). Por otra, las frutas de hueso se procesan de manera más concentrada, el melocotón durante cuatro meses (julio-octubre), el albarcoque dos meses (mayo-julio) y otros dos meses la ciruela (julio-agosto). En el caso de las frutas de pepita, especialmente en pera, la campaña comprende cuatro meses (septiembre-diciembre). Por último, la campaña de elaboración de aceituna se extiende durante todo el año, basado en prácticas de conservación y envasado básicas aplicadas tras la recolección.

Por otro lado, la naturaleza y el volumen de los subproductos de origen frutícola dependen estrictamente de dos factores fundamentales, como son la naturaleza biológica de cada especie vegetal y de sus frutos en primer lugar; y del tipo de proceso productivo al que son sometidos en segundo lugar. Destacan:

a) Subproductos de frutos cítricos que consisten exclusivamente en las cortezas de los mismos, resultado de un proceso de aprovechamiento de la pulpa tanto para conserva como, especialmente, para zumos, con un porcentaje de residuo máximo en el caso del limón (60 \% del peso bruto), medio en el de la naranja (50\%) e inferior en el de la mandarina ( $40 \%$ ), pero elevados de forma general.

b) Subproductos de frutas de hueso que consisten principalmente en los huesos de los frutos, extraídos en el proceso de transformación para la elaboración de frutas en conserva, mermeladas, etc., con promedios del 7,5 \% en el caso del melocotón y del $7 \%$ del peso bruto en el del albaricoque; y otros restos vegetales -partes de fruto desechadas en el proceso productivo- con promedios del $10 \%$ en melocotón y $8 \%$ en albaricoque. Por su parte, en el caso de la 
ciruela, los huesos y corazones son extraídos conjuntamente por lo que constituyen un único tipo de residuo, representando un $8,5 \%$ del peso bruto.

c) Subproductos de frutas de pepita que consisten en corazones, pieles y semillas, representando un elevado porcentaje sobre el peso bruto en el caso de la pera (25\%), siendo inferior en el caso de especies minoritarias como la manzana $(10,8 \%)$ y del membrillo $(10,8 \%)$.

d) En cuanto a las aceitunas preparadas, los huesos representan en torno al $15 \% \mathrm{y}$ otros restos orgánicos -frutos desechados especialmente- el $10 \%$ del peso bruto total.

La dimensión temporal de la generación de subproductos (Figura 1) muestra un alto grado de concentración en los meses centrales del año (mayo-septiembre), con cifras en torno al $75 \%$, estando relacionada con los factores siguientes:

a) El volumen de materia prima procesada, y la distribución temporal del mismo, durante el periodo anual, definiendo campañas específicas (Tabla 4).

b) La potencialidad de generación de subproductos de cada orientación productiva, es decir de cada especie vegetal (materia prima) procesada para la obtención de una gama de producto y/o producto-mercado singular, determinada por el rendimiento físico de la materia prima procesada en cada caso específico.

En este sentido, el elevado volumen de alcachofa procesada y el importante potencial de generación de subproductos -principalmente brácteas- con rendimientos inferiores al $50 \%$, explican en gran medida el volumen de subproductos generados durante el primer y el cuarto trimestre del año, periodo en el que la producción de elaborados de alcachofa es dominante. Por otro lado, la combinación de diferentes campañas, especialmente las de frutas de hueso (albaricoque y melocotón) y de pepita (pera), entre otras, explica la concentración tanto de la producción (77 \%) como de la generación de subproductos (74 \%) en el periodo de cinco meses comprendidos entre mayo y septiembre. En este caso, el porcentaje de generación de subproductos es menos elevado debido al predominio de la composición productiva basada en las orientaciones productivas anteriormente mencionadas, que presentan elevados rendimientos físicos, con promedios en torno al $82 \%$. 


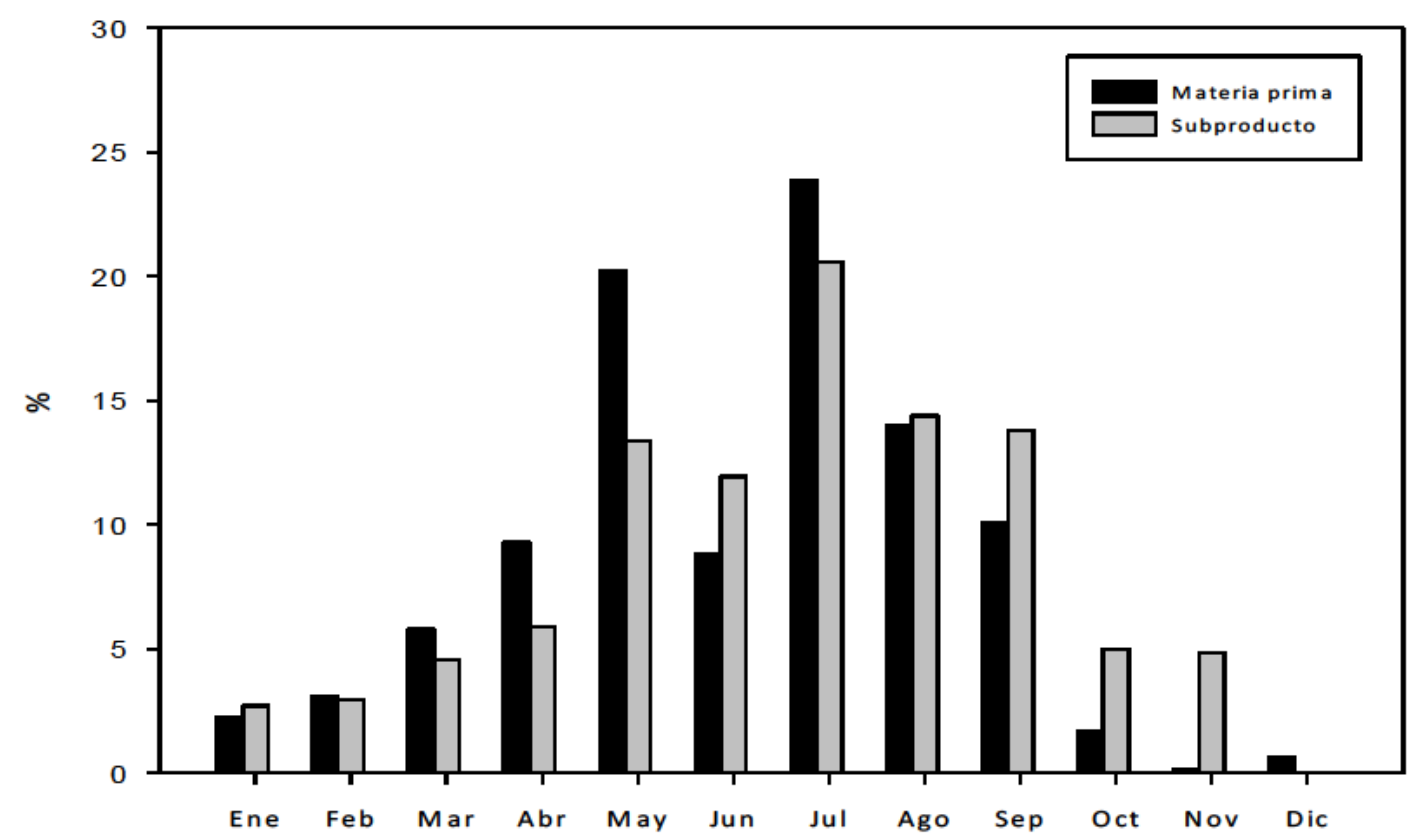

Figura 1. Dimensión temporal anual de la generación de subproductos

El destino de los subproductos hortícolas es fundamentalmente el de alimentación animal directa, sin transformación previa, para especies ganaderas de rumiantes (cabra y oveja especialmente), gestionados por gestores autorizados de acuerdo con la legislación vigente. En este aspecto, el coste de gestión para las empresas se limita a un canon de $0,02 € / \mathrm{kg}$, no obteniendo retorno económico alguno excepto en el caso de una empresa que comercializa una parte importante del residuo de alcachofa, con un precio de entre 10 y $12 € / T$, que le supone un retorno económico de 80.000-90.000 euros anuales, lo que demuestra la viabilidad potencial de la valorización de subproductos, incluso a nivel primario.

La gestión de los subproductos de origen frutícolas se basa en el criterio de eliminación fácil y rápida de los mismos como medio para resolver un problema, ya que es de esta manera como es percibido por las empresas. Por ello, el destino de los subproductos se caracteriza por su ambivalencia con la concurrencia de varios destinos posibles, determinados por la "facilidad" en su eliminación, el cumplimiento formal de las especificaciones de la normativa ambiental y el ahorro de costes en el proceso de gestión y eliminación, por medio de soluciones que, en general, no producen valor para las empresas, a pesar de la existencia de reconocidas oportunidades de valorización basadas en tecnologías de tratamiento disponibles. El destino concreto de estos subproductos se determina principalmente de acuerdo a su naturaleza:

a) Los huesos de melocotón, albaricoque y aceituna se destinan a valorización energética, opción que cuenta con una demanda destacada lo que implica la obtención de un retorno económico derivado de su comercialización, aunque 
en un mercado informal, lo que se traduce en una notable dispersión en los precios que oscilan entre los $4,98 € / T$ y los $50 € / T$ (incluyendo secado previo) en los huesos de melocotón y albaricoque, y entre 10 y $30 € / T$ en los de aceituna. Por el contrario, los de pera no se comercializan por esta vía debido a su escaso potencial energético.

b) Las cortezas de frutos cítricos se destinan exclusivamente a alimentación animal, gestionándose mayoritariamente por medio de gestores autorizados con un coste de $0,02 € / \mathrm{kg}$ de canon. Por el contrario, un número limitado de empresas de mayor dimensión los comercializan de forma independiente para este mismo destino, con secado previo, al precio de 12-15 €/T.

c) El resto de subproductos generados por las operaciones de transformación de frutas (destríos de frutos, partes de frutos, pieles, semillas, etc.) se destinan exclusivamente a alimentación animal directa mediante gestores autorizados e incluye el pago del canon establecido $(0,02 € / \mathrm{kg})$.

\subsection{Aproximación a la economía de los biorresiduos/subproductos}

El punto de partida del análisis económico de los biorresiduos (subproductos vegetales) generados por empresas de la industria de transformados vegetales, relativo a las principales orientaciones productivas, se focalizó en determinar el valor -coste de producción- medio estimado a partir de los datos proporcionados por las empresas colaboradoras, mediante la adición de:

a) Coste promedio unitario de la materia prima $(€ / T)$.

b) Coste promedio unitario del proceso o procesos a los que se somete a dicha materia prima para la obtención de una gama de productos-mercado $y$, adicionalmente, de los subproductos originados en el curso de dicho proceso productivo.

El resultado de la adición de ambos nos proporcionó el valor del coste total de producción en sentido estricto y restringido, "a salida de fábrica", es decir excluyendo costes adicionales de comercialización e impuestos, constituyendo así una magnitud y un parámetro técnico-económico idóneo para el tipo de análisis que se pretende realizar.

En primer lugar, se obtuvo el coste total de producción de las empresas utilizando como referencia las toneladas procesadas de las principales orientaciones productivas (OPs) según datos anuales tipo aportados por la Agrupación de Empresas de Alimentación de Murcia, Alicante y Albacete (Agrupal). El coste total de producción fue de cerca de 500 millones de euros (Tabla 5) destacando el peso del componente coste de la materia prima respecto al coste total, con especial relevancia en el caso de las frutas de hueso (melocotón y albaricoque), con un 38,88 y $36,88 \%$ respectivamente. 
Tabla 5. Valores totales de producción en el subsector conservas vegetales de la Región de Murcia. Principales operaciones productivas (OPs)

\begin{tabular}{lrrrrrrrrr}
\hline & \multicolumn{1}{c}{1} & \multicolumn{1}{c}{2} & \multicolumn{1}{c}{4} & \multicolumn{1}{c}{4} & \multicolumn{1}{c}{5} & 6 & \multicolumn{1}{c}{7} & \multicolumn{1}{c}{8} & 9 \\
\hline Alcachofa & 120.000 & 26,9 & 350 & 1.000 & 1.350 & 25,9 & 42.000 .000 & 162.000 .000 & 32,6 \\
Pimiento & 60.000 & 13,5 & 320 & 1.450 & 1.770 & 18,1 & 19.200 .000 & 106.000 .000 & 21,4 \\
Tomate & 29.000 & 6,5 & 130 & 400 & 530 & 24,5 & 3.770 .000 & 15.370 .000 & 3,1 \\
Melocotón & 120.000 & 26,9 & 350 & 550 & 900 & 38,9 & 42.000 .000 & 108.000 .000 & 21,8 \\
Albaricoque & 65.000 & 14,6 & 350 & 600 & 950 & 36,8 & 22.750 .000 & 61.750 .000 & 12,5 \\
Pera & 19.500 & 4,4 & 250 & 650 & 900 & 27,8 & 4.875 .000 & 17.550 .000 & 3,5 \\
Fresa & 22.000 & 4,9 & 250 & 650 & 900 & 27,8 & 5.500 .000 & 19.800 .000 & 4,0 \\
Mandarina & 10.500 & 2,4 & 140 & 400 & 540 & 25,9 & 1.470 .000 & 5.670 .000 & 1,1 \\
TOTAL & 446.000 & 100,0 & & & & & & 496.340 .000 & 100,0 \\
\hline
\end{tabular}

1: Volumen de materia prima procesada (T/año)

2: Porcentaje materia prima procesada según OPs (\%)

3: Coste unitario de materia prima por OPs $(€ / T)$

4: Coste unitario de procesado $(€ / T)$

5: Coste unitario de producción $(€ / T)$ incluyendo coste de materia prima y coste de procesado

6: Porcentaje coste materia prima según coste producción (\%)

7: Coste total asociado a la materia prima procesada anual (€/año)

8: Coste total estimado de la producción anual ( $€ /$ año)

9: Porcentaje coste estimado de la producción anual por orientaciones productivas (\%)

La OP alcachofa es la que ocupa la primera posición en el coste total, representando casi el $33 \%$ del valor total estimado, debido a la combinación de una alta producción y de un coste total de producción relativamente elevado (1.350 €/T). En segundo lugar, se encuentra la OP pimiento, con una cantidad absoluta menor que representa un $21,4 \%$, pero con un coste total unitario mayor $(1.770 € / T)$.

En el caso de las OPs de frutas, destaca la del melocotón que supone más del $21 \%$ del valor estimado, especialmente por el elevado volumen de materia prima procesada para diferentes productos-mercado, combinado con un relativamente alto coste unitario de producción, inducido principalmente por el coste de la materia prima, como ya se ha comentado. De igual forma, el albaricoque, con similares estándares productivos, alcanza un $12,5 \%$ del total del valor estimado debido al menor volumen de materia prima procesada. El resto de OPs consideradas presentan valores absolutos y relativos muy inferiores, debido tanto a los menores volúmenes de materia prima procesada como a costes de producción más reducidos, especialmente en los casos del tomate o de la mandarina.

El impacto de los biorresiduos y/o subproductos en los diferentes procesos productivos viene dado por una condición inherente a los mismos ya que, para la fabricación de productos-mercado alimentarios es necesario tanto la eliminación de productos agrarios enteros que no reúnen los estándares de calidad requeridos, como de las partes (huesos, tejidos, semillas, etc.) obtenidas en el proceso de acondicionamiento para la elaboración de los productos alimentarios. Esto implica la generación de importantes volúmenes de biorresiduos aun en el caso de empresas y procesos que alcanzan elevados niveles de eficiencia técnica y aprovechamiento 
productivo, como en los de los casos estudiados (Tablas 2 y 3 ), de forma que los subproductos generados oscilan entre el $50 \%$ en el caso del procesado de alcachofa hasta el $18 \%$ en los caso de procesado de tomate, albaricoque y melocotón, o incluso $10 \%$ en el caso de la fresa. Además, otro factor determinante en el coste de generación de biorresiduos es el del grado de elaboración, diferenciación y sofisticación del producto final de forma que, a mayor grado, corresponde un mayor coste imputable a los biorresiduos por dos causas:

a) Un mayor nivel de eliminación de partes de los frutos que constituyen la materia prima del proceso, con la correlativa repercusión en su coste imputable al producto-mercado final, debido a un menor grado de aprovechamiento de los mismos.

b) Un coste más elevado del proceso de acondicionamiento de esos frutos, previo al proceso especifico de conservación, al comprender más operaciones y más complejas.

A continuación, la Tabla 6 muestra de un modo análogo a la Tabla 5, los costes asociados a la producción de subproductos para las OPs consideradas en el año referencia del subsector de conservas vegetales. La columna 6 contiene el coste bruto estimado de la generación del subproducto correspondiente, el cual está calculado a partir de la suma del coste de adquisición atribuible a la proporción no útil de la materia prima procesada (ver Tabla 6, columna 2) y del coste de producción atribuible a la proporción no útil de materia prima incluyendo los costes totales de procesamiento estricto en el marco del proceso productivo (ver Tabla 6, columna 4), y multiplicado por las toneladas procesadas en el año de referencia utilizado (ver Tabla 6, columna 1). Este coste representa el $15 \%$ de los costes totales (ver Tabla 5, columna 8), siendo la generación del subproducto de alcachofa la de mayor coste, con aproximadamente un $31,5 \%$ del coste total asociado a la generación de los subproductos y muy diferenciada del resto. Esta diferencia se debe al alto porcentaje de materia prima desechada junto con el mayor coste de procesado, tal como se ha discutido anteriormente. 
Tabla 6. Economía de generación y gestión de subproductos en el subsector conservas vegetales. Principales operaciones productivas (OPs)

\begin{tabular}{lrlrrrrrr}
\hline & 1 & 2 & \multicolumn{1}{c}{3} & \multicolumn{1}{c}{4} & \multicolumn{1}{c}{5} & \multicolumn{1}{c}{6} & \multicolumn{1}{c}{7} & 8 \\
\hline Alcachofa & 120.000 & 50 & 175 & 500 & 250 & 425 & 51.000 .000 & 31,48 \\
Pimiento & 60.000 & 30 & 96 & 120 & 36 & 132 & 7.920 .000 & 7,46 \\
Tomate & 29.000 & 18 & 23,4 & 50 & 9,0 & 32,4 & 939.600 & 6,11 \\
Melocotón & 120.000 & 18 & 63 & 40 & 7,2 & 70,2 & 8.424 .000 & 7,80 \\
Albaricoque & 65.000 & 18 & 63 & 55 & 9,9 & 72,9 & 4.738 .500 & 7,67 \\
Pera & 19.500 & 35 & 87,5 & 65 & 22,7 & 110,2 & 2.149 .875 & 12,25 \\
Fresa & 22.000 & 10 & 25 & 65 & 6,5 & 31,5 & 693.000 & 3,50 \\
Mandarina & 10.500 & 45 & 63 & 40 & 18 & 81 & 850.500 & 15,00 \\
TOTAL & 446.000 & & & & & & 76.715 .475 & \\
\hline
\end{tabular}

1: Volumen de materia prima procesada (T/año)

2: Porcentaje de subproducto generado (\%)

3: Coste unitario de la materia prima atribuible a la proporción de subproducto generado $(€ / T)$. Es el producto del porcentaje de subproducto generado de cada OP (columna 2) y su precio unitario medio (ver Tabla 5, columna 3 ) 4: Coste promedio de producción, relativo exclusivamente a la fase o fases del proceso productivo en que se separan los biorresiduos y se generan los subproductos $(€ / T)$. Calculado según datos de la encuesta y a partir del coste unitario de procesamiento (ver Tabla 5, columna 4)

5: Coste promedio de producción del subproducto $(€ / T)$. Es el producto del porcentaje de subproducto generado (columna 2) y el coste promedio de producción de las fases donde se generan los subproductos (columna 4)

6: Coste bruto de producción del subproducto $(€ / T)$. Es la suma de los costes atribuibles al subproducto por la compra de la materia prima (columna 3 ) y de procesamiento de la misma (columna 5 )

7: Coste bruto estimado de los subproductos generados (€/año). Es el producto del coste bruto de producción del subproducto (columna 6) y el volumen de materia prima procesada (columna 1)

8: Porcentaje del coste de los subproductos atribuible a cada una de las OPs (\%)

Por otro lado, algunas de las empresas actualmente obtienen un beneficio en la gestión de los subproductos y podrían ser costes a reducir. A partir de las encuestas realizadas se obtuvo información acerca de que los subproductos de alcachofa y pimiento (Tabla 2) se gestionan para alimentación animal anualmente con un precio de venta de aproximadamente $10-12 € / T$, lo que permite obtener cerca de $570.000 € /$ año de beneficios. También se perciben beneficios por la venta de huesos de melocotón y albaricoque (aproximadamente $7.000 \mathrm{~T} / \mathrm{año}$ ), con un promedio de $36 € / \mathrm{T}$, aportando a las empresas casi $250.000 € /$ año. El resto de biorresiduos aportan menores beneficios o no presentan valor actualmente debido a su naturaleza. Estos datos representan, en todo caso, un porcentaje muy reducido del valor total de la producción estimada del producto principal con un promedio de cerca del $0,17 \%$, por lo que es despreciable del cálculo actualmente. Una mayor valorización de los biorresiduos permitiría ampliar dicho porcentaje y por tanto podrían representar un factor positivo de competitividad de las empresas de transformados vegetales, incidiendo especialmente en el coste de las materias primas que, como destacábamos anteriormente, es el mayoritario en su estructura de costes.

Finalmente, mediante las encuestas se reveló un interés económico del entorno empresarial y una preocupación por la inversión necesaria para desarrollar una valorización de estos materiales en la propia empresa. El camino actual parece orientado a la relación entre empresa productora de biorresiduos y empresa de 
valorización por el interés en el beneficio asociado de la comercialización de los biorresiduos.

\subsection{Caracterización de los subproductos agroalimentarios}

La Tabla 7 muestra los resultados obtenidos en el análisis físico-químico de los subproductos de mayor importancia caracterizados, mientras que las Tablas 8 y 9 incluyen aquellos otros parámetros de interés para posibles opciones de valorización. Finalmente se exponen los datos de análisis de metales pesados, microbiológicos y restos de plaguicidas para evaluar la posible contaminación de los subproductos y sus limitaciones.

En la Tabla 7 se puede observar las diferencias significativas entre los diferentes subproductos para un mismo parámetro. Se puede decir que, en general, no se observa una clara diferenciación entre hortalizas y frutas. Evaluando los parámetros más diferenciadores se observa que el valor del $\mathrm{pH}$ más bajo corresponde a los subproductos de cítricos, siendo únicamente diferentes de la alcachofa y el tomate. Este valor de $\mathrm{pH}$ ácido puede limitar su valorización. En el caso de la conductividad eléctrica sí que se observa que los subproductos procedentes de hortalizas tienen un mayor contenido en sales, con más de $3.500 \mu \mathrm{S} / \mathrm{cm}$, por lo que será un parámetro condicionante en las posibles opciones de valorización, junto con el $\mathrm{pH}$. El contenido en agua de todos los subproductos es elevado, con un rango entre 78,5 y 91,9\%, estando en el límite inferior el subproducto de fresa, ya que mayoritariamente está formado por el subproducto procedente de tamizadoras para la elaboración de pulpas de fresa. En cuanto al contenido en materia orgánica, se puede decir que todos los subproductos contienen un elevado contenido dado su origen, lo que favorece su valorización agrícola. Por otro lado, el mayor contenido en macronutrientes (NPK) se encuentra en el subproducto de tomate, siendo también destacable en pimiento y alcachofa, $y$, en cuanto al contenido en micronutrientes, destaca el alto porcentaje de magnesio y sodio en los subproductos de alcachofa y pimiento, aunque también el resto de parámetros son interesantes en comparación con los otros subproductos.

En la Tabla 8 se puede observar que, a nivel nutricional, destaca el mayor valor energético que presenta el subproducto de pera con $1.580 \mathrm{~kJ} / 100 \mathrm{~g}$, frente al menor valor del subproducto de tomate con $1.271 \mathrm{~kJ} / 100 \mathrm{~g}$, debido principalmente al peso de los hidratos de carbono en su cálculo. Además, es de interés el mayor contenido en proteínas de aquellos subproductos procedentes del procesado de hortalizas, además de aquellos de la producción de elaborados de fresa. 

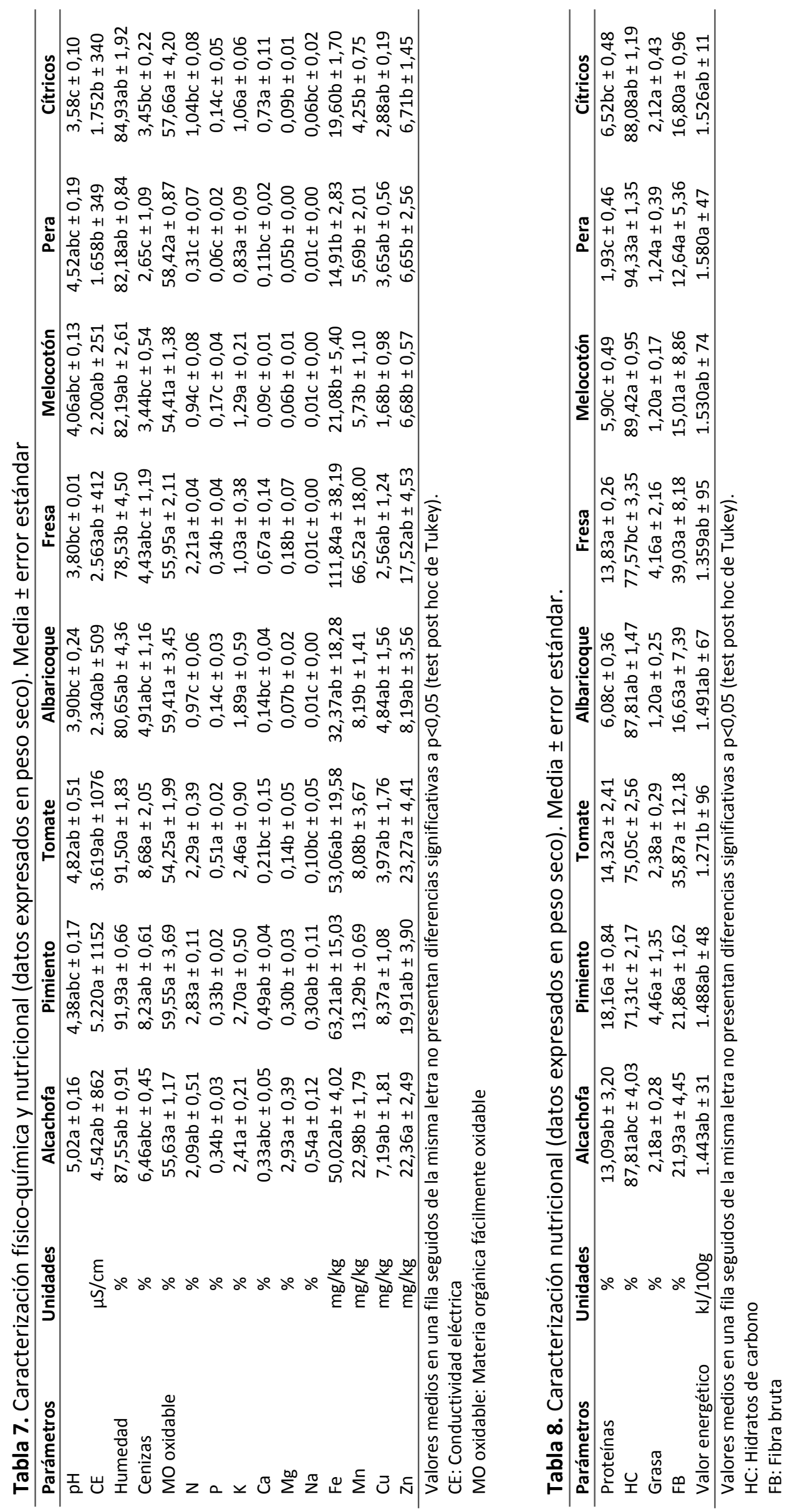
En relación con otros compuestos/coproductos de interés, en la Tabla 9 se recogen los datos obtenidos en el análisis de fibra alimentaria, licopeno, $\beta$-caroteno, cinarina y hesperidina. Se obtuvo que los subproductos procedentes de etapas de tamizado para la elaboración de pulpas y concentrados, junto con los subproductos de alcachofa, son los de mayor contenido en fibra alimentaria. En cuanto a carotenoides, destacó la presencia de licopeno en el subproducto de tomate. También se obtuvo una alta concentración de cinarina en el subproducto de alcachofa, pero el amplio rango observado indica una diferenciación dentro de este subproducto debida a la generación del mismo antes o después de un tratamiento térmico, puesto que el compuesto se solubiliza en agua y los subproductos de alcachofa escaldados presentan una menor concentración. Por último, se pudo corroborar la presencia de hesperidina en los subproductos de cítricos, lo que respalda la actual obtención de la misma a nivel industrial, principalmente en el subproducto de naranja.

Tabla 9. Determinación de compuestos de interés (datos expresados en peso fresco). Rango obtenido

\begin{tabular}{|c|c|c|c|c|c|c|c|c|}
\hline Compuestos & Unidades & Alcachofa & Pimiento & Tomate & Albaricoque & Fresa & Melocotón & Cítricos \\
\hline Fibra alimentaria & $\mathrm{g} / 100 \mathrm{~g}$ & $7,5-10,8$ & - & $5,7-9,3$ & $1,2-8,7$ & $11,0-13,3$ & $7,2-15,7$ & $7,0-8,7$ \\
\hline Licopeno & $\mathrm{mg} / \mathrm{kg}$ & - & $<0,5-29,6$ & $64,0-130$ & $0,5-0,7$ & - & - & - \\
\hline$\beta$-caroteno & $\mathrm{mg} / \mathrm{kg}$ & - & $3,7-36,2$ & $<0,5-17,6$ & $1,2-8,4$ & - & - & $<0,5-2,0$ \\
\hline Hesperidina & $\mathrm{mg} / \mathrm{Kg}$ & - & - & - & - & - & - & $1.154-3.998$ \\
\hline
\end{tabular}

En cuanto a contaminación de los materiales, como cabe esperar por el uso de las materias primas, en el análisis de metales pesados todos los resultados estuvieron por debajo del límite de detección de medida (Cd: <0,1 mg/kg; $\mathrm{Cr}:<20 \mathrm{mg} / \mathrm{kg}$; Ni: $<10$ $\mathrm{mg} / \mathrm{kg}$; Pb: <0,1 mg/kg; $\mathrm{Hg}$ : $<0,1 \mathrm{mg} / \mathrm{kg}$; As: $<0,5 \mathrm{mg} / \mathrm{kg}$, datos en peso seco). Tan sólo en el caso del plomo se encontró presencia de restos de este metal en pequeñas concentraciones en casi todos los subproductos procedentes de hortalizas (con el máximo de 1,31 mg/kg en el subproducto de pimiento). También el subproducto de cítricos, aunque concretamente sólo en el de limón, se cuantificó una concentración de plomo superior al límite de detección.

Por otro lado, tampoco se detectó contaminación microbiológica por Salmonella y Listeria monocytogenes en ninguna muestra. Sin embargo, la concentración de Estreptococos fecales fue superior a 150.000 UFC/g en el caso del melocotón y el pimiento. Esto puede ser debido a una contaminación en el almacenamiento del subproducto (en el suelo), dado que por la calidad de las materias primas procesadas esta contaminación podría suponer un riesgo para la salud. El resto de análisis no aportó información que diferencie a los subproductos estudiados dado que la práctica de manipulación y almacenamiento del subproducto en cada una de las empresas va a ser el condicionante de su presencia, así como la materia prima de origen. En cuanto a la presencia de restos de plaguicidas químicos o materias activas en los subproductos en estudio, se puede decir que no se observaron, de manera 
general, en elevadas concentraciones, pero dependiendo de la procedencia de la materia prima se encontraron las indicadas en la Tabla 10. Destacó la alta concentración de imazalil en cítricos y procloraz en el subproducto de limón, que son sustancias activas con actividad fungicida preventiva muy utilizadas para evitar enfermedades postcosecha.

Tabla 10. Materias activas encontradas en los diferentes subproductos

\begin{tabular}{|c|c|c|c|c|c|c|c|}
\hline \multicolumn{8}{|c|}{ MATERIAS ACTIVAS } \\
\hline Alcachofa & Pimiento & Tomate & Albaricoque & Fresa & Melocotón & Pera & Cítricos \\
\hline IMIDACLOPRIL & FLUIOXINIL & - & CIPRODINIL & AZOXISTROBIN & TIACLOPRID & ABAMECTINA & SPIRODICLOFEN \\
\hline CIPERMETRINAS & PIRIMETANIL & & TEBUCONAZOL & BUPIRIMATO & CIALOTRINA-Lambda & TIAMETOXAM & FENPROPIMORF \\
\hline & & & CIALOTRINA-Lambda & CLORPIRIFOS & CIPRODINIL & IMIDACLOPRID & ORTOFENILFENOL \\
\hline & & & CIPROCONAZOL & CLORPIRIFOS-METIL & FENHEXAMIDA & & PIRIPROXIFEN \\
\hline & & & CAPTAN & MICLOBUTANILO & PIRIDABEN & & FENBUTESTAN \\
\hline & & & IMIDACROPIL & PENCONAZOL & & & CLORPIRIFOS \\
\hline & & & & ETOXAZOL & & & PIRIMETANIL \\
\hline & & & & SPINOSADA $(A+D)$ & & & HEXITIAZOX \\
\hline & & & & ABAMECTINA & & & PROPARGITA \\
\hline & & & & FENXAMIDA & & & PROCLORAZ \\
\hline & & & & BOSCALID & & & \\
\hline
\end{tabular}

En resumen, todos los subproductos presentaron características interesantes para su valorización en diversos campos, destacando los subproductos de pimiento y alcachofa, por su mayor volumen de generación comentado previamente.

\subsection{Opciones de valorización de los subproductos agroalimentarios}

Según la Ley 22/2011, de residuos y suelos contaminados (BOE, 2011), la estrategia para la correcta gestión de residuos se centra en la prevención, es decir, en intentar evitar la generación de los residuos. Para ello los esfuerzos se deben centrar en el incremento de la eficiencia de los procesos y en los planes de prevención de generación de residuos. Esto se logra a través de la aplicación de tecnologías de minimización, así como impulsando la valorización de los subproductos, y promocionando la reutilización tanto interna como externa, así como el reciclaje. En nuestro estudio se ha tenido en cuenta que, tras la reducción, se debería potenciar el uso alimentario (alimentación humana y animal) en primer lugar, y posteriormente otros aprovechamientos industriales como son la valorización agronómica y la energética.

La caracterización previa de los biorresiduos/subproductos nos permite orientarnos en las diferentes opciones de valorización, pero no se debe olvidar que las empresas deben tener la prioridad de evaluar el mercado potencial. La contaminación detectada en los subproductos analizados puede ser despreciable para un uso posterior debido a que los procesos con destino a la obtención de un producto para agricultura higienizan el material o bien no se ven alterados por el tóxico presente. En otros casos, como en el destino alimentación humana, es necesario llevar a cabo un protocolo de gestión que minimice dicha contaminación o la elimine. 
A continuación, se muestran posibles opciones de valorización para los subproductos clasificadas por el destino: alimentación humana mediante obtención de compuestos de interés, alimentación animal, agrícola y energía. En el estudio de la alimentación animal se indican estudios encaminados a mejorar el aporte de estos subproductos como alimentación animal ya que es la opción actual mayoritaria y también podría aportar mayor valor a los subproductos.

De ellas, la aplicación agrícola y el destino a alimentación animal son prácticas de valorización finalistas, en cualquier caso, mientras que las otras dos pueden generar a su vez un nuevo biorresiduo con otras características, que hace necesario un nuevo proceso de valorización. En todo caso, la selección de las opciones de valorización ha de cumplir con:

a) La opción debe ser viable técnica y económicamente y con expectativas comerciales, inequívocamente superior a otras opciones concurrentes.

b) En relación con las diferentes opciones técnicas se debe establecer una jerarquía y, sí es posible, una secuencia de acciones de valorización con obtención de diferentes coproductos.

c) El establecimiento de la prioridad, si es posible, de desarrollar el proceso de valorización en la misma unidad y/o planta de producción en que se ha generado el biorresiduo/subproducto, como actividad contigua y/o subsiguiente a la actividad principal.

A este respecto, se puede destacar la amplia información disponible sobre procesos de obtención de coproductos destinados a la alimentación humana, que en muchas ocasiones puede emplear equipos ya utilizados en la línea principal de la actividad agroalimentaria, o bien otros fácilmente accesibles debido a que son empleados dentro de otro subsector alimentario. En cuanto a valorización agrícola, el compostaje es el tratamiento mayoritario con numerosas ventajas.

En la Tabla 11 se resumen las principales opciones de valorización y se indican sus características. 


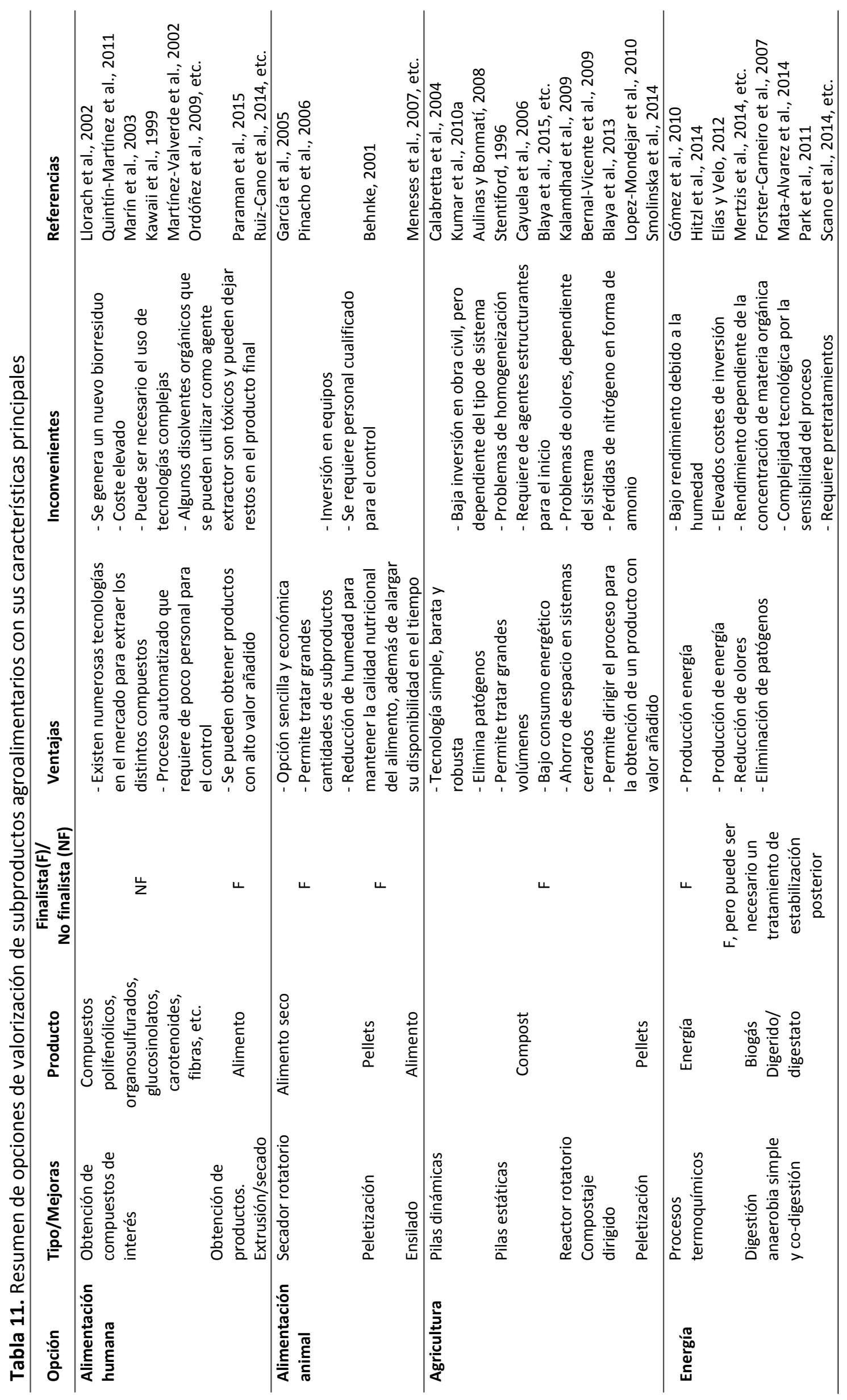




\subsubsection{Valorización con destino alimentación humana. Obtención de compuestos de interés}

Los principales "activos" contenidos en un material vegetal son de interés y pueden ser extraídos mediante diversas técnicas extractivas, pero también pueden ser dispuestos tal y como se encuentran en el material vegetal fresco una vez triturado o previo tratamiento de secado. El objetivo de la extracción es el aprovechamiento de los subproductos orgánicos para la obtención de compuestos naturales de alto valor añadido para la industria alimentaria, cosmética y/o farmacéutica por sus características funcionales, antimicrobianas o antioxidantes.

Los compuestos polifenólicos, organosulfurados, glucosinolatos, carotenoides, fibras, etc. son algunos de los denominados compuestos bioactivos que se encuentran en frutas y hortalizas con capacidad antioxidante o protectora, con los consiguientes beneficios para nuestra salud. Algunos de ellos se han caracterizado en los subproductos evaluados en este estudio.

Las alcachofas son ricas en compuestos polifenólicos. Concretamente, diversos autores (Fratianni et al., 2007; Coinu et al., 2006) señalaron que las hojas externas de alcachofa de algunas variedades poseen concentraciones importantes de compuestos fenólicos con actividad antioxidante. Los principales compuestos fenólicos encontrados en las brácteas fueron el ácido 1,5-0-dicafeilquínico (cinarina), seguido del ácido clorogénico y la 7-O-glucuronida. También se han encontrado concentraciones de cinarina en el tallo. Otro compuesto fenólico que se puede encontrar en elevadas concentraciones en las hojas externas de la alcachofa es el ácido cafeico. Llorach et al. (2002) detectaron una concentración de derivados del ácido cafeico para restos de alcachofas escaldadas de entre $103-243 \mathrm{mg} / \mathrm{g}$ en peso seco de extracto y de entre $99-154 \mathrm{mg} / \mathrm{g}$ en material sin procesar utilizando agua y metanol como disolventes de extracción (siguiendo un protocolo con posible aplicación industrial). En cuanto a las concentraciones de cinarina, en ensayos realizados con brácteas de alcachofa de la variedad Blanca de Tudela (característica de la Región de Murcia), se encontraron concentraciones de $73 \mathrm{mg} / \mathrm{kg}$ en brácteas frescas (QuintínMartínez et al., 2011).

A escala piloto se han obtenido extractos ricos en compuestos fenólicos utilizando agua como disolvente (Quintin-Martínez et al., 2011; Larrosa et al., 2002), seguido de etapas de concentración y secado para obtener un producto más estable y de fácil almacenamiento. Este proceso vuelve a generar un biorresiduo "agotado" que requiere de gestión. En todo caso, se obtiene un coproducto sin necesidad de realizar grandes inversiones de equipos.

Otros materiales ricos en compuestos polifenólicos son los cítricos. Los subproductos de los cítricos representan una importante fuente de flavonoides (Horowitz, 1961), encontrándose la mayoría de los mismos en la corteza 
(Anagnostopoulou et al., 2006; Marín et al., 2003). Los principales flavonoides encontrados en los cítricos son las flavanonas, flavonas, flavonoles y antocianinas. Las flavanonas son los más abundantes (Peterson et al., 2006), siendo la hesperidina la más importante en naranja y limón (Kawaii et al., 1999), mientras que la narirutina es el principal flavonoide encontrado en la mandarina (Levaj et al., 2009). Por otra parte, el contenido en estos polifenoles es más elevado en la corteza de los cítricos que en el resto del fruto (Gorinstein et al., 2001; Belitz y Grosch, 1999) localizándose principalmente en el albedo y en las membranas internas de la naranja (TomásBarberán y Clifford, 2000).

De acuerdo a su estructura y propiedades químicas, los compuestos flavonoides poseen de moderada a alta polaridad, por lo que son eficazmente extraídos con disolventes polares, tales como el metanol, no siendo eficaz en estos casos la extracción con fluidos supercríticos. Se han desarrollado métodos de extracción basados en el tratamiento alcalino de las cáscaras de cítricos y posterior precipitación de hesperidina desde soluciones acidificadas, con posteriores pasos de recristalización para aumentar la pureza del producto comercial. Varios trabajos se han publicado en este sentido: López-Sánchez (1986) y Lo Curto et al. (1992). El agua subcrítica también parece ser una excelente alternativa para la extracción de flavonoides. Así, Cheigh et al. (2012) observaron que la extracción de hesperidina de la piel de cítricos es 2-3 veces superior a la extraída con disolventes como el metanol y el etanol y hasta 30 veces superior cuando se utiliza agua caliente. También se ha desarrollado una implementación a estos métodos en combinación con la aplicación de ultrasonido (Ma et al., 2008; Khan et al., 2010). Otra aproximación para mejorar la extractabilidad de la hesperidina ha sido el tratamiento con microondas, el cual mejora la eficiencia en comparación con los métodos convencionales de calefacción (Wannberg et al., 2006; Ahmad et al. 2012).

Además, Li et al. (2006) evaluaron las condiciones para la extracción de compuestos fenólicos a partir de cáscaras de cítricos utilizando extracción acuosa con diferentes tipos de celulasas comerciales (Cellulase $\mathrm{MX}^{\circledR}$, Cellulase $\mathrm{CL}^{\circledR}$ y Kleepase $\mathrm{AFP}^{\circledR}$ ). Se encontró que la extracción con celulasas incrementa ligeramente la actividad antioxidante, al compararla con extractos obtenidos con agua, y para algunos extractos se alcanza una actividad comparable a la obtenida con un extracto etanólico.

Finalmente se puede apuntar que, Biogolden Solutions está trabajando con una tecnología innovadora de deshidratación que no sólo permite eliminar el agua, sino que también mantiene el contenido y características de los ingredientes a extraer, proporcionando una intensa y homogénea microperforación del producto, lo cual permite un fácil acceso posterior de los disolventes extractivos. En este sentido, disolventes menos agresivos pueden ser utilizados con rendimientos de producción muy superiores, reduciendo el tiempo de extracción necesario hasta 6 veces menos que los procedimientos clásicos. 
Por otro lado, el licopeno es el carotenoide mayoritario en el tomate maduro (Nguyen y Schwartz, 1999). En cuanto a la concentración de este carotenoide en el tomate, los tomates de la variedad Pera, utilizada habitualmente en conserva, presentan concentraciones de licopeno superiores a $50 \mathrm{mg} / \mathrm{kg}$ (Martínez-Valverde et al., 2002). En este sentido, Ordóñez et al. (2009) señalaron concentraciones promedio de $111 \mathrm{mg} / \mathrm{kg}$ peso fresco.

Para la extracción del licopeno se utilizan diversas técnicas; la más común es la extracción por etapas con disolventes orgánicos (hexano, acetona, cloroformo, etanol, etc., o bien mezcla de ellos), aunque actualmente se está utilizando la extracción con fluidos supercríticos, con grandes ventajas sobre los demás métodos (Guash, 2002).

Cardona et al. (2006) señalaron que el método de extracción con disolventes es eficaz y se pueden utilizar materiales frescos. Strati y Oreopoulou (2011) indicaron que el uso de una mezcla de disolventes polares y no polares, como acetato de etilo y hexano, para la extracción de carotenoides a partir residuos de tomate, es la más adecuada en comparación con otras mezclas. Se obtuvieron carotenoides no polares (licopeno y $\beta$-caroteno) en porcentajes suficientes ( $96 \%$ del total de carotenoides), así como polares como la luteína (4 \% del total de carotenoides extraídos).

Huang et al. (2008) predijeron una recuperación de licopeno del $93 \%$ usando $\mathrm{CO}_{2}$ supercrítico y etanol en un $16 \%$ como co-disolvente. Además, Topal et al. (2006) indicaron que la temperatura y la presión tenían efecto sobre la extracción de licopeno sin utilizar cualquier modificador (co-disolvente), e igualmente Rozzi et al. (2002) demostraron que ajustando la temperatura, la presión, el flujo y el volumen de $\mathrm{CO}_{2}$, se podía recuperar un $61 \%$ de licopeno de la piel de tomate y semillas. Con objeto de evitar la degradación de este carotenoide, los autores recomendaron un ultracongelado posterior del extracto.

El uso de enzimas es otra metodología empleada para favorecer la extracción de licopeno. Lavecchia y Zuorro (2008) señalaron que el pretratamiento de la piel de tomate con enzimas (Peclyve LI) mejoraba notablemente la extracción del licopeno de la piel. También Navarro-González et al. (2011) evaluaron la extracción de licopeno de la fibra de tomate utilizando diferentes métodos: tratamiento enzimático con Rapidase $^{\circledR}$ y Biocelullase a dos concentraciones diferentes $(200 \mathrm{U} / \mathrm{kg}$ y $400 \mathrm{U} / \mathrm{kg}$ ), maceración y extracción asistida por ultrasonidos (UAE). El tratamiento con maceración fue el que mejor rendimiento tuvo, con $4 \mathrm{mg} / 100 \mathrm{~g}$, seguido del tratamiento con UAE $(3,8 \mathrm{mg} / 100 \mathrm{mg})$ y tratamiento enzimático con la enzima Rapidase $^{\circledR}(3,6-3,8 \mathrm{mg} / 100 \mathrm{~g})$. Sin embargo, en todos los métodos de extracción quedaba licopeno residual en la muestra, lo cual indica que se necesitan tratamientos más agresivos para una recuperación más eficiente, tales como la extracción con fluidos supercríticos. 
Numerosas investigaciones llevadas a cabo han generado diversas patentes para la extracción de licopeno. Gómez-Prieto et al. (2003) han patentado un procedimiento que permite obtener cristales todo-trans- licopeno con un tamaño inferior a $10 \mathrm{~mm}$ y una pureza superior al $85 \%$. Este licopeno puede ser utilizado en las industrias de alimentos, cosméticas y farmacéuticas, así como en la fabricación de alimentos funcionales y nutracéuticos. Este procedimiento utiliza los fluidos supercríticos para la extracción y aislamiento de los carotenoides del tomate. También Calvo Rodríguez et al. (2007) desarrollaron una patente para la obtención de licopeno con alto grado de pureza en forma de todo-trans-licopeno empleando una extracción sólido-líquido con un disolvente de grado alimentario, a baja temperatura y en ausencia de luz, donde se obtienen extractos lipídicos enriquecidos en todo-translicopeno y cristales de todo-trans-licopeno con alto grado de pureza útiles para la fabricación de alimentos funcionales y su adición a alimentos, además de a preparados farmacéuticos o a cosméticos. Sabio Rey (2005) elaboraron una patente referente a un procedimiento alternativo para obtener formulaciones ricas en licopeno mediante solubilización directa, basado en el carácter liposoluble del licopeno. Dicho procedimiento proporciona directamente la formulación que se quiere preparar sin el empleo de disolventes orgánicos u otros agentes químicos. Además, tiene otras muchas ventajas, entre las que podemos señalar que se trata de un procedimiento más sencillo: menor coste del proceso, mayor rapidez, menos componentes utilizados en el proceso, menor consumo de energía, menos etapas en la obtención de la formulación final, etc.

Como se comentaba previamente, la obtención de estos compuestos de interés genera un nuevo biorresiduo que es necesario gestionar. Sin embargo, existen procesos finalistas, que permiten el uso completo de los subproductos para la elaboración de nuevos alimentos, obteniendo productos ricos en fibra, etc.

El contenido en fibra alimentaria y fitoquímicos de las pulpas obtenidas tras la extracción de zumo de frutas ofrecen una atractiva oportunidad para la elaboración de nuevos productos. La tecnología de extrusión, que es un proceso continuo con alta versatilidad y productividad, permite elaborar snacks a partir de la pulpa (Paraman et al., 2015). Estudios recientes han indicado claramente el potencial de incorporar diversas frutas y vegetales en productos extruidos, como pulpa de manzana (Alavi et al., 2011; Karkle et al., 2012), orujo de uva (Altan et al., 2008; Kumar et al., 2010b), pulpa de tomate (Altan et al., 2008), y de pulpa de zanahoria (Altan et al., 2008) en diversas matrices de productos. También la elaboración de nuevos ingredientes en base a todo el subproducto es una opción interesante. En este caso las tecnologías de secado y molienda son suficientes para su elaboración. Estudios científicos han descrito el desarrollo de productos de polvo de pieles de manzana (Bomben et al., 1971; Wolfe y Liu, 2003; Rupasinghe et al., 2008; Henríquez et al., 2010). Sin embargo, se ha de tener en cuenta que el secado causa cambios físicos, estructurales, químicos y 
biológicos que pueden afectar a los atributos de calidad del producto, tales como textura, color, sabor y valor nutricional, y particularmente de sus nutrientes y fitoquímicos porque son relativamente inestables al calor (Nicoli et al., 1999; Kwok et al., 2004; Chang et al., 2006; Vega-Galvez et al., 2009).

También, en el estudio realizado por Ruiz-Cano et al. (2014), se obtuvo que diferentes fracciones de subproductos de alcachofa contienen alto contenido de fibra dietética $(53,6-67,0 \%$ y bajas cantidades de grasas (2,5 a 3,7 \%). Por lo tanto, pueden ser considerados valiosos ingredientes para la fabricación industrial de alimentos ricos en fibra y con bajo contenido de grasa, que puede reducir el riesgo de graves trastornos, tales como la obesidad, las enfermedades cardiovasculares, diabetes, cáncer de colon-rectal y otros (Man y Cummings, 2009; Sánchez-Muniz, 2012). Las tecnologías de deshidratación y secado a baja temperatura (secador de banda o en lecho fluidizado) son las más empleadas para evitar la pérdida de atributos de calidad.

Por otro lado, la pectina se puede considerar otro compuesto de interés. La pectina es conocida principalmente por ser un agente gelificante y está ampliamente aplicada en la producción de mermeladas, gelatinas, zumos de frutas, productos de confitería y panadería (Willats et al., 2006). También se emplea en otras industrias como la farmacéutica, que requieren modificar la viscosidad de sus productos, y en la industria de los plásticos, así como en la fabricación de productos espumantes (Gómez y Juan, 1998). Desde el punto de vista de mejora de la salud, en diferentes tipos de pectina se han encontrado efectos positivos sobre el control de la diabetes, riesgos de infartos, niveles de colesterol y ciertos trastornos intestinales como el estreñimiento. Se obtiene de materiales vegetales que tienen un alto contenido en ésta, tales como manzanas, frutas cítricas, piña, tomate de árbol o aceitunas. Según el tratamiento que se haga a las materias primas se obtienen diferentes calidades de pectinas, de acuerdo con las necesidades de los productos terminados.

Existen numerosos procesos patentados para obtener las pectinas, y en cada uno de ellos se obtienen productos de diferente calidad, así como sus posibles aplicaciones, dependen mucho del método de obtención. Un proceso patentado consiste en convertir la materia prima en una sal cálcica de pectina en un medio líquido, para luego secarla y obtener así un pectinato que, cuando se pone en agua, la absorbe para formar partículas estables de un diámetro medio equivalente mayor de 100 micrómetros (Glahn, 2001). En otro método se encontró que la pectina puede hidrolizarse y extraerse del tejido vegetal, tal como la cáscara de cítricos o la pulpa de vegetales que contengan esta sustancia, sin adicionar un ácido. Así se logra solubilizar pectinas con alto contenido de metoxilos y luego recuperarlas por concentración y secado (Ehrlich, 1997).

Un proceso ambientalmente recomendable consiste en hacer reaccionar una suspensión acuosa de una fibra comestible con una solución de un metal alcalinotérreo y luego separar la suspensión resultante en una fracción sólida rica en 
pectina y la fracción líquida con menor contenido en esta, pasando finalmente el material por una columna de intercambio iónico (Graves et al., 1994). Un proceso de índole biotecnológica para preparar la pectina consiste en someter el tejido vegetal que contiene sustancias pécticas a la acción de microorganismos del género Bacillus, cuya actividad permite la liberación y recuperación de las pectinas (Sakai, 1989). También se pueden obtener pectinas de muy buena calidad a partir del material vegetal aplicándole presión y con calentamiento por microondas (Fishman et al., 2000), de tal manera que la pectina puede extraerse en menores tiempos y con mejor calidad y rendimiento.

Comercialmente la pectina se extrae tratando la materia prima con ácido mineral, caliente y diluido a pH bajo. Los ácidos minerales más usados en la extracción industrial son: el clorhídrico, el nítrico y el sulfúrico. Separar la pectina caliente del residuo sólido no es un paso fácil, ya que la fase líquida es viscosa y la sólida blanda, pero ha de ser lo más eficiente posible para producir un extracto rico en pectina de lo más concentrado.

Finalmente, la pectina a partir de las cáscaras de la naranja también se puede obtener por un proceso en el cual éstas se someten a una extracción en contracorriente con una solución que tenga un solvente inmiscible en agua, para extraer los azúcares, los aceites esenciales y los bioflavonoides (Bonnell, 1985).

\subsubsection{Valorización con destino alimentación animal}

El uso de subproductos de la industria de procesado de vegetales como alimentación animal es una forma económica y medioambiental de proceder para disminuir la generación de residuos y reducir los costes de su gestión (Meneses et al., 2007). Por ello es la solución que hoy en día utilizan la mayoría de las empresas para la gestión de sus subproductos vegetales y es la más extendida en la Región de Murcia. Se entiende por esta como la cantidad de sustancias nutritivas (alimentos) a proporcionar a los animales, que son adecuadas para procurar un estado óptimo a dichos animales. Esta opción de valorización presenta dos problemas principales, uno asociado con la contaminación química y microbiológica de los mismos, y otro asociado con su limitación de disponibilidad por su alto contenido en agua y alta biodegradabilidad. En este caso, el secado de los materiales permite reducir dicha humedad y eliminar parcialmente los microorganismos presentes manteniendo la calidad nutricional del alimento (García et al., 2005).

Pinacho et al. (2006) evaluaron la efectividad del secado de residuos de frutas y hortalizas y obtuvieron que el secado más efectivo para este tipo de residuos es el secado en continuo en un secador rotatorio donde la temperatura en el interior es de $70{ }^{\circ} \mathrm{C}$. Además, el sistema rotatorio es simple, rápido y un método económico para obtener un producto con características nutricionales y microbiológicas para 
alimentación animal. Su elemento más característico es el trómel, un aparato cilíndrico fabricado normalmente en metal galvanizado, con una ligera inclinación que permite el avance del producto durante el secado en el interior del secadero y la caída progresiva del residuo según se va secando. El secado se efectúa por una circulación de aire caliente, en el mismo sentido o sentido opuesto del material orgánico, que se obtiene de un quemador de combustible y que entra al trómel impulsado por un ventilador. Además, su régimen de trabajo en continuo presenta como ventaja el tratar grandes cantidades de residuos.

También la alimentación animal mediante pellets crea nuevas fuentes de riqueza que aportan mayor rentabilidad al proceso industrial de partida. La elaboración de pellets mediante peletizado consiste en la compresión y aglomeración de pequeñas partículas de una mezcla, en unidades mayores, mediante un proceso mecánico combinado con la humedad, el calor y la presión; dando como resultado final una mejora de las características de los alimentos, teniendo estos propiedades de alimentos balanceados pecuarios (Behnke, 2001). El proceso se inicia con la molienda de los restos orgánicos para convertirlos en harinas homogéneas que luego son formuladas o mezcladas con nutrientes también naturales y de alto valor nutritivo. Estas harinas se someten al proceso de peletizado en peletizadoras, este continúa con su empaquetado mediante un proceso húmedo y con calor, donde la temperatura alcanzada se mueve en el rango de 82 a $88{ }^{\circ} \mathrm{C}$, con un $15-17 \%$ de humedad durante 30-45 segundos. Al utilizar calor se logra la gelatinización de los almidones y mayor absorción de los nutrientes, además disminuye el número de agentes patógenos que pudieran estar contaminando el producto, mientras que con la humedad hay una mayor lubricación, ablandamiento. Una vez en esta situación, la peletizadora produce una compresión que obliga al producto a salir por sus orificios, generando el pellet de un determinado diámetro, mientras que el largo dependerá de la calibración de la cuchilla que realiza el corte de las partículas largas.

Otra opción muy usual es el ensilado, que conserva los subproductos por un periodo de tiempo largo. Durante el ensilado, bacterias de ácido láctico fermentan los carbohidratos del material, produciendo ácidos grasos y ácido láctico, que bajan el $\mathrm{pH}$ y así ayudan a conservar el material (Meneses et al., 2007). Esta técnica utiliza bolsas plásticas extensibles o bien pequeñas bolsas a abrir según demanda. El subproducto de tomate fue evaluado por Denek y Can (2006) tras el ensilado con aditivos para reducir la humedad de la mezcla y observaron que se trata de un forraje de alta calidad para la alimentación de ovejas. También para la alimentación de rumiantes, Meneses et al. (2007) evaluaron las características de subproducto de alcachofa cruda tras el ensilado, observando que se puede utilizar porque sus características varían poco, aunque son necesarios estudios en animales para evaluar la palatabilidad y su ingesta. A este respecto, son numerosos los estudios encaminados a optimizar el aporte de los subproductos como alimento para animales. 
Finalmente, Shdaifat et al. (2013) incluyeron subproductos tales como pulpa de tomate y pulpa de cítricos en la dieta de ovejas lactantes y obtuvieron que hasta un $20 \%$ en peso seco de la dieta convencional puede ser sustituida por estos subproductos sin producir efectos en el peso del animal, en la producción de leche e incluso en las características de la leche. También Volanis et al. (2006) utilizaron pulpa de cítricos ensilada en sustitución de parte del concentrado y no observaron diferencias en la producción diaria de leche, pero sí observaron mayor porcentaje de grasa en la leche de ovejas alimentadas con pulpa cítrica. Otros autores, en cambio, sí obtuvieron menor producción de leche con dietas que incluían cítricos, pero no varió la producción y porcentaje de grasa (Castrillo et al., 2004; Salvador et al., 2008). Otros animales, como la cabra, el cordero, la vaca y el cerdo también han sido evaluados cuando se han alimentado con subproductos (Romero-Huelva et al., 2012; Ben Salem y Znaidi, 2008; Weiss et al., 1997; O`Sullivan et al., 2003). En porcino, el principal subproducto cítrico estudiado es la pulpa cítrica y los niveles de inclusión habituales suelen situarse en torno a un 10-15 \% y un máximo de 20 \% (Domínguez y Cervantes, 1980; O`Sullivan et al., 2003; Cerisuelo et al., 2010) en base seca. Niveles de inclusión superiores pueden llegar a penalizar los rendimientos productivos (O`Sullivan et al., 2003).

\subsubsection{Valorización agrícola}

El compostaje es un proceso bioquímico que convierte los componentes de residuos orgánicos en sustancias estables como el humus que puede ser utilizado como un enmendante del suelo o un fertilizante orgánico (Tiquia, 2010; Coelho et al., 2011; Lashermes et al., 2012).

En primer lugar, podemos citar trabajos donde se han utilizado subproductos y residuos de origen agroindustrial, destacando aquellos que han empleado residuos del procesado de cítricos (Calabretta et al., 2004; Tittarelli et al., 2002), subproductos de café (Nogueira et al., 1999), subproductos de fabricación de azúcar (Meunchang et al., 2005), o bien otros residuos que incluyen frutas y hortalizas de desecho de mercado (Kulcu y Yaldiz, 2004; Kumar et al., 2010a; Kopc`ic et al., 2014; Aulinas y Bonmatí, 2008). Por lo tanto, son numerosas las experiencias de compostaje desarrolladas en los últimos años para la valorización de subproductos de la industria agroalimentaria. Además, el compostaje es una tecnología muy industrializada.

Los principales factores que controlan el proceso de compostaje de biorresiduos son la temperatura, el contenido en humedad, el $\mathrm{pH}$, la aireación, la relación C/N, el tamaño de partícula y el contenido de nitrógeno (Kumar et al., 2010a), que no son independientes, aunque sí que se correlacionan. A nivel industrial, el compostaje depende de la implantación de las mejores prácticas de gestión para asegurar un producto de alta calidad al menor coste. La aireación es uno de los 
parámetros más importantes a optimizar, que depende de la naturaleza del material a compostar. Los sistemas de aireación más comunes son el volteo y la aireación forzada (Cayuela et al., 2006).

En términos generales, el proceso de compostaje con aireación forzada es más rápido y da como resultado un compost de alta calidad (Stentiford, 1996). Sin embargo, ello tiene la desventaja, comparado con el volteo, de una homogeneización limitada y la formación de gradientes de temperatura. Además, requiere de una mayor adición de agua debido a la evaporación que tiene lugar. Por otro lado, la principal desventaja en los sistemas de aireación por volteo es la dificultad de controlar la temperatura y las pérdidas de nitrógeno durante el volteo (Cayuela et al., 2006).

En cuanto a la maquinaria para el volteo, existen volteadoras anexas a tractores, equipos autónomos de volteo o incluso se pueden utilizar palas cargadoras. Las volteadoras, a su vez, pueden mover los residuos lateralmente (mueven lateralmente el contenido de la hilera, pasándolo a la siguiente) o longitudinalmente, moviendo el material hacia delante.

Por lo tanto, el compostaje es un proceso que puede clasificarse en sistemas dinámicos y estáticos dependiendo de si el material se remueve o no. En el método dinámico, se mueve periódicamente el material que se va a fermentar para introducir oxígeno, controlar la temperatura y mezclar el material con el fin de obtener un producto más uniforme. En el método estático, el material que se va a fermentar permanece estático y el aire es inyectado a través del material. Existe una segunda clasificación, en función del grado de control de las variables del proceso, encontrándose el compostaje abierto (o en hileras) y el compostaje cerrado. Este último incluye a todos los sistemas en los que se lleva a cabo el proceso en algún tipo de reactor. Una de las ventajas de los procesos llevados a cabo en un reactor es que se puede utilizar una alimentación con una baja relación $\mathrm{C} / \mathrm{N}$, tal como demostraron Kumar et al. (2010a) para residuos de alimentos, además de que requiere de menos espacio y es mucho más controlable. Sin embargo, presenta desventajas como su mayor inversión inicial y su mayor consumo de energía, además de un pretratamiento de los materiales iniciales y una capacidad limitada. En términos de aplicación y debido a las emisiones al ambiente, a nivel mundial, los reactores se implantan en zonas cercanas a núcleos urbanos, mientras que los sistemas en hileras se emplean en lugares alejados de los núcleos urbanos (Li et al., 2013).

Un sistema de compostaje en hileras de alto rendimiento emplea hileras con una sección transversal normalmente de 2 a 2,50 m de altura por 4,50 a $5 \mathrm{~m}$ de anchura. Las dimensiones de la hilera dependen del tipo de equipamiento que se va a utilizar para voltear los residuos fermentables. Aunque la fermentación se realiza al aire libre, es conveniente realizarla bajo techado, para permitir un control de la humedad y la temperatura y minimizar la producción de lixiviado. Si tras voltear el montón la temperatura no sube, se considera terminada la fase de compostaje. Esto 
sucede, para este método, hacia los dos meses y medio a tres meses. La frecuencia de volteo y su número durante el proceso depende de la composición y del contenido de humedad del producto a fermentar, así como de la climatología de la zona.

Actualmente vienen cobrando importancia los métodos mixtos en los que las hileras además de ser volteadas periódicamente, son aireadas por inyección de aire en la primera etapa del tratamiento, acelerando así el proceso de fermentación. El material a compostar se coloca en una serie de canales que pueden ser de forma rectangular o circular. Los rectangulares se construyen paralelos entre sí, delimitados por muros de escasa altura sobre los que se colocan unos raíles por los que se mueve la volteadora, recorriéndolos longitudinalmente.

Existen dos modalidades de compostaje en canal tipo rectangular, compostaje continuo y compostaje "en batch". En el compostaje continuo la materia a digerir se introduce por un extremo y se extrae por el otro, cada vez que la volteadora agita el material lo hace avanzar unos metros. De esta forma, conforme se llevan a cabo los volteos se va haciendo hueco para colocar nuevo material fresco en el principio del canal y se va acercando al final del canal donde está listo para la fase de maduración. A diferencia de este método, en el compostaje "en batch" no se produce el avance de la masa fermentante a lo largo del canal tras los volteos, la descarga del canal completo se produce cuando toda su masa está lista para pasar a la fase de maduración. Generalmente llevan incorporada ventilación forzada, lo que le confiere una gran flexibilidad de operación, ya que se combina los beneficios de la aireación forzada con los de los volteos periódicos. En los circulares, el sistema de agitación se coloca sobre un puente móvil que gira desde el centro del reactor (similar al funcionamiento del puente de un clarificador de una estación de tratamiento de aguas). La velocidad de giro suele estar en torno a las 2 vueltas por hora. La alimentación se realiza por el perímetro exterior, según va girando el puente.

Cabe recordar que, independientemente del método utilizado, la transformación acelerada afecta fundamentalmente a los materiales fácilmente biodegradables (hidratos de carbono, etc.) por lo que el proceso debe completarse con una estabilización al aire libre, que permita el ataque de los materiales lentamente biodegradables (lignocelulósicos).

Por otro lado, cuando se pretende reutilizar los residuos orgánicos en el lugar donde se han generado, el proceso de compostaje descentralizado utilizando un reactor de tambor rotatorio es una opción interesante, con la que además se reduce el material a transportar y por tanto los costes de transporte (Kalamdhad et al., 2009). Este tambor rotatorio aporta agitación, aireación y mezclado del compost para producir un producto final uniforme sin problemas de olor y lixiviados. Además, el tiempo de compostaje se reduce a entre 2 y 3 semanas (Kalamdhad et al., 2009). 
El proceso de compostaje requiere de una mezcla de partida adecuada, donde la adición de un agente estructurante puede ser necesaria para favorecer el inicio del proceso ajustando la relación $\mathrm{C} / \mathrm{N}$, el $\mathrm{pH}$ y la humedad principalmente (Kumar et al., 2010a). En todo caso, el agente estructurante no debe ser de un tamaño de partícula muy grande porque las partículas pequeñas pueden crear una estructura real de poro y lograr una distribución homogénea de tamaño de poro en la alimentación para que actúe como una consumidora eficiente de oxígeno (Li et al., 2013). Las características de los distintos materiales a emplear definen su uso como agente estructurante, pero la madera y los materiales residuales como restos de poda son los más utilizados. En otro caso, las características de los distintos materiales pueden clasificarlos como agentes co-compostantes.

Por otro lado, el compost maduro también se ha utilizado como ingrediente en un nuevo proceso de compostaje (Komilis et al., 2004; Stabnikova et al., 2005), ya que ello puede diluir el residuo fresco y reducir la disponibilidad de energía por unidad de volumen, reduciendo a su vez el riesgo de olores y la inhibición por una alta concentración de ácidos orgánicos, además de aportar una diversidad microbiana que ayude a acelerar el inicio del proceso (Nakasaki y Akiyama, 1988).

Como ya se ha comentado, la principal aplicación del compost es como enmienda orgánica en agricultura, es decir, como un material destinado a mantener o incrementar el contenido de materia orgánica del suelo, pero también puede ser utilizado como fertilizante siempre que se cumplan los parámetros establecidos en la normativa, con el objetivo de incrementar el rendimiento de las cosechas, con beneficios que se manifiestan de forma más clara a medio y largo plazo. Pero además de estas aplicaciones, que se pueden considerar tradicionales, ligadas eminentemente a la agricultura, el compost puede encontrar aplicación en otros campos más innovadores y la calidad exigida al mismo puede variar. Uno de los más prometedores y que requiere de un compost de alta calidad es la elaboración de sustratos, aplicación en la que puede ser utilizado sólo o mezclado con otros productos, como sustituto de materiales como la turba, que es un recurso escaso y no renovable. Además, hay evidencia de que el compost, a diferencia de la turba, presenta capacidad reguladora del crecimiento de la planta e inhibición patogénica (Atiyeh et al., 2002; Tilston et al., 2002), y estos factores aportan un valor añadido logrando compost de alta calidad, que constituyen así una alternativa ecológica al uso de pesticidas. En este aspecto, los compost de materiales agroindustriales han mostrado una cierta capacidad de efecto supresivo en patógenos (Kavroulakis et al., 2010; Bernal-Vicente et al., 2008; Alfano et al., 2011), pero no se puede aplicar de una manera general sin que sea exactamente determinado en el compost (Bonanomi et al., 2010). En el estudio de Blaya et al. (2015) se obtuvo que los residuos agroindustriales tales como los restos de producción de aceite de oliva y los restos de ajo junto con lodo de depuración del sector agroalimentario y poda de vid como agente estructurante presentan efecto supresivo 
frente a fitopatógenos específicos tales como $F$. oxysporum f. sp. melonis en melón y $P$. capsici en plántulas de pimiento.

El compostaje de restos vegetales con la adición de microorganismos beneficiosos tales como Trichoderma harzianum ( $T$. harzianum), permiten obtener un compost con valor añadido en cuanto al incremento de su capacidad biocontrol frente a fitopatógenos, debido tanto al efecto directo del microorganismo $T$. harzianum contra varios patógenos incluyendo Fusarium spp., Phytophthora spp., Sclerotinia spp., Rhizoctonia spp. y Pythium spp. (Bernal-Vicente et al., 2009; Hjeljord y Tronsmo, 1998; Trillas et al., 2006); así como a los cambios inducidos sobre las características bióticas y abióticas de los compost (Blaya et al., 2013). Igualmente, en los experimentos realizados por Lopez-Mondejar et al. (2010) se obtuvo que la combinación de compost de cítricos con $T$. harzianum T-78 puede ser una alternativa viable para sustituir a la turba y poder minimizar la aplicación de químicos necesarios para el control de Fusarium en la producción de plántulas de melón en invernadero.

Los subproductos agroalimentarios también han sido evaluados como granulados (peletizados) portadores de agentes biocontrol para su aplicación en cultivos afectados por patógenos (Smolinska et al., 2014). Además, la tecnología de peletización permiten obtener un producto de valor añadido con la ventaja de que se proporciona un almacenamiento a largo plazo de los subproductos y su uso en el momento adecuado para las plantas (Smolinska et al., 2014), ya que son materiales muy biodegradables y su uso está limitado.

\subsubsection{Valorización energética}

Para el tratamiento de residuos agroindustriales con el fin de obtener energía se han considerado diversas tecnologías que bien producen electricidad, bien generan un nuevo producto para su posterior utilización como biocombustible. En el primer caso, Gómez et al. (2010) indicaron que la combustión en parrilla seguida de un ciclo de turbina de vapor (GF/ST), la co-combustión en calderas de carbón pulverizado (CF/ST) y la digestión anaerobia seguida por la combustión en un motor de combustión interna $(A D / I C E)$ eran las mejores tecnologías para los residuos de origen agroindustrial, ya que otras como la gasificación no están tan probadas y requieren de grandes inversiones. En el segundo caso, la carbonización hidrotermal (HTC) permite obtener un biocombustible a partir de biomasa húmeda (Hitzl et al., 2014), al igual que la pirólisis a baja temperatura (Elías y Velo, 2012).

En el caso concreto de los subproductos de la industria de conservas vegetales las tecnologías de combustión, así como la pirólisis y la gasificación no son adecuadas para la mayoría de ellos debido a la alta humedad de estos materiales, lo que supondría un bajo rendimiento y la necesidad de etapas de secado previas para alcanzar la humedad requerida en la alimentación del 10 \% (Elías y Velo, 2012). Sin 
embargo, sí son de interés para los huesos de aceituna y de frutas por su bajo contenido en agua y su poder calorífico, como lo demuestran los experimentos de gasificación realizados por Mertzis et al. (2014) y Rovas y Zabaniotou (2015).

Por otro lado, la digestión anaerobia (DA) es una de las tecnologías más sostenibles para producir biogás a partir de biorresiduos (Forster-Carneiro et al., 2007), pero cuando se emplea un solo sustrato (monodigestión) presenta algunos inconvenientes debido a las propiedades de los sustratos, que pueden ser solucionados con la adición de cosustratos (Mata-Alvarez et al., 2014). El empleo de cosustratos permite alimentar diferentes sustratos salvando el inconveniente de la temporalidad, como es el caso de los restos de frutas y hortalizas. Por tanto, la codigestión es la adición simultanea de dos o más sustratos para salvar los inconvenientes y mejorar la viabilidad económica de las plantas de DA debido a la mayor producción de metano (Mata-Alvarez et al., 2000). En la bibliografía son numerosos los estudios sobre digestión anaerobia de residuos de frutas y hortalizas (van den Berg y Lentz, 1977; Knol et al., 1978; Hills y Roberts, 1982; Lane, 1984; Bouallagui et al., 2004; Romano y Zhang, 2008; Garcia-Peña et al., 2011; Jiang et al., 2012; Scano et al., 2014).

Los residuos de frutas y hortalizas han sido utilizados como cosustratos de procesos de digestión anaerobia de lodos de depuración (Park et al., 2011). En este caso, la producción de biogás fue incrementándose entre el 8 y el $17 \%$ al añadir 280 $420 \mathrm{~kg} /$ día. También se han aplicado residuos de frutas y hortalizas junto con purines de vacuno y gallinaza (Callaghan et al., 2002) y se ha observado el incremento de metano de 0,23 a $0,45 \mathrm{~m}^{3} / \mathrm{kg}$ SV al aumentar la proporción de residuos de frutas y hortalizas del 20 al 50 \% en la alimentación. Llaneza Coalla et al. (2009) observaron que se produce un aumento de la producción de biogás al incrementar la proporción de pulpa de manzana en una alimentación junto con residuos de matadero. Estos autores utilizaron un experimento en continuo que incluía una unidad de digestión de mezcla completa con agitación continua (CSTR) que trabajaba en condiciones mesofílicas $\left(38^{\circ} \mathrm{C}\right)$, pero también un tanque de homogeneización y otro de hidrólisis previo para favorecer el rendimiento. Otros autores como Arhoun et al. (2013) observaron que la alimentación en continuo de una mezcla de subproductos de pera junto con lodo de depuración, manteniendo una agitación constante, permitía obtener una menor producción de ácidos grasos y, por tanto, se limitaba la reducción del pH en el reactor frente a la alimentación en discontinuo.

Son muchos los estudios que utilizan un reactor de mezcla completa, con alimentación en continuo y condiciones mesófilas que operan en sistemas de una sola etapa, pero para mejorar la co-digestión o permitir una mayor carga orgánica se utilizan también sistemas que operan en condiciones termófilas y con otras configuraciones del reactor (Mata-Alvarez et al., 2014). En la bibliografía son muchas las configuraciones de los digestores (Shen et al., 2013; Franchetti, 2013; Raven y 
Gregersen, 2007; Shahriari et al., 2013), que además utilizan unidades de pretratamiento y postratamiento en una amplia variedad de configuraciones, a su vez, para tratar una mayor concentración de sólidos y alimentaciones de naturaleza heterogénea (Rapport et al., 2012). En Europa las tecnologías en seco de una sola etapa denominadas Dranco, Kompogas y Valorga son las que se encuentran mayoritariamente para el tratamiento de residuos biodegradables (Rapport et al., 2012).

También Scano et al. (2014) utilizaron una planta piloto con un reactor tubular horizontal para llevar a cabo un proceso de digestión anaerobia de residuos de frutas y hortalizas. La planta además disponía de un pretratamiento de los sustratos para adecuar el tamaño, un tanque de alimentación con agitador, un sistema de bombeo de alimentación neumático y otro para la salida del digestato, un medidor de biogás y una unidad de tratamiento del biogás, además de un tanque de almacenamiento del digestato. Ellos indicaron que es necesario mantener la carga orgánica diaria (ORL) para mantener estable el proceso, un buen balance de la mezcla para obtener un rendimiento adecuado, además de sugerir que es necesario separar las fases de hidrólisis y acidogénesis de la fase de metanogénesis.

En todo caso, si se utiliza la co-digestión en una instalación ya existente, la carga orgánica ORL, que permita un buen rendimiento de un gas de calidad, es probablemente el parámetro de diseño crítico (Gómez et al., 2006; Lindorfer et al., 2008; Fernández Rodríguez et al., 2012; Duan et al., 2012).

También, se han evaluado pretratamientos térmicos y con ultrasonidos para solubilizar la materia orgánica en el caso de subproductos tales como los restos de aceitunas (Gianico et al., 2013), obteniendo que ellos favorecen una mayor producción de biogás.

Finalmente, se conoce que la digestión anaerobia de residuos orgánicos produce un nuevo residuo semilíquido: el digestato, que ha de ser gestionado, y que puede ser utilizado en agricultura después de un proceso de estabilización o de compostaje (Álvarez et al., 2010). Nicoletto et al. (2014) evaluaron su uso en cultivo de lechuga y obtuvieron que junto con una fertilización mineral se puede aportar los nutrientes suficientes para el cultivo.

Por otro lado, la carbonización hidrotermal (HTC) es otra tecnología, puesta en el mercado para la gestión de biorresiduos, con la que se puede obtener un biocombustible para la producción de energía. El proceso HTC se lleva a cabo en reactores con condiciones acuosas a $180-250^{\circ} \mathrm{C}$ y a presión autógena. Posteriormente, y para la producción de un biocombustible sólido, el agua de proceso se puede reducir al 50 \% mediante una etapa de deshidratación mecánica primero y después un secado térmico para reducir el contenido de agua por debajo de $5 \%$. Finalmente el producto obtenido, carbono HTC, puede ser peletizado para su aplicación como biocombustible 
(Hitzl et al., 2014). Estos autores han evaluado la alimentación de materiales lignocelulósicos tales como las podas de jardines y otros con humedades de más del $90 \%$ como cortezas de naranja y biorresiduos de cebolla, y han obtenido un producto relativamente estable con un alto contenido en carbono y por tanto alta densidad energética interesante para su uso como biocombustible.

\section{Conclusión}

El procesado de las materias primas tales como la alcachofa, pimiento, tomate y cítricos genera un alto volumen de biorresiduos en la Región de Murcia, debido a su mayor actividad económica y características naturales específicas, así como a los procesos de transformación a las que son sometidas. El destino de estos biorresiduos es fundamentalmente el de alimentación animal, por lo que son considerados subproductos agroalimentarios, con un coste de gestión limitado a un canon por el transporte, aunque también nulo según acuerdos con ganaderos de la zona y positivo en la gestión de los huesos. En todo caso, el destino de los subproductos se caracteriza por su ambivalencia con la concurrencia de varios destinos posibles, determinados por la "facilidad" en su eliminación, el cumplimiento formal de las especificaciones de la normativa ambiental y el ahorro de costes en el proceso de gestión y eliminación, por medio de soluciones que, en general, no producen valor para las empresas a pesar de la existencia de reconocidas oportunidades de valorización basadas en tecnologías de tratamiento disponibles.

La caracterización de estos subproductos ha puesto de manifiesto la "disponibilidad" de los subproductos agroalimentarios para gestionarse y valorizarse siguiendo la jerarquía establecida en la normativa de residuos, reduciendo en primer lugar su generación mediante la obtención de coproductos en la propia empresa o actividad empresarial, y pudiendo llevarse a cabo valorizaciones finalistas ambientalmente sostenibles, como son la alimentación animal controlada, el compostaje y la digestión anaerobia, esta última seguida de un tratamiento de estabilización posterior.

Finalmente, el estudio reveló un interés económico del entorno empresarial y una preocupación por la inversión necesaria para desarrollar una valorización de estos materiales en la propia empresa. El camino actual parece orientado a la relación entre empresa productora de biorresiduos y empresa de valorización por el interés en el beneficio asociado de la comercialización de los biorresiduos.

\section{Bibliografía}

Ahmad, J., Langrish, T.A.G., 2012. Optimisation of total phenolic acids extraction from mandarin peels using microwave energy: The importance of the Maillard reaction. J. Food Eng. 109, 162-174. 
Alavi, S., Karkle, E., Adhikari, K., Keller, L., 2011. Extrusionresearch for addressing the obesity challenge. Cereal Food. World 56, 56-60.

Alfano, G., Lustrato, G., Lima, G., Vitullo, D., Ranalli, G., 2011. Characterization of composted olive mill wastes to predict potential plant disease suppressiveness. Biol. Control 58, 109-207.

Altan, A., McCarthy, K.L., Maskan, M., 2008. Evaluation of snackfoods from barley-tomato pomace blends by extrusionprocessing. J. Food Eng. 84, 231-242.

Álvarez, J.A., Otero, L., Lema, J.M., 2010. A methodology for optimising feed composition for anaerobic co-digestion of agro-industrial wastes. Bioresour. Technol. 101, 1153-1158.

Anagnostopoulou, M.A., Kefalas, P., Papageorgiou, V.P., Assimopoulou, A.N., Boskou D., 2006. Radical scavenging activity of various extracts and fractions of sweet orange peel (Citrus sinensis). Food Chem. 94(1), 19-25.

AOAC, 2000. Official Methods of Analysis of AOAC International, 17th ed. The Association. Gaithersburg, MD.

Arhoun, B., Bakkali, A., El Mail, R., Rodriguez-Maroto, J.M., Garcia-Herruzo, F., 2013. Biogas production from pear residues using sludge from a wastewater treatment plant digester. Influence of the feed delivery procedure. Bioresour. Technol. 127, 242-247.

Atiyeh, R.M., Arancon, N.Q., Edwards, C.A., Metzger, J.D., 2002. The influence of earthworm-processed pig manure on the growth and productivity of marigolds. Bioresour. Technol. 81, 103-108.

Aulinas Masó, M., Bonmatí Blasi, A., 2008. Evaluation of composting as a strategy for managing organic wastes from a municipal market in Nicaragua. Bioresour. Technol. 99, 5120-5124.

Bacenetti, J., Duca, D., Negri, M., Fusi, A., Fiala, M., 2015. Mitigation strategies in the agro-food sector: The anaerobic digestion of tomato purée by-products. An Italian case study. Sci. Total Environ. 526, 8897.

Bampidis, V.A., Robinson, P.H., 2006. Citrus by-products as ruminant feeds: A review. Anim. Feed Sci. Technol. 128, 175-217.

Behnke, K.C., 2001. Productivity parameters using pelleted vs. mash feeds. Dept. of Grain Science and Industry - Kansas State University. Kansas - USA.

Belitz, H.D., Grosch, W., 1999. Fruits and fruit products. In: Hadziyev, D. (Ed.), Food chemistry. Berlin, Heidelberg, New York, London, Paris, Tokyo. Springer Verlag. pp. 748-799.

Ben Salem, H. Znaidi, I.-A., 2008. Partial replacement of concentrate with tomato pulp and olive cakebased feed blocks as supplements for lambs fed wheat straw. Anim. Feed Sci. Technol. 147, 206-222.

Bernal-Vicente, A., Ros, M., Pascual, J.A., 2009. Increased effectiveness of the Trichoderma harzianum isolate T-78 against Fusarium wilt on melon plants under nursery conditions, J. Sci. Food Agric. 89, 827833.

Bernal-Vicente, A., Ros, M., Tittarelli, F., Intrigliolo, F., Pascual, J.A., 2008. Citrus compost and its water extract for cultivation of melon plants in greenhouse nurseries: evaluation of nutritive and biocontrol effects. Bioresour. Technol. 99, 8722-8728.

Blaya, J., Lloret, E., Ros, M., Pascual, J.A., 2015. Identification of predictor parameters to determine agroindustrial compost suppressiveness against Fusarium oxysporum and Phytophthora capsici diseases in muskmelon and pepper seedlings. J. Sci. Food Agric. 95, 1482-1490.

Blaya, J., Lopez-Mondejar, R., Lloret, E., Pascual, J.A., Ros, M., 2013. Changes induced by Trichoderma harzianum in suppressive compost controlling Fusarium wilt. Pestic. Biochem. Phys. 107, 112-119. 
BOE, 1992. Real Decreto 930/1992, de 17 de julio, por el que se aprueba la norma de etiquetado sobre propiedades nutritivas de los productos alimenticios. Boletín Oficial del Estado 187, 27381-27383.

BOE, 2001. Real Decreto 3484/2000, de 29 de diciembre, por el que se establecen las normas de higiene para la elaboración, distribución y comercio de comidas preparadas. Boletín Oficial del Estado 11, 14351441.

BOE, 2011. Ley 22/2011, de 28 de julio, de residuos y suelos contaminados. Boletín Oficial del Estado $181,85650-85705$.

BOE, 2013. Real Decreto 506/2013 sobre productos fertilizantes. Boletín Oficial del Estado 164, 5111951207.

Bomben, J.L., Guadagni, D.C., Harris, J.G., 1971. Apple-flavored thickener from apple peel: converting an uneconomical byproduct into a useful product. Food Technol. 25, 1108-1117.

Bonanomi, G., Antignani, V., Capodilupo, M., Scala, F., 2010. Identifying the characteristics of organic soil amendments that suppress soil-borne plant diseases. Soil Biol. Biochem. 42, 136-144.

Bonnell, J.M., 1985. Process for the production of useful products from orange peel. U.S. Patent $4,497,838$.

Bouallagui, H., Torrijos, M., Godon, J.J., Moletta, R., Ben Cheikh, R., Touhami, Y., et al., 2004. Two-phases anaerobic digestion of fruit and vegetable wastes: bioreactors performance. Biochem. Eng. J. 21, 193197.

Calabretta, M.L., Tittarelli, F., Trinchera, A., Di Bartolomeo, E., Giuffrida, A., De Simone, C., Pierandrei, F., Salerno, A., Rea, E., Intrigliolo, F., 2004. Citrus waste a matrix for compost production. In: Proceedings of 10th International Society of Citriculture Congress. Agadir. Morocco. pp. 15-20.

Callaghan, F.J., Wase, D.A.J., Thayanithy, K., Forster, C.F., 2002. Continous codigestion of cattle slurry with fruit and vegetable wastes and chicken manure. Biomass Bioenergy. 27, 71-77.

Calvo Rodríguez, M.M., Rodríguez Castillo, M.J., Medina Martínez, R., Santa-María Blanco, J.G., 2007. Obtención de todo-trans-licopeno utilizando disolventes de grado alimentario a baja temperatura. Oficina española de patentes y marcas. Número de publicación 2259342.

Cardona, E.M., Ríos, L.A., Restrepo, G.M., 2006. Extracción del carotenoide licopeno del tomate chonto (Lycopersicum esculentum). Vitae, revista de la facultad de química farmacéutica 13(2), 44-53.

Castrillo, C., Barrios-Urdaneta, M., Fondevila, M., Balcells, J., Guada, A., 2004. Effects of substitution of barley with citrus pulp on diet digestibility and intake and production of lactating ewes offered mixed diets based on ammonia-treated barley straw. Anim. Sci. 78, 129-138.

Cayuela, M.L., Sánchez-Monedero, M.A., Roig, A., 2006. Evaluation of two different aeration systems for composting two-phase olive mill wastes. Process Biochem. 41, 616-623.

Cerisuelo, A., Castelló, L., Moset, V., Martínez, M., Hernández, P., Piquer, O., Gómez, E., Gasa, J., Lainez, M., 2010. The inclusion of ensiled citrus pulp in diets for growing pigs: Effects on voluntary intake, growth performance, gut microbiology and meat quality. Livest. Sci. 134, 180-182.

Chang, C., Lin, H., Chang, C., Liu, Y., 2006. Comparisons on the antioxidant properties of fresh, freezedried and hot-air-dried tomatoes. J. Food Eng. 77, 478-485.

Cheigh, C., Chung, E., Chung, M., 2012. Enhanced extraction of flavanones hesperidin and narirutin from Citrus unshiu peel using subcritical water. J. Food Eng. 110, 472-477.

Coelho, C., Cavani, L., Halle, A.T., Guyot, G., Ciavatta, C., Richard, C., 2011. Rates of production of hydroxyl radical and singlet oxygen from irradiated compost. Chemosphere 85, 630-636. 
Coinu, R., Stefania, C., Pier-Paolo, U., Nadia, M., Patrizia, P., Flavia, F., Romani, A., 2006. Dose-effect study on the antioxidant properties of leaves and outer bracts of extracts obtained from Violetto di Toscana artichoke. Food Chem. 101, 524-531.

CREM, 2015. Datos estadísticos de la Región de Murcia. Centro Regional de Estadística de la Región de Murcia. Disponible en: http://www.carm.es/econet/sicrem/PU_datosBasicos/sec49.html.

Denek, N., Can, A., 2006. Feeding value of wet tomato pomace ensiled with wheat straw and wheat grain for Awassi sheep. Small Ruminant Res. 65, 260-265.

Domínguez, P.L., Cervantes, A., 1980. Ensilaje de cítricos en la ceba de cerdos. Rasgos de comportamiento y canal. Cienc. Téc. Agric. Ganado Porcino 3, 77-95.

DOUE, 1996. Directiva 96/25/CE del Consejo, de 29 de abril de 1996, sobre la circulación de materias primas para la alimentación animal y por la que se modifican las Directivas 70/524/CEE, 74/63/CEE, 82/471/CEE y 93/74/CEE y se deroga la Directiva 77/101/CEE. Diario Oficial de las Comunidades Europeas 125, 35-58.

DOUE, 2005. Reglamento (CE) no 183/2005 del Parlamento Europeo y del Consejo, de 12 de enero de 2005, por el que se fijan requisitos en materia de higiene de los piensos. Diario Oficial de las Comunidades Europeas 35, 1-22.

DOUE, 2010. Directiva 2010/75/UE del Parlamento Europeo y del Consejo de 24 de noviembre de 2010 sobre las emisiones industriales (prevención y control integrados de la contaminación). Diario Oficial de las Comunidades Europeas 334, 17-119.

Duan, N., Dong, B., Wu, B., Dai, X., 2012. High-solid anaerobic digestion of sewage sludge under mesophilic conditions: feasibility study. Bioresour. Technol. 104, 150-156.

Ehrlich, R.M., 1997. Methods for making pectin and pectocellulosic products. U.S. Patent 5,656,734.

Elías Castells, X., Velo García, E., 2012. Monografía La pirólisis: Tratamiento y valorizacion energética de residuos. En: Elías Castells (Ed.), Tratamiento y valorización energética de residuos. Madrid. Ediciones Díaz de Santos.

EPA, 1998. Method EPA 3015. Microwave Assisted Acid Digestion of Sediments, Sludges, Soils and Oils. Washington, DC.

Fernández Rodríguez, J., Pérez, M., Romero, L.I., 2012. Mesophilic anaerobic digestion of the organic fraction of municipal solid waste: optimisation of the semicontinuous process. Chem. Eng. J. 193-194, 10-15.

Fishman, M.L., Chau, H.K., Hoagland, P., Ayyad, K., 2000. Characterization of pectin, ash extracted from orange albedoby microwave heating, under pressure. Carbohydr. Res. 323(1-4), 126-138.

Forster-Carneiro, T., Perez, M., Romero, L.I., Sales, D., 2007. Dry-thermophilic anaerobic digestion of organic fraction of the municipal solid waste: focusing on the inoculum sources. Bioresour. Technol. 98, 3195-3203.

Franchetti, M., 2013. Economic and environmental analysis of four different configurations of anaerobic digestion for food waste to energy conversion using LCA for: a food service provider case study. J. Environ. Manage. 123, 42-48.

Fratianni, F.; Marina, T.; De Palma, M.; Rosa, P.; Filomena, N., 2007. Polyphenolic composition in different parts of some cultivars of globe artichoke (Cynara cardunculus L. var. scolymus (L.) Fiori). Food Chem. 104, 1282-1286.

García, A.J., Esteban, M.B., Márquez, M.C., Ramos, P., 2005. Biodegradable municipal solid waste: characterisation and potential use as animal feedstuVs. Waste Manage. 25, 780-787. 
Garcia-Peña, E.I., Parameswaran, P., Kang, D.W., Canul-Chan, M., Krajmalnik-Brown, R., 2011. Anaerobic digestion and co-digestion processes of vegetable and fruit residues: process and microbial ecology. Bioresour. Technol. 102, 9447-9455.

Gianico, A., Braguglia, C.M., Mescia, D., Mininni, G., 2013. Ultrasonic and thermal pretreatments to enhance the anaerobic bioconversion of olive husks. Bioresour. Technol. 147, 623-626.

Gil Hernández, A., 2005. Tratado de nutrición. 1ạ Edición. Madrid. Acción Médica.

Glahn, P.E., 2001. Pectin process and composition. U.S. Patent 6,207,194 y U.S. Patent 6,159,503.

Gómez, X., Cuetos, M.J., Cara, J., Morán, A., García, A.I., 2006. Anaerobic co-digestion of primary sludge and the fruit and vegetable fraction of the municipal solid wastes. Conditions for mixing and evaluation of the organic loading rate. Renew. Energ. 31, 2017-2024.

Gómez, Z., Juan, F., 1998. Factibilidad Técnica del Aislamiento y la Caracterización de Pectina Cítrica para el Sector Agroindustrial. Trabajo de Grado. Facultad de Administración. Corporación Universitaria Lasallista. Medellín. Colombia.

Gómez, A., Zubizarreta, J., Rodrigues, M., Dopazo, C., Fueyo, N., 2010. An estimation of the energy potential of agro-industrial residues in Spain. Resour. Conserv. Recy. 54, 972-984.

Gorinstein, S., Martín, O., Park, Y., Haruenkit, R., Lojek, A., Cíz, M., Caspi, A., Libman, I., Trakhtenberg, S., 2001. Comparison of some biochemical characteristics of different citrus fruits. Food Chem. 74(3), 309315.

Gómez Prieto, M.S., Ruiz del Castillo, M.L., Santa-Maria Blanco, J.G., Blanch Manzano, G.P., Herraiz Carasa, M., 2003. Extracción fraccionada de carotenoides de fuentes naturales con alto contenido en licopeno mediante fluidos supercríticos. Oficina española de patentes y marcas. Número de publicación 2197014.

Graves, J.A., Smith, P.R., Rhodes, C.G., 1994. Intermetallic Matrix Composites II. In: Miracle, D.B., Anton, D.L., Graves, J.A. (Eds.). Vol. 273. MRS Sym Proc., Pittsburgh, PA, pp. 31-42.

Guash, L., 2002. Supercritical fluid extraction and selective fractionation of lycopene and other carotenoids from natural sources. Oficina de patentes Venezolanas 200201310.

Henríquez, C., Speisky, H., Chiffelle, I., Valenzuela, T., Araya, M., Simpson, R., Almonacid, S., 2010. Development of an ingredient containing apple peel, as a source of polyphenols and dietary fibre. J. Food Sci. 75, H172-H181.

Hills, D., Roberts, D., 1982. Conversion of tomato, peach and honeydew solid waste into methane gas. Transactions of the ASAE 25(3), 820-826.

Hitzl, M. et al. 2014. The hydrothermal carbonization (HTC) plant as a decentral biorefinery for wet biomass. Catal. Today (2014), http://dx.doi.org/10.1016/j.cattod.2014.09.024.

Hjeljord, L., Tronsmo, A., 1998. Trichoderma and Gliocadium in biological control: an overview. In: Harman, G.E., Kubicek C.P. (Eds.), Trichoderma and Gliocadium. London. Taylor and Francis Inc. pp. 185204.

Horowitz, R.M., 1961. The citrus flavonoids. In: Sinclair, W.B. (Ed.), The orange. Its biochemistry and physiology. Los Angeles, CA. University of California. Division of Agricultural Science. pp. 334-372.

Huang, W., Li, Z., Niu, H., Li, D., Zhang, J., 2008. Optimization of operating parameters for supercritical carbon dioxide extraction of lycopene by response surface methodology. J. Food Eng. 89(3), 298-302. 
INE, 2013. Encuesta Industrial Anual de Empresas 2013. Instituto Nacional de Estadística. Disponible en: http://www.magrama.gob.es/es/alimentacion/Temas/industria-agroalimentaria/informacioneconomica-sobre-la-industria-agroalimentaria/.

Jiang, Y., Heaven, S., Banks, C.J., 2012. Strategies for stable anaerobic digestion of vegetable waste. Renew. Energ. 44, 206-214.

Kalamdhad, A.S., Singh, Y.K., Ali, M., Khwairakpam, M., Kazmi, A.A., 2009. Rotary drum composting of vegetable waste and tree leaves. Bioresour. Technol. 100, 6442-6450.

Karkle, E.L., Alavi, S., Dogan, H., 2012. Cellular architecture and itsrelationship with mechanical properties in expandedextrudates containing apple pomace. Food Res. Int. 46, 10-21.

Kavroulakis, N., Ntougias, S., Besi, M., Katsou, P., Damaskinou, A., Ehaliotis, C., et al., 2010. Antagonistic bacteria of composted agro-industrial residues exhibit antibiosis against soil-borne fungal plant pathogens and protection of tomato plants from Fusarium oxysporum f. sp. radicis-lycopersici. Plant Soil 33, 233-247.

Kawaii, S., Tomono, Y., Katase, E., Ogawa, K., Yano, M., 1999. Quantitation of flavonoid constituents in citrus fruits. J. Agric. Food. Chem. 47, 3565-3571.

Khan, M.K., Abert-Vian, M., Fabiano-Tixier, A-S., Dangles, O., Chemat, F., 2010. Ultrasound-assisted extraction of polyphenols (ûavanone glycosides) from orange (Citrus sinensis L.) peel. Food Chem. 119(2), 851-858.

Kitson, R.E., Mellon, M.G., 1944. Colorimetric determination of $P$ as molybdovanato phosphoric acid. Ind. Eng. Chem. 42(3), 379-383.

Knol, W., Vander Most, M., Waart, J., 1978. Biogas Production by anaerobic digestion of fruit and vegetable wastes, a preliminary study. J. Sc.i Food Agric. 29(9), 822-830.

Komilis, D.P., Ham, R.K., Park, J.K., 2004. Emission of volatile organic compounds during composting of municipal solid wastes. Water Res. 38, 1707-1714.

Kopc 'ic', N., Vukovic' Domanovac, M., Kuc`ic', D., Briški, F., 2014. Evaluation of laboratory-scale invessel co-composting of tobacco and apple waste. Waste Manage. 34, 323-328.

Kulcu, R., Yaldiz, O., 2004. Determination of aeration rate and kinetics of composting some agricultural wastes. Bioresour. Technol. 93, 49-57.

Kumar, M., Ou, Y., Lin, J., 2010a. Co-composting of green waste and food waste at low C/N ratio. Waste Manage. 30, 602-609.

Kumar, N., Sarkar, B.C., Sharma, H.K., 2010b. Development and characterization of extruded product of carrot pomace, rice flour and pulse powder. Afr. J. Food Sci. 4(11), 703-717.

Kwok, B.H.L., Hu, C., Durance, T., Kitts, D.D., 2004. Dehydration techniques affect phytochemical contents and free radical scavenging activities of Saskatoon berries (Amelanchier alnifolia Nutt). J. Food Sci. 69, 122-125.

Lane, A.G., 1984. Laboratory-scale anaerobic digestion of fruit and vegetable solid wastes. Biomass 5(4), 245-259.

Larrosa, M., Llorach, R., Espín, J.C., Tomás-Barberán, F.A., 2002. Increase of antioxidant activity of tomato juice upon functionalisation with vegetable byproduct extracts. LWT-Food Sci. Technol. 35(6), 532-542.

Lashermes, G., Barriuso, E., Houot, S., 2012. Dissipation pathways of organic pollutants during the composting of organic wastes. Chemosphere 87, 137-143. 
Lavecchia, R., Zuorro, A., 2008. Enhancement of lycopene extraction from tomato peels by enzymatic treatment. Eur. Food Res. Technol. 228(1), 153-158.

Levaj, B., Dragović-Uzelac, V., Kovačević, D.B., Krasnići, N., 2009. Determination of Flavonoids in Pulp and Peel of Mandarin Fruits. Agric. Conspec. Sci. 74(3), 221-225.

Li, B.B., Smith, B., Hossain, M.M., 2006. Extraction of phenolics from citrus peels. Sep. Purif. Technol. 48, 189-196.

Li, Z., Lu, H., Ren, L., He, L., 2013. Experimental and modeling approaches for food waste composting: A review. Chemosphere 93, 1247-1257.

Lindorfer, H., Corcoba, A., Vasilieva, V., Braun, R., Kirchmayr, R., 2008. Doubling the organic loading rate in the co-digestion of energy crops and manure - a full scale case study. Bioresour. Technol. 99, 11481156.

Llaneza Coalla, H., Blanco Fernández, J.M., Morís Morán, M.A., López Bobo, M.R., 2009. Biogas generation apple pulp. Bioresour. Technol. 100, 3843-3847.

Llorach, R., Tomás-Barberán, F.A., Ferreres, F., 2002. Artichoke (Cynara scolymus L.) byproducts as a potential source of health-promoting antioxidant phenolics. J. Agric. Food Chem. 50(12), 3458-3464.

Lo Curto, R., Tripodo, M.M., Leuzzi, U., Giuffre, D., Vaccarino, C., 1992. Flavonoids recovery and SCP production from orange peel. Bioresour. Technol. 42, 83-87.

Lopez-Mondejar, R., Bernal-Vicente, A., Ros, M., Tittarelli, F., Canali, S., Intrigiolo, F., Pascual, J.A., 2010. Utilisation of citrus compost-based growing media amended with Trichoderma harzianum T-78 in Cucumis melo L. seedling production. Bioresour. Technol. 101, 3718-3723.

López-Sánchez, M., 1986. Procedure for obtaining hesperidin from citrus. Spanish Patent, 545275.

Ma, Y., Ye, X., Hao, Y., Xu, G., Xu, G., Liu, D., 2008. Ultrasound-assisted extraction of hesperidin from Penggan (Citrus reticulata) peel. Ultrason. Sonochem. 15, 227-232.

Man, J.I., Cummings, J.H., 2009. Possible implications for health of the different definitions of dietary fibre. Nutr. Metab. Cardiovasc. Dis. 19(3), 226-229.

Marín, F.R., García-Rosado, A., Frutos, M.J., Pérez-Álvarez, J.A., Benavente-García, O., Castillo, J., 2003. Industrial citrus byproducts. A source of functional dietary fibre-flavonoids. In New functional ingredients and foods abstract book (2-A03). Copenhagen. pp. 9-11.

Martínez-Valverde, I., Periago, M.J., Provan, G., Chesson, A., 2002. Phenolic compounds, lycopene and antioxidant activity in commercial varieties of tomato (Lycopersicon esculentum). J. Sci. Food Agric. 82, 323-330.

Mata-Alvarez, J., Dosta, J., Romero-Güiza, M.S., Fonoll, X., Peces, M., Astals, S., 2014. A critical review on anaerobic co-digestion achievements between 2010 and 2013. Renew. Sust. Energ. Rev. 36, 412-427.

Mata-Alvarez, J., Macé, S., Llabrés, P., 2000. Anaerobic digestión of organic solid wastes. An overview of research achievements and perspectives. Bioresour. Technol. 74, 3-16.

Meneses, M., Megías, M.D., Madrid, J., Martínez-Teruel, A., Hernández, F., Oliva, J. 2007. Evaluation of the phytosanitary, fermentative and nutritive characteristics of the silage made from crude artichoke (Cynara scolymus L.) by-product feeding for ruminants. Small Ruminant Res. 70, 292-296.

Mertzis, D., Mitsakis, P., Tsiakmakis, S., Manara, P., Zabaniotou, A., Samaras, Z., 2014. Performance analysis of a small-scale combined heat and power system using agricultural biomass residues: the SMARt-CHP demonstration project. Energy 64, 367-374. 
Meunchang, S., Panichsakpatana, S., Weaver, R.W., 2005. Co-composting of filter cake and bagasse; byproducts from a sugar mill. Bioresour. Technol. 96, 437-442.

Nakasaki, K., Akiyama, T., 1988. Effects of seeding on thermophilic composting of household organic waste. J. Ferment. Technol. 66, 37-42.

Navarro-González, I., García-Valverde, V., García-Alonso, J., Periago, M., 2011. Chemical profile and functional and antioxidant properties of tomato dietary fiber. Food Res. Int. 44(5), 1528-1536.

Nguyen, M., Schwart, S., 1999. Lycopene: chemical and biological properties. Food Technology 58(2), 3844.

Nicoletto, C., Santagata, S., Zanin, G., Sambo, P., 2014. Effect of the anaerobic digestion residues use on lettuce yield and quality. Sci. Hort. 180, 207-213.

Nicoli, M., Anese, M., Parpinel, M., 1999. Influence of processing on the antioxidant properties of fruits and vegetables. Trends Food Sci. Technol. 10, 94-100.

Nielsen, S., 2003. Food Analysis Laboratory Manual. New York. Kluwer Academic/Plenum Publishers.

Nogueira, W.A., Nogueira, F.N., Devens, D.C., 1999. Temperature and pH control in composting of coffee and agricultural wastes. Water Sci. Technol. 40(1), 113-119.

Ordóñez, A.L., Balanza, M.E., Martin, F.R., Flores, C.A., 2009. Estabilidad del Carotenoide Licopeno en Tomates en Conserva. Información Tecnológica 20(4), 31-37.

O’Sullivan, T.C., Lynch, P.B., Morrissey, P.A., O'Grady, J.F., 2003. Evaluation of citrus pulp in diets for sows and growing pigs. Ir. J. Agr. Food Res. 42, 243-253.

Paraman I., Sharif, M.K., Supriyadi, S., Rizvi, S.S.H., 2015. Agro-food industry byproducts into valueadded extruded foods. Food Bioprod. Process. 96, 78-85.

Park, N.D., Thring, R.W., Garton, R.P., Rutherford, M.P., Helle, S.S., 2011. Increased biogas production in a wastewater treatment plant by anaerobic co-digestion of fruit and vegetable waste and sewer sludge - a full scale study. Water Sci. Technol. 64, 1851-1856.

Peterson, J.J., Beecher, G.R., Bhagwat, S.A., Dwyer, J.T., Gebhardt, S.E., Haytowitz, D. B., Holden, J.M., 2006. Flavanones in grapefruit, lemons, and limes: A compilation and review of the data from the analytical literature. J. Food Compost. Anal. 1, 74-80.

Pinacho, A., García-Encina, P.A., Sancho, P., Ramos, P. and Márquez, M.C., 2006. Study of drying systems for the utilization of biodegradable municipal solid wastes as animal feed. Waste Manage. 26(5), 495503.

Porter, M., Van der Linde, C., 1995. Green and competitive: ending the stalemate. Harvard Bus. Rev. 73, 120-134.

Quintín-Martínez, D., Martínez-Sanmartín, A., García-Gómez, P., 2011. Conception of future foods enriched with active compounds (polyphenols) obtained by the valorization of artichoke by-products. B.i.o.n 'days, valorization of organic byproducts, Valance-France.

Rapport, J.L., Zhang, R., Williams, R.B., Jenkins, B.M., 2012. Anaerobic digestion technologies for the treatment of Municipal Solid Waste. Int J Environ Waste Manage. 9, 100-122.

Raven, R.P.J.M., Gregersen, K.H., 2007. Biogas plants in Denmark: successes and set-backs. Renew. Sust. Energ. Rev. 11, 116-132.

Rodriguez, R.O., Jimenez, A., Fernandez-Bolan, J., Guillen, R., Heredia, A., 2006. Dietary fibre from vegetable products as source of functional ingredients. Trends in Food Sci. Technol. 17, 3-15. 
Romano, R.T., Zhang, R., 2008. Co-digestion of onion juice and wastewater sludge using an anaerobic mixed biofilm reactor. Bioresour. Technol. 99, 631-637.

Romero-Huelva, M., Ramos-Morales, E., Molina-Alcaide, E., 2012. Nutrient utilization, ruminal fermentation, microbial abundances, and milk yield and composition in dairy goats fed diets including tomato and cucumber waste fruits. J. Dairy Sci. 95(10), 6015-6026.

Rovas, D., Zabaniotou, A., 2015. Exergy analysis of a small gasification-ICE integrated system for CHP production fueled with Mediterranean agro-food processing wastes: The SMARt-CHP. Renew. Energ. 83, 510-517.

Rozzi, N.L., Singh, R.K., Vierling, R.A., Watkins, B.A., 2002. Supercritical fluid extraction of lycopene from tomato processing byproduct.J. Agric. Food Chem. 50, 2638-2643.

Ruiz-Cano, D., Pérez-Llamas, F., Frutos, M.J., Arnao, M.B., Espinosa, C., López-Jiménez, J.A., Castillo, J., Zamora, S., 2014. Chemical and functional properties of the different by-products of artichoke (Cynara scolymus L.) from industrial canning processing. Food Chem. 160, 134-140.

Rupasinghe, H.V., Wang, L., Huber, G., Nancy, L., Pitts, N., 2008. Effect of baking on dietary fibre and phenolics of muffins incorporated with apple skin powder. Food Chem. 107, 1217-1224.

Sabio Rey, E., 2005. Procedimiento para preparar formulaciones enriquecidas en licopeno libres de disolventes orgánicos, formulaciones obtenidas, composiciones que comprenden dichas formulaciones y uso de las mismas. Oficina española de patentes y marcas. Número de publicación 2241503.

Sakai, T., 1989. Process for preparing pectin. U.S. Patent 4,835,262.

Salvador, S.C., Pereira, M.N., Santos, J.F., Melo, L.Q., Chaves, M.L. ,2008. Resposta de vacas leiteiras à substiuiçao total de milho por polpa cítrica e à suplementaçao com microminerais orgânicos II: Desempenho e economia. Arq. Bras. Med. Vet. Zootec. 60, 1142-1149.

Sánchez-Muniz, F. J., 2012. Dietary fibre and cardiovascular health. Nutrición Hospitalaria 27(1), 31-45.

Scano, E.A., Asquer, C., Pistis, A., Ortu, L., Demontis, V., Cocco, D., 2014. Biogas from anaerobic digestion of fruit and vegetable wastes: Experimental results on pilot-scale and preliminary performance evaluation of a full-scale power plant. Energ. Convers. Manage. 77, 22-30.

Shahriari, H., Warith, M., Hamoda, M., Kennedy, K.J., 2013. Evaluation of single vs. staged mesophilic anaerobic digestion of kitchen waste with and without microwave pretreatment. J. Environ. Manage. $125,74-84$.

Shdaifat, M.M., Al-Barakah, F.S., Kanan, A.Q., Obeidat, B.S., 2013. The effect of feeding agricultural byproducts on performance of lactating Awassi ewes. Small Ruminant Res. 113(1), 11-14.

Shen, F., Yuan, H., Pang, Y., Chen, S., Zhu, B., Zou, D, Liu, Y., Mac, J., Yu, L., Li, X., 2013. Performances of anaerobic co-digestion of fruit \& vegetable waste (FVW) and food waste (FW): single-phase vs. twophase. Bioresour. Technol. 144, 80-85.

Smolinska, U., Kowalska, B., Kowalczyk, W., Szczech, M., 2014. The use of agro-industrial wastes as carriers of Trichoderma fungi inthe parsley cultivation. Sci. Hort. 179, 1-8.

Stabnikova, O., Ding, H.B., Tay, J.H., Wang, J.Y., 2005. Biotechnology for aerobic conversion of food waste into organic fertilizer. Waste Manage. Res. 23, 39-47.

Stentiford E.I., 1996. Composting control: principles and practice. In: De Bertoldi, M, Sequi, P., Lemmes, B.Y., Papi, T. (Eds.), The science of composting. UK. Blackie Academic \& Professional. pp. 49-59.

Strati, I.F., Oreopoulou, V., 2011. Process optimisation for recovery of carotenoids from tomato waste. Food Chem. 129, 747-752. 
Tilston, E.L., Pitt, D., Groenhof, A.C., 2002. Composted recycled organic matter suppresses soil-borne diseases of field crops. New Phytol. 154, 731-740.

Tiquia, S.M., 2010. Reduction of compost phytotoxicity during the process of decomposition. Chemosphere 79, 506-512.

Tittarelli, F., Trinchera, A., Intrigliolo, F., Benedetti, A., 2002. Evaluation of organic matter stability during the composting process of agroindustrial wastes. In: Insam, H., Riddech, N., Klammer, S. (Eds.), Microbiology of Composting. Heidelberg. Springer-Verlag. pp. 397-406.

Tomás-Barberán, F.A., Clifford, M.N., 2000. Flavanones, chalcones and dihydrochalcones-nature, occurrence and dietary burden. J. Sci. Food Agric. 80, 1073-1080.

Topal, U., Sasaki, M., Goto, M., Hayakawa, K., 2006. Extraction of lycopene from tomato skin with supercritical carbon dioxide: effect of operating conditions and solubility analysis. J. Agric. Food Chem. 54(15), 5604-5610.

Trillas, M.I., Casanova, E., Cotxarrera, L., Ordovás, J., Borrero, C., Avilés, M., 2006. Composts from agricultural waste and the Trichoderma asperellum strain T-34 suppress Rhizoctonia solani in cucumber seedlings. Biol. Control 39, 32-38.

van den Berg, L., Lentz, C., 1977. Methane production during treatment of food plant wastes by anaerobic digestion. In: Loehr, R.C. (Ed.), Food, Fertilizer, and Agricultural Residues. Ann Arbor Science, Ann Arbor. pp. 381-393.

Vega-Gálvez, A., Di Scala, K., Rodríguez, K., Lemus-Mondaca, R., Miranda, M., López, J., Perez-Won, M., 2009. Effect of air-drying temperature on physico-chemical properties, antioxidant capacity, colour and total phenolic content of red pepper (Capsicum annuum L. var. Hungarian). Food Chem. 117, 647-653.

Volanis, M., Zoiopoulos, P., Panagou, E., Tzerakis, C., 2006. Utilization of an ensiled citrus pulp mixture in the feeding of lactating dairy ewes. Small Rumin. Res. 64, 190-195.

Walkley, A., Black, I., 1934. An examination of the Degtjareff method and a proposed modification of the chromic matter and a proposed modification of the chromic acid titration method. Soil Sci. 34, 29-38.

Wannberg, J., Ersmark, K., Larhed, M., 2006. Microwave-Accelerated Synthesis of Protease Inhibitors. Topics in Current Chemistry, 266. Berlin Heidelberg. Springer-Verlag. pp. 167-198.

Weiss, W.P., Frobose, D.L., Koch M.E., 1997. Wet Tomato Pomace Ensiled with Corn Plants for Dairy Cows. J. Dairy Sci. 80(11), 2896-2900.

Willats, W.G.T., Knox, P., Mikkelsen, J.D., 2006. Pectin: new insights into an old polymer are starting to gel. Trends Food Sci. Technol. 17, 97-104.

Wolfe, K., Liu, R.H., 2003. Apple peels as a value-added food ingredient. J. Agric. Food Chem. 51, 16761683. 

V. Valorización de restos de poda de vid de la Región de Murcia 



\section{Valorización de restos de poda de vid de la Región de Murcia}

\section{Introducción}

Los sistemas agrarios intensivos son la base de la producción agrícola de la Región de Murcia, entre los que se encuentran el cultivo de viñedos, que presentan la ventaja de grandes producciones, pero también el inconveniente de generar una gran cantidad de biorresiduos o subproductos. Actualmente estos procesos de intensificación productiva han provocado un desbordamiento de todo tipo de residuos agroindustriales bajo diferentes formas para los que no existe una normativa específica y por lo que se aplica la ley de residuos vigente, la Ley 22/2011 de residuos y suelos contaminados (MAGRAMA, 2012). En esta ley destaca que, los restos agrícolas no se consideran residuos si se destinan a la producción de energía a base de biomasa o son empleados en el sector agrario. Sin embargo, se han de llevar a cabo buenas prácticas de aplicación para cumplir con la Ley 43/2002, de sanidad vegetal (BOE, 2002), que indica en su artículo 13 la obligación que tienen los titulares de las explotaciones agrícolas de mantener sus cultivos en buen estado fitosanitario para evitar la propagación de plagas y enfermedades.

En la Región de Murcia se cultivaron 25.724 ha de viñedos para uva de vino en 2013, según el Centro Regional de Estadística de Murcia (CREM, 2015), concentradas en dos áreas diferenciadas: la Comarca del Altiplano, en la que se ubican las Denominaciones de Origen (D.O.) Jumilla y Yecla; y una segunda área polarizada especialmente, pero no exclusivamente, en la Comarca del Noroeste, con la denominación de origen Bullas. La D.O. Jumilla comprende el municipio de Jumilla y otros seis municipios limítrofes de la provincia de Albacete (Comunidad Autónoma de Castilla La Mancha). En la Tabla 1 se indica la superficie de cultivo según localización. Actualmente en el municipio de Jumilla, el cultivo de vid es el mayor de la Región y está en torno a las 13.000 ha, casi el total de las mismas están inscritas en la denominación de origen. La D.O. Yecla ocupa el término municipal de Yecla y en el año 2013 el cultivo de uva para la elaboración de vino fue de 8.325 ha en el municipio, estando bajo la D.O. Yecla 5.824 ha en la campaña 2012/2013. Finalmente, según la D.O. Bullas, el área de influencia de la misma está localizada en los términos municipales de Bullas, Cehegín, Mula, Ricote, Calasparra, Caravaca de la Cruz, Moratalla, Lorca, Totana y Cieza, indicada en la Orden de 24 de mayo de 2006, de la Consejería de Agricultura y Agua, por la que se aprueba el Reglamento de la Denominación de Origen Bullas y de sus órganos de gestión y control (BORM, 2006). Desde el año 2006 se ha visto reducida la superficie del cultivo en estos municipios y según datos del año 2013 ocupa 2.834 ha, de las que 1.036 se incluyeron en la D.O. Bullas en la campaña 2012/2013. Es destacable que, aunque Bullas da nombre a una Denominación de Origen, no es en este municipio donde se presenta una alta 
superficie de cultivo de viñedos, como sí ocurre con Yecla y Jumilla. La variedad dominante en cada una de las zonas es Monastrell, aunque existe una diversificación hacia otras como Cabernet-Sauvignon o Syrah.

Tabla 1. Superficie de cultivo de viñedos en las tres principales áreas de la Región de Murcia

\begin{tabular}{lcc} 
& Hectáreas cultivadas & Hectáreas cultivadas con D.O. \\
\hline Jumilla & 13.327 & $\sim 13.000$ \\
Yecla & 8.325 & 5.824 \\
Bullas & 2.834 & 1.036 \\
\hline
\end{tabular}

Elaboración propia. Fuente: Datos campaña 2012/2013

D.O.: Denominación de origen

En estas zonas es donde se focaliza la producción de residuos de carácter leñoso, originados en las operaciones de poda principalmente, que son necesarias para, entre otras, regular la calidad de la vid individual (Jackson, 2000), y que requieren de una gestión. Según Askew y Holmes (2002) la quema de podas o su incorporación al suelo al final de la cosecha previo triturado son las prácticas más habituales en agricultura. La primera se basa en la eliminación del residuo (que no cumple con la jerarquía de gestión que establece la normativa de residuos), aunque es una forma eficaz y poco costosa de eliminar los restos agrícolas en caso de presencia de plagas y enfermedades. La segunda favorece el reciclaje de la poda mejorando las condiciones físicas del suelo y aportando materia orgánica al suelo, pero produce, o puede contribuir, a la compactación del suelo y/o a la aparición de plagas de insectos xilófagos. Por lo tanto, es necesario llevar a cabo nuevas actuaciones que contemplen una correcta gestión, además de los valores intrínsecos de estos materiales residuales en el ámbito agronómico especialmente.

El objetivo de este capítulo fue determinar el potencial de residuos de la industria vitivinícola en la Región de Murcia en su dimensión de la viticultura, caracterizarlo y proponer nuevas opciones de valorización de los mismos que respondan a demandas medioambientales y sean beneficiosas para el sector agrícola. Como objetivos concretos dentro del estudio realizado podemos destacar: 1) Análisis de la problemática de los restos de cultivos en las áreas de tradición vitivinícola de especial relevancia en la Región de Murcia: Bullas, Jumilla y Yecla; y 2) Estudio de oportunidades tecnológicas destinadas a fundamentar soluciones a estos restos de cultivos generados, atendiendo a sus características.

\section{Materiales y métodos}

\subsection{Potencial de los restos de poda de vid}

Para estimar la cantidad de residuos generados y las características del modo de generación en todos los casos, se utilizaron los coeficientes determinados a través de encuestas y entrevistas realizadas a viticultores, y complementados por mediciones 
específicas en campo y en planta de producción en aquellos casos en que la información era incompleta o deficiente, y que se encuentran disponibles en las bases de datos del CEBAS-CSIC a partir del trabajo realizado por Segura (2010). Estos coeficientes se han aplicado, proyectado y extrapolado a las superficies ocupadas y a las producciones de uva y vino en las áreas de estudio. Asimismo, se ha tenido en cuenta la dimensión espacial de las áreas de estudio, además de la dimensión temporal y fuente de generación de los residuos.

\subsection{Caracterización}

\subsubsection{Métodos analíticos y estadísticos}

$\mathrm{El} \mathrm{pH}$ y la conductividad eléctrica (CE) de los restos de poda fueron analizados en un extracto soluble en agua 1:10 (p/v). La humedad se determinó por diferencia de peso entre material inicial y seco a $105{ }^{\circ} \mathrm{C}$ (24 horas). El nitrógeno total (N) y el carbono orgánico total de los mismos fueron determinados por microanálisis automático (Navarro et al., 1991). El fósforo (P) fue determinado espectrofotométricamente midiendo la intensidad de la coloración amarilla del ácido molibdovanadato fosfórico (Kitson y Mellon, 1944); y el potasio (K) por fotometría de llama.

Para el análisis de metales pesados, las muestras de poda fueron secadas al aire. Las concentraciones de cadmio $(\mathrm{Cd})$, cromo $(\mathrm{Cr})$, cobre $(\mathrm{Cu})$, mercurio $(\mathrm{Hg})$, níquel (Ni), plomo $(\mathrm{Pb})$ y cinc $(\mathrm{Zn})$ fueron determinadas por espectrofotometría de masas con plasma de acoplamiento inductivo (ICP-MS) (EPA, 1998), tras una digestión $\mathrm{HNO}_{3} / \mathrm{HClO}_{4}$. Los valores fueron expresados como $\mathrm{mg} / \mathrm{kg}$ de metal en peso seco de restos de poda de vid.

El análisis de contaminantes orgánicos en los restos de poda se llevó a cabo mediante técnicas de extracción seguidas de técnicas cromatográficas, empleando la técnica cromatografía de gases-espectrometría de masas (GC-MS), de acuerdo a protocolos del laboratorio instrumental del Centro Tecnológico Nacional de la Conserva y Alimentación (CTC). Tanto plaguicidas organoclorados, como organofosforados también fueron determinados utilizando un sistema cromatográfico de gases HP-6890 con detector de masas, expresándose los resultados como mg/kg.

Los valores medios de cada parámetro fueron determinados usando el análisis de la varianza con un factor (ANOVA). Para el análisis estadístico se utilizó el software SPSS 22.0 (SPSS Inc., Chicago, IL, EE.UU.).

\subsection{Opciones de valorización de los restos de poda de vid}

Se realizó un amplio estudio de oportunidades tecnológicas, sistemas de gestión y valorización de este tipo de materiales y bibliografía científico-técnica. Se 
utilizaron buscadores habituales y metabuscadores, como Copernic, con capacidad de chequear en distintos sistemas y redes de información y vigilancia. El enfoque metodológico para la revisión bibliográfica se basó en la utilización de palabras clave dirigidas a proyectos de $\mathrm{I}+\mathrm{D}$, tesis doctorales, artículos técnicos y patentes, y en bases de datos de revistas científicas, como Scopus y ScienceDirect dirigidas a la evaluación de artículos científicos principalmente. Las palabras clave seleccionadas fueron: poda viñedo; sarmientos de vid; valorización poda viñedo; compost poda viñedo; agente estructurante sarmientos vid; gestión restos poda.

Finalmente, se dispuso de un amplio inventario de oportunidades tecnológicas y de gestión sobre el que operar analíticamente. Se estudiaron, analizaron y preseleccionaron aquellas que por sus características se adaptaban a las condiciones y volumen de los restos de poda de la viticultura. Las premisas utilizadas fueron una relación oportunidad-beneficio interesante para su implantación en la Región y fácil transferencia al sector vitivinícola, especialmente a los viticultores.

\section{Resultados y discusión}

\subsection{Potencial de valorización de restos de poda de vid en la Región de Murcia}

La estimación de la cantidad de los restos leñosos de poda, conocidos como sarmientos, se ha realizado utilizando el coeficiente determinado a partir de los datos disponibles en las bases de datos del CEBAS-CSIC (Segura, 2010). Se tuvo en cuenta el volumen, variedad, sistema de cultivo (vaso o espaldera) y densidad para cuantificar los residuos de poda generados en base a las cepas o hectáreas cultivadas. En las Tablas 2 y 3 se indican los valores medios de los residuos generados de acuerdo al tipo de cultivo elegido para cada plantación en la D.O. Bullas y Jumilla respectivamente. En todo caso, el tipo de plantación tiene una fuerte influencia en la cantidad de residuos generados, como han indicado Velázquez-Martí et al. (2011).

Este coeficiente aplicado a la superficie de cultivo nos permite determinar la cantidad de restos de poda generados para cada una de las variedades y poder establecer un ratio de generación de restos de poda de vid, que es de aproximadamente $3 \mathrm{~T} /$ ha año. La variedad Monastrell es la que, en promedio, mayor cantidad de residuo genera en la cepa y es determinante en el ratio total debido a su alto porcentaje de cultivo en la Región de Murcia, lo que homogeneiza la producción de este residuo en todas las áreas evaluadas en base a la superficie de cultivo. Este ratio es similar al indicado por el Ministerio de Agricultura, Alimentación y Medio Ambiente (MAGRAMA, 2012) y algo superior al determinado por Perpiñá et al. (2008), que fue de 2,5 T/ha, al de Spinelli et al. (2012) que fue de $2 \mathrm{~T} /$ ha en peso fresco, y al intervalo propuesto, de entre 1,4 y $2,0 \mathrm{~T} / \mathrm{ha}$ de cultivo de vino, por Jiménez et al. (2006b). 

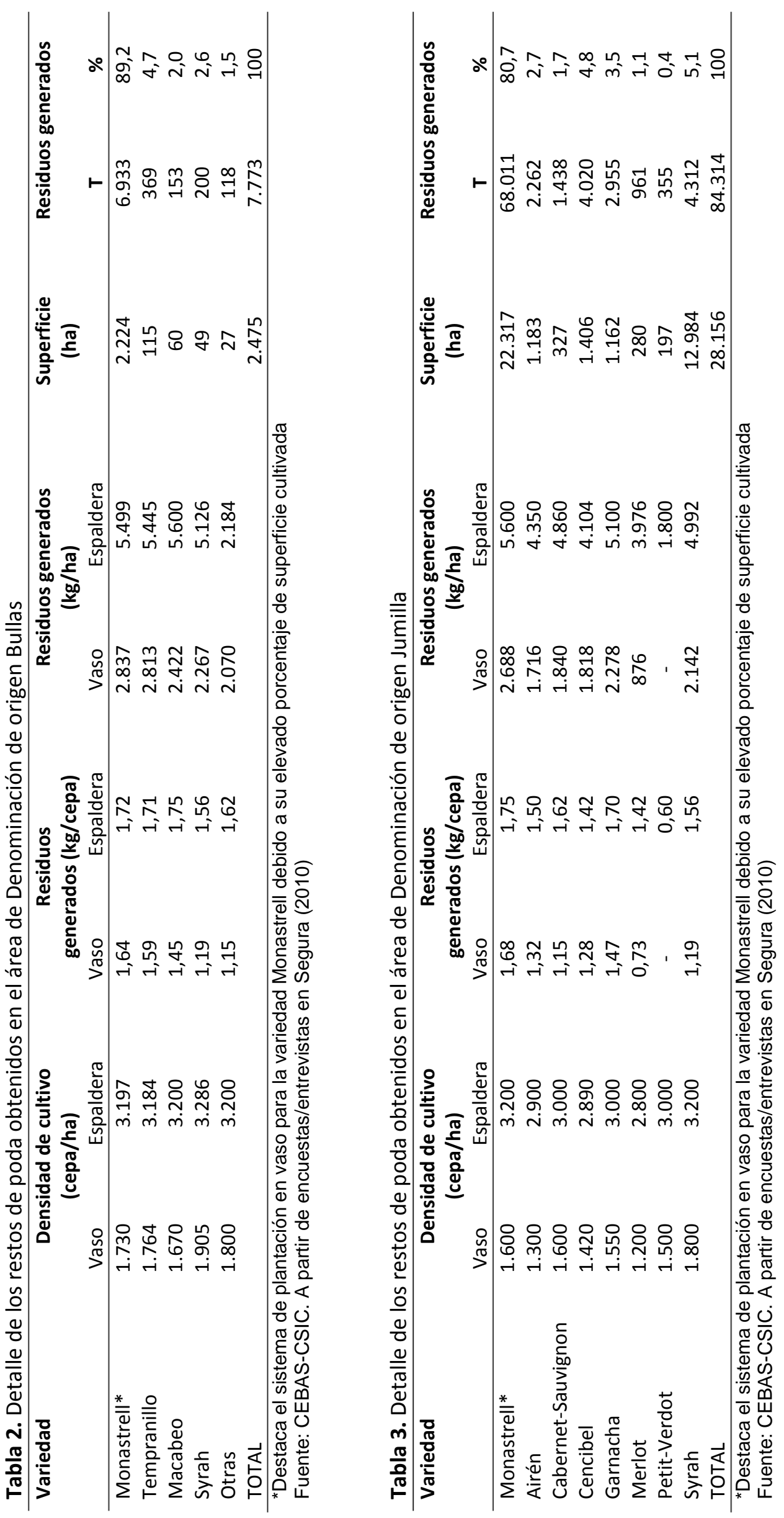
Teniendo en cuenta la superficie de cultivo del año 2013 en la Región de Murcia (25.724 ha), el potencial anual de poda de vid es de 77.172 toneladas, pero con un elevado volumen en relación con su peso. Dado que los municipios de Jumilla y Yecla son los que mayor superficie de viñedos tienen, la comarca del Altiplano es el foco prioritario de estos residuos con cerca del $85 \%$ de la producción. La comarca del Noroeste solo presenta 3.360 toneladas de residuos de poda de vid al año. Además, estos residuos están sujetos a la estacionalidad de las operaciones que los generan. En concreto, enero y febrero son los meses de generación de estos residuos potencialmente valorizables. Estos datos indican la importancia de este potencial para las áreas involucradas, que mediante sistemas de gestión que valoricen los mismos, pueden crear nuevas oportunidades de negocio al tiempo que minimizan los efectos medioambientales negativos de otras vías de gestión.

\subsection{Caracterización de los restos de poda de vid}

En la Tabla 4 se muestra la caracterización de estos residuos/subproductos. El contenido en humedad es bajo, aunque varía según el momento de la medición, dependiente del régimen de lluvias o el secado en el campo previo a su traslado al punto de almacenamiento donde se toma la muestra. Del resto de parámetros se puede indicar su alto contenido en materia orgánica y alta relación $\mathrm{C} / \mathrm{N}$.

Tabla 4. Caracterización físico-química, de metales pesados y de plaguicidas de la poda de vid. Datos expresados en peso seco, excepto el contenido en plaguicidas (peso fresco)

\begin{tabular}{lcc}
\hline Parámetros & Unidades & Media \pm error estándar \\
\hline Físico-químicos & & $6,43 \pm 0,01$ \\
$\mathrm{pH}$ & $\mathrm{dS} / \mathrm{m}$ & $1,55 \pm 0,01$ \\
Conductividad eléctrica & $\%$ & $27,02 \pm 6,49$ \\
Humedad & $\%$ & $49,19 \pm 2,53$ \\
Carbono orgánico total & $\%$ & $0,78 \pm 0,61$ \\
Nitrógeno & $\%$ & $0,11 \pm 0,01$ \\
Fósforo & $\%$ & $0,46 \pm 0,05$ \\
Potasio & & $64,35 \pm 5,70$ \\
Relación C/N & & \\
Metales pesados & $\mathrm{mg} / \mathrm{kg}$ & $3,77 \pm 0,70$ \\
Cd & $\mathrm{mg} / \mathrm{kg}$ & $4,86 \pm 1,76$ \\
Cu & $\mathrm{mg} / \mathrm{kg}$ & $0,02 \pm 0,01$ \\
$\mathrm{Cr}$ & $\mathrm{mg} / \mathrm{kg}$ & $1,73 \pm 0,37$ \\
$\mathrm{Ni}$ & $\mathrm{mg} / \mathrm{kg}$ & $0,81 \pm 0,37$ \\
Pb & $\mathrm{mg} / \mathrm{kg}$ & $12,54 \pm 3,25$ \\
Zn & $\mathrm{mg} / \mathrm{kg}$ & $0,003 \pm 0,00$ \\
$\mathrm{Hg}$ & $\mathrm{mg} / \mathrm{kg}$ & $0,13 \pm 0,04$ \\
As & & \\
Plaguicidas & $\mathrm{mg} / \mathrm{kg}$ & $<\mathrm{LQ}$ \\
Organoclorados y organofosforados & & \\
(ver Apéndice) & & \\
\hline LQ: Límite de cuantificación & &
\end{tabular}


Por otro lado, según el análisis a restos de poda de vid realizado por Romero (2005), los sarmientos y la madera proveniente de la poda de la vid presentan un contenido medio-bajo de humedad y un alto contenido en celulosa y lignina (Tabla 5). Esta caracterización estuvo enfocada al uso de la poda de vid como biomasa, por lo que también el autor determinó su poder calorífico inferior ( $\mathrm{PCI})$.

Tabla 5. Caracterización de los restos de poda de vid para su uso como biomasa

\begin{tabular}{lcc}
\hline Parámetros & Unidades & Valor \\
\hline Celulosa & $\%$ & 35,61 \\
Hemicelulosa & $\%$ & 39,20 \\
Lignina & $\%$ & 23,43 \\
Humedad residual & $\mathrm{kg}$ agua $/ 100 \mathrm{~kg}$ residuo seco & 10,54 \\
$\mathrm{PCl}$ & $\mathrm{kcal} / \mathrm{kg}$ & 4.500 \\
\hline
\end{tabular}

Fuente: Romero (2005)

$\mathrm{PCl}$ : Poder calorífico inferior

\subsection{Opciones de valorización de los restos de poda de vid}

En vista de los resultados obtenidos de potencial de residuos/subproductos en el cultivo de viñedos y la gestión actual del mismo se procede a presentar diferentes alternativas que brinden una solución viable para el sector.

Muchos autores han propuesto el uso de podas de vid como una fuente renovable de azúcares que pueden ser convertidos en varios productos (Devesa-Rey et al., 2011). Entre ellos, Rivas et al. (2007) y Portilla et al. (2008) propusieron la producción de ácido láctico y xilitol de los sarmientos de vid, además de biosurfactantes. Las podas también contienen ácidos hidroxicinámico e hidrobenzoico, compuestos ampliamente utilizados en alimentación y en la industria farmacéutica y cosmética, que pueden ser obtenidos después de tratamientos de hidrólisis (Max et al., 2009, 2010). Según Peralbo-Molina y Luque de Castro (2013), el interés nutraceutico de la poda de vid debería ser evaluado por los beneficios para la salud que tienen los compuestos fenólicos. Además, según Jimenez et al. (2004; 2006a), la poda también tiene una salida en la industria del papel, ya que en las zonas con un alto cultivo de viñedos la obtención de pulpa de papel es una alternativa, como también indicaron Mansouri et al. (2012). Otra opción es su utilización como bioadsorbente de metales pesados en aguas residuales (Karaoğlu et al., 2010). Sin embargo, el desarrollo de estos procesos industriales aún encuentra dificultades.

Por otro lado, la poda puede ser empleada como alimento de ganado, así Molina-Alcaide et al. (2008) estudiaron la composición química de la poda de vid con otros subproductos del proceso de vinificación, así como la digestibilidad intestinal de sus nutrientes, y encontraron que puede constituir una fuente válida de energía y proteínas para los rumiantes. Aun así, esta práctica no está extendida.

Para los restos de poda las alternativas propuestas están relacionadas con su uso en aplicación agrícola y como biomasa para la producción de energía, teniendo en 
cuenta que se trata de valorizaciones finalistas y de gran interés en el ámbito agroindustrial, aunque entre ellas se puede destacar la obtención de compost. En la Tabla 6 se resumen las opciones de valorización seleccionadas y se indican características de interés. 


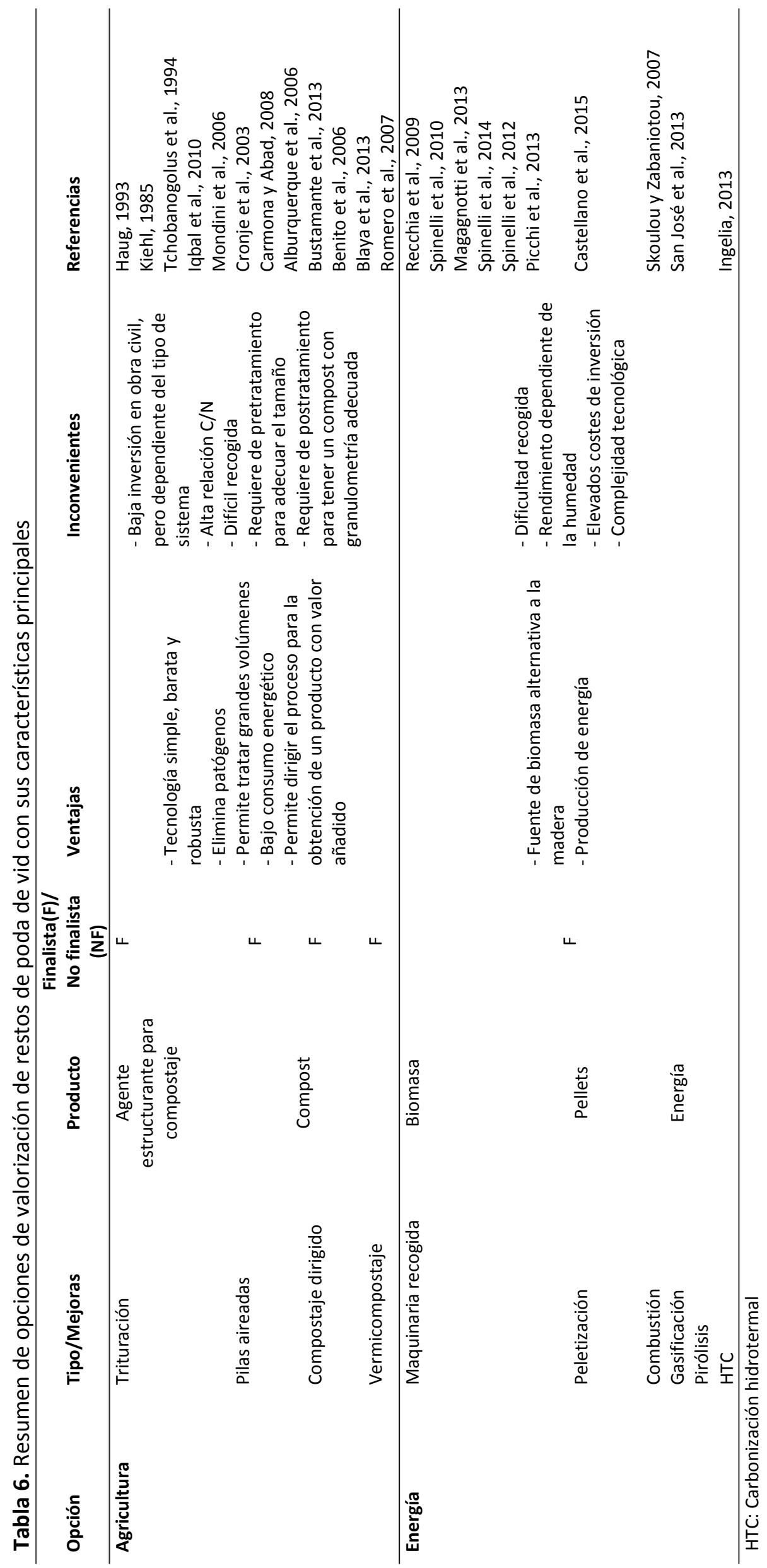




\subsubsection{Valorización agrícola}

La utilización de los sarmientos como enmienda del suelo es una de las alternativas de valorización de los mismos; aunque para ello se requiere de un acondicionamiento previo, como puede ser un troceado antes de ser introducido en el suelo, o bien tratamientos de compostaje que estabilicen y valoricen el efecto de los sarmientos en el suelo.

Los restos de poda de vid pueden ser compostados, al igual que otros materiales orgánicos, para obtener un compost de calidad que pueda utilizarse como enmienda orgánica o sustrato de cultivo; sin embargo, la efectividad del tratamiento depende del control del proceso de compostaje que asegure una correcta proliferación microbiana y, por consiguiente, una adecuada mineralización de la materia orgánica (Cronje et al., 2003). Además, para que el proceso se pueda iniciar deben cumplirse unas condiciones iniciales de composición (relación $\mathrm{C} / \mathrm{N}$ ), humedad y estructura (porosidad).

Los restos de cultivos leñosos presentan un alto contenido en carbono y poco nitrógeno, y por lo tanto una alta relación $\mathrm{C} / \mathrm{N}$ para que el proceso tenga lugar de manera óptima (el intervalo óptimo para la mayoría de residuos orgánicos está entre 25 y 35); además de, una baja humedad. Se trata de un material cuyo proceso transcurrirá muy lento debido a las dificultades que encontrarán los microorganismos de acceder al nitrógeno como nutriente, la competencia entre ellas limitará la reproducción de sus poblaciones y por tanto su acción descomponedora será reducida. También requerirá de la adición de agua para favorecer el crecimiento de los microorganismos, pero sin que pueda llegar a impedir que el oxígeno entre en los poros.

Por su parte, la porosidad viene dada por la estructura del material y puede ser necesario reducir su tamaño para favorecer la descomposición, ya que cuanto mayor sea la superficie expuesta al ataque microbiano por unidad de masa, más rápida y completa será la reacción, pero sin que el producto sea muy fino para evitar la compactación y que por tanto se limite la aireación. Las dimensiones consideradas óptimas son distintas según los criterios de distintos autores, variando entre 1 y $5 \mathrm{~cm}$ (Haug, 1993), entre 2 y $5 \mathrm{~cm}$ (Kiehl, 1985) o entre 2,5 y 2,7 cm (Tchobanogolus et al., 1994).

El compostaje es un proceso aerobio, por lo que se debe garantizar la presencia de oxígeno en todo momento. Las pilas de compostaje presentan porcentajes variables de oxígeno en el aire de sus espacios libres: la parte más externa contiene casi tanto oxígeno como el aire (18-20\%); hacia el interior el contenido de oxígeno va disminuyendo, mientras que el de dióxido de carbono va aumentando, hasta el punto de que a una profundidad mayor de $60 \mathrm{~cm}$ el contenido de oxígeno puede estar entre 
0,5 y $2 \%$ (Ekinci et al., 2004). Para evitar problemas de aireación se utilizan agentes estructurantes durante el compostaje.

Desde un punto de vista práctico, los agentes estructurantes deben ser materiales fibrosos orgánicos con bajo contenido en humedad (Miner et al., 2001; Eftoda y McCartney, 2004; Iqbal et al., 2010), como son los restos de poda. No obstante también el compostaje de estos materiales lignocelulósicos se lleva a cabo y puede presentar más ventajas que inconvenientes según Mondini et al. (2006): 1) su recogida selectiva es mucho más fácil que el de otras materias primas, como los residuos sólidos urbanos; 2) la tecnología necesaria para el compostaje de estos materiales es más simple, ya que no producen olores, para que puedan ser compostados adecuadamente en pilas; y 3) que, por lo general, presentan buenas propiedades físicas y bajas concentraciones de elementos potencialmente tóxicos y otros contaminantes.

Por tanto, el compostaje es una opción de valorización de especial interés, puesto que permite trabajar adicionando e integrando diversos materiales, y más cuando las materias brutas no presentan separadamente las características idóneas, de tal manera que se pueden combinar varias para obtener mezclas adecuadas de tal forma "que no falte de nada y todo esté en la adecuada proporción". Así, la industria agroalimentaria puede gestionar de manera integral la variedad de biorresiduos que genera, desde podas de cultivos a restos vegetales de procesos de transformación y residuos del tratamiento de sus aguas residuales. Estos dos últimos, por su elevado contenido de humedad y baja estructura debida a la ausencia de lignina y celulosa, dificultan el proceso de compostaje y por lo tanto requieren de un soporte estructural para que se formen espacios y poros que mejoren el movimiento del aire en el interior de las pilas de compostaje, además de regular el contenido de agua. También estos dos suelen poseer una relación $\mathrm{C} / \mathrm{N}$ baja (inferior a 18-19), que hacen que el proceso de compostaje se lleve a cabo rápidamente (Golueke et al., 1987; Zhu, 2006), pero se desprende el nitrógeno en exceso en forma de amoniaco, produciéndose una autorregulación de la relación C/N (Jhorar et al., 1991). Estas pérdidas, si bien no afectan negativamente al compostaje, sí que reducen la concentración de nitrógeno en el compost final, siendo el nitrógeno un nutriente fundamental para los cultivos. Con la adición de los restos de poda se puede ajustar la relación $\mathrm{C} / \mathrm{N}$ a un intervalo óptimo para que se produzca un proceso de compostaje adecuado en el que se obtenga un compost de calidad.

Cabe recordar que, independientemente del método de compostaje utilizado, la transformación acelerada afecta fundamentalmente a los materiales fácilmente biodegradables (hidratos de carbono, etc.) por lo que el proceso debe completarse con una estabilización al aire libre, que permita el ataque de los materiales lentamente biodegradables (lignocelulósicos). 
Una vez completado el proceso de compostaje, puede ser necesario cribar el compost maduro dándole una forma esponjosa, homogénea y de granulometría apropiada para la aplicación a la que se destine; por ejemplo, para la aplicación del compost en semilleros, la granulometría debería estar entre 0,25 y $5 \mathrm{~mm}$ (Carmona y Abad, 2008). La parte más gruesa que se obtiene durante este proceso, formada principalmente por los materiales leñosos más resistentes a la descomposición, se puede incorporar al compost final mediante molienda, o se puede recuperar para volver a incorporar como material estructurante de nuevas pilas, con la ventaja de llevar ya disponible los microorganismos que deben iniciar la colonización. En muchos casos, debido a las altas tasas de aportación de estructurante para conseguir una textura adecuada de las pilas, es de gran interés, sobre todo económico, recuperar este material que puede llevar en algunos de los casos un coste asociado de adquisición, cuando no se pueda disponer de suficiente cantidad de restos de poda.

En la bibliografía se pueden encontrar diversos estudios donde se evalúan diferentes materiales como agentes estructurantes (Georgacakis et al., 1996; Tognetti et al., 2007; Adhikari et al., 2008, 2009; Chang y Chen, 2010; lqbal et al., 2010). En concreto para el caso de la vid podemos encontrar estudios como el de Alburquerque et al. (2006), que evaluaron tallos de la vid y hojas del olivo para tratar por compostaje el alperujo, y el de Bustamante et al. (2013) que utilizaron restos de poda de vid para el tratamiento de la fracción sólida del digerido de purines, obteniendo un compost con características finales adecuadas para uso agrícola.

En cuanto al compostaje de restos de poda, también son varios los estudios que se han llevado a cabo para ellos solos. Benito et al. (2006) evaluaron las características de diferentes compost de podas y obtuvieron que el compost presenta una relación $\mathrm{C} / \mathrm{N}$ alta debido a la materia recalcitrante del material de partida, pero que puede ser un componente aceptable de un sustrato para el crecimiento de plantas ornamentales. También Blaya et al. (2013) evaluaron compost de poda de vid para su uso como sustratos de cultivo, que mostraron alto contenido en nutrientes en comparación con la turba, además de efecto supresivo frente a Fusarium. Estos mismos autores, al inicio de la fase de maduración adicionaron Trichoderma harzianum y observaron que el mayor grado de supresividad se alcanzó en este compost debido a su capacidad biocontrol. Por lo tanto, el tratamiento mediante compostaje también permite dirigir el proceso para obtener un producto con efecto mejorador.

Por otro lado, Romero et al. (2007) realizaron experiencias de vermicompostaje con materiales de la industria vitivinícola y restos de poda de vid, y obtuvieron que este tratamiento también es adecuado para la transformación de la materia fresca en formas húmicas, mejorando así la calidad de estos materiales como enmiendas orgánicas del suelo. 


\subsubsection{Valorización energética}

La poda de vid es una forma de biomasa que puede emplearse para la generación de energía térmica con producción de calor y agua caliente sanitaria, pudiendo abastecer desde pequeños hogares a ciudades e industrias al sustituir antiguas calderas de combustibles fósiles por nuevas calderas de biomasa. También la poda puede emplearse con fines de producción eléctricos, destacando que no se necesitan tratamientos especiales. En el primer caso, la combustión directa es la tecnología más empleada, mientras que en el segundo caso, la tecnología más desarrollada está basada en instalaciones de combustión en pequeños sistemas de gasificación acoplados a motogeneradores (Agencia extremeña de la energía, 2015). El contenido energético de la biomasa, en base a su poder calorífico inferior, es una de las propiedades para su utilización como combustible a estos sistemas. Según diversos autores (Spinelli et al., 2012; Picchi et al., 2013), el uso de la poda de vid como biomasa, podría sustituir los usos tradicionales de la madera en la producción de energía.

Es destacable que la producción y obtención de esta biomasa desde la explotación agrícola, con fines energéticos o eléctricos, debe estar mecanizada para optimizar los costes. En este aspecto es amplia la maquinaria (tractores) que se ha propuesto y evaluado para la implementación de la recogida de la poda de vid (Recchia et al., 2009; Spinelli et al., 2010; Magagnotti et al., 2013), incluso en zonas de difícil acceso como la montaña (Spinelli et al., 2014). Además, requiere de un pretratamiento tales como reducción de la granulometría, para posibilitar su manejo, almacenaje y fundamentalmente transporte; y reducción de humedad mediante secado natural o forzado. En la actualidad existen numerosas tecnologías y son también numerosas las casas que comercializan la maquinaria, y que por tanto favorecen este tipo de gestión.

Sin embargo, el inconveniente de este método de gestión es de índole técnicoeconómico. Un agricultor individual medio no tiene capacidad por sí mismo para, adquirir la maquinaria necesaria para triturar los restos de poda $\mathrm{y}$, gestionar el almacenamiento y transporte a planta de los restos, por lo que la asociación de productores agrícolas es la forma para conseguir que el proceso global le sea viable económicamente. Otra opción es subcontratar los servicios a empresas gestoras que enfoquen su actividad en la producción de biomasa que directamente la aporte a plantas eléctricas o bien produzcan pellets para su comercialización. En este aspecto, la peletización es una tecnología que permite obtener un biocombustible de baja humedad, denso y uniforme que puede ser utilizado en diferentes aplicaciones, incluyendo estufas domésticas, calderas y plantas industriales de energía. Castellano et al. (2015) estudiaron la peletización de materiales residuales como la poda de vid y determinaron que dichos pellets, con un alto contenido en lignina, tienen una alta durabilidad mecánica y una baja fracción de finos. Por lo tanto, en lo relativo a estos 
parámetros pueden clasificarse como pellets de calidad teniendo en cuenta las especificaciones de la norma EN-1491-2 para pellets de madera.

La combustión, la gasificación y la pirólisis se consideran métodos de explotación para los residuos agrícolas (Skoulou y Zabaniotou, 2007), con numerosas tecnologías aplicadas, más o menos novedosas, como las que han sido probadas para la poda de vid (San José et al., 2013).

La combustión directa es un método termoquímico en el que se produce la oxidación completa de la biomasa (leñas, maderas, briquetas, pellets, etc.) liberando gran cantidad de calor. El proceso se produce normalmente en exceso de oxígeno, alcanzando temperaturas entre $800-1.100{ }^{\circ} \mathrm{C}$ y en un sistema que tiene como elemento principal una caldera u horno (Masera et al., 2005). La tecnología de parrilla es la más difundida para la combustión de la biomasa. El horno se compone esencialmente de parrilla (fija, horizontal e inclinada, móvil o vibratoria) y de la cámara de combustión, que hace posible la combustión de los gases y cuyas paredes están revestidas interiormente por un material refractario. Para grandes equipos está en auge la tecnología de lecho fluidizado, que se está utilizando tanto en grandes plantas térmicas, como termoeléctricas alimentadas con biomasa. La tecnología de lecho fluidizado presenta la ventaja de trabajar a temperaturas inferiores, unos $800{ }^{\circ} \mathrm{C}$ frente a los alrededor de $1.000{ }^{\circ} \mathrm{C}$ que trabajan los equipos de parrilla, lo que disminuye las emisiones de óxidos de nitrógeno y la formación de aglomerados y escorias producidos en la combustión de la biomasa.

A parte de estas tecnologías de combustión existe un desarrollo muy importante en plantas de gasificación. Se trata también de un proceso termoquímico en el que un sustrato carbonoso (carbón, biomasa, restos agrícolas) es transformado en un gas combustible mediante una serie de reacciones que ocurren en presencia de un agente gasificante (generalmente aire), en un ambiente pobre en oxígeno a unas temperaturas entorno a los $400{ }^{\circ} \mathrm{C}$. El gas obtenido está constituido fundamentalmente por metano, hidrógeno y monóxido de carbono, que es susceptible de ser utilizado como combustible en ciclos de generación eléctrica. En las mismas se da el proceso denominado pirólisis, en el que se produce un residuo final denominado biochar, formado principalmente por carbono y gases condensables (hidrocarburos ligeros y pesados) y no condensables (metano, vapor de agua, monóxido de carbono, hidrógeno y dióxido de carbono) (Rodríguez et al., 2004). Cuando la temperatura del biochar supera los $700{ }^{\circ} \mathrm{C}$, tienen lugar las reacciones propias de gasificación, que se dividen en reacciones heterogéneas (el biochar reacciona con oxígeno, vapor de agua, dióxido de carbono e hidrógeno) y homogéneas (los gases reaccionan entre sí).

Para la producción de energía eléctrica, las plantas se basan en sistemas convencionales (ciclo Rankine) empleados por el sector térmico y que son utilizados en la práctica totalidad de las actuales plantas comerciales de biomasa. Estos ciclos se 
desarrollan en una caldera donde se genera vapor que alimenta a una turbina acoplada a su vez por un alternador.

En otro campo, aunque relacionado con la energía, se encuentra la obtención de algunos productos mediante tratamientos térmicos de conversión de la biomasa. La carbonización hidrotermal, probada para restos de poda de jardines (Ingelia, 2013) y de aplicación potencial para los restos de poda de vid, permite producir un biocombustible sólido para una utilización posterior.

\section{Conclusión}

El estudio realizado permite constatar el elevado volumen de biorresiduos/subproductos en el cultivo de viñedos. En este estudio se opta por proporcionar y transferir una solución directa y efectiva como es la valorización mediante compostaje para la obtención de compost, puesto que otras soluciones como fuente de biomasa, o extracción de compuestos de interés, requiere de una mayor capacidad técnico-económica por parte de los viticultores, y por tanto con una mayor dificultad de implantación. El compostaje, es por tanto una opción directa, efectiva, sencilla de implementar y con un coste de inversión reducido, lo que garantiza su viabilidad. Además, permite gestionar y valorizar conjuntamente otros tipos de biorresiduos generados en la industria agroalimentaria y dirigir el proceso hacia la obtención de compost y biomateriales más sofisticados y de mayor valor añadido.

\section{Bibliografía}

Adhikari B. J., Barrington S., Martínez J., King S., 2008. Characterization of food waste and bulking agents for composting. Waste Manage. 28, 795-804.

Adhikari, B. J., Barrington, S., Martínez, J., King, S., 2009. Effectivness of three bulking agents for food waste composting. Waste Manage. 29, 197-203.

Agencia extremeña de la energía, 2015. Los residuos agrícolas de poda. Disponible en: http://www.agenex.net/images/stories/deptos/residuos-agricolas-de-poda.pdf

Alburquerque, J.A., González, J., García, D., Cegarra, J., 2006. Effects of bulking agent on the composting of "alperujo", the solid by-product of the two-phase centrifugation method for olive oil extraction. Process Biochem. 41, 127-132.

Askew, M.F., Holmes, C.A., 2002. Potential for biomass energy crops agriculture Europe land use policy rural economy terms. Int. sugar J. 104(1247), 482-591 (Reprinted Aspects Appl Biol 2001; 65: 365-374).

Benito, M., Masaguer, A., Moliner, A., De Antonio, R., 2006. Chemical and physical properties of pruning waste compost and their seasonal variability. Bioresour. Technol. 97, 2071-2076.

Blaya, J., Lopez-Mondejar, R., Lloret, E., Pascual, J.A., Ros, M., 2013. Changes induced by Trichderma harzianum in suppressive compost controlling Fusarium wilt. Pestic. Biochem. Physiol. 107, 112-119. 
BOE, 2002. Ley 43/2002, de 20 de noviembre, de sanidad vegetal. Boletín Oficial del Estado 279, 4097040988.

BOE, 2011. Ley 22/2011, de 28 de julio, de residuos y suelos contaminados. Boletín Oficial del Estado $181,85650-85705$.

BORM, 2006. Orden de 24 de mayo de 2006, de la Consejería de Agricultura y Agua, por la que se aprueba el Reglamento de la Denominación de Origen Bullas y de sus órganos de gestión y control. Boletín Oficial de la Región de Murcia 133, 18160- 18173.

Bustamante, M.A., Restrepo, A.P., Alburquerque, J.A., Pérez-Murcia, M.D., Paredes, C., Moral, R., Bernal, M.P., 2013. Recycling of anaerobic digestates by composting: effect of the bulking agent used. J. Clean. Prod. 47, 61-69.

Carmona, E., Abad, M., 2008. Aplicación del compost en viveros y semilleros. En: Moreno, J., Moral, R. (Eds.), Compostaje. Madrid. Mundi-Prensa. pp. 397-424.

Castellano, J.M., Gómez, M., Fernández, M., Esteban, L.S., Carrasco, J.E., 2015. Study on the effects of raw materials composition and pelletization conditions on the quality and properties of pellets obtained from different woody and non woody biomasses. Fuel 139, 629-636.

Chang, J.I., Chen, Y.J., 2010. Effects of bulking agents on food waste composting. Bioresour. Technol. 101, 5917-5924.

CREM, 2015. Datos estadísticos de la Región de Murcia. Centro Regional de Estadística de la Región de Murcia. Disponible en: http://www.carm.es/econet/sicrem/PU_datosBasicos/sec49.html.

Cronje, A., Turner, C., Williams, A., 2003. Composting under controlled conditions. Environ. Technol. 24(10), 1221-1234.

Devesa-Rey, R., Vecino, X., Varela-Alende, J.L., Barral, M.T., Cruz, J.M., Moldes, A.B., 2011. Valorization of winery waste vs. the costs of not recycling. Waste Manage. 31, 2327-2335.

Eftoda, G., McCartney, D., 2004. Determining the critical bulking requirement for municipal solid biosolids composting. Compos. Sci. Util. 12(3), 208-218.

Ekinci, K., Keener, H.M., Elwell, D.L., 2004. Effects of aeration strategies on the composting process: Part I. Experimental studies. Trans. ASAE 47(5), 1697-1708.

EPA, 1998. Method EPA 3015. Microwave Assisted Acid Digestion of Sediments, Sludges, Soils and Oils. Washington, DC.

Georgacakis, D., Tsavdaris, A., Bakouli, J. Symeonidis, S., 1996. Composting solid swine manure and lignite mixtures with selected plant residues. Bioresour. Technol. 56, 195-200.

Golueke, C.G., Diaz, L.F. 1987. Composting and the Limiting Factors Principle. Biocycle 28(4), 22-25.

Haug, R.T., 1993. The Practical Handbook of Compost Engineering. California. USA. Lewis Publishers. pp. 717.

Ingelia, 2013. Entrevista personal.

Iqbal, M.K., Shafiq, T., Ahmed, K., 2010. Characterization of bulking agents and its effects on physical properties of compost. Bioresour. Technol. 101, 1913-1919.

Jackson, R.S., 2000. Vineyard practice. Wine Science (2nd Edition). pp. 96-203.

Jhorar, B.S., Phogat, V., Malik, E., 1991. Kinetics of composting rice straw with glue waste at different $\mathrm{C} / \mathrm{N}$ ratios in a semiarid environment. Arid Soil Rest. Rehabil. 5, 297-306. 
Jimenez, L., Angulo, V., De La Torre, M.J., Ramos, E., Caparros, S., Perez, A., 2006a. Simulation of the hydrothermal treatment applied to the wine shoots, like previous stage in the cellulose paste production. Afinidad 63(524), 277-285.

Jimenez, L., Angulo, V., García, G., Rodriguez, A., 2004. Obtención de pastas de celulósicas a partir de sarmiento de vid. Afinidad 61(511), 194-203.

Jiménez, L., Angulo, V., Ramos, E., De la Torre, M.J., Ferrer, J. L., 2006b. Comparison of various pulping processes for producing pulp from vine shoots. Ind. Crop. Prod. 23(2), 122-130.

Karaoğlu, M.H., Zor, Ş., Uğurlu, M., 2010. Biosorption of $\mathrm{Cr}(\mathrm{III})$ from solutions using vineyard pruning waste. Chem. Eng. J. 159, 98-106.

Kiehl, F.J., 1985. Fertilizantes orgânicos. Sâo Paulo. Editora Agronômica Ceres Ltda.

Kitson, R.E., Mellon, M.G., 1944. Colorimetric determination of P as molybdovanato phosphoric acid. Ind. Eng. Chem. 42(3), 379-383.

Magagnotti, N., Pari, L., Picchi, G., Spinelli, R., 2013. Technology alternatives for tapping the pruning residue resource. Bioresour. Technol. 128, 697-702.

MAGRAMA, 2012. Producción y consumo sostenibles y residuos agrarios. Disponible en: http://www.magrama.gob.es/es/calidad-y-evaluacion-

ambiental/publicaciones/Residuos_agrarios_tcm7-232332.pdf

Mansouri, S., Khiaria, R., Bendouissa, N., Saadallah, S., Mhenni, F., Mauret, E., 2012. Chemical composition and pulp characterization of Tunisian vine stems. Ind. Crop. Prod. 36, 22-27.

Masera O. R., Aguillón J., Gamino B., 2005. Estimación del recurso y prospectiva tecnológica de la biomasa como energético renovable en México. Universidad Nacional Autónoma de México. México.

Max, B., Salgado, J.M., Rodríguez, N., Cortés, S., Converti, A., Domínguez, J.M., 2010. Biotechnological production of citric acid. Brazilian J. Microbiol. 41(4), 862-875.

Max, B., Torrado, A.M., Moldes, A.B., Converti, A., Domínguez, J.M., 2009. Ferulic acid and p-coumaric acid solubilization by alkaline hydrolysis of the solid residue obtained after acid prehydrolysis of vine shoot prunings: effect of the hydroxide and pH. Biochem. Eng. J. 43(2), 129-134.

Miner, F.D., Koeing, R., Miller, B.E., 2001. The influence of bulking material type and volume on in-house composting in high-rise, caged layer, facilities. Compos. Sci. Util. 9, 50-59.

Molina-Alcaide, E., Moumen, A., Martín-García, A.I., 2008. By-products from viticulture and the wine industry: potential as sources of nutrients for ruminants. J. Sci. Food Agric. 88(4), 597-604.

Mondini, C., Sánchez-Monedero, M.A., Sinicco, T., Leita, L., 2006. Evaluation of extracted organic carbon and microbial biomass as stability parameters in ligno-cellulosic waste composts. J. Environ. Qual. 35, 2313-2320.

Navarro, A.F., Cegarra, J., Roig, A., Bernal, M.P., 1991. An automatic microanalysis method for the determination of organic carbon in wastes. Commun. Soil Sci. Plant Anal. 22, 2137-2144.

Peralbo-Molina, A., Luque de Castro, M.D., 2013. Potential of residues from the Mediterranean agriculture and agrifood industry. Trends Food Sci.Technol. 32, 16-24.

Perpiñá, C., Alfonso, D., Pérez-Navarro, A., Peñalvo, E., Vargas, C., Cárdenas, R., 2008. Methodology based on geographic information systems for biomass logistics and transport optimisation. Renew. Energ. 34, 555-565.

Picchi, G., Silvestri, S., Cristoforetti, A., 2013. Vineyard residues as a fuel for domestic boilers in Trento Province (Italy): Comparison to wood chips and means of polluting emissions control. Fuel 113, 43-49. 
Portilla, O., Rivas, B., Torrado, A., Moldes, A.B., Domínguez, J.M., 2008. Revalorisation of vine trimming wastes using Lactobacillus acidophilus and Debaryomyces hansenii. J. Sci. Food Agric. 88(13), 2298-2330.

Recchia, L., Daou, M., Remediotti, M., Cini, E., Vieri, M., 2009. New shredding machine for recycling pruning residuals. Biomass Bioenergy 33, 149-154.

Rivas, B., Torrado, A., Rivas, S., Moldes, A.B., Domínguez, J.M., 2007. Simultaneous lactic acid and xylitol production from vine trimming wastes. J. Sci. Food Agric. 87(8), 1603-1612.

Rodríguez, M., Corvalán, P., Gutiérrez, M., 2004. La utilización potencial de la biomasa forestal en Chile como fuente de energía. Segundo Congreso Chileno de Ciencias Forestales. Universidad Austral de Chile. $17 \mathrm{pp}$.

Romero, F.J., 2005. Central térmica de biomasa de $5 \mathrm{MW}$ de potencia. Proyecto Fin de carrera. Escuela Universitaria de Ingeniería Técnica Agrícola de Ciudad Real. Universidad de Castilla-La Mancha. Ciudad Real. España.

Romero, E., Plaza, C., Senesi, N., Nogales, R., Polo, A., 2007. Humic acid-like fractions in raw and vermicomposted winery and distillery wastes. Geoderma 139, 397-406.

San José, M.J., Alvarez, S., García, I., Peñas, F.J., 2013. A novel conical combustor for thermal exploitation of vineyard pruning wastes. Fuel 110, 178-184.

Segura, P., 2010. Encuestas y entrevistas a viticultores de la Región de Murcia del año 2010. Datos CEBAS-CSIC.

Skoulou, V., Zabaniotou, A., 2007. Investigation of agricultural and animal wastes in Greece and their allocation to potential application for energy production. Renew. Sust. Energ. Rev. 11, 1698-1719.

Spinelli, R., Lombardini, C., Pari, L., Sadauskiene, L., 2014. An alternative to field burning of pruning residues in mountain vineyards. Ecol. Eng. 70, 212-216.

Spinelli, R., Magagnotti, N., Nati, C., 2010. Harvesting vineyard pruning residues for energy use. Biosyst. Eng. 105, 316-322.

Spinelli, R., Nati, C., Pari, L., Mescalchin, E., Magagnotti, N., 2012. Production and quality of biomass fuels from mechanized collection and processing of vineyard pruning residues. Appl. Energy 89, 374-379.

Tchobanogolus, G., Theisen, H., Vigil, S., 1994. Gestión integral de residuos sólidos. Madird. McGrawHill. 1107 pp.

Tognetti, C., Mazzarino, M.J., Laos, F., 2007. Improving the quality of municipal organic waste compost. Bioresour. Technol. 98, 1067-1076.

Velázquez-Martí, B., Fernández-González, E., López-Cortés, I., Salazar-Hernández, D.M., 2011. Quantification of the residual biomass obtained from pruning of vineyards in Mediterranean area. Biomass Bioenergy 35, 3453-3464.

Zhu, N.W., 2006. Composting of high moisture content swine manure with corncob in a pilot-scale aerated static bin system. Bioresour. Technol. 97(15), 1870-1875. 


\section{Gestión de lodos agroalimentarios mediante diferentes estrategias de co-compostaje: estudio del valor añadido de los compost obtenidos}





\section{Gestión de lodos agroalimentarios mediante diferentes estrategias de co-compostaje: estudio del valor añadido de los compost obtenidos}

\section{Introducción}

La industria agroalimentaria es la principal actividad de la industria manufacturera europea, representando el 14,6 \% de su facturación total y un valor superior a los 1.048 .000 millones de euros, con un incremento del 3,1 \% respecto al año anterior (MAGRAMA, 2015). Los procesos de producción de este sector industrial presentan un gran consumo de agua, generando efluentes con una elevada carga orgánica, a causa de la aportación de restos vegetales; compuestos solubles en agua tales como proteínas, carbohidratos, compuestos fenólicos, etc.; o bien de restos de aceites y grasas empleados en el proceso industrial en el que se generan.

En los últimos años, las empresas del sector agroalimentario, que comprende los transformados de frutas y hortalizas, zumos y congelados de hortalizas han mejorado notablemente la calidad de sus procesos productivos y han instalado sistemas de depuración de aguas para tratar sus vertidos orgánicos, de acuerdo con la Directiva 91/271/CEE de 21 de mayo (DOCE, 1991). El tratamiento biológico es el proceso utilizado más comúnmente para tratar aguas residuales de contenido orgánico (Christensen et al., 2009) y ricas en nutrientes (Najafpour et al., 2006) como son las aguas de industrias alimentarias, pero generan un "nuevo" residuo orgánico, el denominado lodo de depuración agroalimentario. Dichos lodos se caracterizan por ser producidos en áreas de producción concentrada, por ejemplo, en un área como la Región de Murcia (11.000 km²) se produjo un volumen de más de 15.000 toneladas en la campaña 2011/2012, previéndose un crecimiento de los mismos hasta 40.000 toneladas anuales para el año 2020 (AGROWASTE, 2014).

Este tipo de residuo es similar a los producidos en las estaciones de depuradoras de aguas residuales urbanas, aunque cabe destacar como principal diferencia la no presencia en cuanto a metales pesados (Kang et al., 2011), u otro elemento de naturaleza tóxica, puesto que proceden de la depuración de aguas residuales cuyo origen es materia orgánica de origen vegetal. Por ello, estos lodos presentan un alto potencial para su uso agrícola, debido a su alto contenido en nutrientes, tales como nitrógeno y fósforo (Singh y Agrawal, 2008; Cheng et al., 2007). Actualmente su gestión tiene un coste y se basa en la "eliminación del problema" mediante gestores autorizados. Así en España, está legislado según la Ley 22/2011, de 28 de julio, de residuos y suelos contaminados (BOE, 2011), priorizando el reciclado y otros tipos de valorización incluida la energética y evitando el depósito en vertedero. Además, con la propuesta del Plan de Economía Circular de la Comisión Europea se pretende que en 2025 se prohíba la entrada de residuos reciclables en los vertederos, 
por lo que opciones como aplicación directa en suelo y el compostaje se postulan como las alternativas de gestión de estos lodos de depuración.

El compostaje está considerado como una opción sostenible de valorización de este tipo de residuos en compost para su empleo como sustrato orgánico o enmienda orgánica, lo que permite reintroducirlos en el sistema económico, contribuyendo por un lado a reducir costes de gestión, al tiempo que se reducen las emisiones de efecto invernadero (Himanen y Hänninen, 2011; Banegas et al., 2007). Aunque existen numerosas definiciones sobre el compostaje, se puede definir como un tratamiento biológico aerobio donde los microorganismos termófilos y mesófilos utilizan la materia orgánica (MO) como sustrato para obtener como producto final un producto denominado compost que se caracteriza por ser un material completamente mineralizado y estabilizado (mayormente constituido por sustancias húmicas), libre de patógenos y fitotóxicos que puede ser utilizado de forma segura en agricultura (Bustamante et al., 2008b; Cherfetz et al., 1996). Diversos tipos de materiales orgánicos pueden ser sometidos a un proceso de compostaje, tales como lodos de depuradora, restos vegetales provenientes de poda, estiércoles y purines, restos de la industria agroalimentaria, residuos forestales, etc.; siendo de especial relevancia aquellos materiales orgánicos que se producen en gran cantidad y dan lugar a problemas de manejo o eliminación (Ingelmo et al., 2012). Por su parte, el lodo de depuración no es capaz de ser compostado por si solo y requiere la adición de un agente estructurante con objeto de mejorar propiedades tales como la aireación, la humedad, la relación $\mathrm{C} / \mathrm{N}$, el tamaño de partícula, el pH y la estructura, favoreciendo la descomposición de la materia orgánica. En este sentido, los subproductos lignocelulósicos tales como la viruta de madera y el serrín son comúnmente utilizados como agente estructurante (Maboeta y van Rensburg, 2003; Pasda et al., 2005; Neves et al., 2009; Li et al., 2013).

El destino y/o uso del compost dependerá de sus características, las cuales vendrán determinadas en gran medida por las materias primas y el proceso de compostaje llevado a cabo. En concreto, el lodo de depuración agroalimentario puede sufrir un proceso de compostaje dirigido y aportar un valor añadido mediante compostaje con otros restos orgánicos generados en la propia industria agroalimentaria, dando lugar a un compost apto para su uso en semillero (Himanen y Hänninen, 2011). El uso de estos compost también podría ayudar a reducir el uso de fungicidas químicos debido a su efecto biopesticida, mientras que la turba casi nunca es supresora contra patógenos (Bernal-Vicente et al., 2008; Bonanomi et al., 2010). En este sentido, actualmente, el empleo de compost cada vez se plantea más como alternativa a la turba para una producción agrícola sostenible. La turba es el sustrato más empleado para la producción de planta en semillero (Marfà et al., 2002; Ribeiro et al., 2007; Caballero et al., 2009). No obstante, la creciente demanda y el aumento del coste de la turba como sustrato de crecimiento en el sector hortofrutícola han 
intensificado la búsqueda de sustratos de alta calidad como alternativa de bajo coste (García-Gómez et al., 2002; Benito et al., 2005; Bustamante et al., 2008c; Ostos et al., 2008).

Por tanto, los objetivos principales de este capítulo fueron: 1) evaluar diferentes aproximaciones para la gestión de lodos procedentes de la industria agroalimentaria mediante compostaje, considerando el tipo y tamaño de partícula del agente estructurante; y 2) estudiar las características de los compost obtenidos mediante técnicas termogravimétricas y evaluar sus propiedades y potencial capacidad supresora de Fusarium oxysporum, para su uso como sustrato o componente de sustratos en el cultivo de plántulas a nivel de semillero.

\section{Materiales y métodos}

Se plantearon cuatro escenarios de compostaje, utilizando lodo agroalimentario y dos agentes estructurantes. Los agentes estructurantes utilizados fueron poda de sarmiento de vid y restos de cultivo de pimiento en invernadero con dos rangos de diámetros de partícula $(<1 \mathrm{~cm}$ y $<3 \mathrm{~cm})$ para seleccionar cuál de ellos era mejor agente estructurante y para asegurar la calidad del producto final (Bustamante et al., 2013). El lodo agroalimentario empleado procedía de una estación depuradora Sociedad de Depuración Virgen de los Dolores S.L., que trata principalmente las aguas residuales del procesado de alcachofa y pimiento mediante la tecnología de reactores biológicos secuenciales (SBR).

\subsection{Proceso de compostaje}

Las mezclas de compostaje se elaboraron utilizando la máxima cantidad de lodo agroalimentario para tratar la mayor cantidad de este residuo (entre el 50 y $60 \%$ en peso fresco), pero teniendo en cuenta que la relación $\mathrm{C} / \mathrm{N}$ fuese la adecuada para un correcto proceso de compostaje, estando en el rango 18-24 (Bernal et al., 2009), y que la humedad también fuese la adecuada (60\%). La Tabla 1 resume los porcentajes de los distintos ingredientes de las pilas, así como su relación $\mathrm{C} / \mathrm{N}$, y contenido en macronutrientes iniciales. Adicionalmente, a las pilas 3 y 4 se les adicionó cáscara de almendra para elevar la relación $\mathrm{C} / \mathrm{N}$ y respetar que el componente mayoritario fuese el lodo, puesto que los restos de cultivo de pimiento mostraban un alto contenido de nitrógeno.

Las mezclas elaboradas se introdujeron en composteras de $350 \mathrm{~L}$ de capacidad, semiherméticas con el fin de que no se perdiera la humedad y permitiese la entrada de aire de un modo homogéneo; cada una de ellas estaba provista de sondas de temperaturas para su monitorización automática. Cuando la temperatura comenzó a decrecer, las pilas se voltearon entre tres y cuatro veces. La humedad se controló para 
que estuviese por encima del $40 \%$. Las pilas pasaron a maduración cuando la temperatura fue cercana a la ambiental. La fase biooxidativa del proceso de compostaje en las pilas duró entre 43 y 56 días, tras los cuales, y cuando se llegó a un valor constante de temperatura, se dejaron madurar durante aproximadamente un mes.

Las pilas fueron muestreadas inicialmente, tras cada volteo, al final de la etapa biooxidativa y al final de la fase de maduración. Las muestras se tomaron manualmente en tres puntos de la pila a lo largo de todo el perfil (desde la parte superior a la inferior), de tal manera que se obtuviese una muestra representativa del compost al mezclar y homogeneizar las muestras de dichos puntos. Posteriormente cada muestra fue dividida en tres partes para su análisis posterior: una de ellas fue secada a $105^{\circ} \mathrm{C}$ durante $24 \mathrm{~h}$ para determinar el contenido de humedad; la segunda se llevó a refrigeración a $4{ }^{\circ} \mathrm{C}$ para su análisis microbiológico; la tercera fue secada al aire y molida hasta tamaño de partícula menor de $0,5 \mathrm{~mm}$ para el resto de análisis de manera general. 


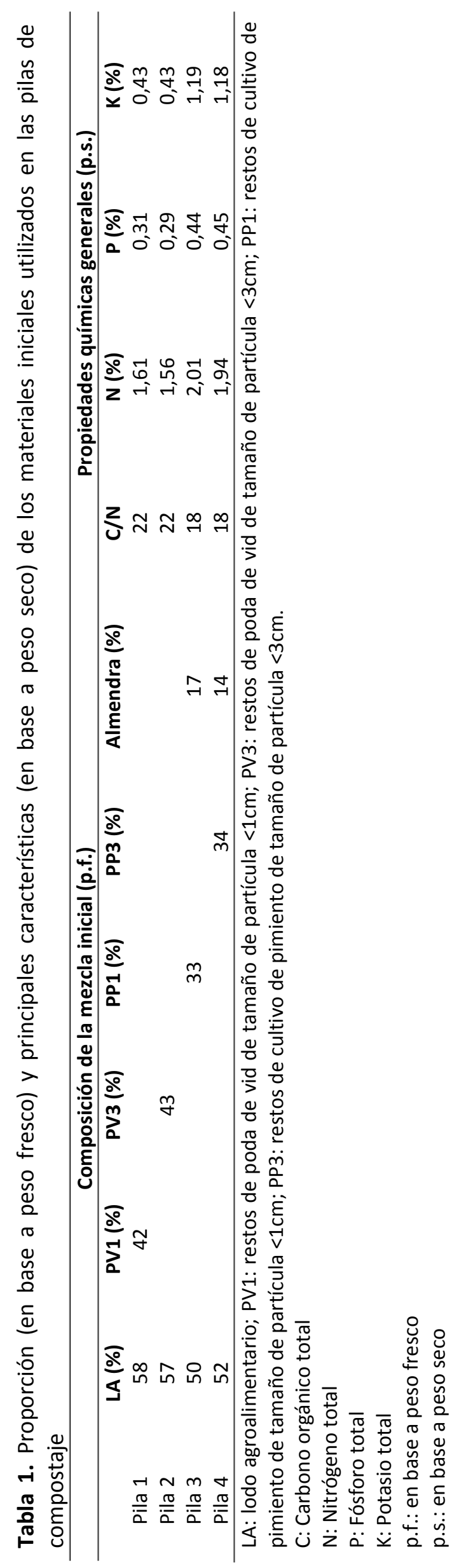




\subsection{Análisis químico de las muestras de compost}

La humedad se determinó de acuerdo al método estándar CEN13039 (European Committee for Standardization, 1999). El nitrógeno total (N) y el carbono orgánico total fueron determinados por microanálisis automático (Navarro et al., 1991). El fósforo (P) fue determinado espectrofotométricamente midiendo la intensidad de la coloración amarilla del ácido molibdovanadato fosfórico (Kitson y Mellon, 1944). Y el potasio (K) por fotometría de llama. También se analizó la posible contaminación por metales pesados $(\mathrm{Cu}, \mathrm{Zn}, \mathrm{Cd}, \mathrm{Cr}, \mathrm{Pb}, \mathrm{Ni}, \mathrm{Hg}$ ) utilizando espectrofotometría de masas con plasma de acoplamiento inductivo (ICP-MS) e igualmente la presencia de plaguicidas en los materiales de partida utilizando un sistema cromatográfico de gases HP-6890 con detector de masas. Durante el compostaje, se evaluó también la pérdida de materia orgánica (MO) y la fracción de carbono hidrosoluble (Ch). La MO fue determinada por pérdida de peso por calcinación a $550{ }^{\circ} \mathrm{C}$ ( 24 horas) de acuerdo al método estándar CEN13039. El Ch fue extraído con agua desionizada 1:20 ( $\mathrm{p} / \mathrm{v})$ y medido en un analizador automático de carbono. La relación de la mineralización de la MO fue medida para determinar la degradación de la materia orgánica en cada intervalo. Para ello, se empleó el contenido en cenizas al inicio $\left(X_{1}\right)$ y al final $\left(X_{2}\right)$, de acuerdo a la ecuación propuesta por Paredes et al. (2000):

$$
\text { Pérdida } M O(\%)=100-100 \frac{\left[X_{1}\left(100-X_{2}\right)\right]}{\left[X_{2}\left(100-X_{1}\right)\right]}
$$

A los compost finales se les determinó el pH y la conductividad eléctrica (CE) en un extracto acuoso 1:5 (p/v) utilizando un pHmetro y un conductímetro (Crison mod. 2001, Barcelona, Spain), así como su contenido en sodio ( $\mathrm{Na}$ ), calcio ( $\mathrm{Ca}$ ), magnesio $(\mathrm{Mg})$, hierro (Fe), cobre (Cu), manganeso $(\mathrm{Mn})$, cinc $(\mathrm{Zn})$, boro $(\mathrm{B})$ y de metales pesados $(\mathrm{Cd}, \mathrm{Cr}, \mathrm{Pb}, \mathrm{Ni}, \mathrm{Hg})$ mediante espectrofotometría de masas con plasma de acoplamiento inductivo (ICP-MS) (EPA, 1998), tras una digestión $\mathrm{HNO}_{3} / \mathrm{HClO}_{4}$.

Finalmente, la toxicidad de los compost fue evaluada mediante el índice de germinación, que fue calculado utilizando semillas de Lepidium sativum L. (Zucconi et al., 1981). El ensayo se realizó por triplicado.

\subsection{Determinación microbiológica y análisis de las actividades enzimáticas}

Los grupos microbiológicos estudiados fueron Salmonella (pre-enriquecimiento agua peptona tamponada $\left(24 \mathrm{~h}\right.$ a $37^{\circ} \mathrm{C}$ ), incubación en caldo Salmonella Xpress ( $24 \mathrm{~h}$ a $41,5^{\circ} \mathrm{C}$ ), test VIDAS), Listeria Monocytogenes (incubación caldo Fraser, $24 \mathrm{~h}$ a $30{ }^{\circ} \mathrm{C}$, test VIDAS), Coliformes fecales (Escherichia Coli (E. Coli)) (incubación TBX, $24 \mathrm{~h}$ a $44^{\circ} \mathrm{C}$ ), estreptococos fecales (incubación KAA, 24-48 h a $37^{\circ} \mathrm{C}$ ) y Clostridium perfringens 
(incubación TSC, $24 \mathrm{~h}$ a $44{ }^{\circ} \mathrm{C}$ ). Los resultados para E. coli, estreptococos fecales y Clostridium perfringens fueron expresados como número de unidades de colonias formadoras por gramo de compost fresco (UFC/g compost) y para Salmonella y Listeria como presencia o ausencia.

La actividad $\beta$-glucosidasa se determinó según el método descrito por Tabatabai (1982). Este método está basado en la estimación colorimétrica de $p$ nitrofenol (PNP) debido a la hidrólisis de p-nitrofenol-b-D-glucopiranósido (PNG) a $37{ }^{\circ} \mathrm{C}$ durante $1 \mathrm{~h}$, y aporta el resultado bajo la forma de producción de p-Nitrofenol (PNP) en los compost. La actividad deshidrogenasa se determinó según el método de Trevors et al. (1986) y modificado por García et al. (1993). El método se basa en la estimación del iodonitrotetrazolio formazan (INTF) formado cuando el material es incubado con 2-p-iodofenol-3-p-nitrofenol-5-feniltetrazolio (INT) durante $20 \mathrm{~h}$ a $20{ }^{\circ} \mathrm{C}$, en oscuridad, ya que se actúa como aceptor de electrones en ausencia de tampón, reduciéndose a su correspondiente sal de formazano de color rojo.

\subsection{Análisis térmico}

Se utilizaron las muestras de compost secadas al aire para el análisis termogravimétrico, pero se molieron y tamizaron hasta un tamaño de 0,125 $\mathrm{mm}$. Para este análisis se utilizó el instrumento Mettler Toledo (TGA/SDTA851e/LF/1600). Todas las muestras fueron combustionadas con una mezcla de oxígeno/helio (20/80\%), un caudal de gas de $100 \mathrm{~mL} / \mathrm{min}$ con un rango de temperatura de 25 a $800{ }^{\circ} \mathrm{C}$, con un rango de calentamiento de $20^{\circ} \mathrm{C} / \mathrm{min}$ y tomando un peso de muestra de cerca de $15 \mathrm{mg}$.

\subsection{Análisis físico}

También las propiedades físicas se determinaron en los compost maduros, en concreto el espacio poroso total, la densidad aparente, contracción del volumen, su contenido en aire y la capacidad total de retención de agua, de acuerdo a los métodos utilizados por Bustamante et al. (2008c).

\subsection{Ensayo en semillero para determinar la capacidad supresiva de los compost obtenidos}

Los tratamientos utilizados como medio de cultivo para el cultivo plántulas de melón fueron 1: $1(\mathrm{p} / \mathrm{p})$ mezcla de compost y turba negra: el compost 1 (T-C1), el 2 (T$\mathrm{C} 2$ ), el 3 (T-C3) y el 4 (T-C4). Se utilizó turba comercial sola como tratamiento de control (control). Las semillas de melón (Cucumis melo L., cv. Giotto) se sembraron en los diferentes medios de cultivo ensayados como tratamientos, con una cubierta de vermiculita, en bandejas de poliestireno de 150 alveolos (aplicando una semilla por 
alveolo). Las semillas germinaron en una cámara de crecimiento a $28 \pm 1{ }^{\circ} \mathrm{C}$ y humedad relativa 90-95\%; pasando posteriormente a semillero, extendiéndose en camas adecuadas para su crecimiento. Una vez que la primera hoja verdadera apareció (15 días después de la siembra), se prepararon seis repeticiones y se inocularon 10 plántulas por réplica con $2 \mathrm{~mL}$ de una suspensión de conidios del patógeno Fusarium oxysporum f. sp. melonis (FOM) con una concentración final de $3,510^{5} \mathrm{UFC} / \mathrm{g}$, con lo que se trabajó con un total de 60 plántulas de melón. Además, de modo análogo, para evaluar el efecto como sustrato orgánico, a otras 10 plántulas (con 6 réplicas para cada medio de cultivo) se les aplicó $2 \mathrm{~mL}$ de agua destilada en vez del patógeno.

El patógeno FOM fue aislado de plántulas de melón infectadas en semillero. Los conidios se recuperaron tal como describió Blaya et al. (2013). Las bandejas se humedecieron periódicamente utilizando riego manual, siguiendo la rutina del semillero. Finalmente, la parte aérea de las plántulas control se pesó 40 días después de trasplantadas. También se determinó el peso en las plántulas inoculadas con FOM y se evaluó el carácter supresivo de los compost. En concreto, la incidencia de FOM se estimó como el porcentaje de pérdida de peso fresco de plántulas de melón en tratamientos infectados con $F$. oxysporum con respecto al mismo tratamiento sin inoculación del fitopatógeno (López-Mondejar et al., 2012).

\subsection{Análisis estadístico}

Los datos de la pérdida de materia orgánica (MO) a lo largo del proceso de compostaje se ajustaron a una ecuación cinética de primer orden utilizando el método de Marquardt-Levenberg (Bernal et al., 1996; Bustamante et al., 2013), mediante el programa Sigmaplot 11.0. La ecuación resultante fue:

$$
\text { Pérdida de } \mathrm{MO}(\%)=\mathrm{A}\left(1-\mathrm{e}^{-\mathrm{Kt}}\right) \text {; }
$$

Donde $\mathrm{A}$ es la máxima degradación de $\mathrm{MO}$ (en \% C), $\mathrm{K}$ es la constante cinética (en $\mathrm{d}^{-1}$ ) y $\mathrm{t}$ es el tiempo de compostaje (en d). El valor cuadrático medio (RMS) y el factor de significancia (F-valor) fueron calculados comparando el ajuste de las diferentes funciones y la significación estadística del ajuste.

Se utilizó el análisis de la varianza con un factor (ANOVA) y el test de la mínima diferencia significativa (LSD) a $p<0,05$ para evaluar la diferencia significativa de los valores medios de cada parámetro durante el compostaje, mientras que el test de Tukey se utilizó para establecer las diferencias significativas de los compost en el ensayo de crecimiento en planta a nivel semillero. Todos los test estadísticos se realizaron con el programa SPSS 22.0 (SPSS Inc., Chicago, IL, EE.UU.). 


\section{Resultados y discusión}

\subsection{Evolución de la temperatura durante el proceso de compostaje}

De acuerdo a estudios previos, la temperatura es uno de los principales factores que controlan el proceso de compostaje aerobio (Chen, 2012). Se requiere que las pilas alcancen altas temperaturas para garantizar la destrucción de los organismos patógenos y una más rápida descomposición de la MO (Chen et al., 2014). El calor generado en el proceso de compostaje es debido al metabolismo microbiológico y a la acumulación de energía retenida en la masa de compostaje (Aydin y Kocasoy, 2002). La Figura 1 muestra las curvas de temperatura de las pilas, donde todas ellas muestran una evolución similar. La fase termófila se alcanzó en los primeros dos días en todas las pilas, manteniéndose aproximadamente 2 semanas, periodo similar o incluso superior al indicado en otros trabajos donde se elaboraron compost de fango aeróbico mezclado con diferentes agentes estructurantes (Doublet et al., 2011; Himanen y Hännien, 2011). Tras el primer volteo se reactivó el incremento de temperatura en las pilas 1,2 y 3, mientras que en la pila 4 no se observó ese incremento hasta más avanzado el proceso. La reactivación del proceso de compostaje tras el volteo también fue observada por Tortosa et al. (2012) y Bustamante et al. (2013). Después de este periodo, la temperatura descendió y en cuatro semanas alcanzó la temperatura ambiente. La fase biooxidativa de las pilas 1 y 2 (que incorporaban materiales de restos de poda de vid) fue de 43 días, mientras que en las pilas 3 y 4 (que incorporaban restos de cultivo de pimiento) fue de 56 días. En otras publicaciones se ha indicado una duración similar de la fase biooxidativa para el compostaje de lodos aeróbicos (Doublet et al., 2011; Himanen y Hänninen, 2011; Bustamante et al., 2014; Banegas et al., 2007).

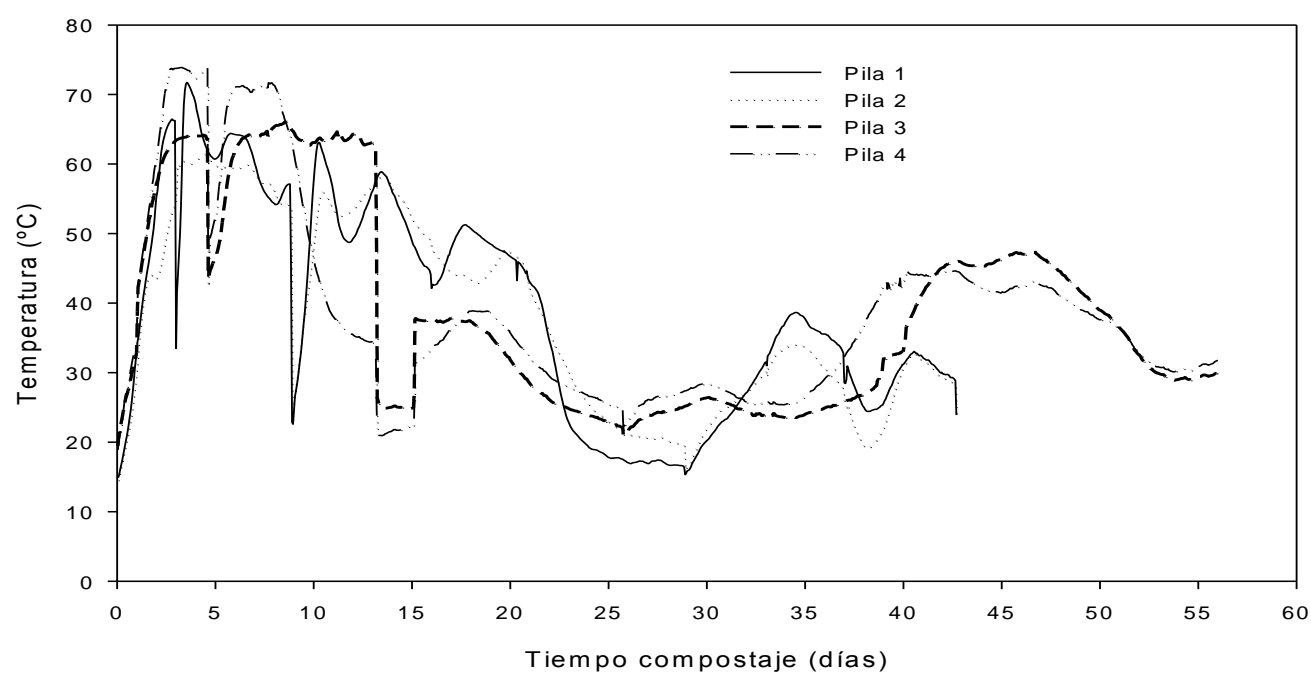

Figura 1. Perfil de temperature de las pilas de compostaje durante el proceso. Pila 1: $58 \% \mathrm{LA}+$ 42 \% PV1; Pila 2: 57 \% LA + 43 \% PV3; Pila 3: 50 \% LA + 33 \% PP1 + $17 \%$ almendra; Pila 4: $52 \%$ $\mathrm{LA}+34 \% \mathrm{PP} 3+14 \%$ almendra. 


\subsection{Evolución de la fracción orgánica y estudio de la calidad del compost}

\subsubsection{Determinaciones químicas y biológicas}

La concentración inicial de $\mathrm{MO}$ en las pilas 1 y 2 fue superior a las pilas 3 y 4 (Tabla 2). Por otro lado, las pilas 1 y 3 , que incluían el material de menor diámetro mostraron menor contenido en $\mathrm{MO}$ que las pilas 2 y 4 respectivamente, debido a que es precisamente en la fracción más fina donde existe otro tipo de materiales de naturaleza mineral y no orgánica, caracterizados por su menor tamaño. El contenido en MO decreció a lo largo del tiempo de compostaje en todas las pilas debido a la disminución de las sustancias fácilmente biodegradables por la acción de los microorganismos (Benito et al., 2003). La MO se redujo en un 10,74, 16,94, 13,22 y $18,65 \%$ en las pilas 1-4 respectivamente, datos cercanos y mayores a los de Himanen y Hänninen (2011), donde observaron que el compostaje de lodo aerobio produjó una disminución de la MO de un 8 \%; a los de Banegas et al. (2007), donde la reducción fue de 12,69 \% empleando serrín com agente estructurante; y a los de Molla et al. (2004), que empleando como agente estructurante paja de arroz, la reducción fue del 13,78 \%.

Tabla 2. Evolución de la materia orgánica ( $\mathrm{MO}$ ), relación $\mathrm{C} / \mathrm{N}$, carbono hidrosoluble (Ch) y el contenido de nitrógeno total $(\mathrm{N})$ durante el compostaje (en base a peso seco). Valores medios \pm error estándar

\begin{tabular}{|c|c|c|c|c|}
\hline Fase de compostaje & MO (\%) & $\mathbf{C} / \mathbf{N}$ & Ch (\%) & $\mathbf{N}(\%)$ \\
\hline \multicolumn{5}{|c|}{ Pila 1: $58 \%$ LA + $42 \%$ PV1 } \\
\hline Inicial (0 días) & $75,83 \pm 0,04$ & $23,75 \pm 0,21$ & $1,49 \pm 0,54$ & $1,61 \pm 0,01$ \\
\hline Final biooxidativa (37 días) & $68,17 \pm 0,32$ & $15,55 \pm 0,14$ & $0,81 \pm 0,28$ & $2,41 \pm 0,01$ \\
\hline Final maduración (78 días) & $67,68 \pm 0,02$ & $16,06 \pm 0,04$ & $0,58 \pm 0,17$ & $2,35 \pm 0,01$ \\
\hline$\angle S D$ & 0,7 & 0,49 & 1,17 & 0,04 \\
\hline Inicial (0 días) & $83,17 \pm 0,07$ & $23,40 \pm 0,27$ & $1,62 \pm 0,48$ & $1,56 \pm 0,02$ \\
\hline Termófila (10 días) & $79,84 \pm 0,11$ & $20,01 \pm 0,23$ & $1,27 \pm 0,18$ & $1,73 \pm 0,02$ \\
\hline Final biooxidativa (37 días) & $70,49 \pm 0,06$ & $17,01 \pm 0,09$ & $0,93 \pm 0,23$ & $2,27 \pm 0,01$ \\
\hline Final maduración (78 días) & $69,08 \pm 0,03$ & $16,05 \pm 0,06$ & $0,83 \pm 0,14$ & $2,36 \pm 0,01$ \\
\hline$\angle S D$ & 0,23 & 0,56 & 0,94 & 0,05 \\
\hline \multicolumn{5}{|c|}{ Pila 3: $50 \%$ LA + $33 \%$ PP1 + $17 \%$ almendra } \\
\hline Final biooxidativa (37 días) & $51,00 \pm 0,10$ & $11,98 \pm 0,21$ & $0,82 \pm 0,21$ & $2,43 \pm 0,02$ \\
\hline Final maduración (78 días) & $46,39 \pm 0,34$ & $10,80 \pm 0,07$ & $0,82 \pm 0,60$ & $2,36 \pm 0,00$ \\
\hline$\angle S D$ & 0,55 & 0,43 & 1,29 & 0,04 \\
\hline \multicolumn{5}{|c|}{ Pila 4: $52 \%$ LA + $34 \%$ PP3 + $14 \%$ almendra } \\
\hline Inicial (0 días) & $61,10 \pm 0,17$ & $18,30 \pm 0,03$ & $1,31 \pm 0,26$ & $1,94 \pm 0,00$ \\
\hline Termófila (10 días) & $55,80 \pm 0,31$ & $16,65 \pm 0,23$ & $0,99 \pm 0,50$ & $1,70 \pm 0,03$ \\
\hline Final biooxidativa (37 días) & $50,19 \pm 0,57$ & $12,05 \pm 0,06$ & $0,90 \pm 0,55$ & $2,39 \pm 0,00$ \\
\hline Final maduración (78 días) & $49,71 \pm 0,34$ & $11,48 \pm 0,09$ & $0,79 \pm 0,27$ & $2,27 \pm 0,01$ \\
\hline$L S D$ & 1,23 & 0,39 & 1,36 & 0,06 \\
\hline
\end{tabular}

La cinética de la mineralización de la MO de todas los pilas se ajustó a un modelo cinético de primer orden, siendo significativa a $p<0,001$ (Figura 2). 
Pila 1: $A=33,41(1,90) ; K=0,2002(0,0543) ; R M S=11,97 ; F=75,23 ;$ SEE $=3,46$

Pila 2: $A=55,52(4,31) ; K=0,0676(0,0140) ; R M S=22,69 ; \quad F=102,40 ; \quad S E E=4,76$

Pila 3: $A=31,76(3,73) ; K=0,0278(0,0069) ; R M S=3,62 ; \quad F=191,70 ;$ SEE $=1,90$

Pila 4: $A=35,44(2,28) ; K=0,0709(0,0168) ; R M S=11,14 ; \quad F=88,21 ; \quad S E E=3,34$

Donde RMS es el valor cuadrático medio y SEE es el error estándar estimado.

La ecuación de la pila 1 tuvo la mayor constante cinética, indicando que la degradación de la mezcla fue más rápida que en las otras pilas. Por otro lado, el mayor valor del producto $\mathrm{A} \times \mathrm{K}$ en las pilas 1 y 2 muestra el mayor ratio de degradación del agente estructurante utilizado (restos de poda de vid). Por lo tanto, se puede afirmar que los restos de poda de vid son más fácilmente biodegradables que los de pimiento. Los valores de $\mathrm{A}$ y $\mathrm{K}$ obtenidos fueron diferentes a los obtenidos en otros experimentos de compostaje utilizando otro tipo diferente de residuos orgánicos (Bernal et al., 1996; Paredes et al., 2002; Bustamante et al., 2008b, 2012), de modo que los lodos agroalimentarios mostraron una mayor biodegradabilidad.

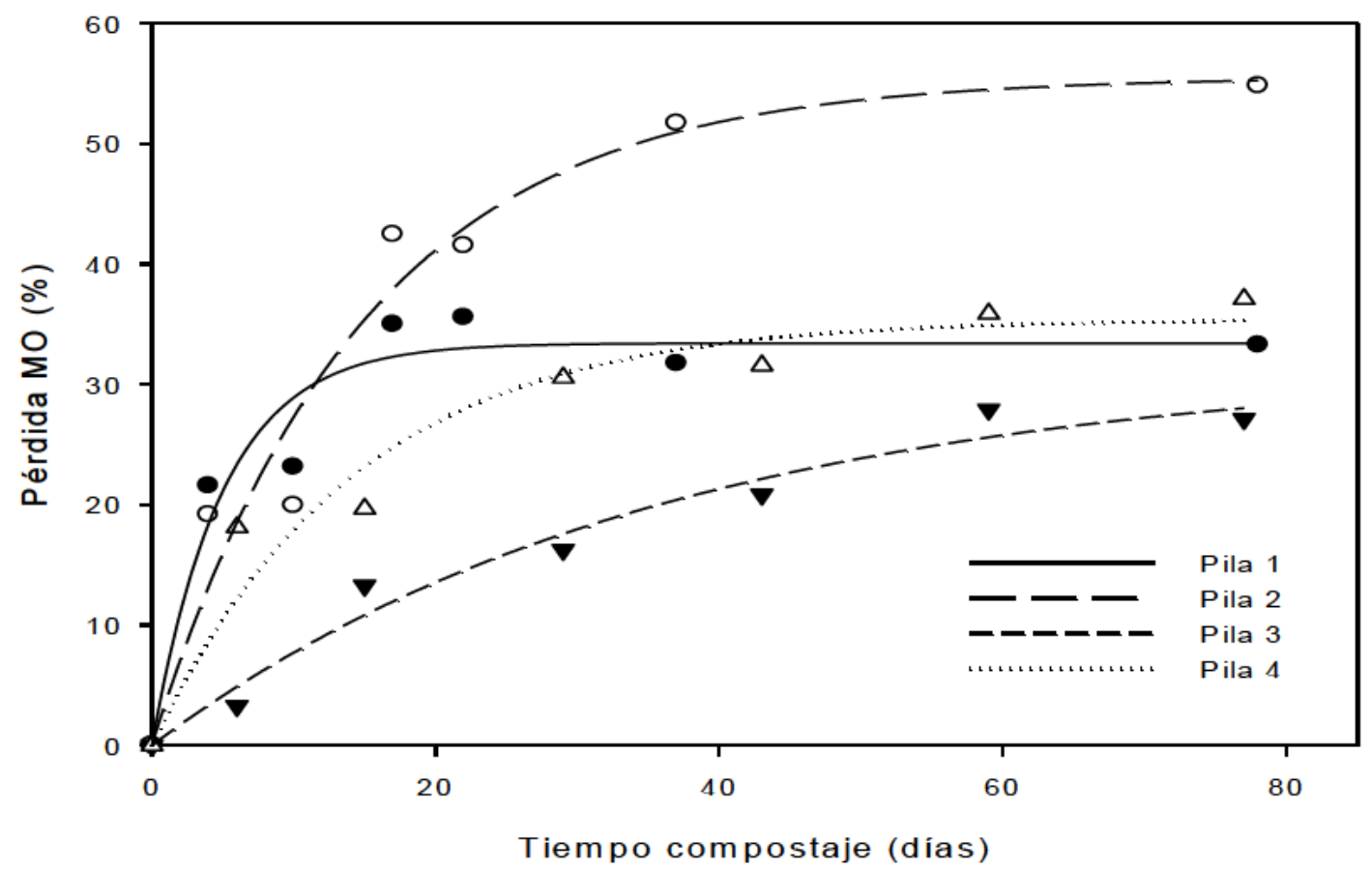

Figura 2. Pérdida de materia orgánica durante el compostaje de las pilas 1-4. Los símbolos indican los datos experimentales $(n=3)$ y las líneas representan la curva de ajuste 
La monitorización de la relación $\mathrm{C} / \mathrm{N}$ ha sido ampliamente empleada como un índice de la estabilidad y madurez de un compost (Chowdhury et al., 2014; Li et al., 2013), sugiriendo que un compost maduro tiene que presentar una relación $\mathrm{C} / \mathrm{N}$ por debajo de 20 (Bernal et al., 1998; Golueke, 1981; Morel et al., 1985; Bernal et al., 2009; Meunchang et al., 2005; Raj y Antil, 2011; Bustamante et al., 2012). La relación C/N de los compost estudiados se muestra en la Tabla 3, donde se observa que en todas las pilas decrece hasta valores entre 10 y 16, lo que indica un aceptable grado de maduración. Las pilas 3 y 4 muestran, desde el inicio, la relación $\mathrm{C} / \mathrm{N}$ menor de 20 , lo que demuestra que este parámetro no puede ser empleado como valor absoluto respecto del estado de madurez (Bustamante et al., 2013) pero sí como parámetro de monitorización, debido a que muestra un descenso en todos los casos (Bustamante et al., 2008b). El carbono orgánico hidrosoluble (Ch) decreció a lo largo del proceso de compostaje, principalmente durante la fase biooxidativa (Tabla 3), como consecuencia de la fácil degradación de los compuestos orgánicos hidrosolubles. Los valores del Ch de todas las mezclas después del compostaje estuvo entre el rango 0,58-0,83 \%, y fueron resultados similares a los obtenidos por otros autores en experiencias de cocompostaje (Bernal et al., 1998; Banegas et al., 2007; Bustamante et al., 2012, 2014) y cercanos a valores límite sugeridos por diferentes autores para considerar un compostaje suficientemente maduro: $<1 \%$ o $<1,7 \%$ (Bernal et al., 2009).

La $\mathrm{MO}$, la relación $\mathrm{C} / \mathrm{N}$ y el $\mathrm{Ch}$ decrecieron en todas las pilas durante el proceso de compostaje, mientras que el nitrógeno $(\mathrm{N})$ incrementó en todas las pilas (Tabla 3 ) debido al efecto de concentración como consecuencia de la descomposición de la MO, que al reducir la masa de compost produce una concentración de elementos minerales. Aunque el nitrógeno también puede descender mediante volatilización en forma de amonio o lixiviación en modo de nitratos, el descenso de la materia orgánica fue mayor. Al final del proceso de compostaje, se observó que el incremento del contenido de nitrógeno fue mayor en las pilas 1 y 2 debido probablemente a que en estas puede haber una menor volatilización que en las pilas 3 y 4 , puesto que la temperatura fue menor (Eklind et al., 2007), aunque otro aspecto a tener en cuenta debe de ser atribuido al tipo de agente estructurante utilizado (Barrington et al., 2002). El incremento en $\mathrm{N}$ fue más notable en la fase biooxidativa, similar a lo que observaron Bustamante et al. (2012) durante el co-compostaje de la fracción sólida de digeridos anaeróbicos y restos de poda de vid. Al final del proceso de compostaje todas las pilas alcanzaron similares contenidos de nitrógeno (2,3-2,4 \%).

El índice de germinación (IG) de los compost obtenidos fue otro parámetro evaluado para determinar la madurez del compost (Zucconi et al., 1981). Todos los compost alcanzaron valores superiores al $60 \%(84,75,79$ y $71 \%$ para los compost 1 , 2,3 y 4 respectivamente) por lo que los compost pueden considerarse maduros $y$ libres de fitotoxicidad. 
Además, durante el compostaje, el material inicial es degradado a través de una variedad de procesos biológicos y bioquímicos donde las enzimas juegan un papel importante (Cayuela et al., 2012), por lo que parámetros como la actividad deshidrogenasa y $\beta$-glucosidasa, han sido ampliamente empleados como indicadores de la maduración del compostaje (Tiquia, 2005). En este estudio se observaron valores de deshidrogenasa de $69,84,77,37,111,04$ y $108,69 \mu \mathrm{mol}$ INTF/g h y de $\beta$-glucosidasa de 16,09, 12,85, 46,22 y 48,96 $\mu \mathrm{g} \mathrm{PNF} / \mathrm{g} \mathrm{h}$ para los compost 1, 2, 3 y 4 respectivamente, con los menores valores en los compost con poda de vid (compost 1 y 2), lo que pone de manifiesto el mayor grado de estabilización de los compost que emplean restos de poda en comparación con los de restos de pimiento, debido a la mayor biodegradabilidad de los primeros, lo que permitiría una estabilidad más rápida. En general, podemos decir que los valores de ambos parámetros presentaron valores relativamente bajos, tal y como mostraron Saviozzi et al. (2004), Tiquia (2005) y Barrena et al. (2008), donde se demuestra como estos valores descienden durante el compostaje debido al descenso de sustratos fácilmente biodegradables.

\subsubsection{Análisis térmico}

El grado de madurez de los compost fue medido por termogravimetría (TG), termogravimetría diferencial (DTG) y análisis térmico diferencial (DTA). Los perfiles de TG, DTG y DTA indican las características de la MO. Los perfiles de las cuatro pilas fueron similares y en la Figura 3 se indica el ejemplo de uno de ellos, pero se observaron diferencias significativas entre las muestras iniciales y las del compost final. La pérdida de masa a diferentes temperaturas se corresponde con diferentes tipos de compuesto. Los carbohidratos, tales como celulosa, son degradados entre $200 \mathrm{y}$ $400{ }^{\circ} \mathrm{C}$, lo que indica que estas pilas fueron ricas en estos compuestos, algo de esperar debido al origen vegetal de los materiales empleados. Entre 400 y $600^{\circ} \mathrm{C}$, la pérdida de masa se corresponde con material alifático. Un parámetro importante obtenido con esta técnica es el parámetro R1, que se corresponde con la pérdida de masa general debida a la pérdida de material alifático (de 430 a $600^{\circ} \mathrm{C}$ ) y moléculas de carbohidratos (de 200 a $430^{\circ} \mathrm{C}$ ) durante el proceso de combustión. El valor de R1 para las muestras iniciales de las pilas $1,2,3$ y 4 fue $0,158,0,156,0,262$ y 0,224 , respectivamente. Y para las muestras finales, este valor fue $0,177,0,180,0,342$ y 0,358 , respectivamente, por lo que se observó que el valor de R1 se incrementó en todas las pilas durante el proceso de compostaje. Esto indica la transformación de la MO, lo que se corresponde con una pérdida del material más degradable y un aumento en los compuestos alifáticos, y por lo tanto un aumento en R1, dando un material final que era maduro y estable. 

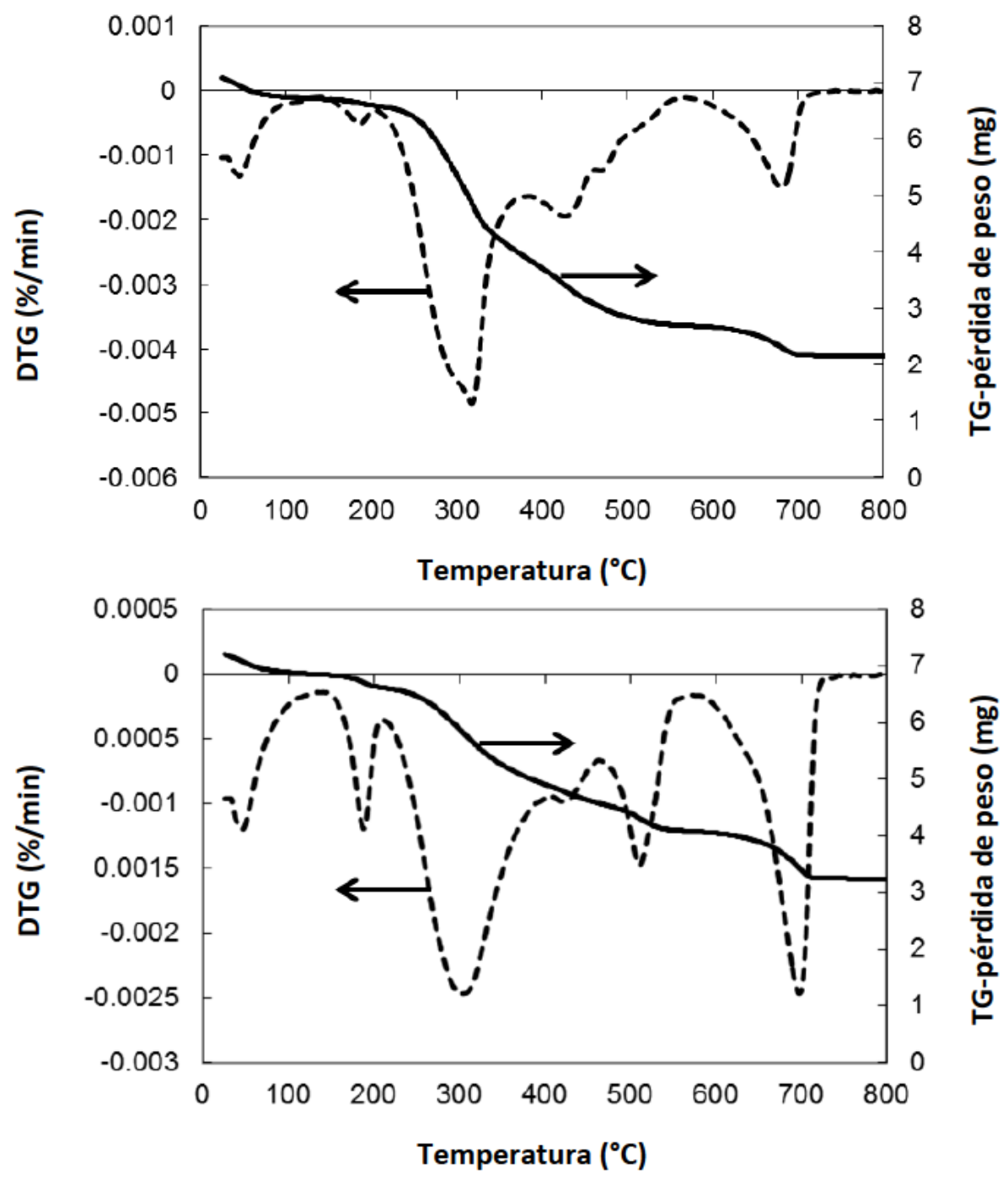

Figura 3. Curva inicial (superior) y final (inferior) obtenidas del análisis TG (línea discontinua) y DTG (línea continua) de las muestras de compost de la pila 4 [52 \% LA + 34 \% PP3 + $14 \%$ almendra].

En la Figura 4 se puede observar el perfil del DTA, donde se muestra el porcentaje de la energía liberada en relación con la temperatura, lo que demuestra la energía que estaría disponible para los microorganismos durante el proceso de compostaje (Otero et al., 2002). El primer pico exotérmico en el rango $200-430{ }^{\circ} \mathrm{C}$ fue característico de los componentes celulósicos, mientras que el segundo pico en el rango $430-600{ }^{\circ} \mathrm{C}$ fue característico de moléculas más recalcitrantes. Así, la energía liberada por debajo de $500{ }^{\circ} \mathrm{C}$ en las pilas 1 y 2 (la poda de la vid) fue alrededor del $96 \%$, tanto en el inicio y el final del proceso de compostaje, mientras que para las pilas 3 y 4 (restos de cultivo de pimiento) los valores iniciales fueron de alrededor del $97 \%$, pero estos disminuyeron a $88 \%$. Los resultados muestran que la poda de la vid contenía más energía disponible para los microorganismos que los restos de cultivo de 
pimiento, lo que explica la mayor biodegradabilidad del agente estructurante en las pilas 1 y 2 .

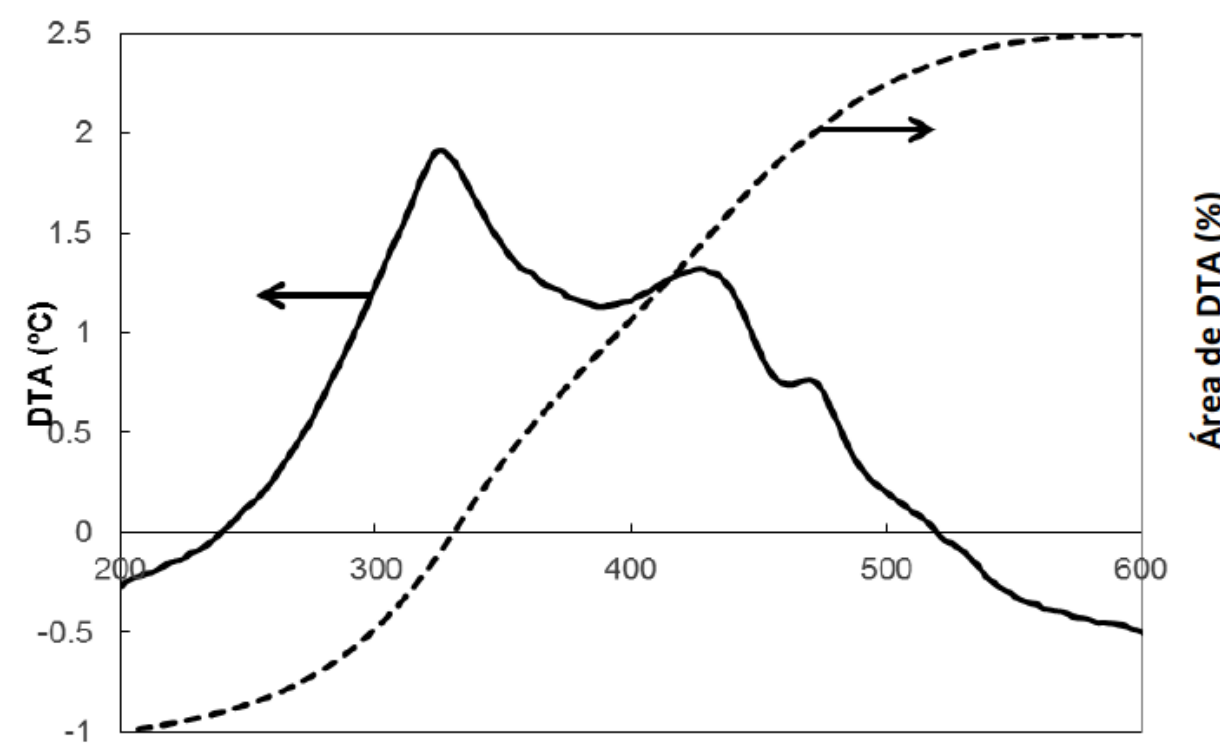

Temperatura $\left({ }^{\circ} \mathrm{C}\right)$

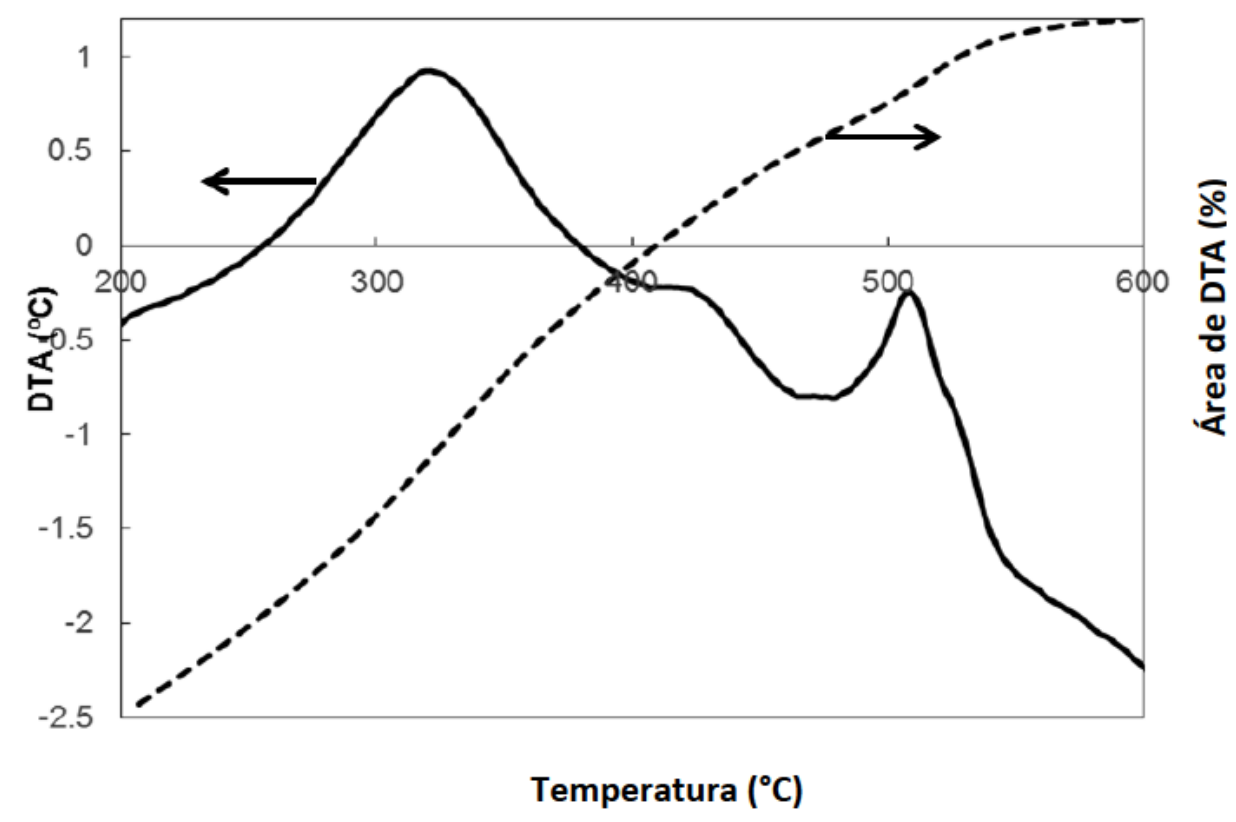

Figura 4. DTA (línea continua) y porcentaje de energía liberada (línea discontinua) de las muestras de compost inicial (superior) y final (inferior) de la pila 4 [52 \% LA + 34 \% PP3 + $14 \%$ almendra]. 


\subsection{Propiedades y potencial valor añadido de los compost obtenidos}

\subsubsection{Propiedades físico-químicas, químicas y microbiológicas}

Las principales propiedades físico-químicas, químicas y microbiológicas de los compost finales se muestran en la Tabla 3. Al final del proceso de compostaje los compost 1 y 2 fueron los que mostraron valores finales de $\mathrm{pH}$ cercanos a la neutralidad y dentro del rango $(6,0-8,5)$ sugerido para su empleo en agricultura (Hogg et al., 2002), aunque fuera del rango de pH óptimo $(5,2-7,0)$ para ser utilizados como sustrato de cultivo (Bunt, 1988). Además, los valores de conductividad en los compost 1 y 2 fueron menores a los de los compost 3 y 4, estos últimos además por encima de 3,5 dS/m, límite indicado por Lemaire et al. (1985) para que las plántulas crezcan vigorosas en un sustrato de cultivo; por lo que podemos decir a priori que, los restos de cultivo de pimiento aportaran mayor cantidad de sales. Estos parámetros son de gran importancia debido a que limitan la disponibilidad de nutrientes, la germinación de semillas y el crecimiento de las plantas.

Las concentraciones de los macronutrientes (NPK) fueron altas y los tamaños de partícula no mostraron diferencias significativas. Estos valores fueron cercanos a los observados por otros autores: algo mayores a los obtenidos en experiencias de cocompostaje con lodos de depuración urbanos (Roca-Pérez et al., 2009; Doublet et al., 2011; Himanen y Hänninen, 2011); y menores a los de otras experiencias de cocompostaje con digestatos de origen agroindustrial (purines y estiércol) y restos de poda de vid o pimiento (Bustamante et al., 2008b, 2012, 2013). Por otro lado, la concentración de micronutrientes fue variable en los cuatro compost, siendo mayor la concentración de calcio y hierro en las pilas con restos de poda de vid como agente estructurante; factores que pueden tener su relativa importancia en el control biológico de algunas enfermedades de plantas. Finalmente, la concentración de metales pesados fue muy inferior a la observada en experiencias con lodos de depuración de origen urbano debido principalmente a que dichos lodos provienen del tratamiento de aguas residuales provenientes de industrias con contaminación en metales pesados (Smith, 2009). Tal y como se ha comentado anteriormente, los materiales de partida de estos compost son de origen vegetal, destacándose su no contaminación con metales pesados. Los contenidos de estos obtenidos para los cuatros compost estuvieron por debajo de los límites establecidos por la legislación española en el Real Decreto 506/2013 sobre productos fertilizantes (BOE, 2013) y las guías europeas, indicadas en el Working document on biological treatment of biowaste (European Commission, 2001).

De acuerdo con esta legislación, los compost también cumplen con el límite máximo de microorganismos patógenos humanos para el empleo de los compost como fertilizantes. La Tabla 3 muestra la ausencia de Salmonella y la concentración de E. coli está por debajo de $1.000 \mathrm{UFC/g}$. Otros patógenos como Listeria monocytogenes, estreptococos fecales o Clostridium perfringens, aunque no exigidos por la legislación, 
también indican la calidad de estos productos (Banegas et al. 2007; Bustamante et al. 2008a). Los 4 compost mostraron ausencia de Listeria monocytogenes; y los estreptococos fecales mostraron valores por debajo del límite de $5.000 \mathrm{UFC/g}$ (peso fresco) recomendado por Strauch (1987) para la higienización del compost. La presencia de Clostridium, un microorganismo anaerobio, en las pilas 1 y 3 y la menor detección en las pilas 2 y 4 puede explicarse como que, en las primeras, el agente estructurante de menor diámetro hubiese permitido la existencia de micronichos anaerobios, lo que hubiese permitido la resistencia de estos, a pesar de los volteos realizados (Pourcher et al., 2005).

Otro aspecto negativo podría ser la presencia de restos de pesticidas químicos en el compost debido a su presencia en los lodos, y de un modo más concreto su presencia en los agentes estructurantes utilizados, debido a que estos materiales provienen del tratamiento de aguas residuales del procesado de materias vegetales provenientes de una actividad agrícola, o directamente de la propia actividad agrícola respectivamente, donde se utilizan pesticidas químicos. En todos los casos, no se observó presencia alguna, ni en los lodos ni en los agentes estructurantes, por lo que los compost tampoco mostraron presencia alguna.

Tabla 3. Propiedades finales de los compost maduros obtenidos. Datos expresados en peso seco excepto los datos referidos a los grupos microbiológicos, que están expresados en UFC/g compost fresco

\begin{tabular}{|c|c|c|c|c|}
\hline & Compost 1 & Compost 2 & Compost 3 & Compost 4 \\
\hline \multicolumn{5}{|c|}{ Propiedades físico-químicas y químicas } \\
\hline $\mathrm{pH}$ & $7,94 b$ & $8,22 b$ & $8,97 a$ & $8,74 a$ \\
\hline $\mathrm{CE}(\mathrm{dS} / \mathrm{m})$ & $3,52 b$ & $3,18 b$ & $5,55 a$ & $5,57 a$ \\
\hline $\mathrm{N}(\%)$ & $2,35 a$ & $2,36 a$ & $2,36 a$ & $2,27 b$ \\
\hline $\mathrm{P}(\%)$ & $0,48 a b$ & $0,46 b$ & $0,64 a b$ & $0,64 a$ \\
\hline K (\%) & $0,61 b$ & $0,63 b$ & $2,06 a$ & $1,83 a$ \\
\hline $\mathrm{Ca}(\%)$ & 10,6 & 12,5 & 8,64 & 8,08 \\
\hline $\mathrm{Mg}(\%)$ & 0,86 & 0,91 & 0,87 & 0,86 \\
\hline $\mathrm{Na}(\%)$ & 0,25 & 0,24 & 0,20 & 0,21 \\
\hline $\mathrm{Fe}(\%)$ & 0,14 & 0,16 & 0,27 & 0,26 \\
\hline $\mathrm{Cu}(\mathrm{mg} / \mathrm{kg})$ & 32,7 & 33,2 & 42,7 & 40,9 \\
\hline $\mathrm{Mn}(\mathrm{mg} / \mathrm{kg})$ & 30,0 & 49,4 & 112 & 70,0 \\
\hline $\mathrm{Zn}$ (mg/kg) & 161 & 169 & 171 & 153 \\
\hline$B(\mathrm{mg} / \mathrm{kg})$ & 65,6 & 67,2 & 82,0 & 72,4 \\
\hline $\mathrm{Cd}(\mathrm{mg} / \mathrm{kg})$ & 0,10 & 0,07 & 0,24 & 0,13 \\
\hline $\mathrm{Cr}(\mathrm{mg} / \mathrm{kg})$ & 33,1 & 25,5 & 18,6 & 49,8 \\
\hline $\mathrm{Pb}(\mathrm{mg} / \mathrm{kg})$ & 5,25 & 3,28 & 12,4 & 7,84 \\
\hline $\mathrm{Ni}(\mathrm{mg} / \mathrm{kg})$ & 13,0 & 11,1 & 8,83 & 27,2 \\
\hline $\mathrm{Hg}(\mathrm{mg} / \mathrm{kg})$ & 0,02 & 0,02 & 0,04 & 0,06 \\
\hline \multicolumn{5}{|l|}{ Patógenos } \\
\hline Salmonella & ND & ND & ND & ND \\
\hline Listeria & ND & ND & ND & ND \\
\hline Clostridium perfringens & $9,00 \cdot 10^{1}$ & $<10$ & $5,10 \cdot 10^{2}$ & $1,10 \cdot 10^{2}$ \\
\hline Estreptococos fecales & $1,40 \cdot 10^{2}$ & $7,00 \cdot 10^{1}$ & $<10$ & $<10$ \\
\hline Escherichia coli & $<10$ & $4,00 \cdot 10^{1}$ & $<10$ & $<10$ \\
\hline
\end{tabular}

CE: Conductividad eléctrica; ND: No detectados en 25 g compost; En filas, los valores medios seguidos de la misma letra no indican diferencias estadísticas significativas de acuerdo al test de Tukey $(a p<0,05)$. 


\subsubsection{Propiedades físicas}

En la Tabla 4 se muestran las principales propiedades físicas de los compost obtenidos y se comparan con los valores recomendados para un sustrato ideal que actúe como medio de crecimiento para la producción de plantas en macetas (Abad et al., 2001). Los resultados mostraron que todos los compost poseían parámetros adecuados para ejercer como sustratos para cultivo sin suelo. En el caso de los compost 1 y 2, los mayores valores de contenido en aire favorecen su uso como sustrato a pesar de la menor capacidad de retención de agua (Bustamante et al., 2012), efecto que se puede contrarrestar con un riego más frecuente y en menores cantidades.

Tabla 4. Propiedades físicas de los compost obtenidos. Valores medios \pm error estándar

\begin{tabular}{lccccc}
\hline & S.I. $^{1}$ & Compost 1 & Compost 2 & Compost 3 & Compost 4 \\
\hline Da (g/cm $\left.{ }^{3}\right)$ & $\leq 0,40$ & $0,23 b \pm 0,00$ & $0,21 \mathrm{c} \pm 0,00$ & $0,26 a \pm 0,00$ & $0,26 a \pm 0,00$ \\
EPT (\% vol) & $>85$ & $87,54 b \pm 0,05$ & $87,85 a \pm 0,07$ & $86,44 \mathrm{~d} \pm 0,01$ & $86,91 \mathrm{c} \pm 0,10$ \\
Contracción (\% vol) & $<30$ & $17,18 \mathrm{~b} \pm 0,08$ & $16,22 \mathrm{~b} \pm 0,35$ & $23,39 \mathrm{a} \pm 1,48$ & $23,36 \mathrm{a} \pm 0,44$ \\
CA $(\% \mathrm{vol})$ & $20-30$ & $36,00 \mathrm{~b} \pm 0,52$ & $48,70 \mathrm{a} \pm 0,08$ & $23,60 \mathrm{c} \pm 0,21$ & $22,50 \mathrm{c} \pm 0,29$ \\
CRA (mL/L) & $550-800$ & $516 \mathrm{c} \pm 4,65$ & $392 \mathrm{~d} \pm 1,40$ & $629 \mathrm{~b} \pm 2,29$ & $644 \mathrm{a} \pm 3,91$ \\
\hline
\end{tabular}

${ }^{1}$ Sustrato ideal de acuerdo a Abad et al. (2001).

Da: Densidad aparente; EPT: Espacio poroso total; CA: Contenido en aire; CRA: Capacidad de retención de agua En filas, los valores medios seguidos de la misma letra no indican diferencias estadísticas significativas de acuerdo al test de Tukey $(a p<0,05)$

\subsubsection{Capacidad supresiva de los compost frente a $F$. oxysporum melonis: ensayo en semillero}

Se realizó un ensayo con plántulas de melón en el que cada uno de los cuatro composts se empleó como sustrato de semillero, empleándose turba como control. Los resultados mostrados indican como el peso fresco de la parte aérea de las plántulas de melón mostraron un efecto similar o mayor a la turba, a los 40 días después de trasplantadas (Figura $5 \mathrm{~A}$ ). Los compost 1 y 2 mostraron un mayor peso fresco de plántulas de melón que los composts 3 y 4 , debido posiblemente al efecto negativo de la conductividad eléctrica de estos (Lemaire et al., 1985).

La Figura 5B, también muestra los valores de peso fresco de la parte aérea de las plántulas de melón en presencia del patógeno Fusarium oxysporum f. sp. melonis (FOM). Estos valores se utilizaron para evaluar el potencial efecto de valor añadido en cuanto a su efecto supresivo. En la misma se demuestra como los tratamientos con los composts 1 y 2 presentaron una menor reducción de peso fresco que en el caso de la turba, indicando el efecto supresivo de los mismos, caso que no ocurrió con los composts 3 y 4 , en los que el descenso de peso fresco fue similar al observado por la turba. Teniendo en cuenta que las diferencias entre los compost 1 y 2 y el 3 y 4 se basaban en el agente co-compostante, no solo pone de manifiesto la importancia del agente empleado para el proceso de compostaje, sino también para el potencial valor del compost obtenido, que en el caso evaluado fue el efecto supresivo. 


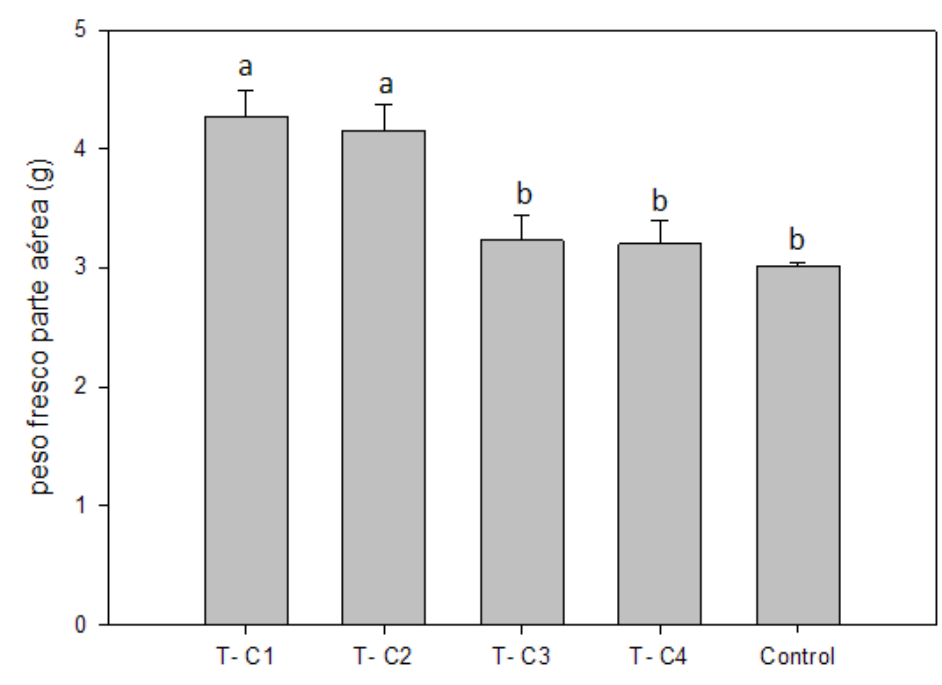

A

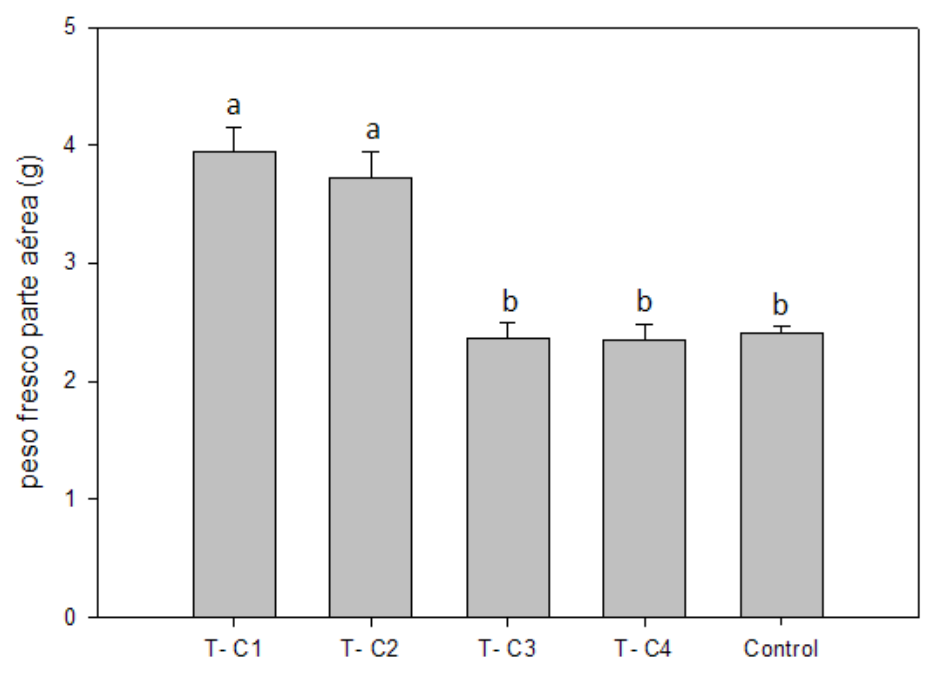

B

Figura 5. Peso fresco de la parte aérea de plántulas de melón (gramos) para diferentes tratamientos, 40 días después de trasplantadas. (A) sin inoculación del patógeno y (B) con inoculación de F. oxyporum (FOM). Las barras de error representan el error estándar. Para todos los compost, los valores con la misma letra no indican diferencias significativas de acuerdo al test de Tukey (a $p<0,05)$

\section{Conclusión}

El co-compostaje de los lodos de depuración generados por el sector de transformados vegetales con restos de poda de vid o restos de cultivo de pimiento, como agente estructurante constituye una opción viable para la gestión y reciclado de estos biorresiduos. Los mejores resultados se obtuvieron para el compost que incorporó como agente estructurante los restos de poda de vid de un tamaño $<1 \mathrm{~cm}$. 
Todos los compost obtenidos presentaron calidad suficiente para ser utilizados como sustituto de la turba en el cultivo de melón en semillero. Además, el compost que incorporó restos de poda de vid como agente estructurante permite su empleo bajo presión de patógeno, consiguiendo de este modo un doble efecto, sustituir a la turba y reducir los niveles de plaguicidas químicos a aplicar.

\section{Bibliografía}

Abad, M., Noguera, P., Burés, S., 2001. National inventory of organic wastes for use as growing media for ornamental potted plant production: case study in Spain. Bioresour. Technol. 77, 197-200.

AGROWASTE, 2014. Resultados del proyecto AGROWASTE LIFE10/ENV/ES/469. Disponible en: www.agrowaste.eu

Aydin, G.A., Kocasoy, G., 2002. Investigation of appropriate initial composition and aeration method for co-composting of yard waste and market wastes. Appropriate Environmental and Solid Waste Management and Technologies for Developing Countries. Vol. 2. Istanbul. Turkey. pp. 1277-1284.

Banegas, V., Moreno, J.L., Moreno, J.I., García, C., León, G., Hernández, T., 2007. Composting anaerobic and aerobic sewage sludges using two proportions of sawdust. Waste Manage. 27, 1317-1327.

Barrington, S., Choinière, D., Trigui, M., Knight, W., 2002. Effect of carbon source on compost nitrogen and carbon losses. Bioresour. Technol. 83, 189-194.

Benito, M., Masaguer, A., De Antonio, R., Moliner A., 2005. Use of pruning waste compost as a component in soil-less growing media, Bioresour. Technol. 96, 597-603.

Benito, M., Masaguer, A., Moliner, A., Arrigo, N., Palma, R.M., 2003. Chemical and microbiological parameters for the characterization of the stability and maturity of pruning waste compost. Biol. Fertil. Soils 37, 184-189.

Bernal, M.P., Alburquerque, J.A., Moral, R., 2009. Composting of animal manures and chemical criteria for compost maturity assessment. A review. Bioresour. Technol. 100, 5444-5453.

Bernal, M.P., Navarro, A.F., Roig, A., Cegarra, J., García, D., 1996. Carbon and nitrogen transformation during composting of sweet sorghum bagasse. Biol. Fertil. Soils 22, 141-148.

Bernal, M.P., Paredes, C., Sanchez-Monedero, M.A., Cegarra, J., 1998. Maturity and stability parameters of compost prepared with a wide range of organic wastes. Bioresour. Technol. 63, 91-99.

Bernal-Vicente, A., Ros, M., Tittarelli, F., Intrigliolo, F., Pascual, J.A., 2008. Citrus compost and its water extract for cultivation of melon plants in greenhouse nurseries: evaluation of nutritive and biocontrol effects. Bioresour Technol 99, 8722-8728.

Blaya, J., Lopez-Mondejar, R., Lloret, E., Pascual, J.A., Ros, M., 2013. Changes induced by Trichoderma harzianum in suppressive compost controlling Fusarium wilt. Pest. Biochem. Physiol. 107, 112-119.

BOE, 2011. Ley 22/2011, de 28 de julio, de residuos y suelos contaminados. Boletín Oficial del Estado $181,85650-85705$.

BOE, 2013. Real Decreto 506/2013 sobre productos fertilizantes. Boletín Oficial del Estado 164, 5111951207.

Bonanomi, G., Antignani, V., Capodilupo, M., Scala, F., 2010. Identifying the characteristics of organic soil amendments that suppress soil-borne plant diseases. Soil Biol. Biochem. 42, 136-144. 
Bunt, A.C., 1988. Media and mixes for container-grown plants: A manual on the preparation and use of growing media for pot plants. London. UK. 2nd Ed. Unwin Hyman Ltd. 309 pp.

Bustamante, M.A., Alburquerque, J.A., Restrepo, A.P., de la Fuente, C., Paredes, C., Moral, R., Bernal, M.P., 2012. Co-composting of the solid fraction of anaerobic digestates, to obtain added-value materials for use in agriculture. Biomass Bioenergy 43, 26-35.

Bustamante, M.A., Moral, R., Bonmatí, A., Palatsí, J., Solé-Mauri, F., Bernal, M.P., 2014. Integrated Waste Management Combining Anaerobic and Aerobic Treatment: A Case Study. Waste and Biomass Valorization 5, 481-490.

Bustamante, M.A., Moral, R., Paredes, C., Vargas-García, M.C., Suárez-Estrella, F., Moreno, J., $2008 a$. Evolution of the pathogen content during co-composting of winery and distillery wastes. Bioresour. Technol. 99, 7299-7306.

Bustamante, M.A., Paredes, C., Marhuenda-Egea, F.C., Pérez-Espinosa, A., Bernal, M.P., Moral, R., 2008b. Co-composting of distillery wastes with animal manures: Carbon and nitrogen transformations in the evaluation of compost stability. Chemosphere 72, 551-557.

Bustamante, M.A., Paredes, C., Moral, R., Agullo, E., Perez-Murcia, M.D., Abad, M., 2008c. Composts from distillery wastes as peat substitutes for transplant production. Resour. Conserv. Recycl. 52, 792799.

Bustamante, M.A., Restrepo, A.P., Alburquerque, J.A., Pérez-Murcia, M.D., Paredes, C., Moral, R., Bernal, M.P., 2013. Recycling of anaerobic digestates by composting: effect of the bulking agent used. J. Clean. Prod. 47, 61-69.

Caballero, R., Pajuelo, P., Ordovás, J., Carmona, E., Delgado, A., 2009. Evaluation and correction of nutrient availability to Gerbera jamesonii $\mathrm{H}$. Bolus in various compost-based growing media. Sci. HorticAmsterdam 122, 244-250.

Cayuela, M.L., Sánchez-Monedero, M.A., Roig, A., Sinicco, T., Mondini, C., 2012. Biochemical changes and GHG emissions during composting of lignocellulosic residues with different $\mathrm{N}$-rich by-products. Chemosphere 88, 196-203.

Chen, Y., 2012. Sewage sludge aerobic composting technology research progress. AASRI Procedia 1, 339343.

Chen, Y., Yu, F., Liang, S., Wang, Z., Liu, Z., Xiong Y., 2014. Utilization of solar energy in sewage sludge composting: Fertilizer effect and application. Waste Manage. 34, 2014-2021.

Cheng, H.F., Xu, W.P., Liu, J.L., Zhao, Q.J., He, Y.Q., Chen, G., 2007. Application of composted sewage sludge (CSS) as a soil amendment for turfgrass growth. Ecol. Eng. 29, 96-104.

Cherfetz, B., Hatcher, P.G., Hadar, Y., Chen, Y., 1996. A first approach to the characterization of the presence of humified materials in organic fertilizers. Agrochimica 32, 510-517.

Christensen, A., Gurol, M.D., Garoma, T., 2009. Treatment of persistent organic compounds by integrated advanced oxidation processes and sequential batch reactor. Water Re. 43, 3910-3921.

Chowdhury, A.K.M.M.B., Michailides, M.K., Akratos, C.S., Tekerlekopoulou, A.G., Pavlou, S., Vayenas, D.V., 2014. Composting of three phase olive mill solid waste using different bulking agents. Int. Biodeterior. Biodegrad. 91, 66-73.

Coble, P.G., Mopper, K., Schultz, C.S., 1993. Fluorescence contouring analysis of DOC intercalibration experiment samples: a comparison of techniques. Mar. Chem. 41, 173-178.

DOUE, 1991. COUNCIL DIRECTIVE of 21 May 1991 concerning urban waste water treatment (91/271/EEC). Diario Oficial de la Unión Europea 135, 40-52. 
Doublet, J., Francou, C., Poitrenaud, M., Houot, S., 2011. Influence of bulking agents on organic matter evolution during sewage sludge composting; consequences on compost organic matter stability and $\mathrm{N}$ availability. Bioresour. Technol. 102, 1298-1307.

Eklind, Y., Sundberg, C., Smars, S., Steger, K., Sundh, I., Kirchmann, H., Jonsson, H., 2007. Carbon turnover and ammonia emissions during composting of biowaste at different temperatures. J. Environ. Qual. 36, 1512-1520.

EPA, 1998. Method EPA 3015. Microwave Assisted Acid Digestion of Sediments, Sludges, Soils and Oils. Washington, DC.

European Commission, 2001. Working document on biological treatment of biowaste. 2nd draft. Brussels; DG ENV.A.2./LM/biowaste/2nd draft.

European Committee for Standardization, 1999. Soil Improvers and Growing Media - Determination of Organic Matter and Ash. Standard CEN EN 13039:1999 E. European Committee for Standardization, Brussels.

Garcia, C., Hernández, T., Costa, F., Ceccanti, C., Ganni, A., 1993. Hydrolases in the organic matter fractions of sewage sludge: changes with composting. Bioresour. Technol. 45, 47-52.

Garcia-Gomez, A., Bernal, M.P., Roig, A., 2002. Growth of ornamental plants in two composts prepared from agro-industrial wastes, Bioresour. Technol. 83, 81-87.

Golueke, C.G., 1981. Principles of biological resource recovery. BioCycle 22, 36-40.

He, M.M., Tian, G.M., Liang, X.Q., 2009. Phytotoxicity and speciation of copper, zinc and lead during the aerobic composting of sewage sludge. J. Hazard. Mater. 163, 671-677.

Himanen, M., Hänninen, K., 2011. Composting of bio-waste, aerobic and anaerobic sludges - Effect of feedstock on the process and quality of compost. Bioresour. Technol. 102, 2842-2852.

Hogg, D., Favoino, E., Centemero, M., Caimi, V., Amlinger, F., Devliegher, W., Brinton, W., Antler, S., 2002. Comparison of Compost Standards within the EU, North America and Australia. The Waste and Resources Programme (WRAP), Oxon.

Ingelmo, F., Molina, M.J., Soriano, M.D., Gallardo, A., Lapeña, L., 2012. Influence of organic matter transformations on the bioavailability of heavy metals in a sludge based compost. J. Environ. Manage. 95, S104-S109.

Jamali, M.K., Kazi, T.G., Arain, M.B., Afridi, H.I., Jalbani, N., Kandhro, G.A., Shah, A.Q., Baig, J.A., 2009. Heavy metal accumulation in different varieties of wheat (Triticum aestivum L.) grown in soil amended with domestic sewage sludge. J. Hazard. Mater. 164, 1386-1391.

Kang, J., Zhang, Z., Wang, J.J., 2011. Influence of humic substances on bioavailability of Cu and Zn during sewage sludge composting. Bioresour. Technol. 102, 8022-8026.

Kitson, R.E., Mellon, M.G., 1944. Colorimetric determination of P as molybdovanato phosphoric acid. Ind Eng Chem. 42(3), 379-383.

Lemaire, F., Dartigues, A., Rivière, L. M., 1985. Properties of substrate made with spent mushroom compost. Acta Hort. 172, 13-29.

Li, Z., Lu, H., Ren, L., He, L., 2013. Experimental and modeling approaches for food waste composting: A review. Chemosphere 93, 1247-1257.

Locatelli, A., Spor, A., Jolivet, C., Piveteau, P., Hartmann, A., 2013. Biotic and Abiotic Soil Properties Influence Survival of Listeria monocytogenes in Soil. PLoS ONE 8(10): e75969. doi: 10.1371/journal.pone.0075969. 
Lopez-Mondejar, R., Blaya, J., Obiol, M., Ros, M., Pascual, J.A., 2012. Evaluation of the effect of chitinrich residues on the chitinolytic activity of Trichoderma harzianum: In vitro and greenhouse nursery experiments. Pest. Biochem. Physiol. 103, 1-8.

Maboeta, M.S., van Rensburg, L., 2003. Vermicomposting of industrially produced woodchips and sewage sludge utilizing Eisenia fetida. Ecotoxicol. Environ. Saf. 56(2), 265-270.

MAGRAMA, 2015. Informe Industria Alimentaria 2013-2014 del Ministerio de Agricultura, Alimentación y Medio Ambiente de España. Disponible en:

http://www.magrama.gob.es/es/alimentacion/temas/industria-agroalimentaria/informacioneconomica-sobre-la-industria-agroalimentaria/

Marfà, O., Lemarie, F., Cáceres, R., Giuffrida, F., Guérin, V., 2002. Relationships between growing media fertility, percolate composition and fertigation strategy in peat-substitute substrates used for growing ornamental shrubs. Sci. Hortic. 94, 309-321.

Meunchang, S., Panichsakpatana, S., Weaver, R.W., 2005. Co-composting of filter cake and bagasse; byproducts from a sugar mill. Bioresour. Technol. 96, 437-442.

Mobed, J.J., Hemmingsen, S.L., Autry, J. L., McGown, L.B., 1996. Fluorescence characterization of IHSS humic substances: Total luminescence spectra with absorbance correction. Environ. Sci. Technol. 30, 3061-3065.

Molla, A.H., Fakhru'l-Razi, A., Alam, Md.Z., 2004. Evaluation of solid state bioconversion of domestic wastewater sludge as a promising environmental-friendly disposal technique. Water Res. 38, 4143-4152.

Morel, J.L., Colin, F., Germon, J.C., Godin, P., Juste, C., 1985. Methods for the Evaluation of the Maturity of Municipal Refuse Compost. In: Gasser, J.K.R. (Ed.), Composting of agricultural and other wastes. Barking. Essex. Elsevier Applied Science Publisher. pp. 56-72.

Najafpour, G.D., Zinatizadeh, A.A.L., Lee, L.K., 2006. Performance of a three-stage aerobic RBC reactor in food canning wastewater treatment. Biochem. Eng. J. 30, 297-302.

Navarro, A.F., Cegarra, J., Roig, A., Bernal, M.P., 1991. An automatic microanalysis method for the determination of organic carbon in wastes. Commun. Soil Sci. Plant Anal. 22, 2137-2144.

Neves, L., Ferreira, V., Oliveira, R., 2009. Co-composting cow manure with food waste: the influence of lipids content. World Acad. Sci. Eng. Technol. 58, 986-991.

Ostos, J.C., Lopez-Garrido, R., Murillo, J.M., Lopez, R., 2008. Substitution of peat for municipal solid waste and sewage sludge based composts in nursery growing media: effects on growth and nutrition of the native shrub Pistacia lentiscus L, Bioresour. Technol. 99, 1793-1800.

Otero, M., Calvo, L.F., Estrada, B., García, A.I., Morán, A., 2002. Thermochim. Acta 389, 121-132.

Paredes, C., Bernal, M.P., Cegarra, J., Roig, A., 2002. Bio-degradation of olive mill wastewater sludge by its co-composting with agricultural wastes. Bioresour. Technol. 85, 1-8.

Pasda, N., Limtong, P., Oliver, R., Montange, D., Panichsakpatana, S., 2005. Influence of bulking agents and microbial activator on thermophilic aerobic transformation of sewage sludge. Environ. Technol. 26(10), 1127-1136.

Pourcher, A.M., Morand, P., Picard-Bonnaud, F., Billaudel, S., Monpoeho, S., Federighi, M., Ferre', V., Moguedet, G., 2005. Decrease of enteric microorganisms from rural sewage sludge during their composting in straw mixture. J. Appl. Microbiol. 99, 528-539.

Raj, D., Antil, R.S., 2011. Evaluation of maturity and stability parameters of composts prepared from agro-industrial wastes. Bioresour. Technol. 102, 2868-2873. 
Ribeiro, H.M., Romero, A.M., Pereira, H., Borges, P., Cabral, F., Vaconcelos, E., 2007. Evaluation of a compost obtained from forestry wastes and solid phase of pig slurry as a substrate for seedlings production. Bioresour. Technol. 98, 3294-3297.

Roca-Pérez, L., Martínez, C., Marcilla, P. Boluda, R., 2009. Composting rice straw with sewage sludge and compost effects on the soil-plant system. Chemosphere 75, 781-787.

Sánchez-Monedero, M.A., Roig, A., Cegarra, J., Bernal, M.P., Noguera, P., Abad, A., Antón, A., 2004. Composts as media constituents for vegetable transplant production. Compost Sci. Util. 12, 161-168.

Singh, R.P., Agrawal, M., 2008. Potential benefits and risks of land application of sewage sludge. Waste Manage. 28(2), 347-358.

Smith, S.R., 2009. A critical review of the bioavailability and impacts of heavy metals in municipal solid waste composts compared to sewage sludge. Environ. Int. 35, 142-156.

Strauch, D., 1987. Microbiological specifications of disinfected compost. In: De Bertoldi, M., Ferranti, M.P., L'Hermite, P., Zucconi, F. (Eds.), Compost: Production, Quality and Use. London. Elsevier. pp. 210229.

Tabatabai, M.A., 1982. Soil enzymes. p. 903-948. In: Page, A.L. (Ed.), Methods of soil analysis. Part 2. Chemical and microbiological properties. Madison. American Society of Agronomy.

Tiquia, S.M., 2005. Microbiological parameters as indicators of compost maturity. J. Appl. Microbiol. 99, 816-828.

Tortosa, G., Alburquerque, J.A., Ait Baddi, G., Cegarra, J., 2012. The production of commercial organic amendments and fertilisers by composting of two-phase olive mill waste ("alperujo"). J. Clean. Prod. 26, 48-55.

Trevors, J.T., 1986. Bacterial growth and activity as indicators of toxicity. In: Bitton, G., Dutka, B.J. (Eds.), Toxicity Testing Using Microorganisms, Vol 1. Florida. CRC Press. Boca Ratón. pp. 9-25.

Wang, X., Chen, T., Ge, Y., Jia, Y., 2008. Studies on land application of sewage sludge and its limiting factors. J. Hazard. Mater. 160, 554-558.

Wong, J.W.C., Fang, M., Su, D.C., 2003. Toxicity evaluation of sewage sludge in Hong Kong. Environ. Int. 27, 373-380.

Zucconi, F., Pera, A., Forte, M., Bertoldi, M., 1981. Evaluating toxicity of immature compost. BioCycle 22, 54-57. 
VII. Compostaje de residuos orgánicos y subproductos agroindustriales para reducir el uso de turba en la producción de plántulas de melón 



\section{Compostaje de residuos orgánicos y subproductos agroindustriales para reducir el uso de turba en la producción de plántulas de melón}

\section{Introducción}

La turba es el medio de cultivo más utilizado para el cultivo sin suelo y/o contenedor, debido a sus características agronómicas positivas tales como propiedades físicas, químicas y constante alta capacidad de retención de agua, porosidad óptima, además de un pH adecuado (Pane et al., 2011). Su inconveniente radica en que representa uno de los mayores costes de producción en los semilleros. Además, las preocupaciones ambientales sobre la extracción de turba de los ecosistemas húmedos se han elevado. Las turberas cubren el $3 \%$ de la superficie terrestre, siendo las turberas boreales y subárticas las que almacenan aproximadamente entre el 15 y el 30 \% del carbono del suelo (Limpens et al., 2008). Por lo tanto, se está realizando un esfuerzo a nivel internacional para evaluar la capacidad de otros sustratos orgánicos como alternativas a la misma (Raviv, 2005; Pane et al., 2011). Los compost pueden ser una alternativa con un valor añadido ya que proporcionan resultados similares a la turba, a la vez que su capacidad supresiva y de fertilización permiten reducir el uso de fungicidas y fertilizantes químicos, contribuyendo a una reducción del coste en la producción (Ros et al., 2005).

La industria de la transformación de frutas y hortalizas de la Región de Murcia producen una gran cantidad de residuos orgánicos, tales como lodos de aguas residuales de los tratamientos de aguas residuales y algunos otros subproductos que no son realmente explotados (AGROWASTE, 2014). El compostaje como opción de valorización de los residuos orgánicos y subproductos produce un compost de alta calidad que se utiliza en la agricultura y más específicamente en semilleros (Blaya et al., 2015).

El compostaje es una práctica antigua en la que se degradan los subproductos o residuos orgánicos a través de la actividad de diferentes grupos de microorganismos, que ha sido ampliamente estudiado (Nagasaki et al., 2005). Dado que la composición microbiana depende de las materias primas iniciales y el proceso de compostaje, la calidad del compost muestra diferencias dependiendo de estos factores (Raviv et al., 1986; Carlile, 2008; Campitelli y Ceppi, 2008), además de afectar a otras características menos estudiadas, como es su supresividad frente a fitopatógenos de planta (Tuomela et al., 2000; Tittarelli et al., 2009; Boldrin et al., 2009; Blaya et al., 2015). Por tanto, el uso de determinadas tipologías de compost como sustrato de cultivo incluye, además de beneficios ambientales al permitir la reducción de turba (Limpens et al., 2008), beneficios relacionados a la mejora del estado nutricional y aporte de una microbiota beneficiosa que permite controlar patógenos de plantas (Yogev et al., 2010; López Mondéjar et al., 2010; Tejada y Benítez, 2011; Blaya et al., 2015). Sin embargo, puede 
presentar limitaciones relativas a propiedades críticas para el cultivo vegetal tales como una inadecuada densidad aparente, alta salinidad, fitotoxicidad, $\mathrm{pH}$, etc. (Raviv, 2011).

Este enfoque se ha considerado teniendo en cuenta el concepto de "economía circular", que mantiene el valor añadido de los productos durante el mayor tiempo posible y elimina los desechos (UE COM (2014)). Además, permite obtener recursos eficientes de acuerdo con la Estrategia Europa 2020 para un crecimiento inteligente, sostenible e integrador (COM (2010) 2020, COM (2011)).

Atendiendo a estas premisas, el objetivo en este capítulo fue evaluar diferentes residuos y subproductos de la industria de procesado de frutas y vegetales de la Región de Murcia en la producción de compost con valor añadido, que puedan ser una alternativa al uso de turba para la industria agrícola, aproximándose a la economía circular. Para este propósito se desarrollaron dos experimentos relacionados: 1) el compostaje de diferentes residuos orgánicos agroindustriales y subproductos y la determinación del compost obtenido como producto de calidad de acuerdo a sus propiedades químicas, microbiológicas y físicas; y 2) la evaluación del compost agroindustrial obtenido como sustituto parcial de la turba para el cultivo de plántulas de melón en semillero. En esta fase también se evaluó su potencial valor añadido como biofertilizantes y su capacidad supresiva contra Fusarium oxysporum f. sp. melonis (FOM) en melón.

\section{Materiales y métodos}

\subsection{Proceso de compostaje}

Se realizaron diez compost en pilas de compostaje (150-220 kg), con relación $\mathrm{C} / \mathrm{N}$ entre 19 y 33 . El sistema de compostaje fue en composteras de $350 \mathrm{~L}$ de capacidad, utilizando lodos agroalimentarios, además de poda de vid como agente estructurante, y otros subproductos de la industria agroalimentaria tales como alcachofa, pimiento rojo, zanahoria, brócoli, naranja, y compost maduro, este último obtenido a partir de lodo agroalimentario y subproductos agroindustriales (poda de vid, restos de alcachofa y orujo). Los materiales se obtuvieron de empresas colaboradoras de la Región de Murcia (Sociedad de Depuración Virgen de los Dolores S.L, Conservas El Raal, Ultracongelados Azarbe, Hero, Citromil y Reciclados Tara S.L). Además, para ajustar la relación $\mathrm{C} / \mathrm{N}$ se adicionó polvo de almendra como ya se indicó en estudios previos. Las mezclas utilizadas se indican en la Tabla 1. 
Tabla 1. Composición de las pilas de compostaje (Datos de porcentaje expresado en peso seco)

\begin{tabular}{lcccccccccc}
\hline & C1 & C2 & C3 & C4 & C5 & C6 & C7 & C8 & C9 & C10 \\
\hline Lodo de alcachofa & - & 27 & 18 & 21 & - & - & - & - & - & - \\
Lodo de pimiento & 35 & - & - & - & 13 & 18 & - & - & - & - \\
Lodo de cítrico & - & - & - & - & - & - & - & - & - & 35 \\
Subproducto de alcachofa & - & 7 & 5 & 6 & - & - & - & 16 & - & - \\
Subproducto de pimiento & - & - & - & - & 12 & - & - & 17 & - & - \\
Subproducto de zanahoria & - & - & - & - & - & 35 & - & - & 15 & - \\
Subproducto de brócoli & - & - & - & - & - & - & 33 & - & 37 & - \\
Subproducto de naranja & - & - & - & - & - & - & 21 & - & & 18 \\
Almendra en polvo & - & - & - & - & - & - & 21 & - & 22 & - \\
Compost maduro & - & & 25 & 14 & - & - & - & - & - & - \\
Restos de poda de vid <1cm & 65 & 66 & 52 & 59 & 75 & 47 & 25 & 68 & 26 & 47 \\
Relación C/N & 22 & 19 & 19 & 19 & 29 & 28 & 27 & 33 & 26 & 28 \\
\hline
\end{tabular}

La temperatura de las pilas se controló diariamente, volteándose en el momento que se observaba un descenso de la temperatura, manteniendo un grado de humedad por encima del $40 \%$. Las pilas pasaron a maduración cuando la temperatura fue cercana a la ambiental. La fase biooxidativa del proceso de compostaje en las pilas duró entre 43 y 72 días, tras los cuales, y cuando se llegó a un valor constante de temperatura, se dejaron madurar durante aproximadamente un mes.

Las pilas fueron muestreadas inicialmente, tras cada volteo, al final de la etapa biooxidativa y al final de la fase de maduración. Las muestras se tomaron manualmente en tres puntos de la pila a lo largo de todo el perfil (desde la parte superior a la inferior), de tal manera que se obtuviese una muestra representativa del compost al mezclar y homogeneizar las muestras de dichos puntos. Posteriormente cada muestra fue dividida en tres partes para su análisis posterior: una de ellas fue secada a $105^{\circ} \mathrm{C}$ durante $24 \mathrm{~h}$ para determinar el contenido de humedad; la segunda se llevó a refrigeración a $4{ }^{\circ} \mathrm{C}$ para su análisis microbiológico; la tercera fue secada al aire y molida hasta tamaño de partícula menor de $0,5 \mathrm{~mm}$ para el resto de análisis de manera general.

\subsection{Propiedades físicas, químicas y microbiológicas de los compost}

Por un lado, las propiedades físicas de los compost maduros, tales como el espacio poroso total (EPT), la densidad aparente (Da) y la capacidad de retención total de agua (CRA), fueron determinadas de acuerdo con el método usado por Bustamante et al. (2008).

Por otro lado, a los compost, y a una turba como control, se les determinó el pH y la conductividad eléctrica (CE) en un extracto acuoso 1:10 (p/v) utilizando un pHmetro y conductímetro (Crison mod. 2001, Barcelona, Spain). La humedad se determinó de acuerdo al método estándar CEN13039 (European Committee for Standardization, 1999). El nitrógeno total (N) y el carbono orgánico total (C) fueron 
determinados por microanálisis automático (Navarro et al., 1991). El carbono orgánico hidrosoluble $(\mathrm{Ch})$ fue extraído con agua desionizada $1: 10(\mathrm{p} / \mathrm{v})$ y medido en un analizador automático de carbono. El fósforo $(P)$ fue determinado espectrofotométricamente midiendo la intensidad de la coloración amarilla del ácido molibdovanadato fosfórico (Kitson y Mellon, 1944). Y el potasio (K) por fotometría de llama. También se analizó su contenido en $\mathrm{Na}, \mathrm{Ca}, \mathrm{Mg}, \mathrm{Fe}, \mathrm{Mn}$ y metales pesados ( $\mathrm{Cu}$, $\mathrm{Zn}, \mathrm{Cd}, \mathrm{Cr}, \mathrm{Pb}, \mathrm{Ni}$ ) mediante espectrofotometría de masas con plasma de acoplamiento inductivo (ICP-MS) (EPA, 1998), tras una digestión $\mathrm{HNO}_{3} / \mathrm{HClO}_{4}$. La actividad deshidrogenasa se determinó según el método de García et al. (1993).

\subsection{Ensayo en semillero (índice de germinación, peso de plántulas de melón e incidencia de la enfermedad de FOM)}

Los diferentes composts, del C1 al C10, se mezclaron con una turba comercial (50/50 v/v) para obtener diferentes tratamientos para el cultivo de melón: tratamientos del T-C1 al T-C10. La turba al $100 \%$ se utilizó como control. Para realizar el experimento, se empleó semillas de melón (Cucumis melo L., cv. Giotto) sembradas en bandejas de 150 alveolos. Se prepararon seis repeticiones de cada tratamiento, donde cada repetición consistió en 10 semillas. Posteriormente se introdujeron en una cámara de germinación a $28 \pm 1{ }^{\circ} \mathrm{C}$ y una humedad relativa entre el 90 y $95 \%$ durante tres días. Una vez germinadas las semillas, se llevaron a una cámara de cultivo en condiciones de iluminación diurna. El índice de germinación (IG) se calculó de acuerdo a Zucconi et al. (1981). Una vez que apareció la primera hoja verdadera se inocularon, con $2 \mathrm{~mL}$ de Fusarium oxysporum f. sp. melonis (FOM) alcanzando una concentración final de $3,5 \times 10^{5} \mathrm{UFC} / \mathrm{g}$ de sustrato, tres de las réplicas. Las otras tres réplicas se dejaron como control, que además sirvieron para evaluar el efecto de este sustrato de cultivo como una alternativa a la turba. El patógeno FOM se aisló a partir de plántulas infectadas en semillero siguiendo el protocolo descrito por Blaya et al. (2013). Las bandejas se humedecieron periódicamente utilizando riego manual, según sus necesidades. Las plántulas de los tratamientos control se pesaron 40 días después de trasplantadas. El efecto supresivo de los diferentes tratamientos se determinó calculando el porcentaje de plántulas enfermas con respecto al total de plántulas y comparando este dato con el resultado obtenido en el tratamiento de turba infectado.

\subsection{Análisis estadístico}

Los datos se sometieron a análisis de la varianza con un factor (ANOVA). Cuando F-estadística fue significativa, se utilizó el test post hoc de Tukey $(p<0,05)$ para separar los valores medios. Además, se hizo una correlación de Pearson entre todos los datos. Los análisis estadísticos se realizaron con el programa SPSS 22.0 (SPSS Inc., Chicago, IL, EE.UU.). 


\section{Resultados}

\subsection{Evolución de la temperatura del proceso de compostaje}

La evolución de la temperatura durante el compostaje se muestra en la Figura 1. Los perfiles de temperatura fueron similares en todas las pilas y todas alcanzaron la fase termófila entre 1 y 2 veces, para después disminuir progresivamente hasta alcanzar valores constantes y cercanos a la temperatura ambiente. Las temperaturas máximas alcanzadas en las pilas de los compost $\mathrm{C} 1, \mathrm{C} 6, \mathrm{C} 7$ y $\mathrm{C9}$ fueron mayores a $70{ }^{\circ} \mathrm{C}$, mientras que las pilas de los compost $\mathrm{C} 2, \mathrm{C} 3$ y $\mathrm{C} 4$ alcanzaron un máximo de $50^{\circ} \mathrm{C}$.

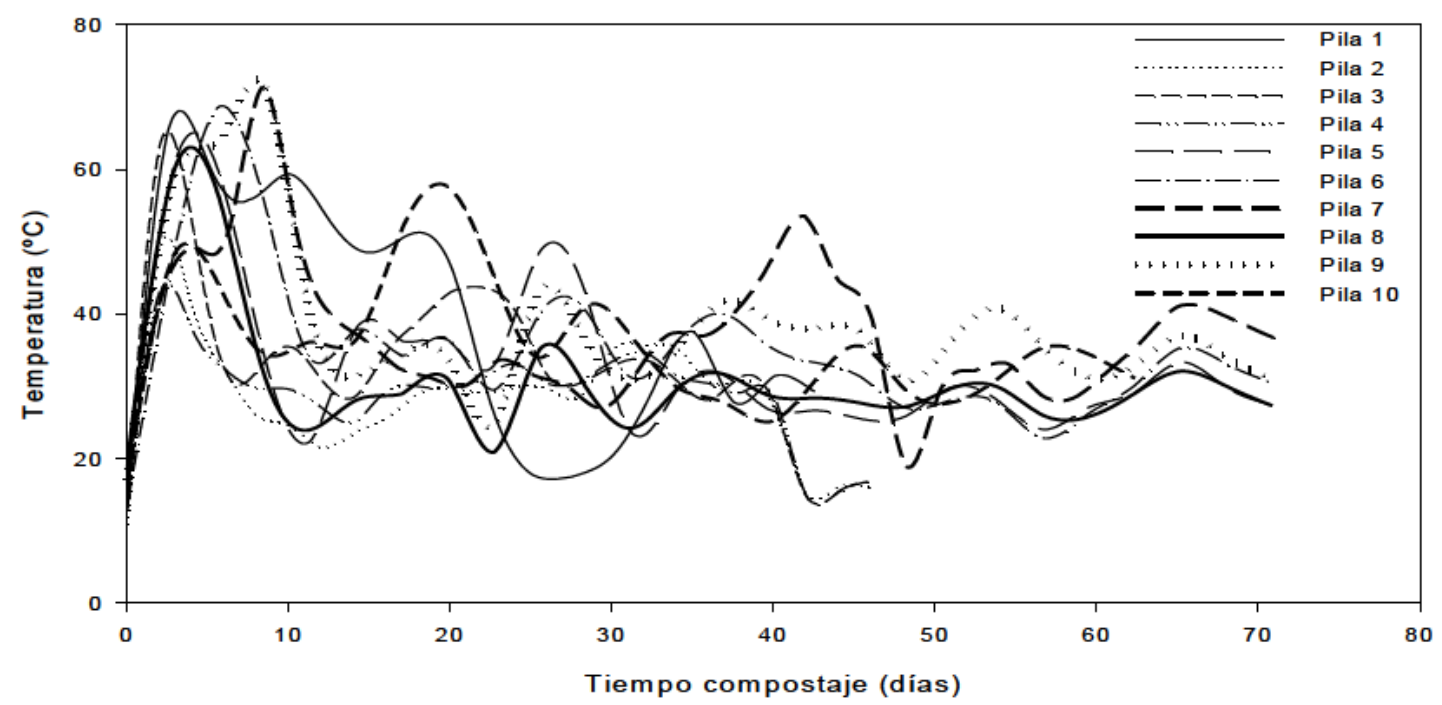

Figura 1. Perfiles de temperatura de las pilas de compostaje durante el proceso

\subsection{Características del compost}

En la Tabla 2 se indican las características químicas del compost final. Tanto los valores del $\mathrm{pH}$, como de la conductividad eléctrica (CE) mostraron diferencias significativas entre compost y turba. Los valores de $\mathrm{pH}$ medios oscilaron entre 6,0 y 9,2 , mientras que los valores de la CE oscilaron entre 1,45 y 3,52 dS/m. Por su parte, la relación $\mathrm{C} / \mathrm{N}$ mostró valores entre 7,1 y 17,1 para el compost.

El contenido de carbono orgánico total mostró un rango entre 26,59 y 43,31 \%, con valores más altos en la turba. El compost C3 y el compost $\mathrm{C} 7$ mostraron el valor más bajo $(F=85,555 ; p<0,05)$, mientras que los compost $C 5, C 7, C 9$ y $C 10$ mostraron los valores más altos $(F=85,555 ; p<0,05)$, por encima del $40 \%$. Por otro lado, los valores del carbono orgánico hidrosoluble y de su relación con el nitrógeno estuvieron dentro del rango $0,19-0,54 \%$ y $0,07-0,25$, respectivamente.

Además, en la Tabla 2 se muestra el contenido de nutrientes de los compost obtenidos. El contenido de nitrógeno total de los compost estuvo entre el 2,23 \% y el 
$3,70 \%$, siendo significativamente mayor que el de la turba, con un 1,3\%. En concreto, los valores más altos se determinaron en el compost C2 y C4. También el compost C2 mostró los valores más altos de fósforo junto con la turba. Sin embargo, los valores más altos de potasio se presentaron en los compost $\mathrm{C} 5, \mathrm{C} 6, \mathrm{C} 7, \mathrm{C} 8, \mathrm{C} 9$ y $\mathrm{C} 10$.

En la Tabla 3 se muestran los resultados del análisis de las propiedades físicas, donde se puede observar que los valores de la densidad aparente de los compost $\mathrm{C} 1 \mathrm{a}$ C4 y la turba fueron $<0,4 \mathrm{~g} / \mathrm{cm}^{3}$, mientras que los de los compost C5 a C10 estuvieron cerca del valor $0,4 \mathrm{~g} / \mathrm{cm}^{3}$. Los datos del espacio poroso total de los compost $\mathrm{C} 1$ a $\mathrm{C} 4$ mostraron valores por encima del $85 \%$, mientras que en los compost C5 a C10 los valores estuvieron por debajo. En cuanto a la capacidad de retención de agua, los datos mostraron valores entre 389 y $547 \mathrm{~mL} / \mathrm{L}$. 

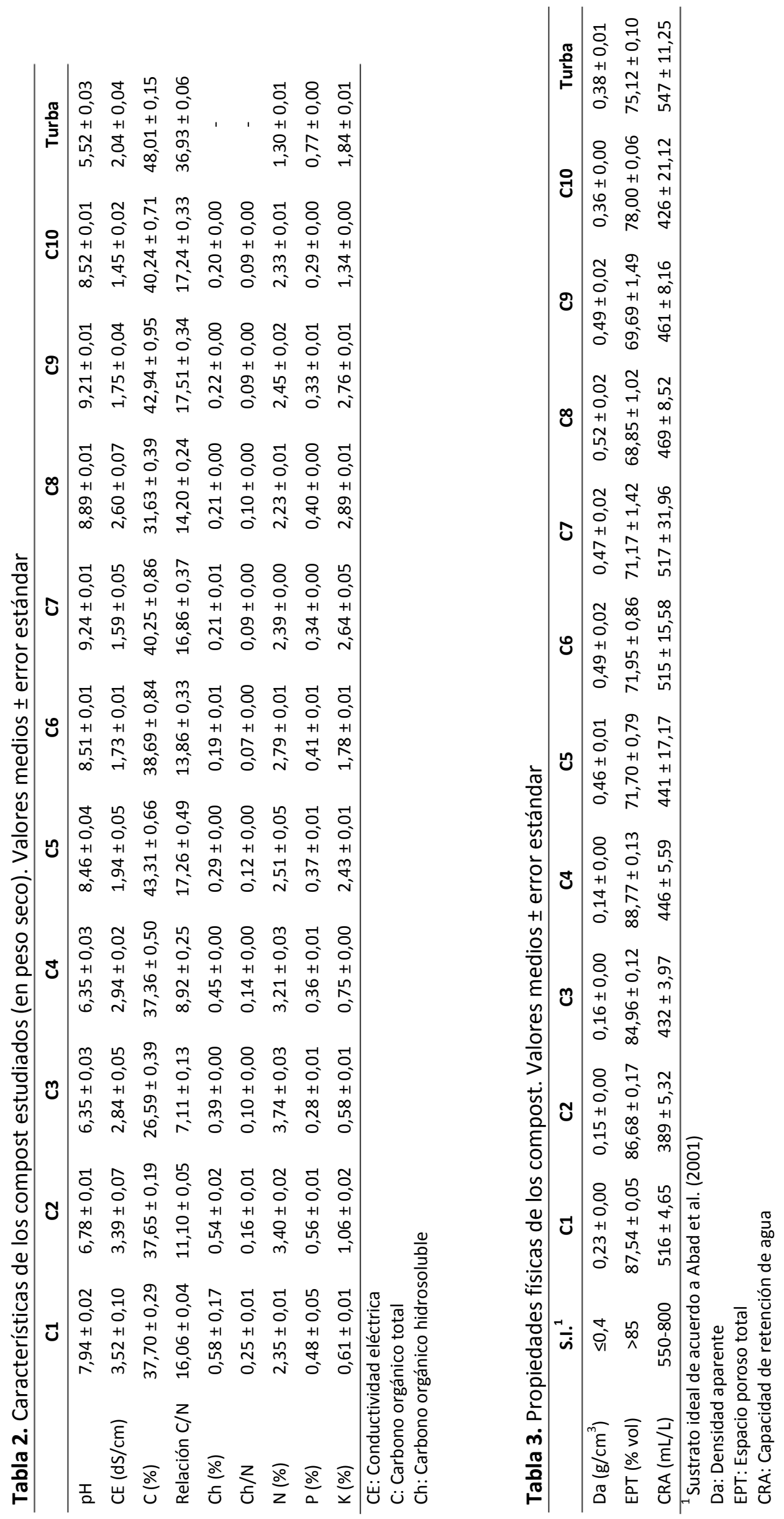
La actividad deshidrogenasa mostró valores que oscilaron entre 3,64 y 69,8 $\mu$ moles INTF/g h. El compost C1 presentó los valores significativamente más altos ( $\mathrm{F}=$ $119,892 ; \mathrm{p}<0,05)$, seguido de los compost C9 y C7, respectivamente. Por otro lado, la actividad deshidrogenasa más baja se mostró en el compost C2 (Figura 2).

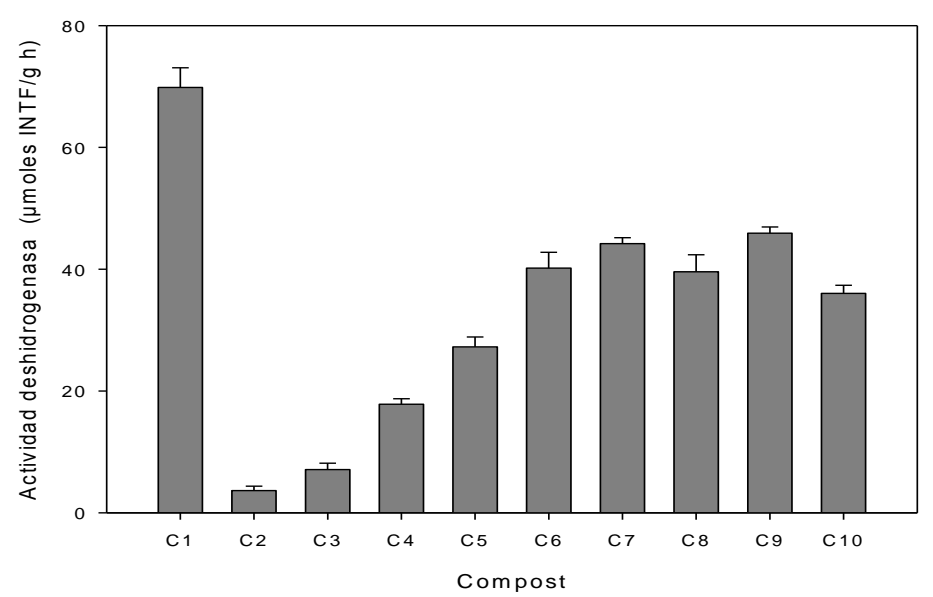

Figura 2. Actividad deshidrogenasa

Los niveles de microorganismos patógenos en todos los compost obtenidos estuvieron por debajo del límite máximo establecido por la legislación española (Real Decreto 506/2013 (BOE, 2013) y las directrices europeas (European Commission, 2001) para su uso como fertilizantes (datos no mostrados).

\subsection{Efecto de los compost como sustrato de cultivo en melón y su capacidad supresividad frente a FOM}

El índice de germinación (IG) presentó valores entre 84,0 \% y 165,7 \% (Figura $3 \mathrm{~A})$, siendo el compost C1 el que mostró el IG más bajo (por debajo del $100 \%$ ), mientras que el resto mostró valores superiores al $100 \%(F=17,712 ; p<0,05)$. Es destacable el mayor valor significativo observado para el compost $C 2$ ( $F=17,712$; $p<0,05)$.

Por otro lado, el crecimiento de las plántulas de melón en cada uno de los tratamientos (mezcla de compost/turba (50/50 v/v) se evaluó midiendo el peso de la parte aérea de las plántulas de melón después de 40 días desde la siembra (Figura 3B). Todos los tratamientos de compost mostraron un peso significativamente mayor que para la turba $(F=7,382 ; p<0,05)$, mostrando el tratamiento T-C2 el valor más alto.

El análisis de la incidencia de la enfermedad para evaluar la capacidad supresividad del compost se indica en la Figura $3 \mathrm{C}$, que refleja que los tratamientos T-C5, T-C7 y T-C8 mostraron el menor porcentaje significativo $(F=16,052 ; p<0,05)$ en 
relación con la turba y estuvieron seguidos por los tratamientos T-C6, T-C10, T-C1 y T-C9 con valores inferiores al $50 \%$.

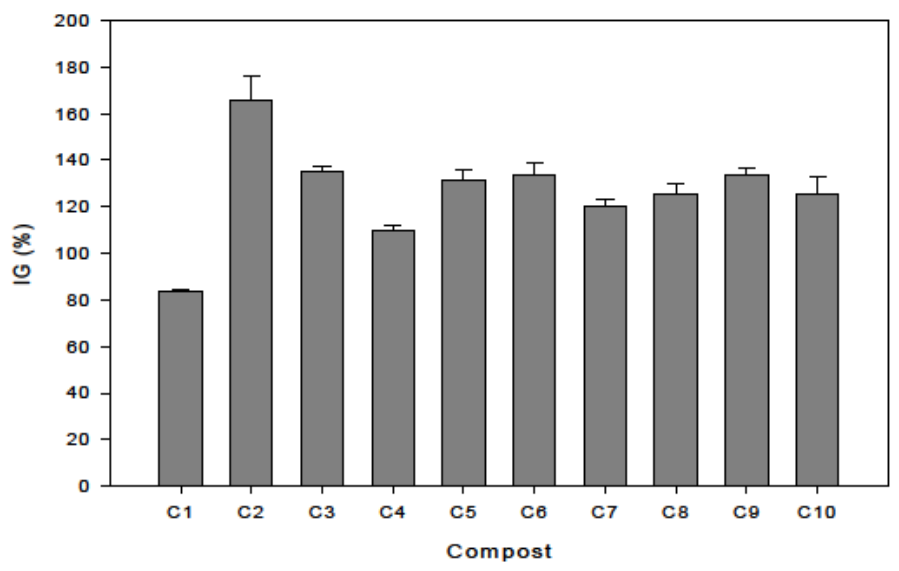

A

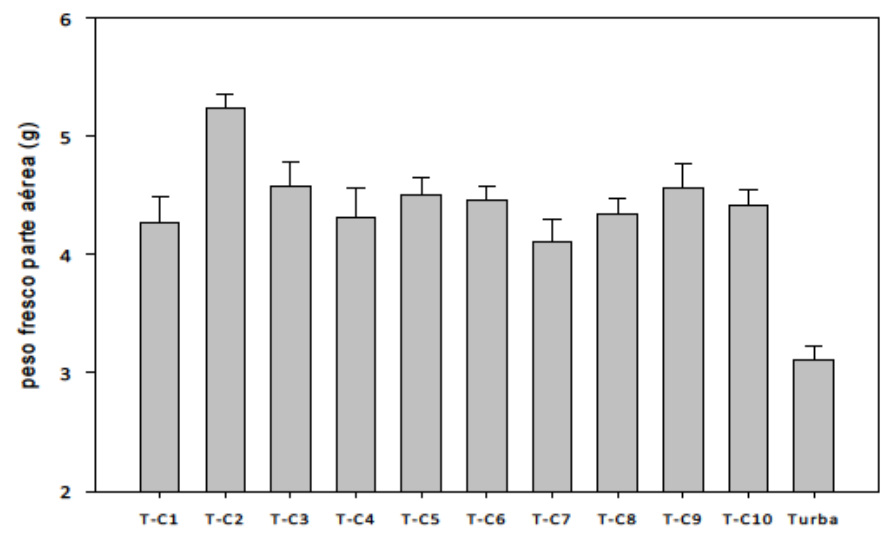

B

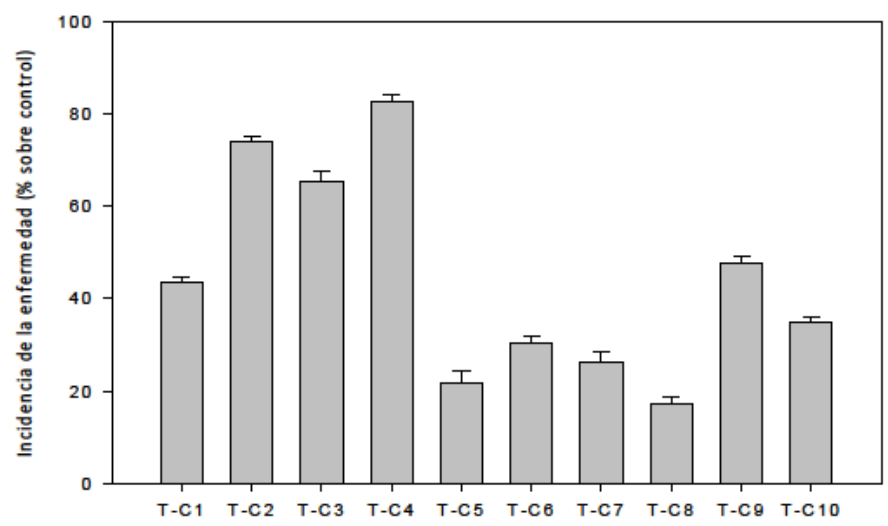

C

Figura 3. Índice de germinación (A); peso de las plántulas de melón en semillero (B); e, incidencia de la enfermedad (Fusarium oxysporum melonis) en el crecimiento de plántulas de melón empleando diferentes compost agroindustriales mezclados con turba (1/1 v/v) (C). 


\section{Discusión}

Este estudio demuestra la viabilidad del uso de residuos orgánicos y subproductos de la industria de transformados vegetales para la producción de compost con valor añadido con efecto biofertilizante y capacidad supresiva frente a FOM, como sustrato de cultivo de alternativa a la turba. Hecho que está de acuerdo con el principio de "economía circular" propuesto por la Unión Europea en el línea Horizonte 2020.

La selección de las materias primas y un adecuado proceso de compostaje son la clave para obtener compost con valor añadido, con un contenido de materia orgánica estable, ausencia de compuestos fitotóxicos y ausencia de contaminación por patógenos.

El perfil de temperatura de las diferentes pilas demostró la actividad microbiana durante el proceso, siendo los microorganismos clave en la transformación de las materias primas para obtener el compost con un valor añadido (Vivas et al., 2009; Bustamante et al., 2014). Los perfiles de temperatura siguieron perfiles similares a otros procesos de compostaje con diferentes materias primas, como lodo de depuración de aguas residuales (Mena et al., 2001) y purines (Ros et al., 2006). Como consecuencia de la rápida descomposición de la materia orgánica fácilmente disponible y los compuestos nitrogenados por los microorganismos (fase termofílica), la temperatura de las pilas de compostaje aumentó inicialmente; posteriormente la tasa de descomposición de la materia orgánica disminuyó, conforme van disminuyendo las fracciones más biodegradables, alcanzando las pilas niveles de temperatura ambiente (Ros et al., 2006). En la bibliografía se indica que el mejor rango de descomposición es entre 50 y $60^{\circ} \mathrm{C}$, aunque también indica la necesidad de llegar a $65-70{ }^{\circ} \mathrm{C}$ para su higienización. La baja temperatura alcanzada por las pilas de compost C2, C3 y C4 fue debida probablemente a la presencia de compuestos polifenólicos presentes en el subproducto de alcachofa (Negro et al., 2012) y a la incorporación de compost maduro (como materia prima), pues este material ya ha sido previamente estabilizado y presenta una baja biodegradabilidad (Bernal-Vicente et al., 2008; Tuomela et al., 2000). Otra de las razones atribuidas a los bajos niveles de temperatura puede ser el alto nivel de humedad de la mezcla inicial de compostaje (Makan et al., 2013) o el uso de un agente estructurante que no permita la entrada del oxígeno necesario en el proceso ( $\mathrm{Ge}$ et al., 2015). Los perfiles observados también fueron similares a los de otros compostajes, como el de digestatos de purines con restos de cultivo de pimiento como agente estructurante (Bustamante et al., 2013), al de lodos de depuración anaerobios con cascarilla de arroz (Chowdhury et al., 2014) o al de lodos con serrín como agente estructurante (Banegas et al., 2007).

Los microorganismos son la clave de la degradación de la materia orgánica producida durante el proceso de compostaje, que involucra una disminución de la relación $\mathrm{C} / \mathrm{N}$. Esta relación ha sido ampliamente mencionada como un índice de 
madurez de compost con valores por debajo de 15-20 (Mathur et al., 1993), como los determinados en los compost ensayados. Sin embargo, este parámetro no se puede utilizar como indicador absoluto, puesto que hay algunas materias primas iniciales con baja relación $\mathrm{C} / \mathrm{N}$ que producen una baja relación de partida $\mathrm{C} / \mathrm{N}$ de la pila de compostaje (Bernal et al., 2009). Otro índice de madurez del compost es el carbono orgánico hidrosoluble (Ch) con valores por debajo de 0,5 g/kg (Garcia et al., 1992), o su relación con la concentración de nitrógeno (relación $\mathrm{Ch} / \mathrm{N}$ ) propuesta por Bernal et al. (1998) y corroborado por Chang et al. (2006), en valores menores de 0,50. Estos valores fueron similares a los determinados por otros autores para compost de diferentes tipos de materias primas (Banegas et al., 2007; Bustamante et al., 2012; 2014). Nuestro estudio mostró que los valores de la concentración de Ch y la relación $\mathrm{Ch} / \mathrm{N}$ para los compost obtenidos fueron menores que los propuestos por García et al. (1992) y Bernal et al. (1998), lo que demuestra la estabilidad y madurez de los diferentes compost.

Durante el compostaje la materia prima se degrada a través de una variedad de procesos biológicos y bioquímicos en el que las enzimas desempeñan un papel clave (Cayuela et al., 2012). Por lo tanto, la actividad deshidrogenasa se ha utilizado ampliamente como indicador de la madurez compost (Tiquia, 2005; Ros et al., 2006) cuyos valores disminuyen a lo largo del proceso de compostaje (Tiquia, 2005). Este parámetro también ha sido utilizado por Blaya et al. (2015) como un indicador de la supresividad del compost. Los valores más bajos de la actividad deshidrogenasa que se observaron en los compost se correspondieron con aquellos que incluían como materias primas lodo de alcachofa, subproducto de alcachofa y restos de poda de vid, además de compost maduro (composts $\mathrm{C} 2, \mathrm{C} 3$ y C4), hecho que se puso de manifiesto en los perfiles de temperatura, donde se observaron los valores más bajos de temperatura alcanzados en la fase termofílica. El compost producido a partir de mezclas con compost maduro puso de manifiesto que la selección de este material no fue acertada, pues mostró una menor actividad deshidrogenasa en el compost C3 que en el C4, el cual tenía mayor proporción de compost maduro, debido probablemente a su difícil degradación y a la dificultad del establecimiento de la comunidad microbiana necesaria para alcanzar picos termófilos.

Por otro lado, el uso de estos compost como sustratos de cultivo no presenta ningún riesgo de contaminación por patógenos, y se pueden considerar biosólidos Clase A de acuerdo con EPA (2003). El pH y la conductividad eléctrica muestran una influencia importante en la calidad de los sustratos (Bunt, 1988; Hogg et al., 2002).

Los valores de $\mathrm{pH}$ determinados en los compost, entre 6,0 y 9,2, fueron valores adecuados en agricultura (Hogg et al., 2002), pero algo mayores a los recomendados para su uso como sustratos de cultivo, con rango óptimo 5,2-7,0 (Bunt, 1988). En concreto, el pH de los sustratos de cultivo es determinante en la incidencia de la fusoriasis, junto a otros factores interrelacionados con este, como es la disponibilidad 
de macro y micronutrientes, que son importantes para el crecimiento, esporulación y la virulencia de F. oxysporum (Jones et al., 1991). De acuerdo con Jones et al. (1991) y Borrero et al. (2004), valores de pH altos pueden ser considerados una característica positiva para enmiendas orgánicas en términos de reducción de las enfermedades de marchitez por Fusarium, efecto que ocurrió en todos los compost ensayados, con valores de incidencia de FOM, excepto para T-C2, T-C3 y T-C4, que fueron los tratamientos que mostraron los niveles más bajos de $\mathrm{pH}$. Este parámetro mostró por tando, una correlación significativa negativa $(-0,732 ; p<0,05)$.

Los valores de la CE fueron inferiores al límite de 3,5 dS/m indicado por Lemaire et al. (1985) para que las plántulas crezcan vigorosamente en un sustrato de cultivo. Además, estos valores estuvieron dentro del rango aceptado por Noguera et al. (2003) para sustratos de cultivo "ideales".

Los valores de las propiedades físicas analizadas para los compost estuvieron cerca de los valores aceptados para ser considerados un sustrato "ideal" (Abad et al., 2001), a excepción de los valores de la capacidad de retención de agua (CRA) que fueron algo menores, lo que indicaría la necesidad de incorporar agua con mayor frecuencia y en pequeñas cantidades (Bustamante et al., 2008). Los datos del espacio poroso total y la densidad aparente de los compost C1, C2, C3 y C4 pusieron de manifiesto que ambos parámetros estuvieron dentro de los valores indicados por Abad et al. (2001) para un "medio de cultivo ideal" que promueva el desarrollo de las raíces. Esto podría ser debido al agente estructurante utilizado, que estuvo presente en todas las mezclas ensayadas en una proporción entre $26 \%-75 \%$, pero también se puede atribuir a la mezcla del agente estructurante con otros materiales como la alcachofa, lodos de alcachofa o pimiento. En todo caso, las plántulas de melón evaluadas en los diferentes tratamientos (mezcla de compost/turba (50/50 v/v) tuvieron un crecimiento adecuado, que fue mejor que en el tratamiento control con turba $100 \%$. Nuestros resultados fueron similares a los observados por Blaya et al. (2013).

Los resultados del ensayo de germinación mostraron un IG superior al $50 \%$, revelando que ningún compost presentó fitotoxicidad de acuerdo con Zucconi et al. (1981). Además, la mayoría de los compost ensayados mostraron un valor superior al $100 \%$ indicando la presencia de sustancias bioestimulantes, que pueden proceder de los subproductos empleados como materias primas (mezclas de sustancias ricas en nitrógeno y hormonas) (Bernal-Vicente et al., 2008; Zorpas y Costa, 2010).

Los compost presentaron un contenido en nutrientes similar a otros compost agroindustriales (Blaya et al., 2015). El peso de la parte aérea de las plántulas de melón cultivadas, en los tratamientos con compost, fueron más altos que los de las plántulas del tratamiento con turba (control), al igual que observó previamente Pérez-Murcia et al. (2006). Otros autores también mostraron que el rendimiento de crecimiento de plantas fue mayor en tratamientos con compost utilizados como sustratos de cultivo sustitutos de la turba (García-Gómez et al., 2002; Benito et al., 2005; Aleandri et al., 
2015). Esto puede deberse a la combinación de diferentes propiedades beneficiosas tales como la mayor disponibilidad de nitrógeno para las plantas (como nitrógeno nítrico y amonio), pero también por otros nutrientes orgánicos intrínsecos del compost (Aleandri et al., 2015), y sus propiedades físicas para garantizar el crecimiento de las plántulas.

Por otro lado, la supresividad de los compost es dependiente del patógeno evaluado, pero principalmente depende del tipo de compost, por sus propiedades bióticas y abióticas (Termorshuizen et al., 2006). Según Rousk et al. (2009), el pH es una característica abiótica involucrada en la supresividad del compost, ya que altos valores de $\mathrm{pH}$ mostraron una menor incidencia de la enfermedad, aunque el $\mathrm{pH}$ también puede producir una influencia no directa sobre la incidencia de la enfermedad. Por su parte, Ntougias et al. (2008) demostraron que valores de pH altos afectaron a la comunidad microbiana de compost, produciendo el aumento de las comunidades microbianas de actinomicetos, que pueden estar implicados en los mecanismos de supresión debido a su capacidad para producir quitinasas y antibióticos (Patel et al., 2010).

Finalmente, las comunidades bacterianas y fúngicas presentes en el compost parece que están afectadas por la composición química de la materia prima utilizada en su elaboración (Hoitink y Boehm, 1999), de manera que aportan supresividad a los compost (Avilés et al., 2011). En los resultados obtenidos se observó que la incidencia de la enfermedad (FOM) fue significativamente más baja en las plántulas de melón cultivadas en el tratamiento T-C8 seguido por el tratamiento T-C5; ambos compost incluyeron subproducto de pimiento como material inicial junto con un alto porcentaje de restos de poda de vid, si se compara con el resto de compost. Por otro lado, las plántulas de los tratamientos T-C2, T-C3 y T-C4 fueron las que presentaron la mayor incidencia de la enfermedad, e incluyeron lodo de procesado de alcachofa y subproducto de alcachofa. A este respecto se determinó una correlación significativa positiva entre la incidencia de la enfermedad y el lodo de alcachofa $(0,794 ; p<0,05)$, y una correlación significativa negativa entre la incidencia de la enfermedad y la presencia de subproductos de pimiento en los compost $(-0,703 ; p<0,05)$.

\section{Conclusión}

El uso de diferentes parámetros es clave para evaluar la calidad de los compost, ayudando a identificar su potencial valor añadido. Los compost de residuos orgánicos y subproductos de la industria de transformados vegetales pueden utilizarse como sustratos de cultivo en mezclas con turba, sustituyéndola en un $50 \%$, con los que se obtienen resultados mejores o al menos comparables a los de la turba. Además, algunos compost pueden ser adecuados para su uso como sustratos de cultivo con valor añadido al reducir la incidencia de la enfermedad FOM en plántulas de melón. Se 
observó que el subproducto de pimiento estimula el control de la fusariosis, mientras que el lodo de alcachofa disminuye dicho control.

\section{Bibliografía}

Abad, M., Noguera, P., Burés, S., 2001. National inventory of organic wastes for use as growing media for ornamental potted plant production: case study in Spain. Bioresour. Technol. 77, 197-200.

Aleandri, M.P., Chilosi, G., Muganu, M., Vettraino, A., Marinari, S., Paolocci, M., Luccioli, E., Vannini, A., 2015. On farm production of compost from nursery green residues and its use to reduce peat for the production of olive pot plants. Sci. Hort. 193, 301-307.

AGROWASTE, 2014. Resultados del proyecto AGROWASTE LIFE10/ENV/ES/469. Disponible en: www.agrowaste.eu

Avilés, M., Borrero, C., Trillas, M.I., 2011. Review on compost as an inducer of disease suppression in plants grown in soilless culture. In: Ferrer, A.S. (Ed.), COMPOST III. Dynamic Soil, Dynamic Plant 5 (Special Issue 2), 1-11.

Banegas, V., Moreno, J.L., Moreno, J.I., García, C., León, G., Hernández, T., 2007. Composting anaerobic and aerobic sewage sludges using two proportions of sawdust. Waste Manage. 27, 1317-1327.

Benito, M., Masaguer, A., De Antonio, R., Moliner A., 2005. Use of pruning waste compost as a component in soil-less growing media. Bioresour. Technol. 96, 597-603.

Bernal, M.P., Alburquerque, J.A., Moral, R., 2009. Composting of animal manures and chemical criteria for compost maturity assessment. A review. Bioresour. Technol. 100, 5444-5453.

Bernal, M.P., Paredes, C., Sanchez-Monedero, M.A., Cegarra, J., 1998. Maturity and stability parameters of compost prepared with a wide range of organic wastes. Bioresour. Technol. 63, 91-99.

Bernal-Vicente, A., Ros, M., Tittarelli, F., Intrigliolo, F., Pascual, J.A. 2008. Citrus compost and its water extract for cultivation of melon plants in greenhouse nurseries. Evaluation of nutriactive and biocontrol effects. Bioresour. Technol. 99, 8722-8728.

Blaya J., Lloret, E., Ros, M., Pascual, J.A., 2015. Identification of predictor parameters to determine agroindustrial compost suppressiveness against Fusarium oxysporum and Phytophthora capsici diseases in muskmelon and pepper seedlings. J. Sci. Food Agric. 95, 1482-1490.

Blaya, J., Lopez-Mondejar, R., Lloret, E., Pascual, J.A., Ros, M., 2013. Changes induced by Trichderma harzianum in suppressive compost controlling Fusarium wilt. Pestic. Biochem. Physiol. 107, 112-119.

BOE, 2013. Real Decreto 506/2013 sobre productos fertilizantes. Boletín Oficial del Estado 164, 5111951207.

Boldrin, A., Andersen, J.K., Moller, J., Christensen, T.H., Favoino, E., 2009. Composting and compost utilization: accounting of greenhouse gases and global warming contributions. Waste Manage. Res. 27, 800-812.

Borrero, C., Trillas, M.I., Ordovás, J., Tello, J., Avilés, M., 2004. Predictive factors for the suppression of Fusarium wilt of tomato in plant growth media. Phytopathology 94, 1094-1101.

Bunt, A.C., 1988. Media and mixes for container-grown plants: A manual on the preparation and use of growing media for pot plants. London. UK. 2nd Ed. Unwin Hyman Ltd. 309 pp. 
Bustamante, M.A., Alburquerque, J.A., Restrepo, A.P., de la Fuente, C., Paredes, C., Moral, R., Bernal, M.P., 2012. Co-composting of the solid fraction of anaerobic digestates, to obtain added-value materials for use in agricultura. Biomass Bioenergy 43, 26-35.

Bustamante, M.A., Moral, R., Bonmatí, A., Palatsí, J., Solé-Mauri, F., Bernal, M.P., 2014. Integrated Waste Management Combining Anaerobic and Aerobic Treatment: A Case Study. Waste Biomass Valorization 5, 481-490.

Bustamante, M.A., Paredes, C., Moral, R., Agullo, E., Perez-Murcia, M.D., Abad, M., 2008. Composts from distillery wastes as peat substitutes for transplant production. Resour. Conserv. Recycl. 52, 792-799.

Bustamante, M.A., Restrepo, A.P., Alburquerque, J.A., Pérez-Murcia, M.D., Paredes, C., Moral, R., Bernal, M.P., 2013. Recycling of anaerobic digestates by composting: effect of the bulking agent used. J. Clean. Prod. 47, 61-69.

Campitelli, P., Ceppi, S., 2008. Chemical, physical and biological compost and vermicompost characterization: A chemometric study. Chemometr. Intell. Lab. 90, 64-71.

Carlile, W.R., 2008. The use of composted materials in growing media. Proceedings of the International Symposium on Growing Media. Acta Hort. 779, 321-328.

Cayuela, M.L., Sánchez-Monedero, M.A., Roig, A., Sinicco, T., Mondini, C., 2012. Biochemical changes and GHG emissions during composting of lignocellulosic residues with different $\mathrm{N}$-rich by-products. Chemosphere 88, 196-203.

Chang, J.I., Tsai, J.J., Wu, K.H., 2006. Thermophilic composting of food waste. Bioresour. Technol. 97(1), 116-122.

Chowdhury, A.K.M.M.B., Michailides, M.K., Akratos, C.S., Tekerlekopoulou, A.G., Pavlou, S., Vayenas, D.V., 2014. Composting of three phase olive mill solid waste using different bulking agents. Int. Biodeter. Biodegr. 91, 66-73.

EPA, 2003. Environmental regulations and technology. Control of pathogens and vector attraction in sewage sludge. Environmental Protection Agency, USA 625-R-92-013.

European Commission, 2001. Working document on biological treatment of biowaste. $2 \mathrm{nd}$ draft. Brussels; DG ENV.A.2./LM/biowaste/2nd draft.

European Committee for Standardization, 1999. Soil Improvers and Growing Media - Determination of Organic Matter and Ash. Standard CEN EN 13039:1999 E. European Committee for Standardization, Brussels.

Garcia, C., Hernandez, T., Costa, F., Ceccanti, B., Ciardi, C., 1992. Changes in ATP content, enzyme activity and inorganic nitrogen species during composting of organic wastes. Can. J. Soil Sci. 72, 243-253.

Garcia, C., Hernández, T., Costa, F., Ceccanti, B., Ganni, A., 1993. Hydrolases in the organic matter fractions of sewage sludge: changes with composting. Bioresour. Technol. 45, 47-52.

Garcia-Gomez, A., Bernal, M.P., Roig, A., 2002. Growth of ornamental plants in two composts prepared from agro-industrial wastes. Bioresour. Technol. 83, 81-87.

Ge, J., Huang, G., Huang, J., Zeng, J., Han, L., 2015. Modeling of oxygen uptake rate evolution in pig manure-wheat straw aerobic composting process. Chem. Eng. J. 276, 29-36.

Hogg, D., Favoino, E., Centemero, M., Caimi, V., Amlinger, F., Devliegher, W., Brinton, W., Antler, S., 2002. Comparison of Compost Standards within the EU, North America and Australia. The Waste and Resources Programme (WRAP), Oxon. 
Hoitink, H.A.J., Boehm, M., 1999. Biocontrol within the context of soil microbial communities: a substrate-dependent phenomenon. Annu. Rev. Phytopathol. 37, 427-446.

Jones, J.B., Jones, J.P., Stall, R.R., Zitter, T.A., 1991. Compedium of tomato diseases. St. Paul. Minesota. The American Phytopathological Society.

Lemaire, F., Dartigues, A., Rivière, L. M., 1985. Properties of substrate made with spent mushroom compost. Acta Hort. 172, 13-29.

Limpens, J., Berendse, F., Blodau, C., Canadell, J.G., Freeman, C., Holden, J., Roulet, N., Rydin, H., Schaepman-Strub, G., 2008. Peatlands and the carbon cycle: from local processes to global implications - a synthesis. Biogeosciences 5, 1475-1491.

Lloret, E., Pastor, L., Martinez-Medina, A., Blaya, J., Pascual, J.A., 2012. Evaluation of the removal of pathogens included in the Proposal for a European Directive on spreading of sludge on land during autothermal thermophilic aerobic digestion (ATAD). Chem. Eng. J. 198, 171-179.

Lopez-Mondejar, R., Bernal-Vicente, A., Ros, M., Tittarelli, F., Canali, S., Intrigiolo, F., Pascual, J.A., 2010. Utilisation of citrus compost-based growing media amended with Trichoderma harzianum T-78 in Cucumis melo L. seedling production. Bioresour. Technol. 101, 3718-3723.

Makan, A., Assobhei, O., Mountadar, M., 2013. Effect of initial moisture content on the in-vessel composting under air pressure of organic fraction of municipal solid waste in Morocco. Iranian J. Environ. Health Sci. Eng. 10(1), 3.

Mathur, S.P., Owen, G., Dinel, H., Schnitzer, M., 1993. Determination of compost ciomaturity:1. Literature-review. Biol. Agric. Hort. 10, 65-85.

Mena, E., 2001. Compostaje de lodos de depuración urbana: Una adecuada estrategia para su reciclado en el suelo. Tesis Doctoral. Universidad de Murcia. Murcia. España.

Nakasaki, K., Nag, K., Karita, S., 2005. Microbial succession associated with organic matter decomposition during thermophilic composting of organic waste. Waste Manag. Res. 23(1), 48-56.

Noguera, P., Abad, M., Puchades, R., Maquieira, A., Noguera, V., 2003. Influence of particle size on physical and chemical properties of coconut coir dust as container medium. Commun. Soil Sci. Plan. 34, 593-605.

Negro, D., Montesano, V., Grieco, S., Crupi, P., Sarli, G., De Lisi, A., Sonnante, G., 2012. Polyphenol compounds in artichoke plant tissues and varieties. J. Food Sci. 77(2), C244-252.

Ntougias, S., Papadopoulou, K.K., Zervakis, G.I., Kavroulakis, N., Ehaliotis, C., 2008. Suppression of soilborne pathogens of tomato by composts derived from agro-industrial wastes abundant in Mediterranean regions. Biol. Fertil. Soils 44, 1081-1090.

Pane, C., Spaccini, R., Piccolo, A., Scala, F., Bonanomi, G., 2011. Compost amendments enhance peat suppressiveness to Pythium ultimum, Rhizoctonia solani and Sclerotinia minor. Biol. Control 56, 115-124.

Patel, A.K., Singh, V.K., Yadav, R.P., Moir, A.J.G., Jagannadham, M.V., 2010. Purification and characterization of a new chitinase from latex of Ipomoea carnea. Process Biochem. 45, 675-681.

Perez-Murcia, M.D., Moral, R., Moreno-Caselles, J., Perez-Espinosa, A., Paredes, C., 2006. Use of composted sewage sludge in growth media for broccoli. Bioresour. Technol. 97, 123-130.

Raviv, M., 2005. Production of high-quality composts for horticultural purposes: a mini-review. Hortic. Technol. 15, 52-57.

Raviv, M., 2011. SWOT Analysis of compost as growing media component. Acta International Symposium on Growing Media, Composting and Substrate Analysis. Barcelona, 17-21 October. In press. 
Raviv, M., Chen, Y., Inbar, Y., 1986. Peat and peat substitutes as growth media for container-grown plants. In: Chen, Y., Avnimelech, Y. (Eds.), The role of organic matter in modern agriculture. Dordrecht. Holanda. Martinus Nijhoff Publishers. pp. 257-287.

Ros, M., García, C., Hernández, T., 2006. A full-scale study of treatment of pig slurry by composting: kinetic changes in chemical and microbial properties. Waste Manag. 26, 1108-1118.

Ros, M., Hernandez, M.T., Garcia, C., Bernal, A., Pascual, J.A., 2005. Biopesticide effect of green compost against Fusarium wilt on melon plants. J. Appl. Microbiol. 98(4), 845-854.

Rousk, J., Brookes, P.C., Bååth E., 2009. Contrasting Soil pH Effects on Fungal and Bacterial Growth Suggest Functional Redundancy in Carbon Mineralization. Appl. Environ. Microbiol. 75, 1589-1596.

Tejada, M., Benítez, C., 2011. Organic amendment based on vermicompost and compost: differences on soil properties and maize yield. Waste Manag. Res. 29, 1185-96.

Termorshuizen, A.J., van Rijn, E., van der Gaag, D.J., Alabouvette, C., Chen, Y., Lagerlöf, J., Steinberg, C., Zmora-Nahum, S., 2006. Suppressiveness of 18 composts against 7 pathosystems: variability in pathogen response. Soil Biol. Biochem. 38, 2461-2477.

Tiquia, S.M., 2005. Microbial parameters as indicators of compost maturity. J. Appl. Microbiol. 99, 816828.

Tittarelli, F, Rea, E., Verrastro, V., Pascual, J.A., Canali, S., Ceglie, F., Trinchera, A., Rivera, C.M., 2009. Compost-based nursery substrates: effect of peat substitution on organic melon seedlings. Compost Sci. Util. 17, 220-228.

Tuomela, M., Vikman, M., Hatakka, A., Itävaara, M., 2000. Biodegradation of lignin in a compost environment: A review. Bioresour. Technol. 72, 169-183.

Vivas, A., Moreno, B., Garcia-Rodriguez, S., Benitez, E., 2009. Assessing the impact of composting and vermicomposting on bacterial community size and structure, and microbial functional diversity of an olive-mill waste. Bioresour. Technol. 100, 1319-26.

Yogev, A., Raviv, M., Hadar, Y., Cohen, R., Wolf, S., Gil, L., Katan, J., 2010. Induced resistance as a putative component of compost suppressiveness. Biol. Control 54, 46-51.

Zorpas, A., Costa, C., 2010. Combination of Fenton oxidation and composting for the treatment of the olive residue and the olive mile wastewater from the olive industry in Cyprus. Bioresour. Technol. 101, 7984-7987.

Zucconi, F., Pera, A., Forte, M., Bertoldi, M., 1981. Evaluating toxicity of immature compost. BioCycle 22, 54-57. 

VIII. Mejora de la calidad de un suelo salino del Mediterráneo mediante una enmienda con compost de restos de poda de vid enriquecido con Trichoderma harzianum T78 



\section{Mejora de la calidad de un suelo salino del Mediterráneo mediante una enmienda con compost de restos de poda de vid enriquecido con Trichoderma harzianum T78}

\section{Introducción}

La salinidad es uno de los parámetros críticos en la calidad del suelo, ya que causa problemas en el ámbito agrícola y contribuye a la degradación del suelo. En las regiones áridas y semiáridas, especialmente, es donde se ve afectada la productividad agrícola debido a que se reduce el crecimiento de las plantas (Pitman y Lauchli, 2004), llegando a provocar el abandono de estos suelos (Qadir et al., 2000). Las estimaciones actuales indican que más del $6 \%$ de la superficie terrestre total está afectada por una alta concentración de sales (Munns y Tester, 2008). Por lo tanto, esto representa una seria amenaza para la producción de alimentos y la sostenibilidad del medio ambiente, especialmente en las regiones áridas y semiáridas (Paranychianakis y Chartzoulakis, 2005).

En los países mediterráneos, las características naturales del clima (veranos cálidos y secos, con una prolongada sequía y las fuertes lluvias durante el otoño), además la inadecuada gestión de la tierra han llevado a una reducción en el contenido de materia orgánica de los suelos (López-Vicente y Navas, 2000). Esta situación tiene una influencia directa y negativa en las propiedades físicas, químicas y biológicas de los suelos y sus procesos, además de causar una degradación de la textura y su estructura, así como una probable pérdida de la fertilidad (Haynes, 2005). El sureste de España, donde se incluye la Región de Murcia, es un área donde este fenómeno se está convirtiendo en un problema grave, porque hay una disminución continua de la materia orgánica del suelo y un mayor uso de agua de riego salina, que están llevando a la desertificación rápida (Marlet et al., 2009). Esto requiere nuevas estrategias, para mitigar este deterioro de la calidad del suelo; entre ellas se encuentra la incorporación de materia orgánica y constituye un importante método de regeneración del suelo y la restauración de su fertilidad (Lakhdar et al., 2010; Larney y Angers, 2012).

La materia orgánica del suelo actúa como un regulador importante de numerosas limitaciones ambientales para la productividad de los cultivos, mediante la aceleración de la lixiviación de sal, disminuyendo el porcentaje de sodio intercambiable y la conductividad eléctrica (CE), además del aumento de la infiltración de agua, la capacidad y la estabilidad de los agregados de retención de agua (EIShakweer et al., 1998; Benboualil et al., 2013). También la aplicación de materiales orgánicos a los suelos salinos es una alternativa eficaz para la mejora de sus propiedades físicas y biológicas (Lakhdar et al., 2010; Mbarki et al., 2010; Benboualil et al., 2013). 
Por otro lado, la aplicación combinada de materia orgánica y microorganismos beneficiosos, que aporten efectos biopesticida y biofertilizante podría contribuir a reducir el efecto negativo que la agricultura intensiva tiene sobre el medio ambiente debido al uso de productos químicos como fertilizantes y pesticidas (García et al., 2004; Kaewchai et al., 2009; Mouria et al., 2013). Trichoderma spp., por ejemplo, se ha utilizado con gran éxito como microorganismos beneficiosos (Amin et al., 2010; Mohamed et al., 2010), ya que inhiben un amplio espectro de enfermedades fúngicas de las plantas mediante una amplia diversidad de mecanismos, tales como elevada capacidad de competición con la comunidad microbiana en la rizosfera, son resistentes a un alto número de fungicidas de suelo y tienen la capacidad de sobrevivir en condiciones desfavorables (Benítez et al., 2004; Vinale et al., 2008). Trichoderma también se puede considerar como un biofertilizante, de tal manera que su empleo permite reducir el consumo de productos químicos, lo que de nuevo, sirve para apoyar una agricultura sostenible y la conservación de los recursos naturales (Harman, 2011; Moradi et al., 2011). Además, algunos Trichoderma spp., pueden mineralizar los nutrientes orgánicos mediante la producción de grandes cantidades de enzimas extracelulares, lo que les permite utilizar los restos de plantas como material nutritivo (Vizcano et al., 2005; Joshi et al., 2012). Según Jayalakshmi et al. (2009) estas especies pueden proporcionar una resistencia inducida a largo plazo a cultivos como el garbanzo. Sin embargo, Trichoderma spp. se ven afectados significativamente por las condiciones ambientales, especialmente por la temperatura y el contenido en agua. Además, uno de los límites críticos para el uso de las cepas de Trichoderma como inoculantes del suelo es su baja tolerancia a la sal (Mohamed y Haggag, 2005).

La calidad de un suelo depende de un gran número de factores físicos, químicos, biológicos, microbiológicos y bioquímicos, pero los dos últimos son los más sensibles debido a su respuesta rápida a los cambios (Kumar et al., 2013). En este aspecto las actividades enzimáticas se han propuesto como una herramienta para monitorear los cambios en la ecología del suelo como resultado de las interacciones entre los inoculantes y las poblaciones microbianas indígenas del suelo (Doyle y Stotzky, 1993). Podría esperarse, por tanto, que la actividad enzimática permite mejorar la disponibilidad de los nutrientes más limitantes, con el fin de satisfacer las demandas metabólicas microbianas (Allison et al., 2011). Entre las enzimas del suelo, $\beta$-glucosidasa, ureasa y fosfatasas son importantes en la transformación de varios nutrientes de las plantas. El objetivo de este capítulo fue comprobar si el uso de un compost de restos de poda de vid enriquecido con una cepa específica de Trichoderma harzianum T78 tenía un efecto positivo en las propiedades biológicas de un suelo con problemas de salinidad. 


\section{Materiales y métodos}

\subsection{Ensayo In vitro}

Se evaluó el crecimiento de T. harzianum T78 (T78) en el medio de cultivo sólido patata dextrosa agar (PDA) para las siguientes concentraciones de sal ( $\mathrm{NaCl}$ ) ensayadas: $0,60,100,200,400,600,800$ y 1.000 mM. Su desarrollo se evaluó midiendo su diámetro de crecimiento a partir de un disco de $5 \mathrm{~mm}$ de diámetro con micelio de Trichoderma de 10 días de edad, situado en el centro de cada placa Petri. La forma y el color de la colonia fueron estudiados en el séptimo día, tiempo suficiente para que la superficie de la placa de estuviera cubierta de esporas. Además se controló la tasa de esporulación al mismo tiempo que el crecimiento de la colonia.

\subsection{Propiedades del suelo y el compost}

El estudio se realizó con un suelo de una zona semiárida - característica de Murcia (Sureste de España), con coordenadas geográficas: 38 $8^{\circ} 1^{\prime} 46^{\prime \prime}$ Norte, 1 199'51" Oeste - expuesto a un típico clima mediterráneo. La zona recibe una precipitación media de $200 \mathrm{~mm} /$ año y tiene una temperatura media anual de 18 a $20{ }^{\circ} \mathrm{C}$. El suelo tenía un $\mathrm{pH}$ de 7,51, una conductividad eléctrica (CE) de 0,43 ms/m (proporción 1:5, suelo: agua), 9,8 g/ $\mathrm{kg}$ de carbono orgánico total (C), 2,6 g/ $\mathrm{kg}$ de fósforo extraído con $\mathrm{NaHCO}_{3}, 1 \mathrm{~g} / \mathrm{kg}$ de nitrógeno total $(\mathrm{N})$ y $2,8 \mathrm{~g} / \mathrm{kg}$ de potasio extraíble. La textura del suelo fue de $39 \mathrm{~g} / \mathrm{kg}$ de arena gruesa, $502 \mathrm{~g} / \mathrm{kg}$ de arena fina, $301 \mathrm{~g} / \mathrm{kg}$ limo y $158 \mathrm{~g} / \mathrm{kg}$ de arcilla.

La materia orgánica aplicada fue compost de restos de poda de vid obtenidos en composteras semiherméticas de $350 \mathrm{~L}$ de capacidad. Las pilas de compostaje se voltearon en dos ocasiones, siendo esto suficiente para lograr la estabilización de la temperatura, y se obtuvo el compost final en cuatro meses (los tres primeros constituyeron la fase biooxidativa, mientras que el último correspondió a la fase de maduración). El compost fue caracterizado y se definió como un material orgánico con bajos niveles de nutrientes y materia orgánica estabilizada, con un $\mathrm{pH}$ de 7,3 , una CE de $8,10 \mathrm{mS} / \mathrm{m}$ (proporción 1:5, suelo: agua), $176 \mathrm{~g} / \mathrm{kg}$ de $\mathrm{C}, 16,1 \mathrm{~g} / \mathrm{k}$ de fósforo total (P), 47,7 g/kg de $\mathrm{N}$ y 14,1 g/kg de potasio total (K). La CE y el $\mathrm{pH}$ se midieron con un conductímetro Crison y un pHmetro Crison modelo 2001, respectivamente. El N y el C fueron determinados por microanálisis automático (Navarro et al., 1991). El P fue determinado espectrofotométricamente midiendo la intensidad de la coloración amarilla del ácido molibdovanadato fosfórico (Kitson y Mellon, 1944). Y el K por fotometría de llama. 


\subsection{Diseño del experimento de incubación}

Se pesaron $150 \mathrm{~g}$ de las muestras de suelo, se llevaron a frascos de Erlenmeyer Pyrex con tapón y se adicionaron las disoluciones de cuatro concentraciones de $\mathrm{NaCl}$ $(0,10,20$ y $60 \mathrm{mM})$, dado que no se observó un efecto negativo en el desarrollo de $T$. harzianum T78 (T78) en el ensayo previo in vitro. Una parte del compost se enriqueció con T78 de acuerdo al procedimiento de Bernal-Vicente et al. (2009). El compost enriquecido o no con T78, se mezcló con el suelo antes de regar, en la proporción de $2 \mathrm{~g}$ de compost por cada $100 \mathrm{~g}$ de suelo.

Una vez que todos los tratamientos se habían preparado, se incubaron en la oscuridad a $25{ }^{\circ} \mathrm{C}$, durante 45 días (ajustado a un $60 \%$ de la capacidad de retención de agua). Se tomaron muestras al inicio ( 0 días, considerado a las 12 horas después de iniciar el experimento), el día 20 y el día 45 y se dividieron para llevar a cabo todos los análisis posteriores, análisis físico-químico, bioquímico y microbiológico. Las submuestras para el análisis de los parámetros microbiológicos se utilizaron inmediatamente, mientras que para determinar las actividades bioquímicas del suelo se mantuvieron a $4{ }^{\circ} \mathrm{C}$, puesto que se realizaron dentro de los 5 días siguientes a la recogida del suelo. Finalmente, las submuestras restantes se secaron al aire para utilizarlas en la determinación de las propiedades físicas y químicas.

\subsection{Parámetros determinados}

El contenido en $\mathrm{C}$ de la biomasa (Cbio) del suelo se determinó mediante el método modificado de extracción-fumigación con cloroformo (Witt et al., 2000). La extracción del mismo se realizó con una solución de 0,5 $\mathrm{M} \mathrm{K}_{2} \mathrm{SO}_{4}$ y su concentración se determinó mediante el método modificado de oxidación del dicromato $\left(\mathrm{K}_{2} \mathrm{Cr}_{2} \mathrm{O}_{7}\right)$ propuesto por Vance et al. (1987).

El número de bacterias y hongos expresado como unidades formadoras de colonias (UFC) se determinó mediante la preparación de diluciones en serie de muestras de suelo mezclados en una solución controlada osmóticamente (solución de Ringer, preparado por adición de 1 comprimido de KM100T (Microtrade UK) y $500 \mathrm{~mL}$ de agua desionizada) y aplicadas sobre un medio específico para cada grupo de microorganismos. Para las bacterias se utilizó el medio triptona soja agar (TSA $4 \mathrm{~g} / \mathrm{L}$, agar $15 \mathrm{~g} / \mathrm{L}$, nistatina $50 \mathrm{mg} / \mathrm{L}$ ), incubando a $25{ }^{\circ} \mathrm{C}$ durante 7 días; y para los hongos se utilizó el medio patata dextrosa agar (PDA, $39 \mathrm{~g} / \mathrm{L}$, rosa de bengala $50 \mathrm{mg} / \mathrm{L}$, estreptomicina $100 \mathrm{mg} / \mathrm{L}$ ), incubando a $28{ }^{\circ} \mathrm{C}$ durante 5 días.

La actividad deshidrogenasa se determinó según el método de García et al. (1994). El método se basa en la estimación del iodonitrotetrazolio formazan (INTF) formado cuando el material es incubado con 2-p-iodofenol-3-p-nitrofenol-5feniltetrazolio (INT) durante $20 \mathrm{~h}$ a $20^{\circ} \mathrm{C}$, en oscuridad, ya que se actúa como aceptor de electrones, reduciéndose a su correspondiente sal de formazano de color rojo. Se 
midió el color a $490 \mathrm{~nm}$ en un espectrofotómetro. La actividad ureasa se determinó a partir del método descrito por Nannipieri et al. (1980) que consiste en incubar las muestras de suelo en presencia de urea y posteriormente medir el amoniaco liberado. Finalmente, las actividades $\beta$-glucosidasa y fosfatasa se determinaron de acuerdo al método descrito por Tabatabai y Bremmer (1969), utilizando como sustrato pnitrofenol-b-D-glucopiranósido (PNG) y p-nitrofenoyl-fosfato, respectivamente para medir la producción de p-nitrofenol (PNP) a 398 nm con un espectrofotómetro.

\subsection{Análisis estadístico}

Se utilizó el análisis de la varianza con un factor (ANOVA) y el test de Tukey para establecer las diferencias significativas a $p<0,05$. Todos los test estadísticos se realizaron con el programa SPSS 22.0 (SPSS Inc., Chicago, IL, EE.UU.).

\section{Resultados y discusión}

\subsection{Demostración In vitro de la tolerancia a la sal de la cepa $T$. harzianum T-78}

T. harzianum T78 no mostró una reducción de crecimiento hasta una concentración de $\mathrm{NaCl}$ de $400 \mathrm{mM}$, ni una reducción significativa en la producción de esporas hasta una concentración de $\mathrm{NaCl}$ de $100 \mathrm{mM}$, después de 7 días de tratamiento. En la Tabla 1 se puede observar que, por encima de $100 \mathrm{mM} \mathrm{NaCl}, T$. harzianum T78 continuó creciendo, pero su crecimiento y esporulación se redujo. Además, el crecimiento morfológico cambió de esponjoso a plano, y la coloración de verde a blanco, cuando la concentración de sal en el medio de cultivo PDA aumentó (Tabla 1; Figura 1).

Tabla 1. Caracterización del crecimiento de T. harzianum T78 y la tasa de esporulación en el medio de cultivo PDA a diferentes concentraciones de sal

\begin{tabular}{|c|c|c|c|c|c|c|c|c|}
\hline \multirow[b]{2}{*}{$\mathrm{NaCl}(\mathrm{mM})$} & \multicolumn{3}{|c|}{ Diámetro crecimiento $(\mathrm{cm})$} & \multicolumn{3}{|c|}{ Tasa esporulación } & \multirow{2}{*}{$\begin{array}{c}\text { Forma de la colonia } \\
\text { en el } 7^{\circ} \text { día }\end{array}$} & \multirow{2}{*}{$\begin{array}{c}\text { Color de la colonia } \\
\text { en el } 7^{\circ} \text { día }\end{array}$} \\
\hline & 0 días & 2 días & 7 días & 0 días & 2 días & 7 días & & \\
\hline 0 & 3 & 7 & 7 & + & +++ & ++++ & Esponjosa & Verde \\
\hline 60 & 2,8 & 7 & 7 & + & +++ & ++++ & Esponjosa & Verde \\
\hline 100 & 2 & 6 & 7 & + & + & +++ & Esponjosa & Verde \\
\hline 200 & 1 & 6 & 7 & - & + & ++ & Esponjosa & Verde blanquecino \\
\hline 400 & 1 & 5 & 7 & - & + & + & Plana & Blanca \\
\hline 600 & 0 & 4,5 & 6 & - & - & + & Plana & Blanca \\
\hline 800 & 0 & 2 & 4 & - & - & + & Plana & Blanca \\
\hline 1.000 & 0 & 1 & 2 & - & - & + & Plana & Blanca \\
\hline
\end{tabular}

(-) no dispersa; (+) poco dispersa; (++) moderadamente dispersa; (+++) muy dispersa; (++++) compacta 


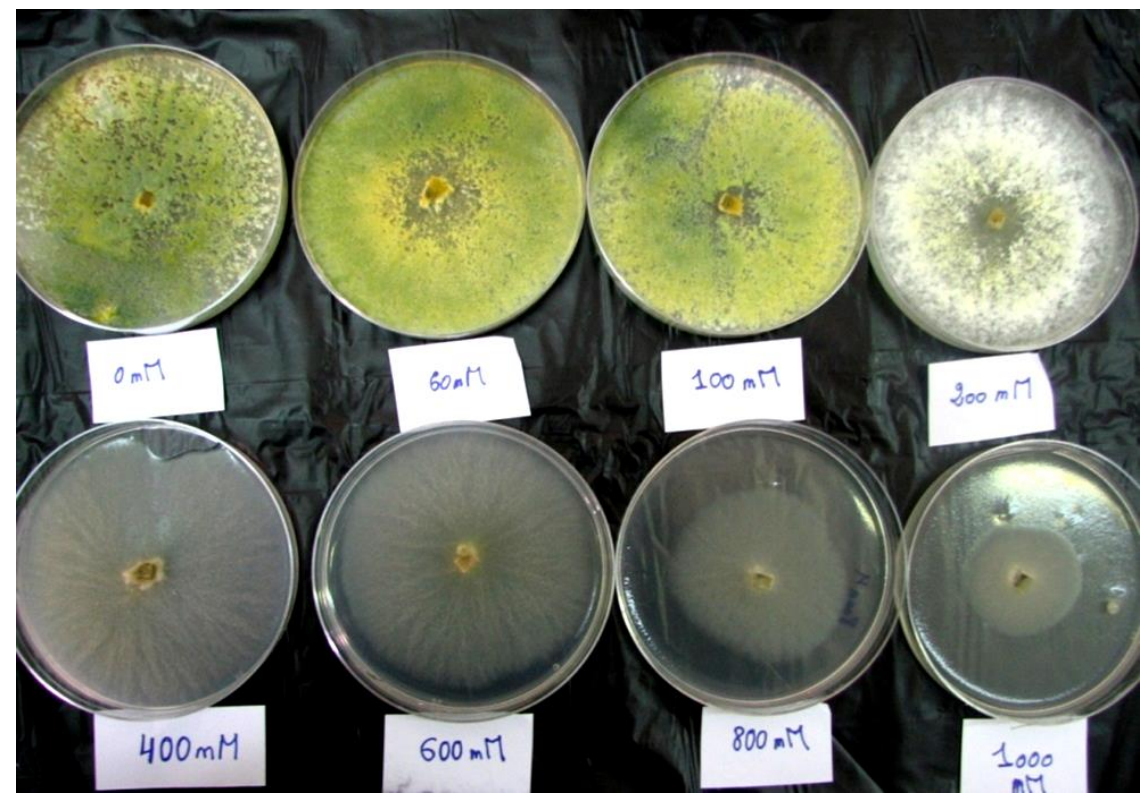

Figura 1. Crecimiento de la cepa $T$. harzianum T-78 bajo diferentes concentraciones de $\mathrm{NaCl}$ en medio de cultivo PDA

Trichoderma spp. Pertenece al género de hongos filamentosos imperfectos que intervienen en la descomposición de los residuos vegetales en el suelo, ampliamente distribuidos en diferentes condiciones ambientales y sustratos (Hassanein, 2012; Kuc, 2001). En concreto, la cepa T. harzianum T78 utilizada en este estudio demostró su tolerancia a la sal, una característica inusual en el género Trichoderma (Mohamed y Haggag, 2005) -conocido por su baja osmotolerancia. Mohamed y Haggag (2005) destacaron diversos enfoques para la obtención de cepas de Trichoderma tolerantes a la sal, tales como mutaciones generales o específicas, producidas por la exposición de las esporas a productos químicos, mutaciones físicas, radiación gamma, fusión de protoplastos, transformación y clonación de genes. En este aspecto, a diferencia del mutante $T$. harzianum osmotolerante seleccionado en una concentración de $\mathrm{NaCl}$ de 69 mM por Mohamed y Haggag (2005), la cepa T78, utilizada en este ensayo, mostró una tolerancia natural para concentraciones de $\mathrm{NaCl}$ de 0 a $1.000 \mathrm{mM}$. Este último nivel de salinidad es lo suficientemente alto como para considerar la cepa T78 como un osmotolerante.

El mecanismo principal que se supone que debe ser adoptado por T78 es la acumulación de sustancias intercelulares específicas que actúan como osmolitos metabólicamente neutros (Peng et al., 1997). Este tipo de información, sobre la influencia de las relaciones externas de agua en las actividades metabólicas de las cepas de Trichoderma, es esencial para la planificación de su aplicación en las estrategias de control biológico (Harman, 2001), por sí solos o en combinación con enmiendas orgánicas (Abdel-Kader et al., 2013). 


\subsection{Ensayo de incubación}

\subsection{1. pH y conductividad eléctrica}

En primer lugar, se puede indicar que la incorporación de compost en el suelo no afectó al valor del pH (Tabla 2), pero sí que se produjo una reducción de este valor al incrementar la concentración de $\mathrm{NaCl}$, pasando de 7,48-7,71 (0 mM NaCl) a 6,99$7,27(60 \mathrm{mM} \mathrm{NaCl})$.

Por otro lado, los valores de la conductividad eléctrica (CE) en el suelo control sí que pasaron de 0,41 dS/m (0 mM NaCl) a 15,30 dS/m (60 mM NaCl). La adición de compost, enriquecido o no con T78, no mostró diferencias en el valor de CE en comparación con el suelo control, excepto a $60 \mathrm{mM}$, mostrando un menor valor (Tabla 2).

Tabla 2. pH y conductividad eléctrica en las muestras de suelo a los 0 días de incubación

\begin{tabular}{lccc}
\hline \multicolumn{1}{c}{ Suelo } & $\mathrm{NaCl}(\mathbf{m M})$ & $\mathbf{p H}$ & $\mathbf{C E}(\mathbf{d S} / \mathbf{m})$ \\
\hline \multirow{3}{*}{ Suelo control } & $\mathbf{0}$ & $7,48 \mathrm{~b}$ & $0,41 \mathrm{a}$ \\
& $\mathbf{1 0}$ & $7,25 \mathrm{ab}$ & $3,21 \mathrm{~b}$ \\
& $\mathbf{2 0}$ & $7,19 \mathrm{a}$ & $6,01 \mathrm{c}$ \\
& $\mathbf{6 0}$ & $7,27 \mathrm{a}$ & $15,30 \mathrm{e}$ \\
\hline \multirow{3}{*}{ Suelo con compost } & $\mathbf{0}$ & $7,61 \mathrm{~b}$ & $0,41 \mathrm{a}$ \\
& $\mathbf{1 0}$ & $7,22 \mathrm{ab}$ & $3,26 \mathrm{~b}$ \\
& $\mathbf{2 0}$ & $7,23 \mathrm{ab}$ & $6,11 \mathrm{c}$ \\
& $\mathbf{6 0}$ & $7,05 \mathrm{a}$ & $12,47 \mathrm{~d}$ \\
Suelo con compost enriquecido & $\mathbf{0}$ & $7,71 \mathrm{~b}$ & $0,46 \mathrm{a}$ \\
con T78 & $\mathbf{1 0}$ & $7,33 \mathrm{ab}$ & $3,41 \mathrm{~b}$ \\
& $\mathbf{2 0}$ & $7,15 \mathrm{a}$ & $6,29 \mathrm{c}$ \\
\hline
\end{tabular}

CE: Conductividad eléctrica

T78: Trichoderma harzianum T78

En columnas, los valores medios seguidos de la misma letra no indican diferencias estadísticas significativas de acuerdo al test de Tukey $(a \mathrm{p}<0,05)$, en comparación con cada una de las concentraciones de sal evaluadas

\subsubsection{Trichoderma harzianum y la evolución de bacterias y hongos}

En la Tabla 3 se puede observar que el suelo utilizado como control tenía una población natural de Trichoderma spp., y que ésta se redujo significativamente (por debajo del límite de detección) a partir de una concentración de $\mathrm{NaCl}$ de $10 \mathrm{mM}$. Los suelos enmendados con compost a una concentración de $0 \mathrm{mM}$ de $\mathrm{NaCl}$ mostraron un aumento significativo en la abundancia natural de Trichoderma spp. (Tabla 3) en comparación con el control, pero a medida que la concentración de $\mathrm{NaCl}$ aumentó, esta abundancia natural de Trichoderma spp. se redujo hasta que no se pudo detectar, de una manera similar a lo observado para el suelo control. Por otro lado, el suelo con compost enriquecido con $T$. harzianum T78 mostró un aumento significativo en la población de Trichoderma en comparación con el control y el suelo con compost; una abundancia que se mantuvo durante el período de incubación (Tabla 3). 
El compost enriquecido con T78 produjo un aumento significativo de Trichoderma a concentraciones crecientes de sal, en comparación con las condiciones de control, apoyando los resultados previos in vitro de Mohamed y Haggag (2005), y que puede deberse también a que Trichoderma puede utilizar compuestos lignocelulósicos, aunque después disminuye. Según resultados previos de Pascual et al. (1998) y Bernal-Vicente et al. (2008), a medida que la disponibilidad de estos compuestos se reduce, debido a la mineralización microbiana, la población de T78 también disminuye con el tiempo. En este estudio, el compost utilizado se obtuvo a partir de restos de poda de viñedos, que son un material rico en compuestos lignocelulósicos, y un sustrato adecuado para especies Trichoderma, y se observó que la población de Trichoderma fue la mayor en suelos con el compost enriquecido con T78.

Se puede decir que la presencia natural de Trichoderma spp. se redujo significativamente en el suelo al incrementar la concentración de sal, demostrando, de manera general, la baja tolerancia de la sal de este género (Mohamed y Haggag, 2005). Este efecto negativo de la salinidad sobre los microorganismos considerados beneficiosos reduciría la supresividad del suelo natural y forzaría el uso de pesticidas y fertilizantes químicos, con consecuencias negativas para el medio ambiente (Harman, 2001). En todo caso, el descubrimiento de la cepa Trichoderma T78 resistente a la sal ofrece nuevas alternativas para el tratamiento de suelos salinos, a pesar de que su baja tolerancia a la sal le podría impedir utilizar sustratos de carbono (Yeo, 1998; Mohamed y Haggag, 2005).

Por otro lado, las comunidades de microorganismos (UFC) tales como bacterias y hongos fueron afectadas de manera diferente al aumentar la concentración de $\mathrm{NaCl}$ (Tabla 3). En el suelo control, las UFC de bacterias no se vieron afectadas por la concentración de sal, mostrando un aumento general durante el periodo de incubación, mientras que las de hongos sí que se vieron afectados y disminuyeron durante el transcurso del experimento (Tabla 3). La adición de compost produjo una reducción general de bacterias, con respecto al control del suelo en el nivel de sal equivalente, pero los hongos no se vieron afectados, mostrando una tendencia similar a la del suelo control. Por su parte, los suelos enmendados con compost enriquecido con T78 mostraron una disminución significativa en las UFC de bacterias y hongos en comparación con el suelo control, independientemente de la concentración de sal (Tabla 3). Las UFC de bacterias presentaron una disminución significativa en el compost enriquecido con T78. El porcentaje de Trichoderma spp. con respecto a los hongos totales fue del 5-12 \% en el control y en el suelo enmendado con compost, mientras que en suelo enmendado con compost inoculado con T. harzianum T78 este valor fue del 50 a $60 \%$. 


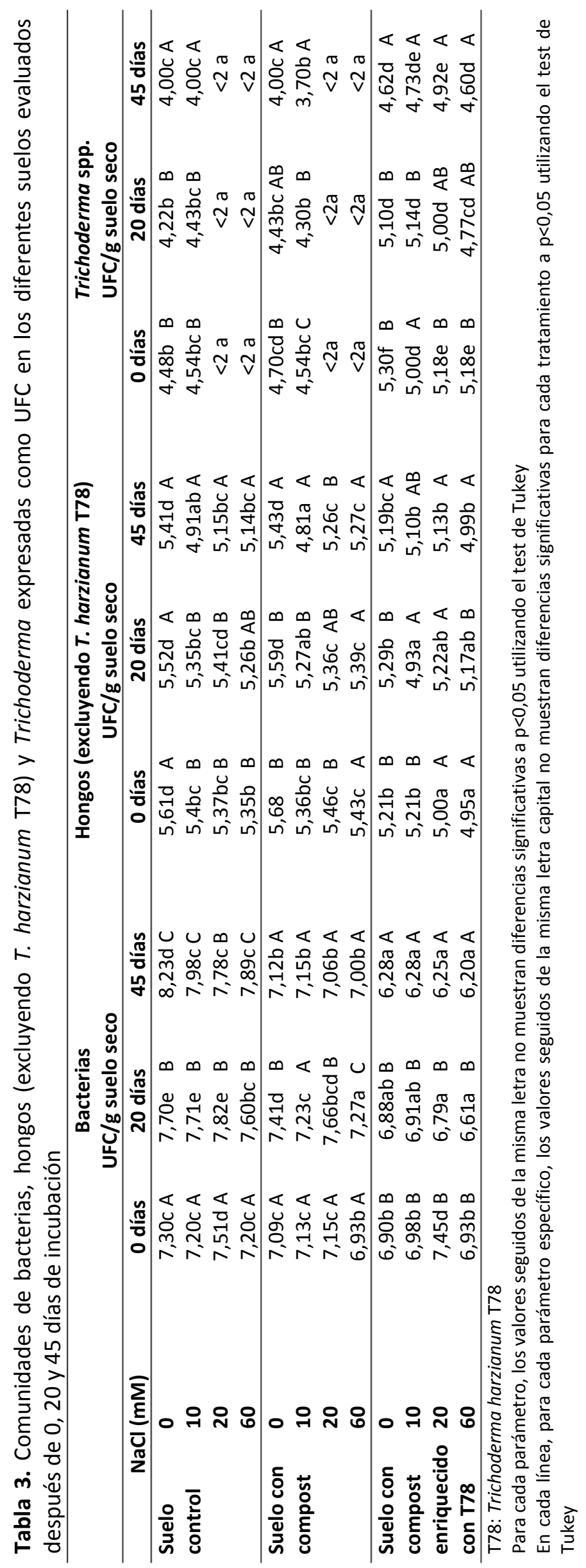


Teniendo en cuenta que la microflora del suelo juega un papel importante en el mantenimiento y/o mejora de la calidad del suelo, mediante la regulación de la descomposición de materia orgánica y la disponibilidad de nutrientes (Rietz y Haynes, 2003; Iwai et al., 2012), la evaluación de las comunidades de microorganismos es de interés. En el estudio se pudo mostrar que la incorporación de la cepa específica $T$. harzianum T78 disminuyó las poblaciones bacterianas y fúngicas del suelo en comparación con el control, independientemente de la concentración de sal, tal como previamente han indicado Vicente Bernal et al. (2008), debido a que es una antagonista microbiana a través de varios mecanismos, principalmente micoparasitismo, la producción de antibióticos y la competencia por los nutrientes. El porcentaje de Trichoderma spp. con respecto al total de hongos disminuyó con el tiempo, pero se mantuvo alrededor del 30-40 \% con respecto al inicial, al verse afectada por la concentración de sal. Por lo tanto, T. harzianum T78 mostró una tolerancia alta a la sal, pero también una gran capacidad para competir por carbono y nutrientes con las poblaciones de hongos naturales.

\subsubsection{Carbono orgánico total, carbono de la biomasa microbiana y actividades enzimáticas}

Al inicio del experimento, el aumento de la concentración de $\mathrm{NaCl}$ en el suelo control disminuyó la concentración de carbono orgánico total (C) en dicho suelo, siendo significativamente diferente en $\mathrm{NaCl} 60 \mathrm{mM}$ (Tabla 4). Este comportamiento se mantuvo después de 20 y 45 días de incubación, con una disminución significativa en el contenido de $\mathrm{C}$ a lo largo del tiempo. El suelo no salino enmendado con compost mostró un aumento en dicho contenido. Por el contrario, el contenido de $\mathrm{C}$ disminuyó en el suelo enmendado con compost enriquecido con T78, además de por el aumento de la salinidad; los valores de $C$ en todos los suelos no salinos fueron más altos que en los suelos tratados con las respectivas concentraciones de $\mathrm{NaCl}$ (Tabla 4), y en particular en el día 45.

Como se esperaba, el $\mathrm{C}$ aumentó después de la aplicación de compost (Whalen et al., 2008; Laudicina et al., 2011), pero disminuyó después de aplicar el compost enriquecido con T78 y especialmente a altas concentraciones de sal. Esto puede explicarse por el hecho de que la respuesta natural de los microorganismos a la salinidad es aumentar su demanda de energía, y como consecuencia de ello se produce una mineralización del carbono. Este resultado contrasta con el de Baumann y Marschner (2013), quienes encontraron que los cambios inducidos por la sal en la comunidad microbiana reducen la eficacia de la utilización de la fuente de carbono. Por otro lado, los resultados observados para el suelo enmendado con compost enriquecido con $T$. harzianum en el día 0 puede ser explicado por los cambios producidos en la comunidad microbiana debido a la presencial de este aislado (BernalVicente et al., 2009). 
También el carbono de la biomasa microbiana (Cbio) se vió afectado significativamente por la concentración de $\mathrm{NaCl}$, dependiendo del suelo evaluado (Tabla 4). En el suelo control, el Cbio incrementó significativamente a concentraciones de $10 \mathrm{mM}$ y $20 \mathrm{mM}$, en comparación con $0 \mathrm{mM}$, pero se redujo significativamente para la concentración más alta $(60 \mathrm{mM})$, una tendencia que se mantuvo durante toda la incubación. El suelo enmendado con compost mostró un aumento en el Cbio en comparación con el control, para $\mathrm{NaCl}$ de $0 \mathrm{mM}$. $\mathrm{Y}$ también el aumento de la concentración de $\mathrm{NaCl}$ en el suelo enmendado con compost produjo un descenso en el Cbio; para una concentración de $\mathrm{NaCl}$ de $60 \mathrm{mM}$ se obtuvo el valor más bajo y esto se mantuvo durante los 45 días de incubación (Tabla 4). Por otro lado, en todos los niveles de salinidad, el compost enriquecido con T78 al ser incorporado al suelo produjo un menor aumento de la biomasa del suelo frente al uso del compost solo, debido probablemente al antagonismo de $T$. harzianum, reduciendo las comunidades de hongos y bacterias que podrían utilizar el carbono y los nutrientes suministrados por el compost.

La biomasa microbiana del suelo se evaluó en base a que está reconocido como un indicador sensible de la calidad del suelo (Rietz y Haynes, 2003; García et al., 2004). El suelo enmendado con compost presentó una mayor biomasa microbiana que el suelo control, debido a su respuesta a la adición de carbono fácilmente disponible, que estimula la microbiota autóctona, así como a la incorporación de microorganismos exógenos (Pascual et al., 1998; Tejada et al., 2006). La disminución que se produjo por el incremento del contenido de sal en el suelo enmendado con compost, puede ser debido a que las concentraciones de sal más altas son tóxicas para la comunidad microbiana (Rietz y Haynes, 2003; García et al., 2004). Nuestros resultados presentan el patrón general que se encuentra en el origen natural de los suelos salinos, donde la biomasa microbiana por lo general se correlaciona negativamente con el contenido total de sal (Egamberdieva et al., 2010; Iwai et al., 2012). En todo caso, aunque la población microbiana está severamente reprimida bajo condiciones salinas, la actividad microbiana sustancial persiste (Rietz y Haynes, 2003). 


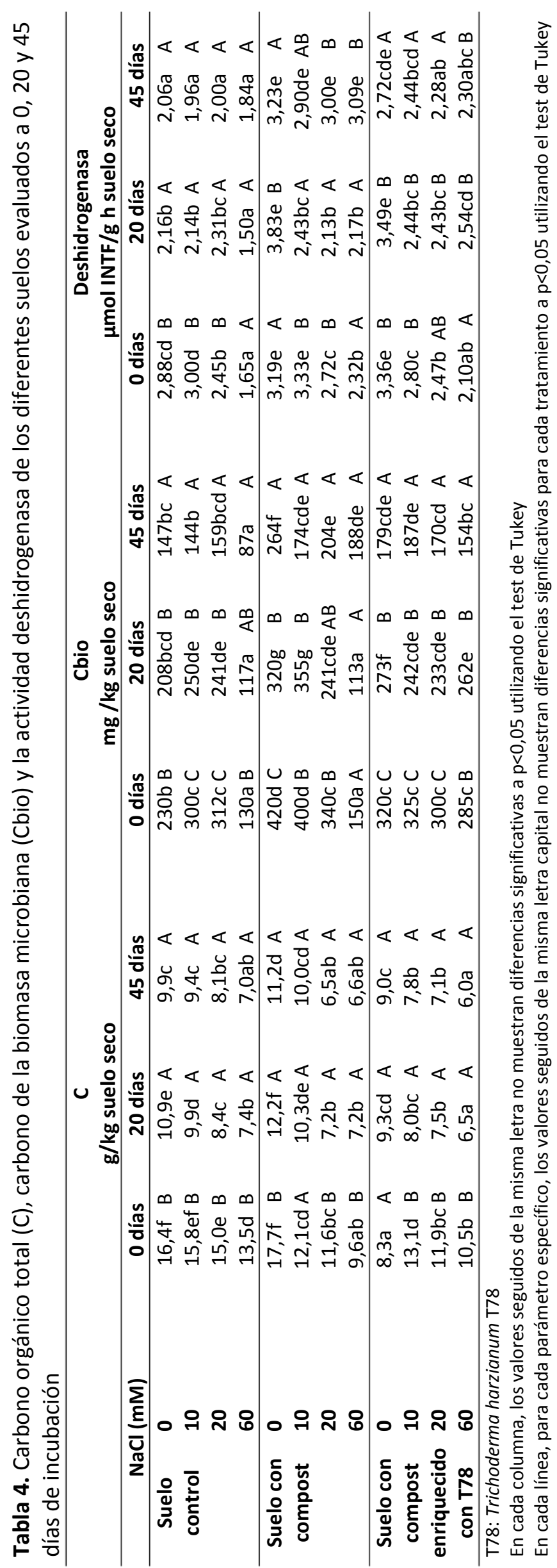


En la Tabla 4 también se indican los resultados de la determinación de la actividad deshidrogenasa. Esta actividad se redujo significativamente a concentraciones por encima de $10 \mathrm{mM}$ de $\mathrm{NaCl}$ en el suelo control. Por su parte, el suelo enmendado con compost mostró un aumento de la actividad deshidrogenasa, pero que disminuyó con el aumento de la concentración de sal, de una manera similar a la del suelo control, como ya observaron otros autores (Marinari et al., 2006; Mijangos et al., 2006). La actividad deshidrogenasa en el suelo enmendado con compost enriquecido con T78 presentó una tendencia similar, con la particularidad de que el aumento inicial fue menor que con compost solo, posiblemente debido a que $T$. harzianum T78 mostró antagonismo contra los microorganismos naturales (Harman, 2001).

Las deshidrogenasas son algunas de las enzimas más importantes del suelo que se utilizan como un indicador de la actividad global microbiana del suelo (Gu et al., 2009; Salazar et al., 2011), ya que se producen en el interior de todas las células microbianas vivas (Zhao et al., 2010; Yuan y Yue, 2012). En nuestros ensayos, esta actividad se redujo significativamente para concentraciones de $\mathrm{NaCl}$ por encima de 10 $\mathrm{mM}$ en suelos no enmedados, lo que demuestra el efecto tóxico de la sal sobre la actividad microbiana. Garcia et al. (1994) también registraron una correlación negativa entre la actividad microbiana y la conductividad eléctrica (CE) de los suelos áridos del Sureste de España, al igual que Wu et al. (2015). El aumento de la actividad deshidrogenasa en suelos con enmiendas de compost, en comparación con los suelos control, se mantuvo con el tiempo, lo que demuestra la capacidad del compost para aumentar la actividad microbiana, de manera sostenible, en condiciones salinas. Resultados similares fueron reportados por las incubaciones de suelo enmendado con compost en ausencia de aplicación de sal (Pascual et al., 1998).

Según Garcia et al. (1994) la comunidad microbiana responde a condiciones adversas con un aumento de su metabolismo, pero esto no se observó en el suelo no enmendado, a causa de que no tuvieron suficiente suministro de nutrientes para permitir la actividad microbiológica. La incorporación de compost produjo un ligero aumento de la biomasa microbiana y actividad deshidrogenasa, lo que indicó un aumento en la abundancia microbiana total, lo que confirma que la comunidad microbiana procesó los nutrientes orgánicos incorporados en el suelo activamente.

Además de los cambios cualitativos y cuantitativos en las comunidades microbianas producidas por la incorporación de compost y el enriquecimiento con T78, y evaluadas para suelos con y sin sal, también hubo cambios en el funcionamiento del sistema, como se evaluó mediante el análisis de la actividad de las enzimas del suelo. En el suelo control, las actividades $\beta$-glucosidasa y fosfatasa se vieron afectadas negativamente por la sal durante toda la incubación (Tabla 5). Los suelos enmendados con compost mostraron, en general, los valores significativamente más altos de las actividades $\beta$-glucosidasa y fosfatasa, frente al suelo control, pero también se vieron 
afectados negativamente por la concentración de $\mathrm{NaCl}$ (Tabla 5). Ambas actividades enzimáticas disminuyeron con el tiempo, pero fueron significativamente mayores que en el control, excepto en la concentración de sal más alta. Por su parte, la incorporación del compost enriquecido con T78 en el suelo alteró las actividades $\beta$-glucosidasa y fosfatasa, con respecto al control y al otro suelo enmendado con compost, dado que no se produjeron diferencias significativas entre las concentraciones de sal evaluadas. 


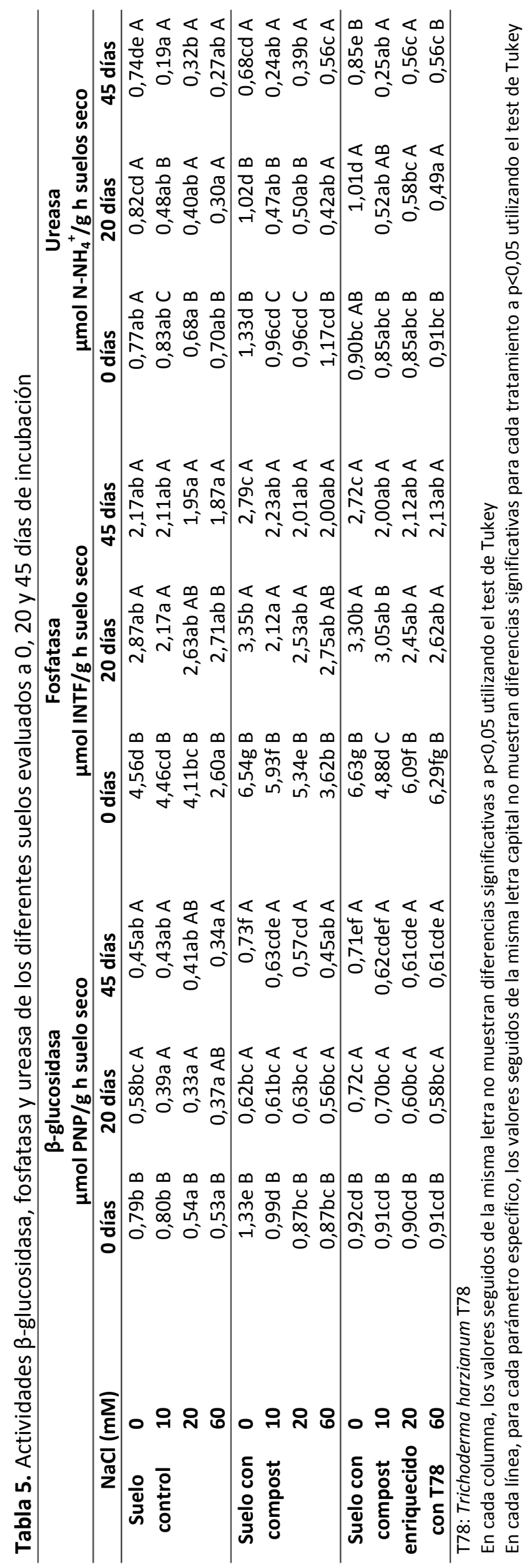


El patrón de las actividades enzimáticas específicas se diferenció entre los suelos enmendados y el control. En el suelo no enmendado, las actividades $\beta$-glucosidasa y fosfatasa se vieron afectadas negativamente por la sal, probablemente debido al efecto negativo sobre la biomasa microbiana, lo que habría disminuido la liberación de enzimas. Las altas concentraciones de sal redujeron la solubilidad de las proteínas enzimáticas y las desnaturalizaron, a través de la interrupción de la estructura terciaria de proteínas esenciales para las actividades enzimáticas (Frankerberger y Bingham, 1982). Por el contrario, las actividades $\beta$-glucosidasa y fosfatasa de los suelos con enmiendas de compost mostraron, en general, valores significativamente más altos. Por otro lado, la tendencia en el tiempo fue similar para todos los tratamientos: ambas actividades enzimáticas disminuyeron con el tiempo, como se esperaba debido a la reducción de compuestos de carbono, pero fueron significativamente mayores en suelos con enmiendas de compost, excepto para la concentración de sal más alta (Pascual et al., 1998).

Es interesante destacar que el efecto inhibidor de la sal fue más pronunciado para la fosfatasa que para $\beta$-glucosidasa, lo que demuestra que el grado de inhibición de $\mathrm{NaCl}$ es específico de la enzima (Pathak y Rao, 1998) y podría ser atribuible a la incorporación de sustratos orgánicos. Por lo tanto, la materia orgánica puede jugar un papel importante en la protección de enzimas, ya que un ligero aumento del carbono orgánico total puede significar que más materia orgánica queda inmovilizada en las redes tridimensionales $\mathrm{y}$ puede proteger a las enzimas de cualquier tipo de inactivación (Lagomarsino et al., 2009). En los suelos enmendados con compost enriquecidos con la cepa T78, la actividad $\beta$-glucosidasa y fosfatasa no mostraron diferencias significativas entre las diferentes concentraciones de sal, y además, no se observó ninguna reducción en la actividad $\beta$-glucosidasa, enzima clave para los microorganismos degradantes de material lignocelulósico, como Trichoderma spp. y como T. harzianum T78, para las distintas concentraciones de sal ensayadas.

Finalmente, en la Tabla 5 también se puede observar la evolución de la actividad ureasa. La actividad ureasa fue evaluada debido a que entre las enzimas que intervienen en el ciclo del nitrógeno del suelo, la ureasa es una de las enzimas más abundantes (Tabatabai y Bremmer, 1969). Los resultados obtenidos indican que la actividad ureasa no estuvo afectada por la concentración de $\mathrm{NaCl}$ en el primer tiempo de muestreo, independientemente de la enmienda, resultados que estuvieron de acuerdo con García et al. (1994). Sin embargo, esta actividad mostró una tendencia similar a la de $\beta$-glucosidasa y fosfatasa para los tiempos de muestreo restantes.

El efecto inicial de la salinidad sobre la actividad ureasa demuestra que el grado de inhibición debido a $\mathrm{NaCl}$ es específico de la enzima; asímismo, ello produce una disminución en el nitrógeno potencialmente mineralizable (Pathak y Rao, 1998). Por tanto, los microorganismos podrían haber resistido mediante el mantenimiento de una mayor actividad ureasa, como respuesta a la presencia de $\mathrm{NaCl}$, pero después de un 
corto período de tiempo esta actividad se inhibió de una manera similar a las otras actividades enzimáticas. Omar et al. (1994) observaron previamente que la actividad ureasa se redujo después de todos los períodos de incubación y con todos los niveles de salinidad utilizados, e indicaron que la disminución de la actividad de la enzima puede contribuir a una inhibición de la síntesis de la enzima, que estaba asociada con una disminución en la población microbiana del suelo.

Finalmente, una mayor biomasa microbiana y de actividades enzimáticas debidas a la incorporación de compost enriquecido con la cepa T78, podrían indicar una mejora en la calidad de suelos salinos enmendados (Bonilla et al., 2012.).

\section{Conclusión}

En el estudio desarrollado en este capítulo se puso de manifiesto que $T$. harzianum T78, es una cepa tolerante a la sal. Su incorporación a suelos salinos mediante su inclusión en compost enriquecidos con esta sepa parece ser una estrategia plausible para su recuperación. Se trata de un método sencillo, con un coste reducido, y altamente sostenible, ya que su incorporación en el sistema puede permitir una reducción de productos químicos como fertilizantes en suelos agrícolas.

\section{Bibliografía}

Abdel-Kader, M.M., Abdel-Kareem, F., El-Mougy, N.S., El-Mohamady, R.S., 2013. Integration between Compost, Trichoderma harzianum and essential oils for controlling peanut crown rot under field conditions. J. Mycol. 1-7.

Allison, S.D., Weintraub, M.N., Gartner, T.B., Waldrop, M.P., 2011. Evolutionary-economic principles as regulators of soil enzyme production and ecosystem function. In: Shukla, G.., Varma, A., Soil Enzymology. Berlin. Germany. Springer. pp. 229-243.

Amin, F., Razdan, V.K., Mohiddin, F.A., Bhat, K.A., Banday, S., 2010. Potential of Trichoderma species as biocontrol agents of soil borne fungal propagules. J. Phytol. 2(10), 38-41.

Baumann, K., Marschner, P., 2013. Effects of salinity on microbial tolerance to drying and rewetting. Biogeochem. 112, 71-80.

Benboualil, E., Hamoudi, S.A., Larich, A., 2013. Short-term effect of organic residue incorporation on soil aggregate stability along gradient in salinity in the lower cheliff plain (Algeria). Afr. J. Agric. Res. 8(19), 2144-2152.

Benítez, T., Rincón, M.A., Limón, M.C., Codón, C.A., 2004. Biocontrol mechanisms of Trichoderma strains. Int. Microbial. 7, 249-260.

Bernal-Vicente, A., Ros, M., Pascual, J.A., 2009. Increased effectiveness of the Trichoderma harzianum isolate T-78 against Fusarium wilt on melon plants under nursery conditions. J. Sci. Food Agric. 89, 827833.

Bernal-Vicente, A., Ros, M., Tittarelli, F., Intrigliolo, F., Pascual, J.A., 2008. Citrus compost and its water extract for cultivation of melon plants in greenhouse nurseries. Evaluation of nutriactive and biocontrol effects. Bioresour. Technol. 99, 8722-8728. 
Bonilla, N., Gutiérrez-Barranquero, J.A., De Vicente, A., Cazorla, F.M., 2012. Enhancing soil quality and plant health through suppressive organic amendments. Diversity 4(4), 475-491.

Doyle, D.J., Stotzky, G., 1993. Methods for the detection of changes in the microbial ecology of soil caused by the introduction of microorganisms. Microb. Releases 2, 63-72.

Egamberdieva, D., Renella, G., Wirth, S., Islam, R., 2010. Secondary salinity effects on soil microbial biomass. Biol. Fertil. Soils 46, 445-449.

El-Shakweer, M.H.A., El-Sayad, E.A., Ewees, M.S.A., 1998. Soil and plant analysis as a guide for interpretation of the improvement efficiency of organic conditioners added to different soil in Egypt. Comm. Soil Sci. Plant Anal. 29, 2067-2088.

Frankerberger, W.T., Bingham, F.T., 1982. Influence of salinity on soil enzyme activities. Soil Sci. Soc. Am. J. $46,1173-1177$.

Garcia, C., Hernandez, T., Costa, F., 1994. Microbial activity in soils under Mediterranean environmental conditions. Soil Biol. Biochem. 26, 1185-1191.

Garcia, C., Pascual, J.A., Mena, E., Hernandez, T., 2004. Influence of the stabilization of organic material on their biopesticide effects in soils. Bioresour. Technol. 95, 215-221.

Gu, Y., Wag, P., Kong, C., 2009. Urease, invertase, dehydrogenase and polyphenoloxidase activities in paddy soils influenced by allelophatic rice variety. Eur. J. Soil Biol. 45, 436-441.

Harman, G.E., 2001. Myth or dogma of biocontrol changes in perceptions derived from research on Trichoderma harziaunum T22. Plant Dis. 84, 377-394.

Harman, G.E., 2011. Multifunctional fungal plant symbionts: new tools to enhance plant growth and productivity. New Phytol. 189, 647-649.

Hassanein, N.M., 2012. Biopotential of some Trichoderma spp. against cotton root rot pathogens and profiles of some of their metabolites. Afr. J. Microbiol. Res. 6(23), 4878-4890.

Haynes, R.J., 2005. Labile organic matter fractions as central components of the quality of agricultural soils: An overview. Adv. Agron. 85, 221-268.

Iwai, C.B., Oo, A.N., Topark-ngarm, B., 2012. Soil property and microbial activity in natural salt affected soils in an alternating wet-dry tropical climate. Geoderma 189-190, 144-152.

Jayalakshmi, S.K., Raju, S., Rani, U., Benagi, V.I., Sreeramulu, K., 2009. Trichoderma harzianum L1 as a potential source for lytic enzymes and elicitor of defense responses in chickpea (Cicer arietinum L.) against wilt disease caused by Fusarium oxysporum f. sp. cicero. Aust. J. Crop Sci. 3(1), 44-52.

Joshi, B.B., Vishwakarma, M.P., Bahukhandi, D., Bhatt, R.P., 2012. Studies on strains of Trichoderma spp. from high altitude of Gargwal Himalaya region. J. Environ. Biol. 33, 843-847.

Kaewchai, S., Soytong, K., Hyde, K.D., 2009. Mycofungicides and fungal biofertilizers. Fungal. Divers. 38, 25-50.

Kuc, J., 2001. Concepts and direction of induced systemic resistance in plants and its application. Eur. J. Plant Pathol. 107, 7-12.

Kumar, S., Chaudhuri, S., Maiti, S.K., 2013. Soil dehydrogenase enzyme activity in natural and mine soil A review. Middle-East J. Sci. Res. 13(7), 898-906.

Lagomarsino, A., Moscatelli, M.C., Di Tizio, A., Mancinelli, R., Grego, S., Marinari, S., 2009. Soil biochemical indicators as a tool to assess the short-term impact of agricultural management on changes in organic $C$ in a Mediterranean environment. Ecol. Indic. 9(3), 518-527. 
Lakhdar, A., Hafsi, C., Debez, A., Montemurro, F., Jedidi, N., Abdelly, C., 2010. Assessing solid waste compost application as a practical approach for salt-affected soil reclamation. Acta Agric. Scand. B 61, 284-288.

Larney, F.J., Angers, D.A., 2012. The role of organic amendments in soil reclamation: A review. Can. J. Soil Sci. 92, 19-38.

Laudicina, V.A., Palazzolo, E., Badalucco, L., 2011. Effects of compost input and tillage intensity on soil microbial biomass and activity under Mediterranean conditions. Biol. Fertil. Soils 47, 63-70.

Lopez-Vicente, M., Navas, A., 2000. Predicting soil erosion with RUSLE in Mediterranean agricultural systems at catchment scale. Soil Sci. 174, 272-282.

Marinari, S., Mancinelli, R., Campiglia, E., Grego, S., 2006. Chemical and biological indicators of soil quality in organic and conventional farming systems in Central Italy. Ecol. Indic. 6(4), 701-711.

Marlet, S., Bouksila, F., Bahri, A., 2009. Water and salt balance at irrigation scheme scale: A comprehensive approach for salinity assessment in a Saharan oasis. Agric. Water Manage. 96, 13111322.

Mbarki, S., Labidi, N., Talbi, O., Jedidi, N., Abdelly, C., Pascual, J.A., 2010. Ameliorative effect of municipal solid waste compost on the biological quality of a Mediterranean salt lake soil. Compost Sci. Util. 18(4), 242-248.

Mijangos, I., Pérez, R., Albizu, I., Garbisu, C., 2006. Effects of fertilization and tillage on soil biological parameters. Enzym. Microb. Technol. 40, 100-106.

Mohamed, H.A.L.A., Haggag, W.M., 2005. Biocontrol potential of salinity tolerant mutants of Trichoderma harzianum against Fusarium oxysporum causing tomato wilt disease. Arab. J. Biotechnol. 8, 35-48.

Mohamed, H.A.L.A., Haggag, W.M., Attallah, A.G., 2010. Genetic enhancement of Trichoderma viride to accommodate different hydrolytic enzymes and their biocontrol potentially against root rot and white mold diseases in bean plants. Agric. Biol. J. N. Am. 1, 273-284.

Moradi, A., Tahmourespour, A., Hoodaji, M., Khorsandi, F., 2011. Effect of salinity on free livingdiazotroph and total bacterial populations of two saline soils. Afr. J. Microbiol. Res. 5(2), 144-148.

Mouria, B., Ouazzani, T.A., Douira, A., 2013. Effet du compost de Trichoderma harzianum sur la suppression de la verticilliose de la tomate. J. Appl. Biosci. 70, 5531-5543.

Munns, R., Tester, M., 2008. Mechanisms of salinity tolerance. Annu. Rev. Plant Biol. 59, 651-681.

Nannipieri, P., Ceccanti, B., Cervelli, S., Matarese, E., 1980. Extraction of phosphatase, urease, protease, organic carbon and nitrogen from soil. Soil Sci. Soc. Am. J. 44, 1011-1016.

Omar, S.A., Abdel-Sater, M.A., Khalli, A.M., Abd-Alla, M.H., 1994. Growth and enzyme activities of fungi and bacteria in soil salinized with sodium chloride. Folia Microbiol. 39, 23-28.

Paranychianakis, N.V., Chartzoulakis, K.S., 2005. Irrigation with saline water in Mediterranean region: from physiology to management practices. Agri. Ecosyst. Environ. 106, 171-187.

Pascual, J.A., Hernandez, M.T., Ayuso, M., García, C., 1998. Enzymatic activities in an arid soil amended with urban wastes. Bioresour. Technol. 64, 31-138.

Pathak, H., Rao, D.L.N., 1998. Carbon and nitrogen mineralization from added organic matter in saline and alkali soils. Soil Biol. Biochem. 30, 695-702. 
Peng, Z., Lu, Q., Verma, D.P.S., 1997. Reciprocal regulation of DELTA1-pyrroline-5-carboxylate synthetase and proline dehydrogenase genes controls proline levels during and after osmotic stress in plants. Mol. Genet. Genomics 253, 334-341.

Pitman, M., Laüchli, A., 2004. Global impact of salinity and agricultural ecosystems. In: Laüchli, A., Lullge, U. (Eds.), Salinity: Environment-Plants-Molecules. Dordrecht. Holland. Springer. pp. 3-20.

Qadir, M., Ghafoor, A., Murtaza, G., 2000. Amelioration strategies for saline soils: A review. Land Degrad. Dev. 11, 501-521.

Rietz, D.N., Haynes, J.R., 2003. Effects of irrigation-induced salinity and sodicity on soil microbial activity. Soil Biol. Biochem. 35(6), 845-854.

Salazar, S., Sanchez, L., Alvarez, J., Valverde, A., Galindo, P., Igual, J., Peix, A., Santa-Regina, I., 2011. Correlation among soil enzyme activities under different forest system management practices. Ecol. Eng. 37, 1123-1131.

Tabatabai, M.A., Bremmer, J.M., 1969. Assay of urease activity in soils. Soil Biol. Biochem. 4, 479-487.

Tejada, M., Garcia, C., Gonzalez, J.L., Hernandez, M.T., 2006. Use of organic amendment as a strategy for saline soil remediation: influence on the physical, chemical and biological properties of soil. Soil Biol. Biochem. 38, 1413-1421.

Vance, E.D., Brookes, P.C., Jenkinson, D.S., 1987. An extraction method for measuring soil microbial carbon. Soil Biol. Biochem. 19, 703-707.

Vinale, F., Sivasithamparam, K., Ghisalberti, E.L., Marra, R., Woo, S.L., Lorito, M., 2008. Trichoderma plant pathogen interactions. Soil Biol. Biochem. 40, 1-10.

Vizcano, J.A., Sanz, L., Basilio, A., Vicente, F., Gutierrez, S., Hermosa, M.R., Monte, E., 2005. Screening of antimicrobial activities in Trichoderma isolates representing three Trichoderma sections. Mycol. Res. $109,1397-1406$.

Whalen, J.K., Benslim, H., Jiao, Y., Sey, B.K., 2008. Soil organic carbon and nitrogen pools as affected by compost applications to a sandy-loam soil in Quebec. Can. J. Soil Sci. 88, 443-450.

Witt, C., Gaunt, J.L., Galicia, C.C., Ottow, J.C.G., Neue, H.U., 2000. A rapid chloroform-fumigation extraction method for measuring soil microbial biomass carbon and nitrogen in flooded rice soils. Biol. Fertil. Soils 30, 510-519.

Wu, Y.P., Zhang, Y., Bi, Y.M., Sun, Z.J., 2015. Biodiversity in saline and non-saline soils along the Bohai Sea coast, China. Pedosphere 25(2), 307-315.

Yeo, A., 1998. Molecular biology of salt tolerance in the context of whole-plant physiology. J. Exp. Bot. 49, 915-929.

Yuan, B., Yue, D., 2012. Soil microbial and enzymatic activities across a chronosequence of Chinese pine plantation development on the loess plateau of China. Pedosphere 22, 1-6.

Zhao, B., Chen, J., Zhang, J., Qin, S., 2010. Soil microbial biomass and activity response to repeated drying-rewetting cycles along a soil fertility gradient modified by long-term fertilization management practices. Geoderma 160, 218-224. 
IX. Co-digestión anaerobia mesófila de lodos agroalimentarios con restos de alcachofa para su biometanización. Dinámica de la comunidad Archaea y características abióticas del proceso 



\section{Co-digestión anaerobia mesófila de lodos agroalimentarios con restos de alcachofa para su biometanización. Dinámica de la comunidad Archaea y características abióticas del proceso}

\section{Introducción}

El sector de transformados de frutas y hortalizas genera grandes cantidades de restos orgánicos en su proceso de producción de conservas, zumos y congelados. En concreto genera subproductos que representan entre desde cerca del 10 hasta el $60 \%$ del peso de la materia prima utilizada, además de lodos del tratamiento de las aguas residuales dependientes de la materia prima procesada (2-8 toneladas de lodos por cada 100 toneladas de materia prima procesada). En la actualidad, los primeros se utilizan como alimento para animales, mientras que los segundos se gestionan a través de un gestor de residuos autorizado que lo deposita en algunos casos en vertederos, no cumpliendo con la legislación vigente, ya que estos residuos orgánicos son altamente biodegradable (Misi y Foster, 2001) y una fuente de molestia en los vertederos (olor problemas, contaminación atmosférica con gases de efecto invernadero), debido a su alto contenido de materia orgánica. Estos subproductos y residuos orgánicos del sector agroalimentario son, sin embargo, materiales adecuados para su alimentación en digestores anaeróbicos (DA), dando lugar a un proceso de biometanización donde se produce el denominado biogás, una energía renovable que ayuda a reducir la dependencia de los combustibles fósiles y contribuye positivamente a las economías nacionales (Mata-Álvarez et al., 2000).

La digestión anaeróbica se produce a través de cuatro etapas principales, denominadas hidrólisis, acidogénesis, acetogénesis y metanogénesis (Demirel y Scherer, 2008). Por otro lado, la co-digestión anaerobia de diferentes residuos permite mejorar la producción de biogás, dando lugar a un tratamiento de residuos más eficiente (Mata-Alvarez et al., 2000; El-Mashada y Zhang, 2010), probablemente debido a una relación de nutrientes mejorada con sustratos mixtos y una mayor capacidad de amortiguación del pH, elemento clave para las bacterias metanogénicas; caracterizadas por actuar en la última fase del proceso de producción de metano. Por esta razón, para maximizar la producción de metano y producción de biogás, es necesario entender el ciclo y la actividad de estos grupos clave para mejorar su crecimiento.

Las técnicas moleculares basadas en el análisis comparativo de secuencias de 16S rDNA son actualmente herramientas estándar empleadas en estudios de ecología microbiana, que han permitido el descubrimiento y la cuantificación de muchas bacterias nuevas y no cultivables. Por otro lado, la tecnología de Microarrays de ADN es uno de los avances más recientes en la tecnología molecular, y permite un formato de alto rendimiento para la detección paralela de genes 16S rRNA de una muestra 
ambiental (Bodrossy y Sessitsch, 2004). El microarray ANAEROCHIP ofrece la posibilidad de analizar toda una serie de metanógenas en cuanto a su presencia o ausencia en una muestra particular de lodos en un solo experimento (Franke-Whittle et al., 2009a). La tecnología Microarray también se ha aplicado y utilizado con éxito en otros hábitats y con diferentes microorganismos, como por ejemplo cianobacterias de ambientes hipersalinos (Loy et al., 2002), suelos (Small et al., 2001) y compost (FrankeWhittle et al., 2009b).

El objetivo buscado en este capítulo fue investigar el rendimiento y la producción de biogás de un reactor de digestión anaerobia para el tratamiento de lodos originados en el tratamiento de los efluentes hídricos del procesamiento de frutas y hortalizas (en concreto de alcachofa y pimiento), así como su rendimiento al llevar a cabo una co-digestión alimentando una mezcla de lodo con restos de alcachofa pretratados. Finalmente se controló la comunidad archaea presente en el digestato (lodo anaerobio) en diferentes momentos del proceso mediante el empleo del microarray ANAEROCHIP, y se cuantificaron usando PCR en tiempo real.

\section{Materiales y métodos}

\subsection{Parámetros físicos y químicos del análisis del lodo}

La conductividad eléctrica (CE) y el pH del lodo fueron medidos directamente con un conductímetro GLP 32 (Crison, Alella, España) y un pHmetro GLP 21 (Crison, Alella, España), respectivamente. El nitrógeno total (N) fue determinado por el método de Kjeldahl. El carbono orgánico total (C) fue determinado por el método descrito por Yeomans y Bremner (1989). El carbono orgánico hidrosoluble (Ch) fue extraído con agua desionizada 1:20 (p/v) y medido en un analizador automático de carbono. El contenido en sólidos totales (ST) y de sólidos volátiles (SV) fue medido de acuerdo a los métodos estándar para la determinación en agua y aguas residuales (APHA, 1995). Para la determinación del amonio se utilizó también el método Kjeldahl. Finalmente, los ácidos grasos volátiles (AGV) fueron medidos utilizando el cálculo de la conocida relación ácidos grasos volátiles/alcalinidad, mediante una valoración con $\mathrm{H}_{2} \mathrm{SO}_{4} 0,1 \mathrm{~N}$, de acuerdo al protocolo facilitado por Hach Lange $\mathrm{GmbH}$. El valor de la concentración de AGV (expresada como $\mathrm{mg} / \mathrm{L}$ de ácido acético) se calculó según la siguiente ecuación:

$A G V=\left(\left(\left(m L\right.\right.\right.$ gastados de $\mathrm{H}_{2} \mathrm{SO}_{4}$ para pasar de $\mathrm{pH} 5,0$ a pH 4,4) $\left.\left.\times 1,66\right)-0,15\right) \times 500$

mientras que, la alcalinidad (expresada como $\mathrm{mg} / \mathrm{L} \mathrm{CaCO}_{3}$ ) se determinó a partir de la siguiente ecuación:

Alcalinidad $=\left(\mathrm{mL}\right.$ gastados de $\mathrm{H}_{2} \mathrm{SO}_{4}$ para llegar hasta $\left.\mathrm{pH} 5,0\right) \times 250$ 


\subsection{El reactor y el análisis de las muestras de digestato}

\subsubsection{Puesta en marcha}

El experimento se realizó utilizando un reactor anaeróbico compuestos por un tanque de agitación continua (8-10 rpm), con una capacidad de volumen de trabajo de $300 \mathrm{~L}$. El reactor se cargó inicialmente con $215 \mathrm{~L}$ de lodos procedentes del tratamiento anaerobio mesófilo de lodos de aguas residuales urbanas y $20 \mathrm{~L}$ de lodos agroalimentarios procedentes de un tratamiento biológico de aguas residuales tipo SBR (reactor discontinuo secuencial), y se calentó hasta $35^{\circ} \mathrm{C}$. La Tabla 1 muestra las propiedades físico-químicas de las materias primas utilizadas.

Tabla 1. Propiedades físico-químicas de los materiales iniciales

\begin{tabular}{|c|c|c|c|}
\hline Parámetros & $\begin{array}{c}\text { Lodo de origen } \\
\text { urbano }\end{array}$ & $\begin{array}{l}\text { Lodo de origen } \\
\text { agroalimentario }\end{array}$ & $\begin{array}{l}\text { Lodo de origen } \\
\text { agroalimentario + } \\
\text { subproducto de } \\
\text { alcachofa pretratada }^{\text {a }}\end{array}$ \\
\hline $\mathrm{pH}$ & 7,8 & $6,35(5,93-6,76)$ & $5,85(5,32-6,41)$ \\
\hline Conductividad eléctrica $(\mu \mathrm{S} / \mathrm{cm})$ & 14.000 & $3.492(2.750-4.090)$ & $6.883(5.080-8.810)$ \\
\hline Materia seca (\%) & 1,4 & $2,94(1,79-4,09)$ & $8,32(7,36-9,84)$ \\
\hline Carbono orgánico total (\%) & 31,5 & $48,87(45,64-50,97)$ & $50,82(48,79-51,53)$ \\
\hline Carbono hidrosoluble (mg/kg) & ND & 3.000 & 15.000 \\
\hline Nitrógeno total (\%) & 12,86 & $8,17(7,87-8,45)$ & $5,05(4,08-6,6)$ \\
\hline Relación $\mathrm{C} / \mathrm{N}$ & 2,45 & $5,96(5,79-6,03)$ & $10,06(11,96-7,81)$ \\
\hline
\end{tabular}

\subsubsection{Proceso de digestión simple}

El reactor se alimentó diariamente con $12 \mathrm{~kg}$ de lodo agroalimentario (peso fresco) generado en una estación depuradora de tres empresas del sector de conservas de frutas y hortalizas de la Región de Murcia (una empresa de conservas y dos empresas productoras de congelados vegetales, principalmente pimiento y alcachofa) y una cantidad equivalente se sacó como efluente (conocido como digerido o digestato), correspondiente a un tiempo de retención hidráulica (TRH) de 22,5 días.

\subsubsection{Co-digestión}

Una vez que se alcanzaron las condiciones de estado estacionario en el reactor, 55 días después del inicio del proceso, se procedió a una co-digestión, alimentando el reactor con una mezcla de lodos agroalimentarios y subproducto de alcachofa (pretratada mecánicamente para adecuar su tamaño) en un proporción 60/40 de los lodos de procesamiento de frutas y vegetales con residuos de alcachofa fresca picada. Las propiedades físico-químicas de la mezcla se muestran en la Tabla 1. En esta ocasión se utilizó una carga orgánica de $11,75 \mathrm{~kg} / \mathrm{d}$ (peso fresco) correspondiente a un tiempo de retención hidráulica (TRH) de 30 días. 
La producción de gas se cuantificó usando un medidor de gases Milligascounter@1 (Ritter, Alemania) situado en la parte superior del reactor. La producción de metano se midió con un monitor Multi Gas X-am 7000 (Dräger, España).

Se tomaron muestras diariamente para el control del proceso desde un grifo situado en la parte inferior. Las muestras de los días 0, 24, 30, 59 y 71 días desde el inicio se guardaron para análisis posteriores.

\subsection{Extracción de ADN}

Se extrajo el ADN a partir de $200 \mathrm{mg}$ de material de digestato peletizado, obtenido después de la centrifugación de $1 \mathrm{~mL}$ de digestato durante 20 min a 13.000 rpm, utilizando el Kit Fast Spin de ADN para suelo (BIO 101, EE.UU.), siguiendo las instrucciones del fabricante. El ADN se sometió a electroforesis en gel de agarosa 1,5\% $(p / v)$ teñido con bromuro de etidio y se visualizó bajo luz UV.

\subsection{Análisis con microarray ANAEROCHIP}

Los oligonucleótidos utilizados para amplificar el gen del 16S rRNA de la comunidad metanogénica en las muestras de digestato mediante PCR fueron 109F (5'ACKGCTCAGTAAC ACGT-3') y 934R (5'-GTGCTCCCCCGCCAATTCCT-3') siguiendo las indicaciones de Franke-Whittle et al. (2009a). La cadena sencilla del producto de PCR marcado con el fluoroforo Cy5 se obtuvo usando una exonucleasa Lambda e hibridada en el array ANAEROCHIP a $55^{\circ} \mathrm{C}$ durante $4 \mathrm{~h}$. Los arrays fueron lavados después de su hibridación y escaneados con el escáner ScanArray Gx scanner (Perkin Elmer, MA, USA). El paquete informático ScanArray Gx (Perkin Elmer, MA, USA) se usó para analizar las imágenes obtenidas como describieron Franke-Whittle et al. (2009a).

La relación señal/ruido (signal to noise ratio (SNR)) para todos los puntos fue calculada usando la siguiente ecuación: SNR = [Ip- (Inp-Ibnp)]/Ibp, donde Ip es la intensidad media de fluorescencia de la sonda, Inp es la intensidad media de fluorescencia de la sonda control, lbnp es la intensidad media de fluorescencia de la zona de fondo alrededor de la sonda de control no vinculante, e IBP es la intensidad media de fluorescencia de la zona de fondo alrededor de la sonda. Las señales fueron tratadas como positivo si se obtuvo un valor de SNR $\geq 2$ (Loy et al., 2002).

\subsection{PCR en tiempo real}

EL ADN extraído de las muestras de los digestatos se utilizaron para la realización de PCR en tiempo real con los oligonucleótidos específicos 240F (5'CCTATCAGGTAGTAGTGGGTGTAAT-3')/589R (5'-CCCGGAGGACTGACCAAA-3') para Methanosarcina, y MS1b (5'-CCGGCCGGATAAGTCTCTTGA-3')/SAE835R (5'- 
GACAACGGTCGCACCGTGGCC-3') para Methanosaeta. Las curvas patrón se realizaron con los productos amplificados de la PCR en la región del 16S rRNA de los cultivos puros Methanosarcina barkeri (DSM 800) y Methanosaeta concilii (DSM 2139). Para ambas curvas se obtuvo un $r^{2}=0,999$. Las amplificaciones mediante PCR en tiempo real se realizaron usando Light Cycler System (Roche Applied Science) en un volumen total de $10 \mu \mathrm{L}$, donde cada reacción contiene una mezcla de $5 \mu \mathrm{L}$ de Quantimix EASY SYB (Biotools, Spain), 0,5 mg/mL BSA, $5 \mu \mathrm{M}$ de cada oligonucleótido y $1 \mu \mathrm{L}$ de una dilución 1/5 de ADN. Los ciclos del termociclado fueron: un ciclo de desnaturalización durante $30 \mathrm{~s}$ a $95^{\circ} \mathrm{C}$, seguido de 40 ciclos de $5 \mathrm{~s}$ a $95^{\circ} \mathrm{C}$, $25 \mathrm{~s}$ a $60^{\circ} \mathrm{C}$ y $1 \mathrm{~s}$ a $80^{\circ} \mathrm{C}$. Las carreras fueron terminadas con un análisis de fusión $\left(65^{\circ} \mathrm{C}\right.$ a $95^{\circ} \mathrm{C}$; con una rampa de $0,1^{\circ} \mathrm{C} / \mathrm{min}$ ). Todas las muestras se analizaron por triplicado.

\subsection{Análisis estadístico}

Los análisis estadísticos de los datos se realizaron con el programa SPSS 20.0 (SPSS Inc., Chicago, IL). La representación gráfica de los parámetros químicos se realizó mediante un análisis de componentes principales (PCA) para la reducción de dimensiones. Por otro lado, el PCA de la relación señal/ruido (SNR) de los datos del estudio de microarrays se realizó utilizando el programa CANOCO para Windows 4.5.

\section{Resultados y discusión}

\subsection{Producción de biogás}

La Figura 1 muestra la producción de biogás acumulada (L/kg de materia seca), observándose que la producción de biogás aumentó durante el proceso de la digestión anaerobia. Cuando se utilizó sólo el lodo de procesamiento de frutas y verduras como material de entrada (primeros 55 días de experimento), el promedio de producción de biogás alcanzó los $244 \pm 88 \mathrm{~L} / \mathrm{kg}$ de materia seca por día. Posteriormente, después de la adición de los subproductos de alcachofa (reducidos de tamaño mediante picado) para constituir la mezcla de alimentación (a partir del día 55), el valor medio de producción de biogás fue de $354 \pm 68$ L/kg de materia seca por día.

El aumento de la producción de biogás también estuvo acompañado por un aumento en la concentración de metano en el biogás producido, que fue del 42 a $65 \%$ durante la primera fase de la digestión con sólo el lodo agroalimentario, y alcanzó valores más altos del $70 \%$ en el proceso de co-digestión cuando se empleó además subproducto de alcachofa. Estos resultados apoyan los hallazgos de otros autores que han realizado experimentos de co-digestión anaerobia con otros materiales de entrada (Goberna et al., 2010; Ashekuzzaman y Poulsen, 2011).

La calidad de biogás está directamente relacionada con la concentración de metano; el biogás producido en el proceso presentó una concentración mínima de 
metano del $40 \%$, pero una vez que el proceso se estabilizó se alcanzó una concentración de aproximadamente el $65 \%$, que es una calidad aceptable.

El aumento de la producción de biogás y contenido de metano se correspondió con una reducción de los sólidos volátiles (Figura 2), que se atribuye a un desarrollo adecuado de las bacterias metanogénicas, que se alimentan de los ácidos orgánicos formados por las bacterias acidogénicas.

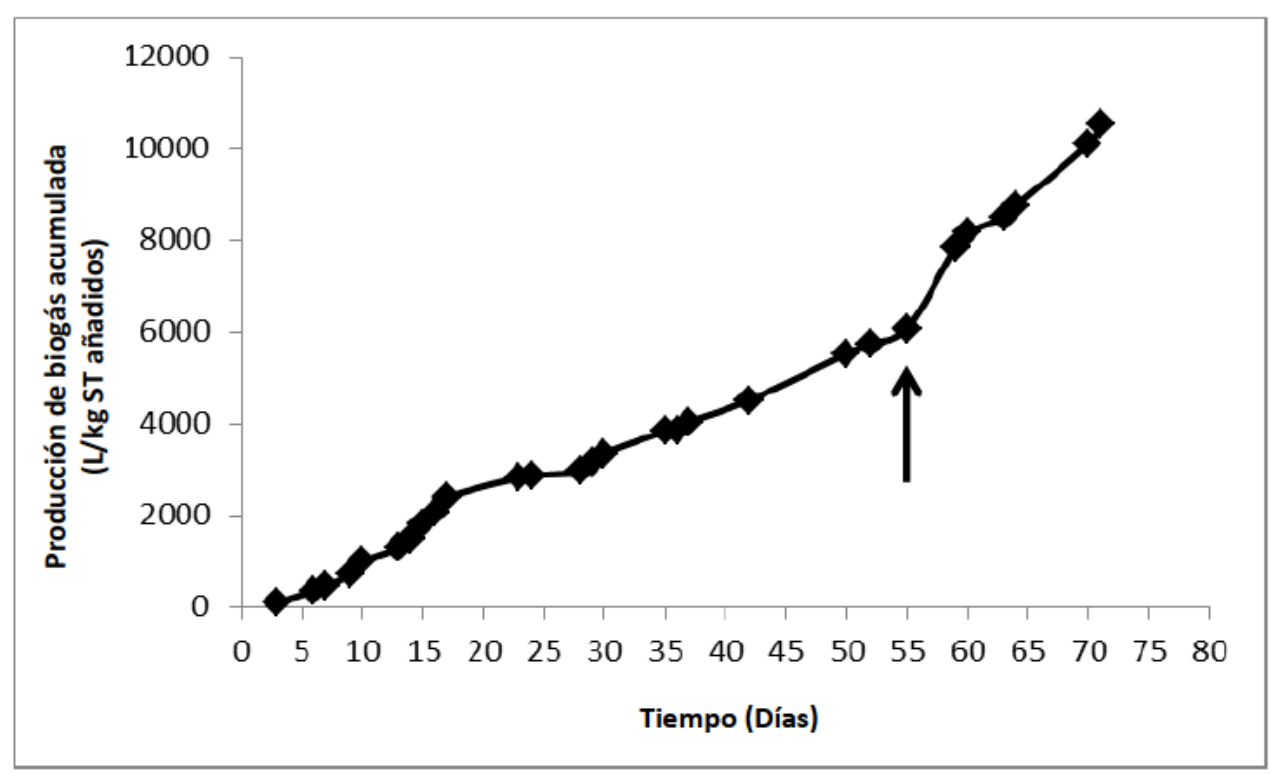

Figura 1. Producción de biogás acumulado durante la digestión anaerobia mesófila (la flecha indica el momento de incorporación del subproducto de alcachofa en la alimentación)

La digestión anaerobia (DA) se considera un proceso complejo, que implica cuatro etapas limitantes, la hidrólisis, acidogénesis, acetogénesis y metanogénesis (Demirel y Scherer, 2008). Cada grupo de microorganismos implicados en estas etapas tiene un conjunto óptimo de condiciones para el crecimiento, incluido el intervalo de $\mathrm{pH}$, la relación $\mathrm{AGV} / \mathrm{alcalinidad,} \mathrm{la} \mathrm{relación} \mathrm{C} / \mathrm{N}$ y la temperatura. $\mathrm{Y}$ además puede verse afectado por diferentes inhibidores como el nitrógeno amoniacal, compuestos fenólicos, plaguicidas, etc.

En todo el experimento, el $\mathrm{pH}$ observado estuvo entorno a la neutralidad (7,0$7,5)$, lo que indicó condiciones estables del digestor. A valores de $\mathrm{pH}$ neutro, las bacterias acidogénicas y metanogénicas pueden crecer y funcionar bien, lo que da lugar a una producción óptima de metano (Alvarez, 2004).

La relación AGV/alcalinidad del digestato se muestra en la Figura 2, e indicó también la viabilidad del proceso. Durante la primera fase de la DA, la relación AGV/alcalinidad varió 0,2 a 0,3 , situándose entre valores adecuados para el óptimo funcionamiento del digestor. Sin embargo, después de 30 días, las proporciones alcanzaron valores cercanos a 0,7 debido a un aumento temporal de los ácidos grasos 
volátiles (Figura 3), lo que además supuso una caída en el pH. Autores como Nordberg et al. (2007) indicaron que el incremento de los ácidos grasos volátiles puede inhibir la DA, y otros como Zhao et al. (2004) indicaron que una relación AGV/alcalinidad de 0,7, está cerca del valor umbral de 0,8 , que advierte de un fallo inminente del digestor. Con el fin de evitar esto, se aumentó la capacidad tampón del medio mediante la adición de bicarbonato de sodio al digestor, consiguiendo reducir la relación AGV/alcalinidad a valores cercanos a 0,3, aunque se incrementó hasta 0,5 después de la adición de los subproductos de alcachofa. Este desequilibrio puede haber sido debido a una sobrecarga orgánica, o a la presencia de un inhibidor de la metanogénesis, causando así un desequilibrio entre la producción y el consumo de ácidos grasos volátiles, lo que dio lugar a una acumulación de ácidos grasos volátiles y una disminución posterior en el $\mathrm{pH}$, acidificando el reactor.

Según Sievers y Brune (1978), la relación C/N para la alimentación de un digestor en condiciones mesófilas estuvo lejos de la óptima, considerada entre 25 y 30. Durante el proceso de DA, el nitrógeno orgánico se hidroliza para producir amonio, que es un nutriente importante para el crecimiento microbiano (Bryant et al., 1971), y cuya deficiencia dentro del reactor puede dar lugar a un fallo en la producción de biogás, pero una concentración excesivamente alta de la misma puede limitar el crecimiento microbiano. En la literatura se han encontrado diferentes comentarios sobre la posible inhibición del proceso de DA dependiente de la concentración de amonio (Chen et al., 2008). El nitrógeno amoniacal es el producto de la degradación de las proteínas y su distribución dentro del reactor como amoniaco $\left(\mathrm{NH}_{3}\right)$ o amonio $\left(\mathrm{NH}_{4}{ }^{+}\right)$varía dependiendo del $\mathrm{pH}$ y la temperatura. Los resultados de este estudio, sin embargo, indican que los niveles de amonio aumentaron en todo el proceso de digestión y no inhibieron la producción de biogás en el digestor (Figura 1 y Figura 2). 

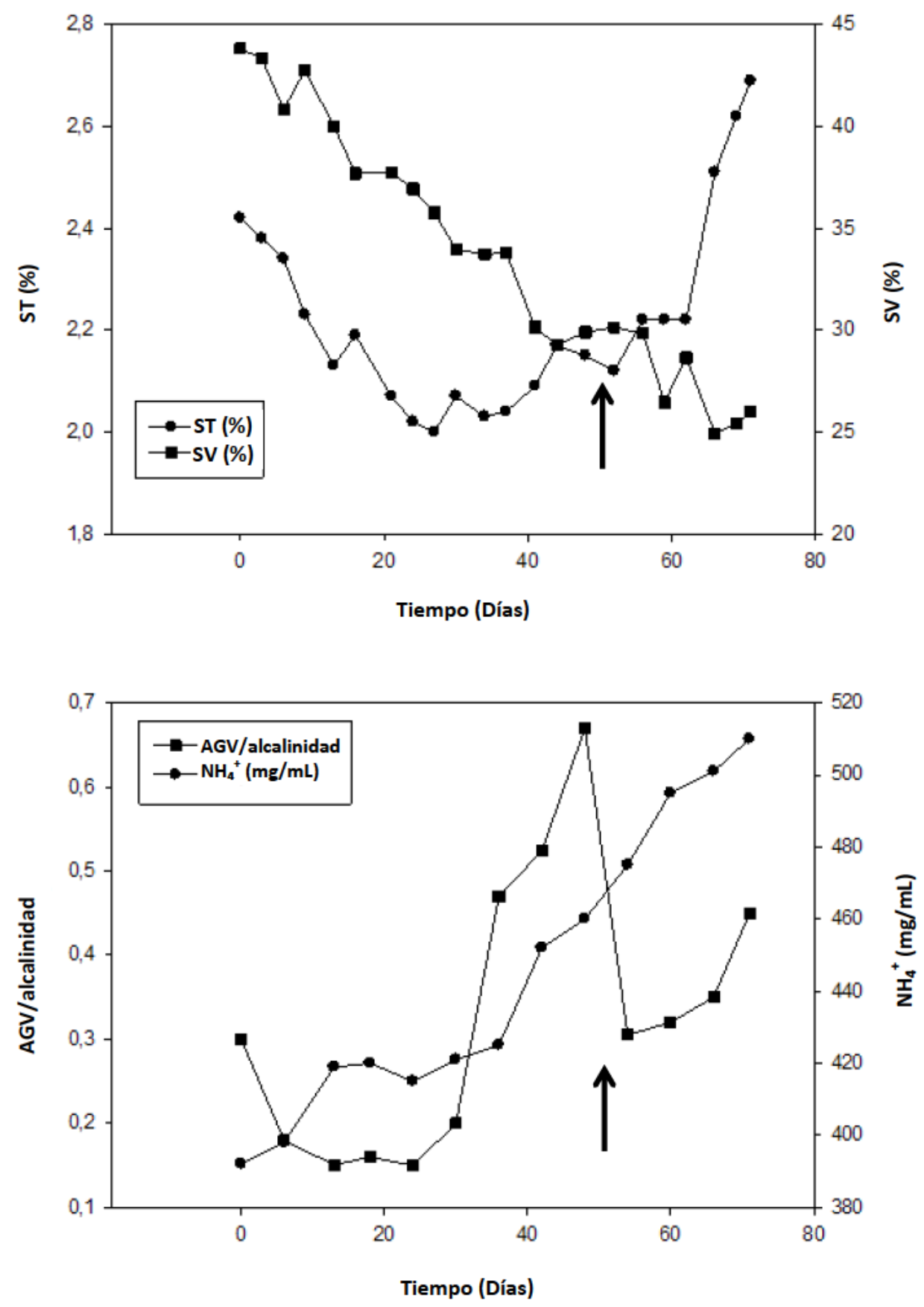

Figura 2. Contenido en sólidos volátiles (SV), sólidos totales (ST), concentración de amonio y relación AGV/alcalinidad durante el proceso de digestión anaerobia mesófila (la flecha indica el momento de incorporación del subproducto de alcachofa en la alimentación) 


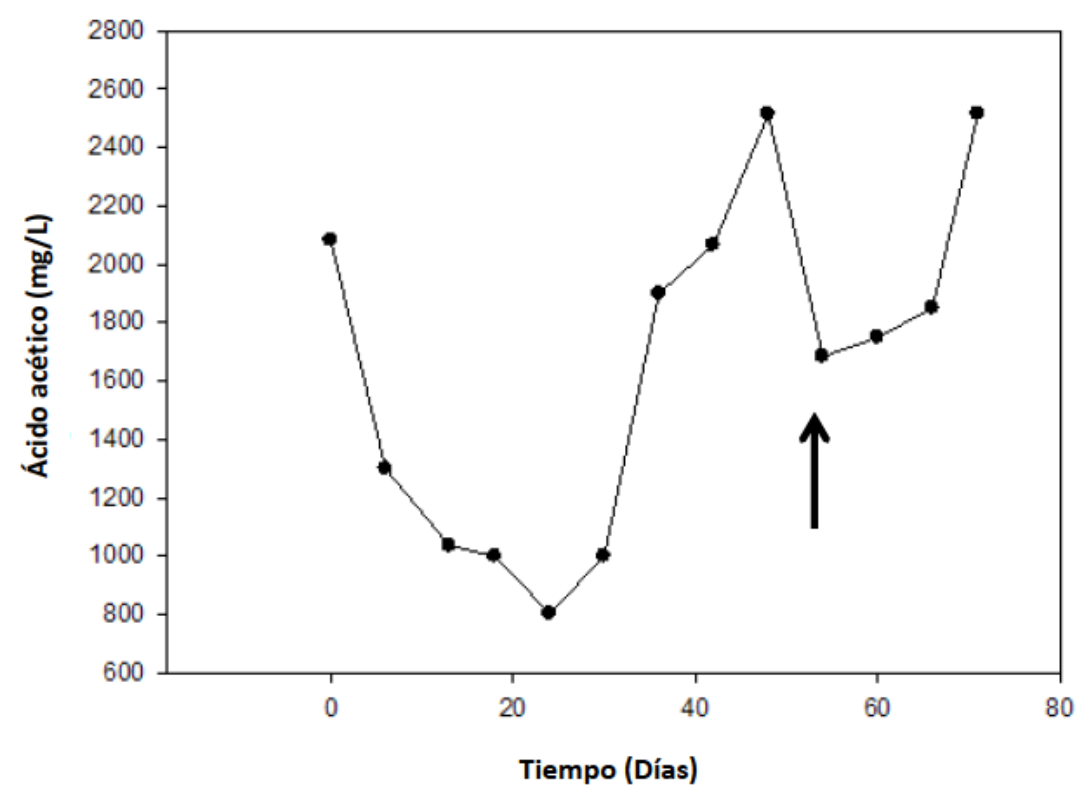

Figura 3. Contenido de AGV durante la digestión anaerobia mesofílica (la flecha indica el momento de incorporación del subproducto de alcachofa en la alimentación)

Finalmente, en la Figura 4 se muestra el resultado del análisis de componentes principales (PCA) de los parámetros físicos y químicos. Las dos componentes extraídas explican el 93 \% de la varianza total. Las muestras del inicio del proceso de la DA (día 0) se agruparon cerca de los mayores valores de $\mathrm{SV}$ y del $\mathrm{pH}$, mientras que las muestras recogidas hacia el final del proceso (días 59 y 71) se agruparon cerca de los niveles más altos de metano, amonio, producción de biogás, relación AGV/alcalinidad y ST. Este agrupamiento parece ser una respuesta al cambio de alimentación en el digestor, pasando de lodo agroalimentario a una mezcla lodo agroalimentario + subproducto de alcachofa, que tiene una mayor concentración de materia orgánica. 


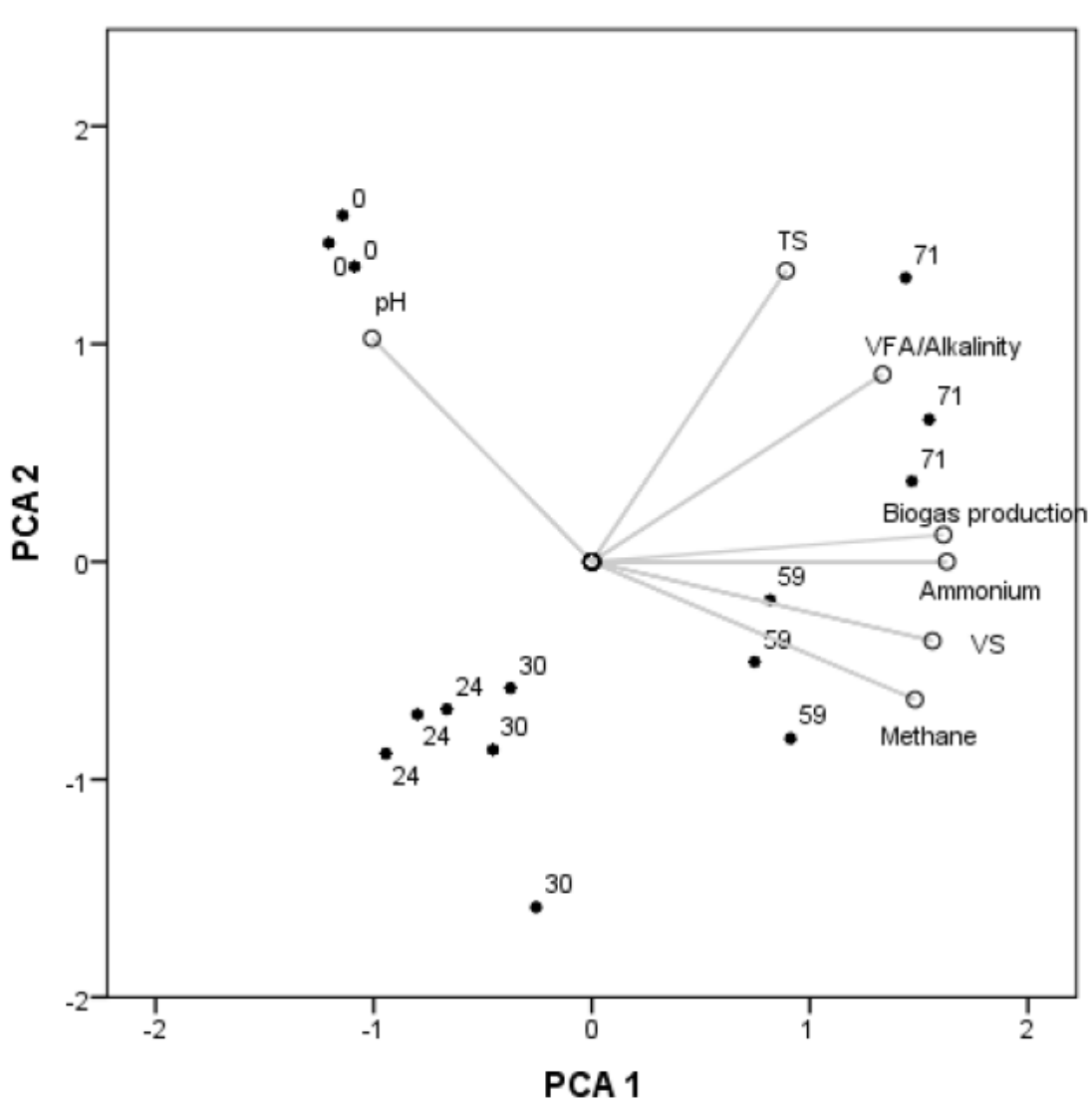

- Muestreo

\begin{tabular}{lcc}
\hline & $\begin{array}{c}\text { PCA 1 } \\
(70,557 \%)\end{array}$ & $\begin{array}{c}\text { PCA 2 } \\
(21,610 \%)\end{array}$ \\
\hline Sólidos totales (TS) & 0,540 & 0,809 \\
Sólidos volátiles (VS) & $-0,946$ & 0,220 \\
pH (pH) & $-0,610$ & 0,621 \\
AGV/alcalinidad (VFA/Alkalinity) & 0,807 & 0,521 \\
Amonio (Ammonium) & 0,986 & 0,000 \\
Producción de biogas (Biogas production) & 0,976 & 0,075 \\
Metano (Methane) & 0,897 & $-0,383$ \\
\hline
\end{tabular}

Figura 4. Análisis de Componentes Principales de los parámetros físicos y químicos. Los números hacen referencia a los días de muestreo

\subsection{Comunidad archaea}

La estructura de la comunidad archaea (Arqueas) presente en el reactor fue estudiada usando el microarray ANAEROCHIP (Franke-Whittle et al., 2009a). Los microarrays permiten la determinación de la presencia o ausencia de un grupo de microorganismos específicos de las muestras de digestato en un único análisis. Los datos obtenidos en los microarray deben tratarse como datos semi-cuantitativos debido a que el uso de la PCR en amplificaciones de ADN medioambiental, puede resultar en una desproporción en la amplificación de ciertos microorganismos, así 
como las diferencias inherentes, según la eficiencia en las hibridaciones de las diferentes sondas utilizadas (Wagner et al., 2007). Los valores de SNR estiman la abundancia de las dianas utilizadas (Cho y Tiedje, 2002). Los valores de SNR obtenidos después de la hibridación de las muestras en el ANAEROCHIP se muestran en la Tabla 2 , donde se observan los cambios en la comunidad de las Arqueas durante el experimento. En el tiempo de muestreo (0 días) los valores sobre el límite de detección fue obtenido por las sondas pertenecientes a las Methanosaeta (Msae 841, Msae 827 y Msae 406), mientras que dos de las tres sondas para Methanosaeta (Msae 827 y Msae 406) mostraron señales positivas para los días de muestreo 24 y 30 . Las Methanosaeta no fueron detectadas en las muestras de los días 59 y 70 . En contraste, las cinco sondas para Methanosarcina (Msar 184, Msar 197, Msar 549, Msar 587 y Msar 601) dieron valores elevados de SNR en los días 59 y 71, y casi no mostraron señal en las muestras tempranas de digestato. También fue interesante el hecho de la desaparición de las Methanoculleus a lo largo del experimento. El análisis de componentes principales (PCA) de las muestras mostraron dos grupos, uno que contiene las muestras de los días 0-30, y el otro que contiene los días 59 y 71 (Figura 5). El género Methanosaeta y el género Methanoculleus dominaron en las muestras de la primera fase del proceso (días 0, 24 y 30), y el género acetoclástico facultativa Methanosarcina dominó en las muestras de la segunda fase del proceso (tiempo de muestreo 59 y 71 días).

Tabla 2. Visualización de los resultados de hibridación de las muestras de los digestatos en el microarray ANAEROCHIP. Los nombres de las sondas están enumerados en cada fila, y columnas representando las diferentes muestras en triplicado. Los valores de SNR para todas las sondas fueron normalizadas respecto a las sonda Arc917, atribuyendo un valor entre 0 y 1 (Arc917 = 1). La intensidad relativa de la señal normalizada SNR de las sondas está indicada en la barra de color

\begin{tabular}{|c|c|c|c|c|c|c|c|}
\hline & & $\begin{array}{ccc} & \text { Día } 0 \\
1 a & 1 b & 1 c\end{array}$ & $\begin{array}{rrr} & \text { Día } 24 \\
3 a & 3 b & 3 c\end{array}$ & $\begin{array}{rrr} & \text { Día } 30 \\
4 a & 4 b & 4 c\end{array}$ & $\begin{array}{rrr} & \text { Día } 59 \\
5 a & 5 b \quad 5 c\end{array}$ & \begin{tabular}{|lll} 
& Día 71 \\
$6 a$ & $6 b$ & $6 c$ \\
\end{tabular} & \\
\hline Archaea & Arc917 & & & & & & \\
\hline Methanoculleus & Mcul393 & & & & & & \\
\hline Methanoculleus & Mcul574 & & & & & & 1- 0,369 \\
\hline Methanoculleus & Mcul302 & & & & & & 0,369-0,156 \\
\hline Methanoculleus & Mcul669 & & & & & & $0,156-0,0369$ \\
\hline Methanoculleus & Mcul170 & & & & & & $0,0369-0,016$ \\
\hline Methanosaeta & Msae841 & & & & & & $0,016-0,006$ \\
\hline Methanosaeta & Msae827 & & & & & & \\
\hline Methanosaeta & Msae406 & & & & & & \\
\hline Methanosarcina & Msar184 & & & & & & \\
\hline Methanosarcina & Msar197 & & & & & & \\
\hline Methanosarcina & Msar587 & & & & & & \\
\hline Methanosarcina & Msar549 & & & & & & \\
\hline Methanosarcina & Msar601 & & & & & & \\
\hline
\end{tabular}




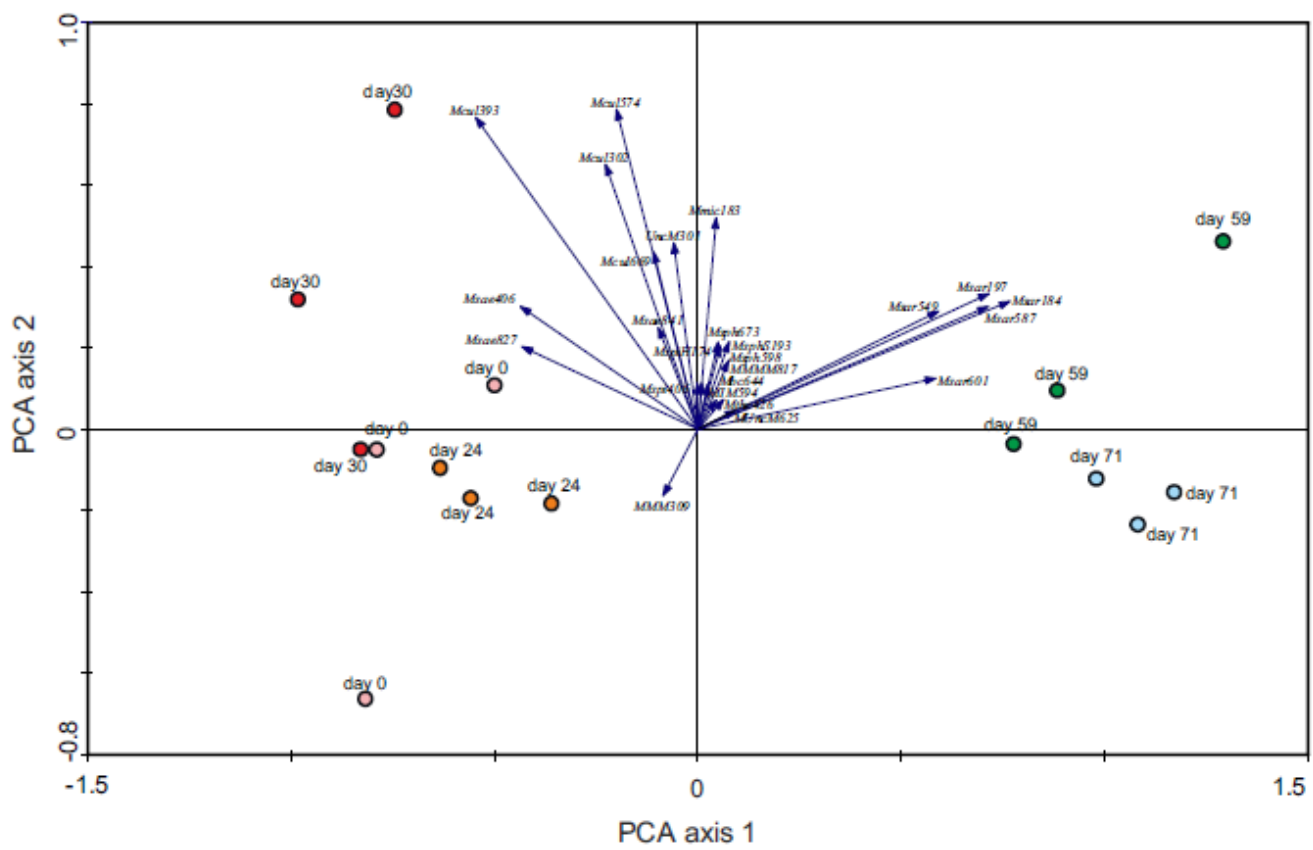

Figura 5. El análisis de Componentes Principales representa los organismos responsables de las diferencias de la comunidad metanogénicas entre las muestras de digestatos. Las longitudes de las flechas indican la importancia para la diferenciación de los digestatos. Las flechas de sondas apuntan en la dirección de las muestras con la señal superior a la media

Otras metanogénicas detectadas en solo una de las tres replicas bajo estudio, incluyó las del género Methanosphaera, Methanospirillum y Methano thermobacter. Esto podría indicar una comunidad metanogénica diversa compuesta de microorganismos capaces de la formación de metano durante el proceso de digestión anaerobia. El hallazgo de estas Arqueas, sin embargo, en una sola réplica de varias muestras, indica cierta heterogeneidad entre las comunidades Arqueas en los diferentes extractos de ADN, el resultado no es inesperado.

La concentración AGV se ha demostrado que está estrechamente relacionada con la concentración de hidrógeno disuelto (Schink, 1997), y el crecimiento de especies Methanoculleus es conocido por ser óptimo a bajas concentraciones de hidrógeno. La aparición de especies Methanoculleus en las fases iniciales de la digestión anaeróbica también fue descrito por Goberna et al. (2009), y la co-existencia de metanógenos aceticlásticos e hidrogenotróficos, como se encontró en este estudio, se ha observado en una digestión anaerobia termofílica (Hori et al., 2006) y en los ecosistemas naturales del medio ambiente, por ejemplo, campos de arroz (Lueders et al., 2002).

De acuerdo con Patil et al. (2010), Methanosarcina y Methanosaeta son géneros que se han encontrado dominantes en los digestatos obtenidos del proceso mesofílico de la digestión anaerobia. Ambos géneros están dentro de las metanogénicas acetoclásticas, las cuales se han descrito como las responsables de aproximadamente el 70 \% del metano producido en los reactores (Ahring et al., 1995). Los precursores más importantes utilizados por las metanogénicas son acetato y 
$\mathrm{H}_{2} / \mathrm{CO}_{2}$ (Garrity y Holt, 2001). El género Methanosaeta pertenece a la familia de Methanosaetaceae e incluye exclusivamente especies acetotróficas, los cuales utilizan acetato como única fuente de energía. Estos microorganismos crecen solo en bajas concentraciones de acetato, mientras que las especies de Methanosarcina son conocidas por dominar en altas concentraciones medioambientales de acetato (Conrad y Klose, 2006). Sin embargo, las Methanosaeta tienen una ventaja competitiva sobre Methanosarcina spp. debido a su mayor afinidad por el sustrato (5-10 veces). Esta superior afinidad por el sustrato se basa en una entrada de alta energía en la activación del acetato por una sintetasa, la acetil-CoA (Kendall y Boone, 2006). Debido a los resultados de las muestras de digestatos obtenidas mediante hibridación con el ANAEROCHIP, estos géneros se emplearon para su cuantificación mediante PCR cuantitativa (Figura 6). El número de copias de Methanosaeta detectada por PCR en tiempo real no varió considerablemente a través del proceso $(8,5-9,0$ log copias $16 \mathrm{~S}$ rRNA/g digestato seco).

Estos resultados contrastan con las que se encontraron en el microarray ANAEROCHIP, donde se encontraron Methanosaeta en el día 0, 24 y 30, pero no se detectó en las muestras de los días 59 y 71 días. Por otro lado, un número significativamente mayor de copias de genes de Methanosarcina fueron encontradas en la segunda fase del proceso de co-digestión anaerobia (de 9,0 log copias $16 \mathrm{~S}$ rRNA/g digestato seco en el día 59 a 12,0 log copias 16S rRNA/g digestato seco en el día 71) respecto a la primera fase (9,0-9,5 log copias $16 \mathrm{~S}$ rRNA/g digestato seco).

Los resultados de PCR en tiempo real indicaron que durante la segunda fase del proceso, las Arqueas del género Methanosarcina estuvieron fácilmente adaptadas a las nuevas condiciones medioambientales (la incorporación de lodo agroalimentario junto con restos de alcachofa picada), empezaron a dominar y fueron responsables del aumento de la producción de metano. Los resultados de PCR en tiempo real apoyan los resultados de los análisis de microarrays, donde no se detectó Methanosarcina en las muestras de los días 0,24 y 30, pero sí se detectó, y en valores más altos, en las muestras de los días 59 y 71. La ventaja competitiva de las Methanosarcina mostrada bajo condiciones de sistema no estable se ha mostrado anteriormente (por ejemplo, McMahon et al., 2004). También se ha observado que las especies Methanosarcina forman agregados multicelulares que pueden adherirse fácilmente a las sustancias sólidas, tales como materiales celulósicos y por lo tanto pueden ofrecer resistencia a la inhibición de sustancias en el reactor (Vavilin et al., 2008). Pueden producir directamente metano a partir de acetato generado a partir de la fermentación de la materia orgánica sólida. Methanosarcina es aparentemente más resistente a los aumentos en la concentración de acetato y, por lo tanto, promueve un proceso de digestión más estable (Conklin et al., 2006). Según De Vrieze et al. (2012), la relación Methanosarcina-Methanosaeta en reactores parece ser aún más importante para determinar la estabilidad operacional del sistema que el número total de Arqueas. 


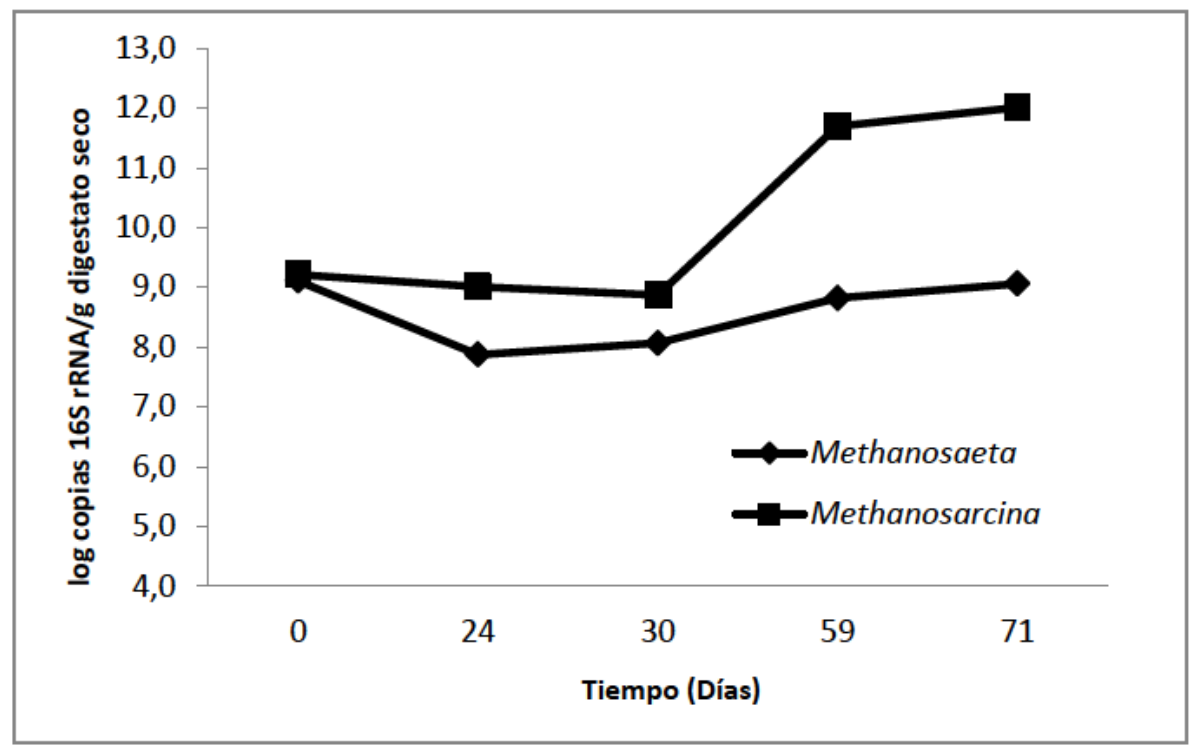

Figura 6. Número de copias del $16 \mathrm{~S}$ rRNA para el grupo de metanogénicas cuantificadas por PCR en tiempo real durante la digestión anaerobia

\section{Conclusión}

Este capítulo de la tesis ha demostrado que la co-digestión mesofílica de los lodos agroalimentarios con subproductos de alcachofa fresca se puede optimizar y utilizar para obtener una alta producción de biogás y de buena calidad. Los resultados, además, proporcionan evidencia de que la metanogénesis aceticlástica, principalmente por Methanosarcina, podría ser la principal vía para la producción de metano.

\section{Bibliografía}

Ahring, B.K., Sandberg, M., Angelidaki, I., 1995. Volatile fatty acids as indicators of process imbalance in anaerobic digestors. Appl. Microbiol. Biotechnol. 43, 559-565.

Alvarez, D., Garrido, N., Sans, R., Carreras, I., 2004. Minimization-optimization of water use in the process of cleaning reactors and containers in a chemical industry. J. Clean. Prod. 12, 781-787.

APHA, AWWA, WEF, 1995. Standard methods for the examination of water and wastewater, 19th ed. American Public Health Association/American Water Works Association/Water Environment Federation, Washington DC, USA.

Ashekuzzaman, S.M., Poulsen, G.T., 2011. Optimizing feed composition for improved methane yield during anaerobic digestion of cow manure based waste mixtures. Bioresour. Technol. 102, 2213-2218.

Bodrossy, L., Sessitsch, A., 2004. Oligonucleotide microarrays in microbial diagnostics. Curr. Opin. Microbiol. 3, 245-254.

Bryant, M.P., Tzeng, S.F., Robinson, I.M., Joyner, A.E., 1971. Nutrient requirements of methanogenic bacteria. In: Pohland, F.G. (Ed.), Anaerobic biological treatment processes. Advances in Chemistry Series. Vol. 105. Washington D.C. Am. Chem. Soc. pp. 23-40. 
Chen, Y., Cheng, J.J., Creamer, S., 2008. Inhibition of anaerobic digestion process: A review. Bioresour. Technol. 99, 4044-4064.

Cho, J.C., Tiedje, J.M., 2002. Quantitative detection of microbial genes by using DNA microarrays. Appl. Environ. Microbiol. 68, 1425-1430.

Conklin, A., Srtensel, H.D., Ferguson, J., 2006. Growth kinetics and competition between Methanosarcina and Methanosaeta in mesophilic anaerobic digestion. Water Environ. Res. 78, 486-496.

Conrad, R., Klose, M., 2006. Dynamics of the methanogenic archaeal community in anoxic rice soil upon addition of straw. Eur. J. Soil Sci. 57, 476-484.

De Vrieze, J., Hennebel, T., Boon, N., Verstraete, W., 2012. Methanosarcina: the rediscovered methanogen for heavy duty biomethanation. Bioresour. Technol. 112, 1-9.

Demirel, B., Scherer, P., 2008. The roles of acetotrophic and hydrogenotrophic methanogens during anaerobic conversion of biomass to methane: a review. Rev. Environ. Sci. Biotechnol. 7, 173-190.

El-Mashada, H.M., Zhang, R., 2010. Biogas production from co-digestion of dairy manure and food waste. Bioresour. Technol. 101, 4021-4028.

Franke-Whittle, I.H., Goberna, M., Pfister, V., Insam, H., 2009a. Design and development of the ANAEROCHIP microarray for investigation of methanogenic communities. J. Microbiol. Methods. 79, 279-288.

Franke-Whittle, I.H., Knapp, B.A., Fuchs, J., Kaufmann, R., Insam, H., 2009b. Application of COMPOCHIP Microarray to Investigate the Bacterial Communities of Different Composts. Microb. Ecol. 57, 510-521.

Garrity, G.M., Holt, J.G., 2001. Euryarchaeota. In: Boone, D.R., Castenholz, R.W. (Eds.), Bergey's manual of systematic bacteriology. Vol. 1. New York. Springer. pp. 211-354.

Goberna, M., Insam, H., Franke-Whittle, I.H., 2009. Effect of biowaste sludge maturation on the diversity of thermophilic bacteria and archaea in an anaerobic reactor. Appl. Environ. Microbiol. 75, 2566-2572.

Goberna, M., Schoen, M.A., Sperl, D., Wett, B., Insam, H., 2010. Mesophilic and thermophilic cofermentation of cattle excreta and olive mill wastes in pilot anaerobic digesters. Biomass Bioenergy 34, 340-346.

Hori, T., Haruta, S., Ueno, Y., Ishii, M., Igarashi, Y., 2006. Dynamic transition of methanogenic population in response to the concentration of volatile fatty acids in a thermophilic anerobic digester. Appl. Environ. Microbiol. 72, 1623-1630.

Kendall, M. M., Boone, D.R., 2006. Cultivation of methanogens from shallow marine sediments at Hydrate Ridge, Oregon. Archaea 2, 31-38.

Loy, A., Lehner, A., Lee, N., Adamczyk, J., Meier, H., Ernst, J., Schleifer, K.H., Wagner, M., 2002. Oligonucleotide microarray for $16 \mathrm{~S}$ rRNA gene-based detection of all recognized lineages of sulfatereducing prokaryotes in the environment. Appl. Environ. Microbiol. 68, 5064-5081.

Lueders, T., Friedrich, M.W., 2002. Effect of amendment with ferrihydrite and gypsum on the structure and activity of methanogenic populations in rice field soil. Appl. Environ. Microbiol. 68, 2484-2494.

McMahon, K.D., Zheng, D.D., Stams, A.J.M. Mackie, R.I., Raskin, L., 2004. Microbial population dynamics during star-up and overload conditions of anaerobic digesters treating municipal solid waste and sewage sludge. Biotechnol. Bioeng. 87, 823-834.

Mata-Alvarez, J., Macé, S., Llabres, P., 2000. Anaerobic digestion of organic solid wastes. An overview of research achievement and perspectives. Bioresour. Technol. 74, 3-16. 
Misi, S.N., Froster, C.F., 2001. Batch co-digestion of multi-component agro-wastes. Bioresour. Technol. 76, 165-168.

Nordberg, A., Jarvis, A., Stenberg, B., Mathisen, B., Svensson, H., 2007. Anaerobic digestion of alfalfa silage with recirculation of process liquid. Bioresour. Technol. 98, 104-111.

Patil, S.S., Kumar, S.M., Ball, A.S., 2010. Microbial community dynamics in anaerobic bioreactors and algal tanks treating piggery wastewater. Appl. Microbiol. Biotechnol. 87, 353-363.

Schink, B., 1997. Energetics of syntrophic cooperation in methanogenic degradation. Microbiol. Mol. Biol. Rev. 61, 262-280.

Sievers, D.M., Brune, D.E., 1978. Carbon/nitrogen ratio and anaerobic digestion of swine waste. Trans. ASAE 21, 537-541.

Small, J., Call, D.R., Brockman, F.J., Starub, T.M. Chandler, D. P., 2001. Direct detection of 16S rRNA in soils extracts by using oligonucleotide microarrays. Appl. Environ. Microbiol. 67, 4708-4716.

Vavilin, V.A., Qu, X., Mazeas, L., Lemunier, M., Duquennoi, C., He, P.J., Bouchez, T., 2008. Methanosarcina as the dominant acetoclastic methanogens during mesophilic anaerobic digestion putrescible waste. Anton. Leeuw. Int. J. G. 94, 593-605.

Wagner, M.H., Smidt, H., Loy, A., Zhou, J., 2007. Unraveling microbial communities with DNAmicroarrays: challenges and future directions. Microb. Ecol. 53, 498-506.

Yeomans, J., Bremner, J.M., 1989. A rapid and precise method for routine determination of organic carbon in soil. Commun. Soil Sci. Plant 19, 1467-1476.

Zhao, H.W., Viraraghavan, T., 2004. Analysis of the performance of an anaerobic digestion system at the Regina wastewater treatment plant. Bioresour. Technol. 95, 301-307. 
X. Discusión general 



\section{Discusión general}

Esta Tesis Doctoral se propuso como objetivo principal poner de manifiesto opciones de valorización de los residuos orgánicos (biorresiduos) producidos en el sector agroindustrial de la Región de Murcia, de tal manera que se genere conocimiento sobre su posibilidad de reciclarlos siguiendo el orden jerárquico que establece la normativa de residuos vigente, sin obviar los beneficios económicos de la comercialización de nuevos productos.

Del estudio realizado se puede decir que, la generación de lodos agroalimentarios es una realidad en las estaciones depuradoras de aguas residuales de las empresas del sector de conservas de frutas y hortalizas (conocido como sector de transformados vegetales) con tratamiento biológico. En la Región de Murcia, se cuantificaron entre 12.895 y 22.520 toneladas de lodos agroalimentarios, correspondientes a datos disponibles desde el año 2008, pudiendo incrementarse dicho potencial debido a la progresiva adecuación de las empresas a la normativa de depuración de aguas residuales, de acuerdo con el Plan General de Saneamiento y Depuración de la Región de Murcia (2001-2010). Este biorresiduo se genera en mayor medida en la comarca de la Huerta de Murcia, pero la comarca de la Vega Media es donde en el futuro más se debe incrementar la generación de lodos como consecuencia de tener un mayor número de empresas que hasta la fecha no disponen de depuradora. Este hecho es importante a la hora de planificar operaciones de valorización de lodos.

Por otro lado, las operaciones de tratamiento de aguas residuales y la subsiguiente retirada de lodos representan, para las empresas del sector de conservas de frutas y hortalizas, un importante esfuerzo técnico, organizativo y económico. De la aproximación económica llevada a cabo se obtuvo que el coste asociado al tratamiento de los efluentes hídricos y gestión de lodos tiene un coste unitario de $1,36 € / \mathrm{m}^{3}$ de agua tratada y de $185 € / T$ de lodo generado. De este último total, el coste asociado al concepto de gestión de los lodos mediante gestor autorizado representa solo el $5 \%$, por lo que "la eliminación del problema" con gestores autorizados no supone un coste destacable para las empresas del sector, lo que afecta en la toma de decisiones para su valorización desde la empresa.

Respecto a las características físico-químicas podemos decir que el origen de estos lodos agroalimentarios asegura un alto contenido en materia orgánica, un contenido en macro y micronutrientes interesante y la práctica seguridad de que el contenido en metales pesados va a estar muy por debajo de los exigidos por la normativa para su uso agrícola, puesto que vienen de una industria, a priori, más exigente que la agrícola, que es la alimentaria. Un riesgo que tampoco debería de aparecer, pero aparece es la presencia de restos de plaguicidas utilizados en la producción o transporte y conservación de la materia prima procesada, aunque los niveles detectados son relativamente bajos. En todo caso, estos restos proceden de 
frutas y hortalizas que tienen que cumplir una legislación que establece unos límites máximos por ello y si se cumple esta normativa, los lodos no deberían sobrepasar los restos de plaguicidas, al menos en un nivel preocupante. Finalmente, desde el punto de vista microbiológico y a pesar de que las depuradoras de empresas de transformados vegetales depuran una cantidad pequeña o nula de aguas fecales (en el peor de los casos el agua residual procedente de los aseos de la empresa es un porcentaje mínimo respecto al generados en los procesos de elaboración de transformados vegetales) presentan microorganismos de origen fecal procedentes, con probabilidad, de los primeros lavados de la materia prima.

La aplicación de lodos al suelo puede ser una de las opciones más económicas y útiles de gestión de lodos de depuradora, donde el transporte, el análisis de los lodos y el suelo, así como el seguimiento necesario son los únicos costes. Sin embargo, el coste se puede incrementar si el suelo es contaminado porque existan bacterias, virus, hongos y parásitos en el lodo. Para evitar esta contaminación se requiere un tratamiento de los lodos y el compostaje ha sido considerado como la opción de valorización más atractiva y viable para el tipo de lodos que se genera en la industria de transformados vegetales. La estabilización anaeróbica puede ser una alternativa a la estabilización aeróbica (compostaje) ya que el lodo después de la fermentación también pueden ser adecuado para su uso en la agricultura y recuperación de suelos. Además, se produce biogás, que tiene un alto contenido en metano, y puede tratarse para la producción de energía.

En el estudio también se pudo determinar que en la Región de Murcia, el procesado de alcachofa, pimiento y cítricos es el que mayor volumen de subproductos genera, con destino fundamentalmente a alimentación animal. En cuanto a la dimensión temporal, la generación de subproductos muestra un alto grado de concentración en los meses centrales del año (mayo-septiembre), con cifras en torno al $75 \%$, estando relacionada con la superposición de diferentes campañas, especialmente las de frutas de hueso (albaricoque y melocotón), y de pepita (pera), entre otras de campañas a lo largo de prácticamente todo el año. El material responsable de los elevados niveles en el resto del año, es fundamentalmente la alcachofa, dado al elevado volumen de producción y al bajo rendimiento inferior al $50 \%$, lo que supone un elevado volumen de subproductos, principalmente brácteas.

Por otro lado, el análisis del coste y de la valorización económica de los biorresiduos y/o subproductos se ha fundado en el concepto básico de "construcción de un producto". En este caso, el subproducto generado se ha considerado como un "material o producto secundario" respecto al producto alimentario primordial, obtenido en el marco de un único proceso de producción. El subproducto puede presentar así el carácter de materia prima de otros procesos productivos -conexos o no con el principal- y para la fabricación de otros productos, con carácter de coproductos respecto al producto o productos principales del proceso principal. 
En este marco, la determinación del impacto de los bioresiduos y/o subproductos en los diferentes procesos productivos y productos finales de varias de las principales orientaciones productivas del sector de transformados vegetales (alcachofa, pimiento, tomate, melocotón y albaricoque) pone de relieve que es determinado por factores tales como que los subproductos generados oscilan entre el $50 \%$ en el caso del procesado de alcachofa hasta el $18 \%$ en los caso de procesado de tomate, albaricoque y melocotón. El coste de las materias primas vegetales es un factor fundamental en este sector, en parte debido al impacto del elevado porcentaje de biorresiduos. Hay que tener en cuenta que, por ejemplo en el caso del procesado de alcachofa para obtener una tonelada de producto elaborado son necesarias dos toneladas como mínimo de materia prima, y en el caso de los frutos de hueso el coste de la materia prima representa el $50 \%$ del coste final aún con un elevado rendimiento del $82 \%$, debido principalmente al sobrecoste derivado del fenómeno de minoración de la materia prima en forma de biorresiduos. Otro factor determinante es el del grado de elaboración, diferenciación y sofisticación del producto final de forma que, a mayor grado, corresponde un mayor coste imputable a los bioresiduos por dos causas:

a) Un mayor nivel de eliminación de partes de los frutos que constituyen la materia prima del proceso, con la correlativa repercusión en su coste imputable al producto-mercado final, debido a un menor grado de aprovechamiento de los mismos.

b) Un coste más elevado del proceso de acondicionamiento de esos frutos, previo al proceso especifico de conservación, al comprender más operaciones y más complejas.

En este sentido, los costes más elevados corresponden a aquellos productos que requieren un procesado más intensivo (p.e.: pelado, cortado, extracción de huesos, etc.) como en el caso de la alcachofa, con un coste imputable a estas operaciones que alcanza hasta un máximo del $50 \%$ de los costes totales de producción; o en el de los frutos de hueso con un promedio del $33 \%$ de esos costes.

En cualquier caso, hay que tener en cuenta otros factores como: la tecnología aplicada al proceso productivo en general $y$, especialmente, la aplicada a las operaciones específicas de acondicionamiento previo del producto, ya que la técnica (mecánica, manual, mixta, etc.) y su nivel de desarrollo e implementación afecta destacadamente a la estructura de costes y a la formación de precios relativos de producción; y la escala de producción, vía volumen de producto procesado ya que, de forma general, las economías de escala influyen destacadamente en la estructura de costes y precios.

De las posibles opciones de valorización para los subproductos, clasificadas por el destino, destaca la aplicación agrícola y el destino animal como finalistas. El compostaje convierte los componentes de residuos orgánicos en sustancias estables como el humus que puede ser utilizado como un enmendante del suelo, un fertilizante 
orgánico o en un sustrato orgánico para su empelo en cultivo sin suelo. Los subproductos analizados son ricos en proteínas y nutrientes, y además de disponer de grandes cantidades existe una amplia variedad, lo que implica que a la hora de establecer una mejora nutricional del compost es de interés "jugar" con los constituyentes del compostaje, seleccionando como agentes co-compostantes los subproductos agroalimentarios con las características más adecuadas. Por otro lado, la digestión anaerobia (biometanización) es una de las tecnologías más sostenibles para producir biogás a partir de biorresiduos, pero presenta inconvenientes cuando se alimenta con un solo material, por lo que la co-digestión, que es la adición simultanea de dos o más sustratos, es la opción más interesante para ajustar los parámetros dentro del digestor y garantizar una alta producción de metano que mejore la viabilidad económica de las plantas de biometanización. Tras el tratamiento se produce un nuevo residuo semilíquido, el digerido o digestato, que ha de ser gestionado, por lo que no se considera una tecnología finalista, sin embargo, puede ser utilizado en agricultura después de un proceso de estabilización o de compostaje.

En la Región de Murcia también es destacable la producción agrícola que garantiza las materias primas para el sector agroalimentario. El cultivo de hortalizas ocupa una superficie de 51.924 hectáreas y el de cultivos leñosos 194.366 hectáreas, según datos del Centro Regional de Estadística de la Región de Murcia del año 2013, destacando el cultivo de vid en los leñosos debido a la actividad vitivinícola con denominación de origen de la Región. Para el correcto desarrollo del cultivo se requiere de poda y aclareos, por lo que también en la actividad agrícola se generan restos vegetales que también son necesarios gestionar. Actualmente la quema de la poda es una práctica extendida, por lo que parece interesante aprovechar la energía perdida y clasificarla como biomasa para sustituir a la madera en la producción de energía; sin embargo, debido a su carácter lignocelulósico puede ser utilizada como un agente estructurante que favorezca un correcto proceso de compostaje.

Una vez determinado el potencial de valorización de los residuos y subproductos agroindustriales, en el trabajo se evaluó la aplicación de estos materiales desde un punto de vista agronómico, pudiendo además obtener energía a través de una valorización energética previa. Se llevaron a cabo experiencias de compostaje donde se seleccionó en primer lugar el tipo de agente estructurante en el compostaje de lodos agroalimentarios, obteniendo que el tipo y su estado físico influye en las características del compost y sobre la potencial funcionalidad del mismo. Posteriormente, los resultados obtenidos demostraron que el uso de agentes cocompostantes, que a priori presentan interesantes características y potencialidades en cuanto a compuestos activos (polifenoles, etc.), aportaron funcionalidad al compost final obtenido:

a) Si se pretende un efecto biofertilizante o bioestimulante el camino a seguir es el empleo de agentes estructurantes que aumenten la estabilidad del compost, 
y aprovechar aquellos agentes co-compostantes que incrementen su contenido en materia orgánica y nutrientes y que no estén muy estabilizados y vean disminuida su actividad microbiana para el correcto desarrollo del proceso de compostaje.

b) Si se pretende un efecto biopesticida se ha de "jugar" con los ingredientes o agentes co-compostantes adicionados al proceso y utilizar un óptimo tamaño de partícula del agente estructurante.

Además, los compost obtenidos a partir de lodos de la industria agroalimentaria y restos vegetales son especialmente atractivos para cultivos agrícolas ecológicos en cuanto a calidad agronómica ya que permiten asegurar los criterios de calidad establecidos en la Clase A en el Real Decreto 506/2013.

También se debe recordar que, el proceso de compostaje asegura la higienización de la pila de compostaje, pero es necesario mantener un control de los parámetros del proceso. Además, de acuerdo a los resultados alcanzados, salvo excepciones, todos los compost obtenidos de la mezcla de lodos del sector de transformados vegetales, poda de vid y otros restos orgánicos del sector presentaron parámetros estructurales dentro del rango recomendado para enmiendas orgánicas.

Con todo ello, el producto final obtenido no presentó desventajas para su uso agrícola, pero sí ventajas asociadas a las funcionalidades que puede adquirir con la selección de adecuados e interesantes agentes co-compostantes. Además, la adición de microorganismos beneficiosos tales como Trichoderma harzianum, permitiría obtener un compost con valor añadido en cuanto al incremento de su capacidad biocontrol, de aplicación en la recuperación de suelos de baja productividad, ya que mejora la calidad microbiológica del suelo y permite reducir el uso de fertilizantes.

Finalmente, la sustitución de una parte importante de turba (sustrato habitual de empresas hortofrutícolas (viveros, semilleros, etc), que tiene un coste elevado, por otros sustratos orgánicos como son los compost obtenidos a partir de restos vegetales y lodos de depuradoras agroalimentarias, puede suponer un beneficio claro para las empresas, ya que por una parte es mucho más económico que la turba, no supone un riesgo para el cultivo, más bien al contrario ya que puede incrementar la producción vegetal e incorpora nutrientes que, en todo caso, supondrá un ahorro en fertilizantes químicos; y por otra, ofrece una salida valorada y adecuada a los biorresiduos generados en el sector de transformados vegetales.

En el campo de la valorización energética, a pesar de la idoneidad de estos lodos del sector de transformados vegetales para la digestión anaerobia, esta actuación no es tan recomendable desde el punto de vista económico por el bajo contenido de materia seca de los lodos. La co-digestión de los lodos con otros restos orgánicos generados en la propia actividad industrial es muy recomendable desde el punto de vista técnico y posiblemente también desde el punto de vista económico. 
Podemos decir, que los biorresiduos y, subsiguientemente, los subproductos deben ser considerados siempre como bienes a gestionar y como fuente de competitividad para las empresas que los generan. Por otra parte, respecto a las opciones de valorización que se adopten deben cumplir condiciones como: 1) la opción debe ser, en términos de coste-beneficio incorporando los costes de oportunidad y las expectativas comerciales, inequívocamente superior a otras opciones concurrentes; 2) en relación con las diferentes opciones técnicas se debe establecer una jerarquía y, sí es posible, una secuencia de acciones de valorización con obtención de diferentes coproductos; y 3) el establecimiento de la prioridad, si es posible, de desarrollar el proceso de valorización en la misma unidad y/o planta de producción en que se ha generado el biorresiduo/subproducto, como actividad contigua y/o subsiguiente a la actividad principal.

Para concluir, se ha puesto de manifiesto, a través del contacto directo con empresas del sector, el interés de las mismas en la valorización de sus biorresiduos. Efectivamente los lodos y restos orgánicos presentan unas características, tales como su alto contenido en materia orgánica y su ausencia de contaminantes, que los hacen idóneos para su valorización agrícola y energética. 
XI. Conclusiones generales 



\section{Conclusiones generales}

1. El sector de conservas de frutas y hortalizas de la Región de Murcia genera lodos de depuración debido al tratamiento biológico de sus aguas residuales, que presentan un alto contenido en materia orgánica, un contenido interesante en nutrientes y ausencia de contaminación por metales pesados, debido a su origen vegetal, que favorece su aplicación en agricultura. Debido a sus características, estos lodos requieren de procesos de estabilización que, además, garanticen su utilización de acuerdo al Código de Buenas Prácticas Agrícolas. El compostaje y la biometanización son tecnologías probadas para otros residuos orgánicos, con garantías para su empleo en este tipo de biorresiduos con los que se puede obtener un producto final con valor añadido. En su incorporación a procesos de compostaje se requiere de un agente estructurante que favorezca el inicio del proceso, pudiendo encontrarse dentro del propio sector agroindustrial, de tal manera que se lleve a cabo una gestión integral de los biorresiduos agroindustriales.

2. En el proceso de elaboración industrial de conservas de frutas y hortalizas también se generan subproductos vegetales diferenciados a lo largo del año según las campañas productivas, cuya gestión actual es su destino a alimentación animal sin control. Estos subproductos presentan características particulares en cuanto a componentes y un interesante contenido nutricional para ser valorizados de acuerdo a la jerarquía de residuos, pudiendo reciclarse en el ámbito agrícola mediante tecnologías de compostaje y biometanización. Se trata de materiales que pueden ser utilizados como agentes cocompostantes o en procesos de co-digestión para garantizar un óptimo proceso de valorización. Además, se pueden obtener compost con valor añadido en cuanto a su capacidad biofertilizante y/o biopesticida.

3. Los sarmiento de vid son un resto agrícola de la poda de los viñedos, con un peso importante en la Región de Murcia, que puede emplearse como agente estructurante en los procesos de compostaje. Además, se ha comprobado que la incorporación de un agente biocontrol como es Trichoderma harzianum, permite dirigir el proceso hacia la obtención de compost con valor añadido.

4. El compostaje de lodos de depuración de aguas residuales del sector de conservas de frutas y hortalizas, con restos de poda de vid con un tamaño de partícula $1 \mathrm{~cm}$, como agente estructurante, demostró los mejores resultados para la obtención de un compost de calidad en comparación con otras granulometrías ensayadas y otros restos de cultivos. En ensayos realizados a nivel semillero con plántulas de melón se obtuvo que estas mostraron un mayor peso fresco, además de una menor reducción de peso fresco en presencia del patógeno Fusarium, frente a la turba (utilizada como control). 
5. Los compost obtenidos a partir de los lodos procedentes de industrias de transformados vegetales, complementados con otros residuos o restos generados en esta industria, como alcachofa, pimiento, brócoli, y cítricos, entre otros, pueden emplearse como sustratos alternativos al uso de la turba, además de presentar un valor añadido. Esto último demuestra la importancia de la inclusión de este tipo de materiales co-compostantes durante el compostaje para la obtención de compost con capacidad biofertilizante o como supresivo frente a enfermedades de plantas. Destacan los compost con subproducto de alcachofa, en cuanto al crecimiento de plántulas de melón, y aquellos con subproducto de pimiento rojo y alta proporción de agente estructurante en la menor incidencia de la enfermedad de fusariosis vascular del melón en semillero comparado con la turba.

6. El tratamiento de suelos salinos con compost obtenidos a partir de restos de poda de vid o sarmientos, enriquecidos con Trichoderma harzianum T78 favorece el desarrollo de poblaciones microbianas, debido a la alta tolerancia a la sal que presenta este microorganismo. La incorporación de este compost a suelos salinos mejora la calidad biológica del suelo de un modo sustancial.

7. En los procesos de compostaje, la elección de los materiales de partida, junto a la potencial inoculación de microorganismos beneficiosos, puede conferir al compost obtenido el valor añadido deseado, lo que convierte esta técnica ancestral, el compostaje, en una técnica muy valiosa de valorización de residuos agroalimentarios.

8. La biometanización es una técnica alternativa de valorización de los residuos agroindustriales. El lodo agroalimentario es un sustrato apto para la obtención de biogás en condiciones mesófilas. Si además, a este se le incorporaba alcachofa, en co-digestión, se obtuvo un valor promedio mayor de producción de biogás. Por otro lado, se estudió la comunidad archaea involucrada en la producción de metano y se observó la importancia de las especies Methanosaeta y Methanosarcina durante el proceso de digestión anaerobia. 
APÉNDICE 

ENCUESTA SOBRE SISTEMA DE DEPURACIÓN DE AGUAS RESIDUALES EN EL SECTOR DE TRANSFORMADOS VEGETALES. GENERACIÓN DE LODOS

\section{DATOS GENERALES DE LA EMPRESA}

Nombre de la empresa:

Dirección:

Municipio:

Persona de contacto:

Email:

\section{DATOS GENERALES DEL SISTEMA DE DEPURACIÓN}

Sistema de depuración:

Capacidad de depuración (diseño-m³ /día):

¿Dispone de pretratamiento? ¿Cuál?

¿Dispone de tratamiento secundario? ¿Cuál?

\section{DATOS DE VERTIDO}

Volumen de agua tratada $\left(\mathrm{m}^{3} / \mathrm{a} \tilde{\mathrm{n} o}\right)$

Volumen de lodos generados (T/año):

\section{OTROS DATOS}

¿La depuradora es mancomunada?

Materias primas procesadas:

\section{OBSERVACIONES}



ENCUESTA SOBRE SUBPRODUCTOS Y RESIDUOS ORGÁNICOS EN EL SECTOR DE TRANSFORMADOS VEGETALES 



\section{DEPURACIÓN DE AGUAS RESIDUALES Y GESTIÓN DE RESIDUOS- AGROWASTE}

\section{DATOS GENERALES DE LA EMPRESA}

Nombre de la empresa:

Dirección y CP:

Persona de contacto:

Email:

PROCESO COMERCIAL

MATERIA PRIMA PROCESADA

\begin{tabular}{|l|l|l|l|l|l|l|l|l|l|l|l|l|l|l|}
\hline TIPO & $\begin{array}{c}\text { Coste } \\
\text { unitario } \\
\text { promedio } \\
\text { (E/T) }\end{array}$ & $\begin{array}{l}\text { Ene } \\
\text { (T) }\end{array}$ & $\begin{array}{l}\text { Feb } \\
\text { (T) }\end{array}$ & $\begin{array}{l}\text { Mar } \\
\text { (T) }\end{array}$ & $\begin{array}{l}\text { Abr } \\
\text { (T) }\end{array}$ & $\begin{array}{c}\text { May } \\
\text { (T) }\end{array}$ & $\begin{array}{l}\text { Jun } \\
\text { (T) }\end{array}$ & $\begin{array}{l}\text { Jul } \\
\text { (T) }\end{array}$ & $\begin{array}{l}\text { Ago } \\
\text { (T) }\end{array}$ & $\begin{array}{l}\text { Sept } \\
\text { (T) }\end{array}$ & $\begin{array}{l}\text { Oct } \\
\text { (T) }\end{array}$ & $\begin{array}{l}\text { Nov } \\
\text { (T) }\end{array}$ & $\begin{array}{l}\text { Dic } \\
\text { (T) }\end{array}$ \\
\hline & & & & & & & & & & & & & \\
\hline & & & & & & & & & & & & \\
\hline & & & & & & & & & & & & \\
\hline & & & & & & & & & & & & \\
\hline & & & & & & & & & & & & \\
\hline & & & & & & & & & & & & \\
\hline & & & & & & & & & & & & \\
\hline & & & & & & & & & & & & & \\
\hline & & & & & & & & & & & & & \\
\hline
\end{tabular}

SUBPRODUCTOS GENERADOS

CUANTIFICACIÓN

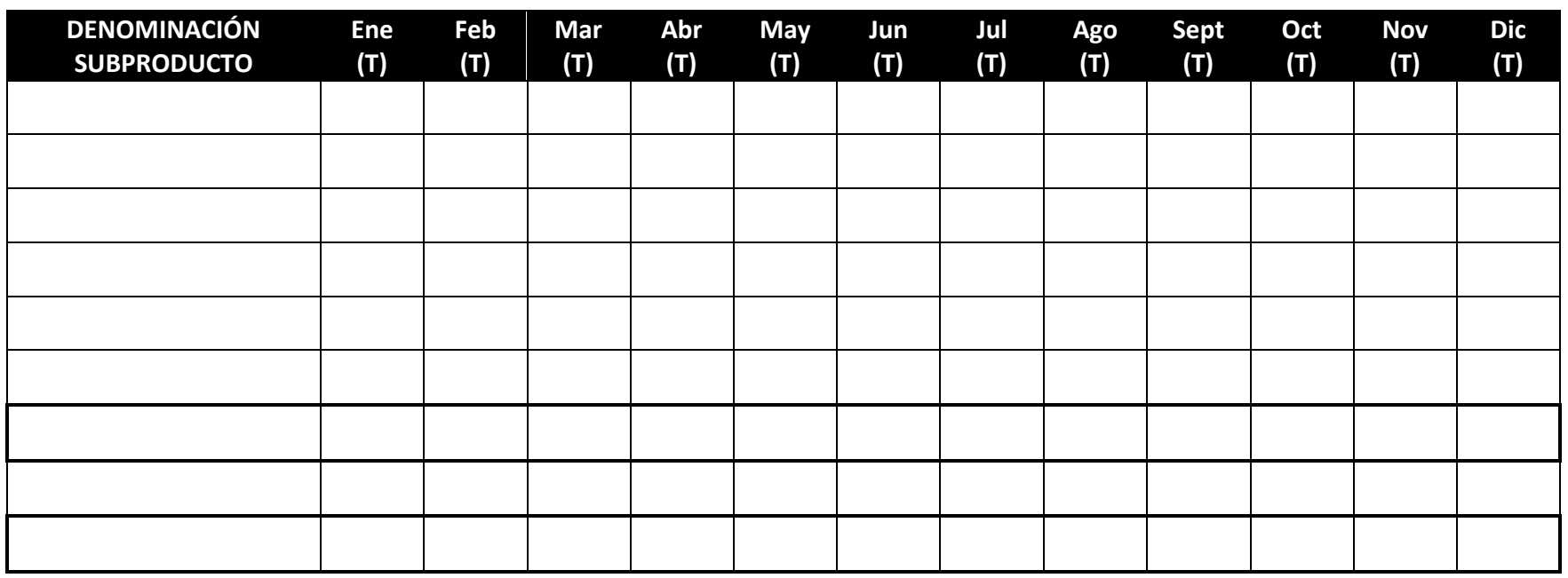



ETAPA DEL PROCESO PRODUCTIVO

\begin{tabular}{|c|c|c|}
\hline $\begin{array}{l}\text { DENOMINACIÓN } \\
\text { SUBPRODUCTO }\end{array}$ & Fase de generación de subproducto & $\%$ subproducto generado \\
\hline & & \\
\hline & & \\
\hline & & \\
\hline & & \\
\hline & & \\
\hline & & \\
\hline & & \\
\hline & & \\
\hline & & \\
\hline & & \\
\hline & & \\
\hline & & \\
\hline & & \\
\hline & & \\
\hline
\end{tabular}

GESTIÓN

\begin{tabular}{|l|l|l|l|}
\hline \multirow{2}{*}{$\begin{array}{l}\text { DENOMINACIÓN } \\
\text { SUBPRODUCTO }\end{array}$} & & & \\
\hline & & & \\
\hline & & & \\
\hline & & & \\
\hline & & & \\
\hline & & & \\
\hline & & & \\
\hline & & & \\
\hline & & & \\
\hline & & & \\
\hline & & & \\
\hline & & & \\
\hline & & & \\
\hline
\end{tabular}



GENERACIÓN RESIDUOS (VERTIDO LODOS)

\begin{tabular}{|l|l|l|l|l|l|l|l|l|l|l|l|l|l|l|}
\hline $\begin{array}{l}\text { LODOS VOLUMEN } \\
\text { GENERADO EMPRESA }\end{array}$ & \multicolumn{2}{|c|}{$\begin{array}{l}\text { Ene } \\
\left(\mathrm{m}^{3}\right)\end{array}$} & $\begin{array}{l}\text { Feb } \\
\left(\mathrm{m}^{3}\right)\end{array}$ & $\begin{array}{l}\text { Mar } \\
\left(\mathrm{m}^{3}\right)\end{array}$ & $\begin{array}{l}\text { Abr } \\
\left(\mathrm{m}^{3}\right)\end{array}$ & $\begin{array}{l}\text { May } \\
\left(\mathrm{m}^{3}\right)\end{array}$ & $\begin{array}{l}\text { Jun } \\
\left(\mathrm{m}^{3}\right)\end{array}$ & $\begin{array}{l}\text { Jul } \\
\left(\mathrm{m}^{3}\right)\end{array}$ & $\begin{array}{l}\text { Ago } \\
\left(\mathrm{m}^{3}\right)\end{array}$ & $\begin{array}{l}\text { Sept } \\
\left(\mathrm{m}^{3}\right)\end{array}$ & $\begin{array}{l}\text { Oct } \\
\left(\mathrm{m}^{3}\right)\end{array}$ & $\begin{array}{l}\text { Nov } \\
\left(\mathrm{m}^{3}\right)\end{array}$ & $\begin{array}{l}\text { Dic } \\
\left(\mathrm{m}^{3}\right)\end{array}$ \\
\hline & & & & & & & & & & & & \\
\hline & & & & & & & & & & & & \\
\hline
\end{tabular}

\section{COSTE UNITARIO PRODUCCIÓN}

\begin{tabular}{|c|c|c|c|}
\hline $\begin{array}{l}\text { DENOMINACIÓN } \\
\text { PRODUCTO }\end{array}$ & $\begin{array}{c}\text { Coste promedio proceso } \\
\text { productivo } \\
(€ / T) \\
\text { Costes totales (fijos y } \\
\text { variables) de producción }\end{array}$ & $\begin{array}{c}\text { Coste estimado promedio del } \\
\text { proceso productivo sin incluir la } \\
\text { fase de generación de } \\
\text { subproducto } \\
\text { (€/T) } \\
\text { Costes totales (fijos y variables) } \\
\text { de producción }\end{array}$ & $\begin{array}{l}\text { Coste estimado promedio del } \\
\text { proceso productivo durante la fase } \\
\text { de generación de subproducto } \\
\text { ( } € / T) \\
\text { Costes totales (fijos y variables) de } \\
\text { producción }\end{array}$ \\
\hline & & & \\
\hline & & & \\
\hline & & & \\
\hline & & & \\
\hline & & & \\
\hline & & & \\
\hline & & & \\
\hline & & & \\
\hline & & & \\
\hline
\end{tabular}

\section{OBSERVACIONES}



TRATAMIENTO DEL VERTIDO

\section{DATOS GENERALES DEL SISTEMA DE DEPURACIÓN}

Tipo de sistema de depuración:

Capacidad de depuración (diseño- $\mathrm{m}^{3} /$ día):

Capacidad de depuración (real o media- $\mathrm{m}^{3} /$ día):

\section{DATOS DE VERTIDO}

\begin{tabular}{|l|l|l|l|l|l|l|l|l|l|l|l|l|}
\hline Depuradora & $\begin{array}{l}\text { Ene } \\
\left(\mathrm{m}^{3}\right)\end{array}$ & $\begin{array}{l}\text { Feb } \\
\left(\mathrm{m}^{3}\right)\end{array}$ & $\begin{array}{l}\text { Mar } \\
\left(\mathrm{m}^{3}\right)\end{array}$ & $\begin{array}{l}\text { Abr } \\
\left(\mathrm{m}^{3}\right)\end{array}$ & $\begin{array}{l}\text { May } \\
\left(\mathrm{m}^{3}\right)\end{array}$ & $\begin{array}{l}\text { Jun } \\
\left(\mathrm{m}^{3}\right)\end{array}$ & $\begin{array}{l}\text { Jul } \\
\left(\mathrm{m}^{3}\right)\end{array}$ & $\begin{array}{l}\text { Ago } \\
\left(\mathrm{m}^{3}\right)\end{array}$ & $\begin{array}{l}\text { Sept } \\
\left(\mathrm{m}^{3}\right)\end{array}$ & $\begin{array}{l}\text { Oct } \\
\left(\mathrm{m}^{3}\right)\end{array}$ & $\begin{array}{l}\text { Nov } \\
\left(\mathrm{m}^{3}\right)\end{array}$ & $\begin{array}{l}\text { Dic } \\
\left(\mathrm{m}^{3}\right)\end{array}$ \\
\hline $\begin{array}{l}\text { Volumen de agua } \\
\text { tratada }\left(\mathrm{m}^{3}\right)\end{array}$ & & & & & & & & & & & \\
\hline $\begin{array}{l}\text { Volumen de lodos } \\
\text { generados (t) }\end{array}$ & & & & & & & & & & & \\
\hline
\end{tabular}

ESTRUCTURA PRODUCTIVA ASOCIADA SISTEMA DE DEPURACIÓN

\begin{tabular}{|c|c|c|c|c|c|c|}
\hline $\begin{array}{c}\text { INFRAESTRUCTURAS } \\
\text { EQUIPOS }\end{array}$ & Descripción física & $\begin{array}{l}\text { Coste total } \\
(€)\end{array}$ & $\begin{array}{l}\text { Vida útil } \\
\text { (años) }\end{array}$ & $\begin{array}{l}\text { Amortización } \\
\text { (€) }\end{array}$ & $\begin{array}{c}\text { Mantenimiento } \\
\text { /Reparaciones } \\
\text { (€) } \\
\end{array}$ & $\begin{array}{l}\text { Subvenciones } \\
\text { (€) }\end{array}$ \\
\hline & & & & & & \\
\hline & & & & & & \\
\hline & & & & & & \\
\hline & & & & & & \\
\hline & & & & & & \\
\hline & & & & & & \\
\hline & & & & & & \\
\hline & & & & & & \\
\hline & & & & & & \\
\hline & & & & & & \\
\hline
\end{tabular}



CONSUMO ENERGÉTICO ASOCIADO SISTEMA DE DEPURACIÓN

\begin{tabular}{|l|l|l|}
\hline EQUIPO & $\begin{array}{c}\text { CONSUMO } \\
(\mathrm{kWh})\end{array}$ & COSTE (€) (€/KWh) \\
\hline & & \\
\hline & & \\
\hline & & \\
\hline & & \\
\hline & & \\
\hline & & \\
\hline & & \\
\hline & & \\
\hline
\end{tabular}

PERSONAL ASOCIADO SISTEMA DE DEPURACIÓN

\begin{tabular}{|l|l|l|}
\hline \multicolumn{1}{|c|}{ Personal } & Horas trabajadas & Coste hora/ salario bruto (€) \\
\hline Trabajo directo & & \\
\hline & & \\
\hline & & \\
\hline Trabajo indirecto & & \\
\hline & & \\
\hline & & \\
\hline & & \\
\hline & & \\
\hline & & \\
\hline
\end{tabular}

OTROS DATOS DE RELEVANCIA

\begin{tabular}{|c|c|c|}
\hline \multirow[t]{2}{*}{ Descripción } & \multicolumn{2}{|c|}{ Coste } \\
\hline & Fijos $(€)$ & Variables $(€)$ \\
\hline Ejemplo: Reactivos & & --- \\
\hline & & \\
\hline & & \\
\hline & & \\
\hline & & \\
\hline & & \\
\hline
\end{tabular}

Coste unitario $\left(€ / \mathrm{m}^{3}\right.$ tratado) 

LISTADO PLAGUICIDAS (Organoclorados y organofosforados)

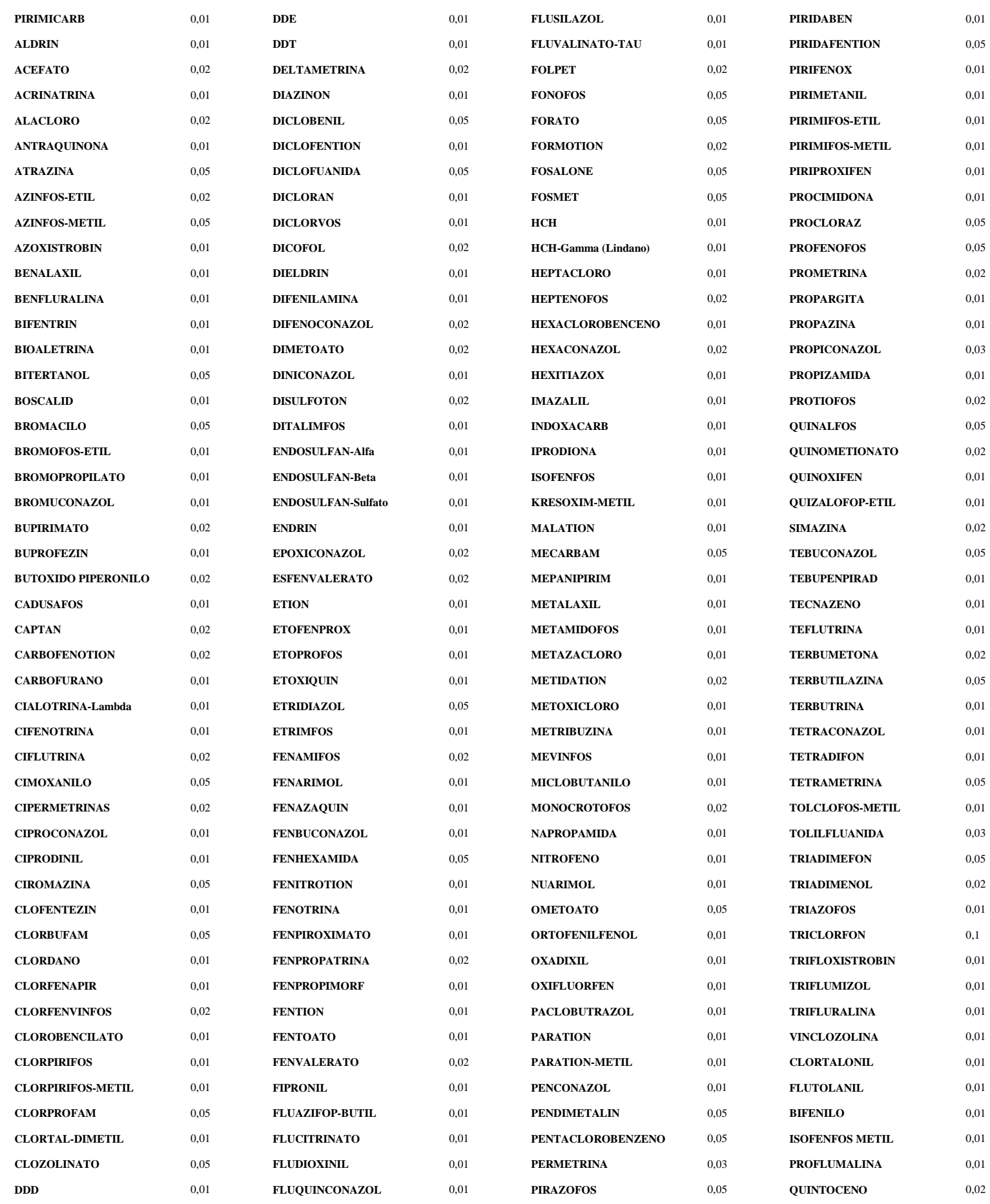






\section{FE DE ERRATAS}

Tesis doctoral: Estudio de los residuos y subproductos agroindustriales de la Región de Murcia. Opciones de valorización mediante compostaje y biometanización

Doctoranda: Ana Belén Morales Moreno

\begin{tabular}{|c|c|c|}
\hline Página & Ubicación & Errata \\
\hline 186 & Bibliografía Capítulo VI & $\begin{array}{l}\text { Falta poner: } \\
\text { Barrena, R., Vázquez, F, Sánchez, A., } 2008 . \\
\text { Dehydrogenase activity as a method for monitoring the } \\
\text { composting process. Bioresour. Technol. 99, 905-908. }\end{array}$ \\
\hline 189 & Bibliografía Capítulo VI & $\begin{array}{l}\text { Falta poner: } \\
\text { Paredes, C., Roig, A., Bernal, M.P., Sánchez-Monedero, } \\
\text { M.A., Cegarra, J., 2000. Evolution of organic matter and } \\
\text { nitrogen during co-composting of olive millwastewater } \\
\text { with solid organic wastes. Biol. Fert. Soils 32, 222-227. }\end{array}$ \\
\hline 190 & Bibliografía Capítulo VI & $\begin{array}{l}\text { Falta poner: } \\
\text { Saviozzi, A., Cardelli, R., Levi-Minzi, R., Riffaldi, R., } \\
2004 . \text { Evolution of biochemical parameters during } \\
\text { composting of urban wastes. Compost Sci. Util. 12, 153- } \\
160 \text {. }\end{array}$ \\
\hline \multirow[t]{2}{*}{215} & $\begin{array}{l}\text { Apartado } 2.2 \text {. } \\
\text { Propiedades del suelo } \\
\text { y el compost }\end{array}$ & $\begin{array}{l}\text { Cambiar: } \\
0,43 \mathrm{~ms} / \mathrm{m} \text { por " } 0,43 \mathrm{dS} / \mathrm{m} \text { " }\end{array}$ \\
\hline & Línea 5 del apartado & \\
\hline \multirow[t]{2}{*}{215} & $\begin{array}{l}\text { Apartado } 2.2 \\
\text { Propiedades del suelo } \\
\text { y el compost }\end{array}$ & $\begin{array}{l}\text { Cambiar: } \\
8,10 \mathrm{mS} / \mathrm{m} \text { por " } 8,10 \mathrm{dS} / \mathrm{m} \text { " }\end{array}$ \\
\hline & Línea 17 del apartado & \\
\hline 221 & Tabla 3 & $\begin{array}{l}\text { Cambiar: } \\
\text { Tabla por la adjuntada como Tabla } 3 \text { en esta fe de erratas }\end{array}$ \\
\hline 224 & Tabla 4 & $\begin{array}{l}\text { Cambiar: } \\
\text { Tabla por la adjuntada como Tabla } 4 \text { en esta fe de erratas }\end{array}$ \\
\hline 226 & Línea 4 de la página & $\begin{array}{l}\text { Falta poner: } \\
\text { "no" entre las palabras suelo y alteró }\end{array}$ \\
\hline 247 & Línea 20 de la página & $\begin{array}{l}\text { Cambiar: } \\
\text { en el día } 59 \text { por “en el día 30" }\end{array}$ \\
\hline
\end{tabular}




\section{Nueva Página 221}

Tabla 3.Comunidades de bacterias, hongos (excluyendo T. harzianum T78) y Trichoderma expresadas como UFC en los diferentes suelos evaluados después de 0,20 y 45 días de incubación

\begin{tabular}{|c|c|c|c|c|c|c|c|c|c|c|}
\hline \multirow[b]{2}{*}{$\mathrm{NaCl}(\mathrm{mM})$} & \multirow[b]{3}{*}{0} & \multicolumn{3}{|c|}{$\begin{array}{c}\text { Bacterias } \\
\text { UFC/g suelo seco }\end{array}$} & \multicolumn{3}{|c|}{$\begin{array}{l}\text { Hongos (excluyendo T. harzianum T78) } \\
\text { UFC/g suelo seco }\end{array}$} & \multicolumn{3}{|c|}{$\begin{array}{l}\text { Trichoderma spp. } \\
\text { UFC/g suelo seco }\end{array}$} \\
\hline & & \multirow{2}{*}{$\begin{array}{c}\text { 0 días } \\
7,30 \text { c } A\end{array}$} & 20 días & \multirow{2}{*}{$\begin{array}{l}45 \text { días } \\
8,23 \mathrm{~d} C\end{array}$} & 0 días & 20 días & \multirow{2}{*}{$\begin{array}{l}45 \text { días } \\
5,41 \mathrm{~d} A\end{array}$} & 0 días & 20 días & \multirow{2}{*}{$\begin{array}{l}45 \text { días } \\
4,00 \text { c } A\end{array}$} \\
\hline Suelo & & & $7,70 \mathrm{e} \quad \mathrm{B}$ & & $5,61 d \quad A$ & $5,52 d \quad A$ & & $4,48 b \quad B$ & $4,22 b \quad B$ & \\
\hline \multirow[t]{3}{*}{ control } & 10 & $7,20 \mathrm{c} \mathrm{A}$ & $7,71 \mathrm{e} \quad \mathrm{B}$ & 7,98 c C & $5,40 b c \quad B$ & $5,35 b c B$ & 4,91ab A & $4,54 b c B$ & $4,43 b c B$ & $4,00 c \mathrm{~A}$ \\
\hline & 20 & $7,51 \mathrm{~d} A$ & $7,82 \mathrm{e} \quad \mathrm{B}$ & $7,78 \mathrm{c} \mathrm{B}$ & $5,37 b c B$ & $5,41 \mathrm{~cd} \mathrm{~B}$ & $5,15 b c A$ & $<2 a$ & $<2 a$ & $<2 a$ \\
\hline & 60 & $7,20 \mathrm{c} \mathrm{A}$ & 7,60 de $B$ & $7,89 \mathrm{c} \mathrm{C}$ & $5,35 b c \quad B$ & $5,26 \mathrm{~b} \mathrm{AB}$ & $5,14 b c A$ & $<2 a$ & $<2 a$ & $<2 a$ \\
\hline Suelo con & 0 & $7,09 \mathrm{~b} \mathrm{~A}$ & $7,41 d \quad B$ & $7,12 \mathrm{~b} \mathrm{~A}$ & $5,68 d \quad B$ & $5,59 d \quad B$ & $5,43 d A$ & $4,70 \mathrm{~cd} \mathrm{~B}$ & $4,43 b c A B$ & $4,00 c \mathrm{~A}$ \\
\hline \multirow{3}{*}{ compost } & 10 & $7,13 b \mathrm{~A}$ & $7,23 \mathrm{c} \quad \mathrm{A}$ & $7,15 b \mathrm{~A}$ & $5,36 b c B$ & $5,27 b$ B & $4,81 a \quad A$ & $4,54 b c$ C & $4,30 \mathrm{~b} \quad \mathrm{~B}$ & $3,70 \mathrm{~b} \mathrm{~A}$ \\
\hline & 20 & $7,15 b \mathrm{~A}$ & 7,66de B & $7,06 \mathrm{~b} \mathrm{~A}$ & $5,46 \mathrm{c} \quad \mathrm{B}$ & $5,36 \mathrm{C} A B$ & $5,26 c \quad B$ & $<2 a$ & $<2 a$ & $<2 a$ \\
\hline & 60 & $6,93 a \mathrm{~A}$ & $7,27 \mathrm{C} \quad \mathrm{B}$ & $7,00 \mathrm{~b} \mathrm{~A}$ & $5,43 \mathrm{c} \quad \mathrm{A}$ & $5,39 c \quad A$ & $5,27 \mathrm{c} \quad \mathrm{A}$ & $<2 a$ & $<2 a$ & $<2 a$ \\
\hline Suelo con & 0 & $6,90 a$ B & 6,88ab B & 6,28 a A & $5,21 b \quad B$ & $5,29 b \quad B$ & $5,19 b c A$ & $5,30 f \quad B$ & $5,10 \mathrm{~d} \quad \mathrm{~B}$ & $4,62 d \quad A$ \\
\hline compost & 10 & $6,98 a$ B & $6,91 \mathrm{ab} \mathrm{B}$ & $6,28 a \mathrm{~A}$ & $5,21 b \quad B$ & $4,93 a \quad A$ & $5,10 \mathrm{~b} \quad \mathrm{AB}$ & $5,00 \mathrm{~d} A$ & $5,14 d \quad B$ & 4,73de A \\
\hline enriquecido & 20 & $7,45 d \mathrm{~B}$ & $6,79 a \quad B$ & $6,25 a \mathrm{~A}$ & $5,00 a \quad A$ & $5,22 a b A$ & $5,13 b \quad A$ & $5,18 \mathrm{e} \quad$ B & $5,00 \mathrm{~d} A B$ & $4,92 \mathrm{e} \quad \mathrm{A}$ \\
\hline con T78 & 60 & $6,93 a \mathrm{~B}$ & $6,61 \mathrm{a} \quad \mathrm{B}$ & 6,20a A & $4,95 a \quad A$ & $5,17 a b$ B & $4,99 \mathrm{~b} \quad \mathrm{~A}$ & $5,18 \mathrm{e} \quad$ B & $4,77 \mathrm{~cd} A B$ & $4,60 \mathrm{~d} A$ \\
\hline
\end{tabular}

T78: Trichodermaharzianum T78

En cada columna, los valores seguidos de la misma letra no muestran diferencias significativas a $p<0,05$ utilizando el test de Tukey

En cada línea, para cada parámetro específico, los valores seguidos de la misma letra capital no muestran diferencias significativas a p<0,05 utilizando el test de Tukey 


\section{Nueva Página 224}

Tabla 4.Carbono orgánico total (C), carbono de la biomasa microbiana (Cbio) y la actividad deshidrogenasa de los diferentes suelos evaluados a 0,20 y 45 días de incubación

\begin{tabular}{|c|c|c|c|c|c|c|c|c|c|c|}
\hline \multirow[b]{2}{*}{$\mathrm{NaCl}(\mathrm{mM})$} & \multirow[b]{3}{*}{0} & \multicolumn{3}{|c|}{$\begin{array}{c}\text { C } \\
\text { g/kg suelo seco }\end{array}$} & \multicolumn{3}{|c|}{$\begin{array}{c}\text { Cbio } \\
\mathrm{mg} / \mathrm{kg} \text { suelo seco }\end{array}$} & \multicolumn{3}{|c|}{$\begin{array}{c}\text { Deshidrogenasa } \\
\mu \mathrm{mol} \text { INTF/g h suelo seco }\end{array}$} \\
\hline & & \multirow{2}{*}{$\begin{array}{c}\text { 0 días } \\
8,30 a \mathrm{~A}\end{array}$} & \multirow{2}{*}{\begin{tabular}{|l}
20 días \\
$9,30 \mathrm{~cd} A$
\end{tabular}} & \multirow{2}{*}{$\begin{array}{l}45 \text { días } \\
9,00 c A\end{array}$} & \multirow{2}{*}{$\begin{array}{l}\text { O días } \\
230 b \mathrm{~b}\end{array}$} & \multirow{2}{*}{$\begin{array}{c}20 \text { días } \\
208 \text { bcd B }\end{array}$} & 45 días & \multirow{2}{*}{$\begin{array}{c}\text { O días } \\
2,88 \mathrm{~cd} \mathrm{~B}\end{array}$} & \multirow{2}{*}{$\begin{array}{r}20 \text { días } \\
2,16 b \mathrm{~A}\end{array}$} & 45 días \\
\hline Suelo & & & & & & & $147 \mathrm{bc} \mathrm{A}$ & & & $2,06 a \quad A$ \\
\hline \multirow[t]{3}{*}{ control } & 10 & $13,1 \mathrm{~d} \mathrm{~B}$ & $8,00 \mathrm{~b} A$ & $7,80 \mathrm{bA}$ & $300 \mathrm{c} C$ & 250de B & $144 \mathrm{~b} \quad \mathrm{~A}$ & $3,00 d \quad B$ & $2,14 \mathrm{~b} A$ & $1,96 a \quad A$ \\
\hline & 20 & $11,9 b c \quad B$ & $7,50 \mathrm{~b} A$ & $7,10 b \mathrm{~A}$ & 312 c C & 241de B & $159 b c d A$ & $2,45 b \quad B$ & $2,31 b c A$ & $2,00 a \quad A$ \\
\hline & 60 & $10,50 \mathrm{~b} \mathrm{~B}$ & $6,50 a \quad A$ & $6,00 \mathrm{a} A$ & 130a B & $117 a \quad A B$ & $87 a$ & $1,65 a \quad A$ & $1,50 a \quad A$ & $1,84 a \quad A$ \\
\hline Suelo con & 0 & $16,40 f \quad B$ & 10,90 e A & $9,90 \mathrm{c} A$ & $420 d \mathrm{C}$ & $320 \mathrm{~g} \quad \mathrm{~B}$ & $264 f \quad A$ & $3,19 \mathrm{e} \quad \mathrm{A}$ & 3,83 e $B$ & $3,23 e \quad A$ \\
\hline \multirow[t]{3}{*}{ compost } & 10 & 15,80 ef B & $9,90 \mathrm{~d} A$ & $9,40 c \mathrm{~A}$ & $400 \mathrm{~d} B$ & $355 \mathrm{~g} \quad \mathrm{~B}$ & 174cde A & $3,33 e \quad B$ & $2,43 b c A$ & $2,90 \mathrm{de} A B$ \\
\hline & 20 & 15,00 e B & $8,40 \mathrm{CA}$ & $8,10 b c A$ & $340 \mathrm{c} \mathrm{B}$ & 241cde AB & $204 \mathrm{e} \quad \mathrm{A}$ & $2,72 \mathrm{C} \quad \mathrm{B}$ & $2,13 b \quad A$ & $3,00 \mathrm{e} \quad \mathrm{B}$ \\
\hline & 60 & $13,50 \mathrm{~d} \mathrm{~B}$ & $7,40 \mathrm{~b} \mathrm{~A}$ & 7,00ab A & 150a A & 113a A & 188de A & $2,32 \mathrm{~b} \quad \mathrm{~A}$ & $2,17 \mathrm{~b} \quad \mathrm{~A}$ & $3,09 \mathrm{e} \quad \mathrm{B}$ \\
\hline Suelo con & 0 & $17,7 f \quad B$ & $12,20 f \quad A$ & $11,20 \mathrm{~d} A$ & 320 c C & $273 f$ & 179cde A & $3,36 \mathrm{e} \quad \mathrm{B}$ & $3,49 \mathrm{e} B$ & 2,72 cde A \\
\hline compost & 10 & $12,10 \mathrm{cdA}$ & 10,30 de A & $10,00 \mathrm{~cd} \mathrm{~A}$ & 325 c C & 242cde B & $187 \mathrm{de} \mathrm{A}$ & $2,80 \mathrm{C} \quad \mathrm{B}$ & $2,44 b c B$ & $2,44 \mathrm{bcd} \mathrm{A}$ \\
\hline enriquecido & 20 & $11,60 \mathrm{bc} \mathrm{B}$ & $7,20 \mathrm{~b} \quad \mathrm{~A}$ & $6,50 a b$ A & $300 \mathrm{c} \mathrm{C}$ & 233cde B & $170 \mathrm{~cd} \mathrm{~A}$ & $2,47 b \quad A B$ & $2,43 b c B$ & $2,28 a b \quad A$ \\
\hline con T78 & 60 & $9,60 \mathrm{~b} \quad$ B & $7,20 b \quad A$ & $6,60 \mathrm{ab} A$ & 285 c B & $262 \mathrm{e}$ & $154 \mathrm{bc} \mathrm{A}$ & $2,10 a b \quad A$ & $2,54 \mathrm{~cd} \mathrm{~B}$ & $2,30 a b c$ B \\
\hline
\end{tabular}

T78: Trichodermaharzianum T78

En cada columna, los valores seguidos de la misma letra no muestran diferencias significativas a $p<0,05$ utilizando el test de Tukey

En cada línea, para cada parámetro específico, los valores seguidos de la misma letra capital no muestran diferencias significativas a $p<0,05$ utilizando el test de Tukey 